DoD Corrosion Prevention and Control Program

\title{
Remote Performance Monitoring of a Thermoplastic Composite Bridge at Camp Mackall, NC
}

Final Report on Project F08-AR13, Task A-Thermoplastic Composite Bridges

Richard G. Lampo, Barry K. Myers, Karl Palutke,

November 2011 and Darryl M. Butler

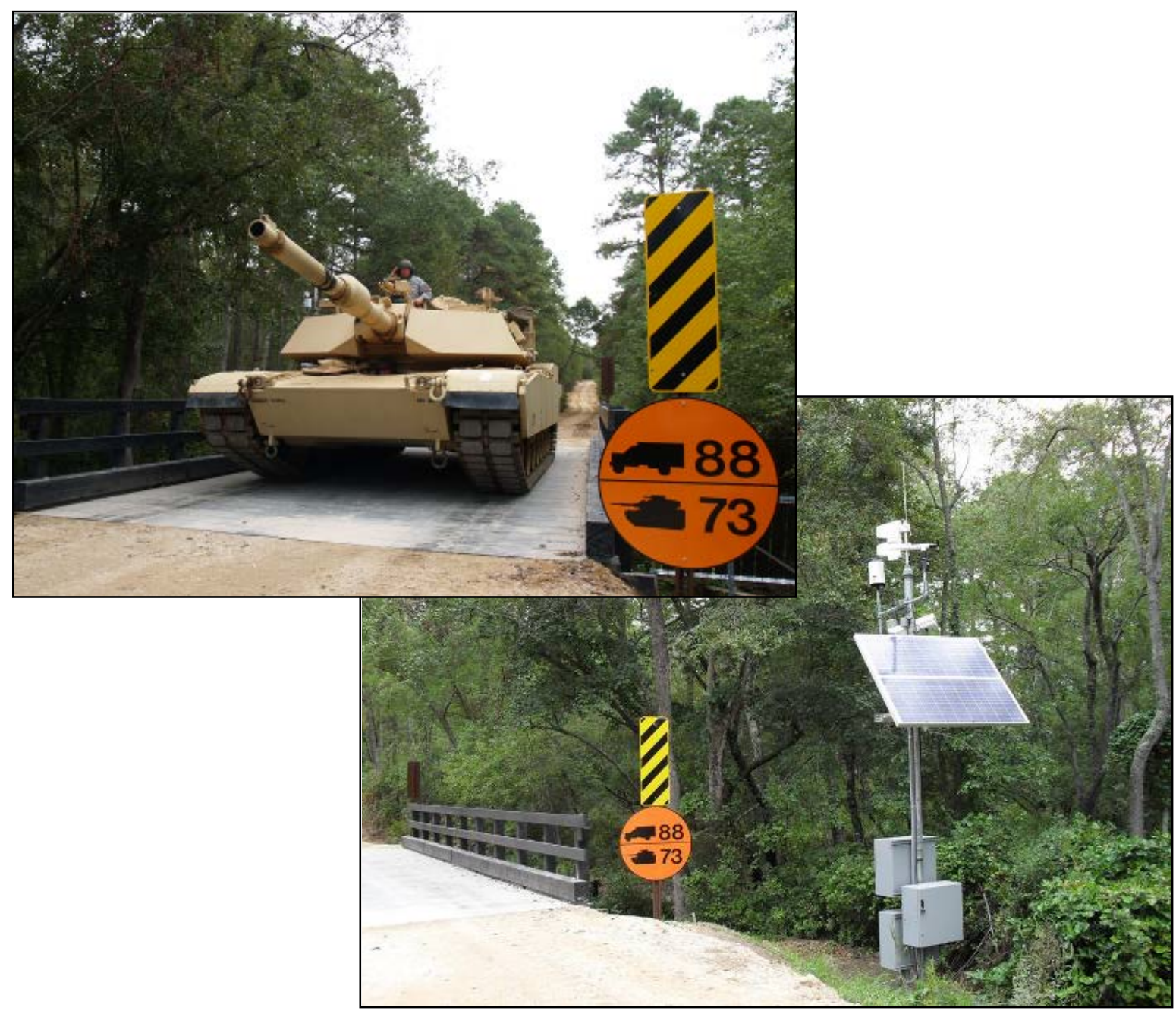



DoD Corrosion Prevention

\section{Remote Performance Monitoring of a Thermoplastic Composite Bridge at Camp Mackall, NC}

Final Report on Project F08-AR13, Task A-Thermoplastic Composite Bridges

Richard G. Lampo

Construction Engineering Research Laboratory

US Army Engineer Research and Development Center

2902 Newmark Drive

Champaign, IL 61822

Barry K. Myers

Engineered Monitoring Solutions

617 N. Main Street

Newberg, Oregon 97132

Karl Palutke

Mandaree Enterprise Corporation

812 Park Drive

Warner Robins, Georgia 31088

Darryl M. Butler

Directorate of Public Works

Building 3-1631, Butner Road

Fort Bragg, NC 28310

Final report

Approved for public release; distribution is unlimited.

Prepared for Office of the Secretary of Defense (OUSD(AT\&L))

3090 Defense Pentagon

Washington, DC 20301-3090

Under CPC Project F08-AR13 


\section{Abstract}

This Corrosion Prevention and Control project demonstrated the use of an automated structural performance monitoring (SPM) system to remotely monitor the long-term performance of an innovative bridge constructed of recycled thermoplastics. The SPM system was designed to automatically collect the desired performance data and to provide the data to remote users for ongoing evaluation of the bridge. The system utilizes resistancetype strain gages and laser displacement sensors to monitor the strain and displacements imposed both by thermal impacts under static loading and dynamic loading created by vehicle crossing events. The system uses programmable automated data acquisition equipment to detect a vehicle event of interest, capture the strain and displacement time histories, and make a photograph of the vehicle for identification purposes.

This report documents the installation and configuration of the SPM system, and describes the data collected from remote monitoring and load testing activities. A review of the data indicates that good-quality continuous data have been collected with minimal labor requirement. The data were used to evaluate how the bridge is performing relative to design assumptions, and to establish a baseline of bridge static and dynamic response for structural performance evaluation over time.

DISCLAIMER: The contents of this report are not to be used for advertising, publication, or promotional purposes. Citation of trade names does not constitute an official endorsement or approval of the use of such commercial products. All product names and trademarks cited are the property of their respective owners. The findings of this report are not to be construed as an official Department of the Army position unless so designated by other authorized documents. 


\section{Executive Summary}

This Corrosion Prevention and Control project demonstrated the use of an automated structural performance monitoring (SPM) system to remotely monitor the long-term performance of an innovative bridge constructed of recycled thermoplastics. The SPM system was designed to automatically collect the desired performance data and to provide the data to remote users for ongoing evaluation of the bridge. The system utilizes resistancetype strain gages and laser displacement sensors to monitor the strain and displacements imposed both by thermal impacts under static loading and dynamic loading created by vehicle crossing events. The system uses programmable automated data acquisition equipment to detect a vehicle event of interest, capture the strain and displacement time histories, and make a photograph of the vehicle for identification purposes.

Data have been collected to evaluate the long-term performance of the bridge. The performance parameters of interest are (1) response of the structural members to thermal loading and the identification of any creep that may occur, (2) structural response to heavy vehicle loads with time, and (3) response to heavy vehicle loads relative to predicted performance based on the bridge design assumptions. Load testing under controlled conditions with heavy vehicles has been performed to collect the data needed to evaluate the third item. This load testing was performed soon after construction, and was repeated at 12 and 24 months to observe for changes in performance over time. The vehicles used in load testing include an M1089 Wrecker, M1 Tank, M978A2R1 Fuel/Water Tanker, and an M88A2 Tank Service Vehicle. The types of heavy vehicles crossing the bridge that have been captured include the M1078, armored HMMWV (High Mobility Multipurpose Wheeled Vehicle), 2-axle cargo truck, 2-axle dump truck, concrete truck, road grader, backhoe, fire truck, dozer with disc implement, and a boom truck.

This report documents the installation and configuration of the SPM system, and describes the data collected from the remote monitoring and load testing activities. A review of the data collected to date indicates that goodquality continuous data have been collected with minimal labor requirement. The data were used to evaluate how the bridge is performing relative 
to design assumptions, and to establish a baseline of bridge static and dynamic response for structural performance evaluation over time.

The data collected to date show that the bridge is performing as designed with no indication of materials degradation due to service use and environmental exposure. A baseline of performance has been established for the bridge over its first two years of service. This baseline can be used to compare with data collected in the future for further evaluation of materials degradation. 


\section{Contents}

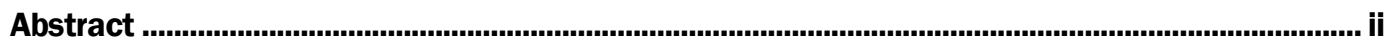

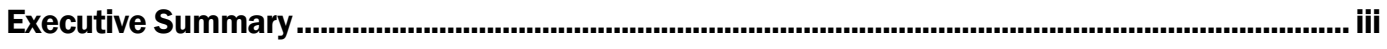

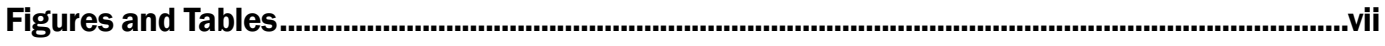

Preface ........................................................................................................................................................ ix

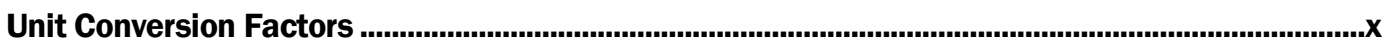

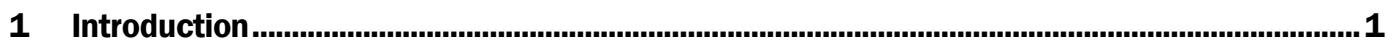

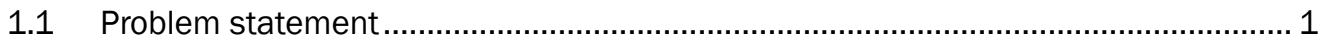

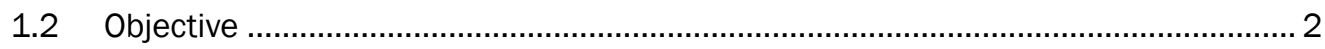

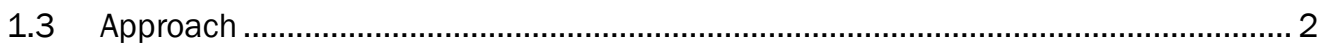

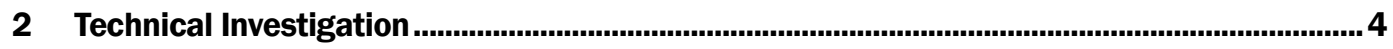

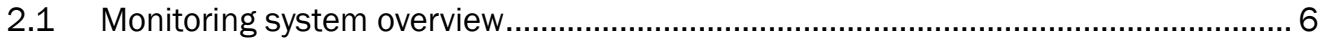

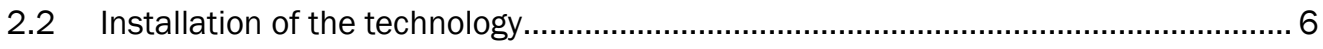

2.2.1 Vertical deflections..................................................................................... 6

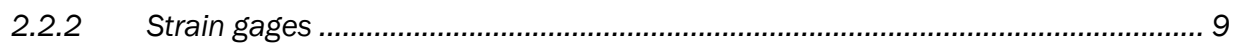

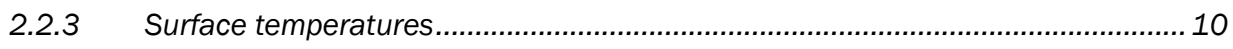

2.2.4 Vehicle crossing images ............................................................................. 10

2.2.5 Weather station........................................................................................ 11

2.2.6 Automated data acquisition ...................................................................... 12

2.2.7 Data management and presentation ................................................................. 13

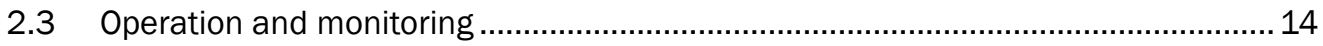

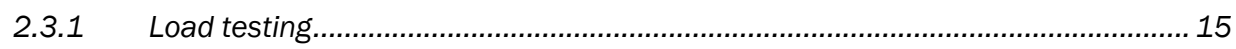

2.3.2 Captured heavy vehicle crossing events.............................................................. 20

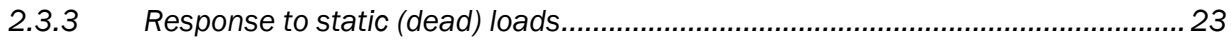

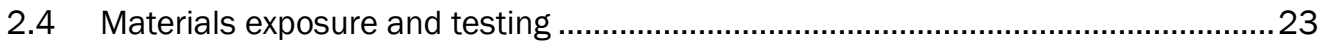

2.4.1 Atmospheric corrosion rate measurement......................................................... 23

2.4.2 Thermoplastic material exposure testing ....................................................... 24

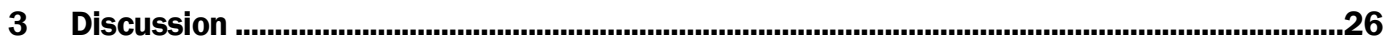

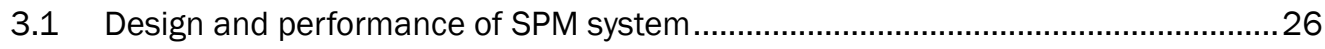

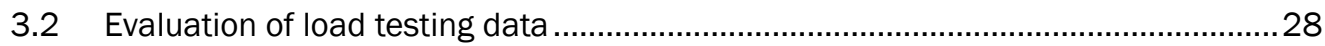

3.3 Evaluation of captured heavy vehicle crossings ....................................................30

3.4 Evaluation of the response to static loads.............................................................3

3.4.1 Atmospheric corrosion rate measurement....................................................... 34

3.4.2 Thermoplastic material exposure testing ........................................................... 36

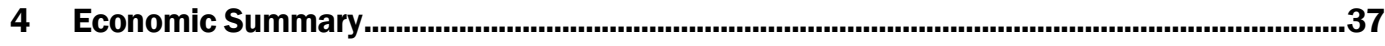

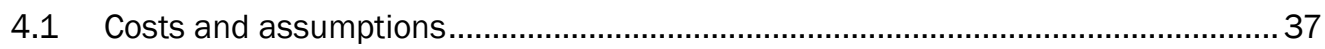

4.2 Projected return on investment (ROI) …….................................................... 39 
5 Conclusions and Recommendations .......................................................................................41

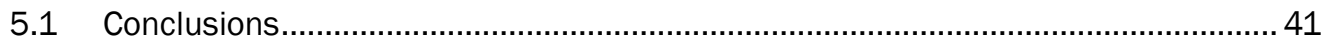

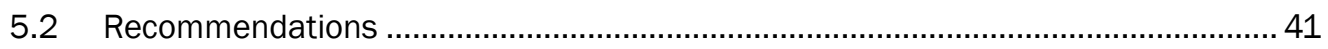

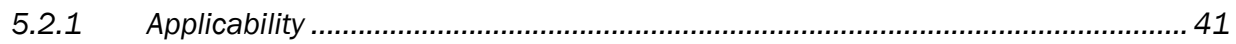

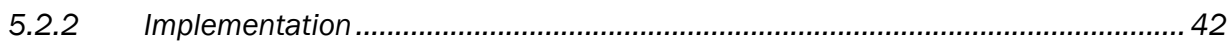

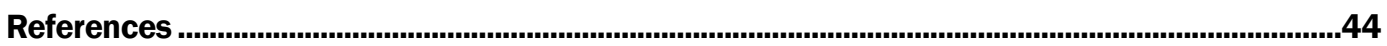

Appendix A: Bridge T-8518 Drawings and Specifications .......................................................45

Appendix B: Design, Construction, and Inspection of Bridge T-8518...........................................58

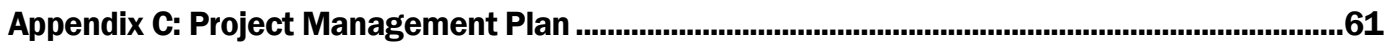

Appendix D: Micro-Epsilon optoNCDT 1300 Laser Sensor Data Sheet ...........................................78

Appendix E: Hitec Products Inc. HB Full Bridge Strain Gage Data Sheet ......................................80

Appendix F: Omega Model ON-909 Surface Temperature Sensor Data Sheet ............................83

Appendix G: Campbell Scientific CC640 Digital Camera Data Sheet ..............................................85

Appendix H: RM Young Model 05103 Wind Monitor Data Sheet ..................................................87

Appendix I: RM Young Model 41372 Temperature and RH Probe Data Sheet...........................89

Appendix J: RM Young Model 52202 Tipping Bucket Rain Gauge Data Sheet ..........................90

Appendix K: Solar Light Model PMA1111 UVA Detector Data Sheet...............................................92

Appendix L: Campbell Scientific Model CR9000X Datalogger Data Sheet ...................................94

Appendix M: Campbell Scientific Model CR1000 Datalogger Data Sheet ................................. 102

Appendix N: Campbell Scientific Raven XT Cellular Modem Data Sheet...................................... 110

Appendix 0: Campbell Scientific LoggerNet Software Data Sheet ..............................................114

Appendix P: Canary Systems MLWeb Software Data Sheet...........................................................122

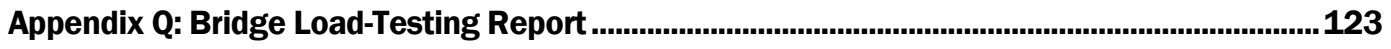

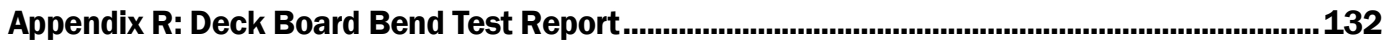

Report Documentation Page 


\section{Figures and Tables}

\section{Figures}

Figure 1. M1A1 Tank crossing thermoplastic bridge..................................................................... 1

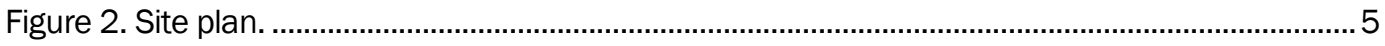

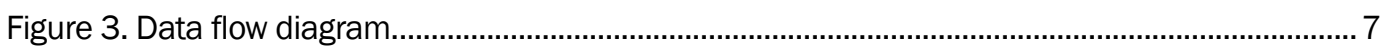

Figure 4. Typical laser sensor installation (midspan of span 2). ......................................................... 8

Figure 5. Typical strain gage and surface temperature sensor installation (top of girders at

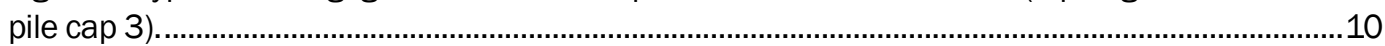

Figure 6. Automated data acquisition equipment installation and weather station sensors............12

Figure 7. Web-enabled project database interface.......................................................................14

Figure 8. Load test vehicle - M1089 Wrecker. ................................................................................15

Figure 9. Load test vehicle - M1A1 main battle tank .....................................................................17

Figure 10. Load test vehicle - M978A2R1 tanker..............................................................................18

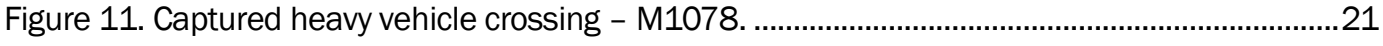

Figure 12. Captured heavy vehicle crossing - armored HMMWV ...................................................21

Figure 13. Captured heavy vehicle crossing - 2 axle cargo truck.........................................................22

Figure 14. Captured heavy vehicle crossing - 2 axle dump truck. ...................................................22

Figure 15. Atmospheric corrosion coupons mounted on bridge ........................................................2

Figure 16. Nominal $2 \times 4$ thermoplastic specimens mounted at bridge site. ...................................25

Figure 17. Example of results from load testing with M1 Tank (bridge response at different vehicle speeds)

Figure 18. Displacement response of the bridge to an M1078 as compared to a concrete

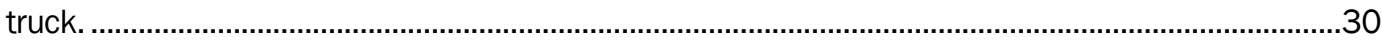

Figure 19. Strain response of the bridge to an m1078 as compared to a concrete truck................31

Figure 20. Comparison of peak displacements from captured heavy vehicle crossings...................31

Figure 21. Comparison of peak strains from captured heavy vehicle crossings...............................32

Figure 22. Estimated vehicle speeds from captured heavy vehicle crossing events. ........................32

Figure 23. Example of bridge response to thermal loading (displacements at span 2

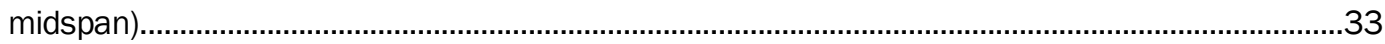

Figure 24. Example of bridge response to thermal loading (displacements at pile cap 3)..............34

\section{Tables}

Table 1. Test plan for load test 1, July 2009...................................................................................

Table 2. Test plan for load test 2, September 2009. ...................................................................17

Table 3. Test plan for load test number 3, January 2010 ...............................................................18

Table 4. Test plan for load test 4, August 2010. ……………….........................................................19

Table 5. Test plan for load test 5, October 2011............................................................................20 
Table 6. Maximum Deflections Measured for the M1089 for Load Tests 1, 2, 4, and 5..................29

Table 7. Atmospheric corrosion data, silver. …………..............................................................34

Table 8. Atmospheric corrosion data, 2024-T2 aluminum...........................................................35

Table 9. Atmospheric corrosion data, 6061-T6 aluminum...............................................................35

Table 10. Atmospheric corrosion data, 7075-T6 aluminum.............................................................35

Table 11. Atmospheric corrosion data, C1010 steel. ...................................................................35

Table 12. Atmospheric corrosion data, CDA101 copper........................................................................35

Table 13. Strength and modulus of elasticity (stiffness) versus time of outdoor exposure. ..............36

Table 14. ROI calculation for plastic bridge performance without remote SPM system....................38

Table 15. ROI calculation for plastic bridge with remote SPM system................................................39 


\section{Preface}

This demonstration was performed for the Office of the Secretary of Defense (OSD) under Department of Defense (DoD) Corrosion Control and Prevention Project F08-AR13, "Remote Monitoring of Degradation of Steel and Reinforced Thermoplastic Composite Bridges." The proponent was the US Army Office of the Assistant Chief of Staff for Installation Management (ACSIM), and the stakeholder was the US Army Installation Management Command (IMCOM). The technical monitors were Daniel J . Dunmire (OUSD(AT\&L)), Paul M. Volkman (IMPW-E), and David N. Purcell (DAIM-FDF).

The work was performed by the Engineering and Materials Branch (CFM), Facilities Division (CF), US Army Engineer Research and Development Center - Construction Engineering Research Laboratory (ERDCCERL), Champaign, IL. The ERDC-CERL project managers were Mr. Richard Lampo and Mr. J ames Wilcoski. At the time this report was prepared, Vicki L. Van Blaricum was Chief, CEERD-CF-M, L. Michael Golish was Chief, CEERD-CF, and Martin J. Savoie (CEERD-CV-ZT) was the Technical Director for Installations. The Deputy Director of ERDC-CERL was Dr. Kirankumar Topudurti, and the Director was Dr. Ilker Adiguzel.

The following Fort Bragg personnel are gratefully acknowledged for their support and assistance in this project:

- Mr. Gregory Bean- Director, DPW, Fort Bragg, NC

- Mr. George Whitley- DPW, Fort Bragg, NC

- Mr. Fred Plummer- DPW, Fort Bragg, NC

- Mr. Lowell Stevens- Range Control, Camp Mackall, NC

- Mr. R.B. Gardner-Facilities Manager, Camp Mackall, NC

- SFC Dale Schrull- NCOIC, Camp Mackall, NC

The Commander and Executive Director of the ERDC was COL Kevin J . Wilson, and the Director was Dr. J effery P. Holland. 


\section{Unit Conversion Factors}

\begin{tabular}{|l|c|l|}
\hline Multiply & By & To Obtain \\
\hline degrees Fahrenheit & $($ F-32)/1.8 & degrees Celsius \\
\hline feet & 0.3048 & meters \\
\hline inches & 0.0254 & meters \\
\hline
\end{tabular}




\section{Introduction}

\subsection{Problem statement}

Working in cooperation with the Directorate of Public Works (DPW) at Fort Bragg, NC, the US Army Engineer Research and Development Center, Construction Engineering Research Laboratory (ERDC-CERL) designed and built a bridge constructed of an innovative thermoplastic composite material and design to replace an unserviceable wooden bridge at Camp Mackall (a sub-installation of Fort Bragg). This structure, Bridge T-8518, is made from approximately 85,000 pounds of recycled plastics. It is the first structure of its kind capable of supporting an M1A1 main battle tank with a military load class of 71 tons [1, 2, 3, 4], as shown in Figure 1 . The objective of the bridge design is to provide a low-maintenance, affordable structure using recycled materials and avoiding the use of any wood components, which require chemical treatments to fight rot or insect attack and costly routine maintenance to repair or replace deteriorated members. Details of the design and specifications for Bridge T-8518 are given in Appendix A. Information on the design approach as well as construction and inspection procedures are given in Appendix B.

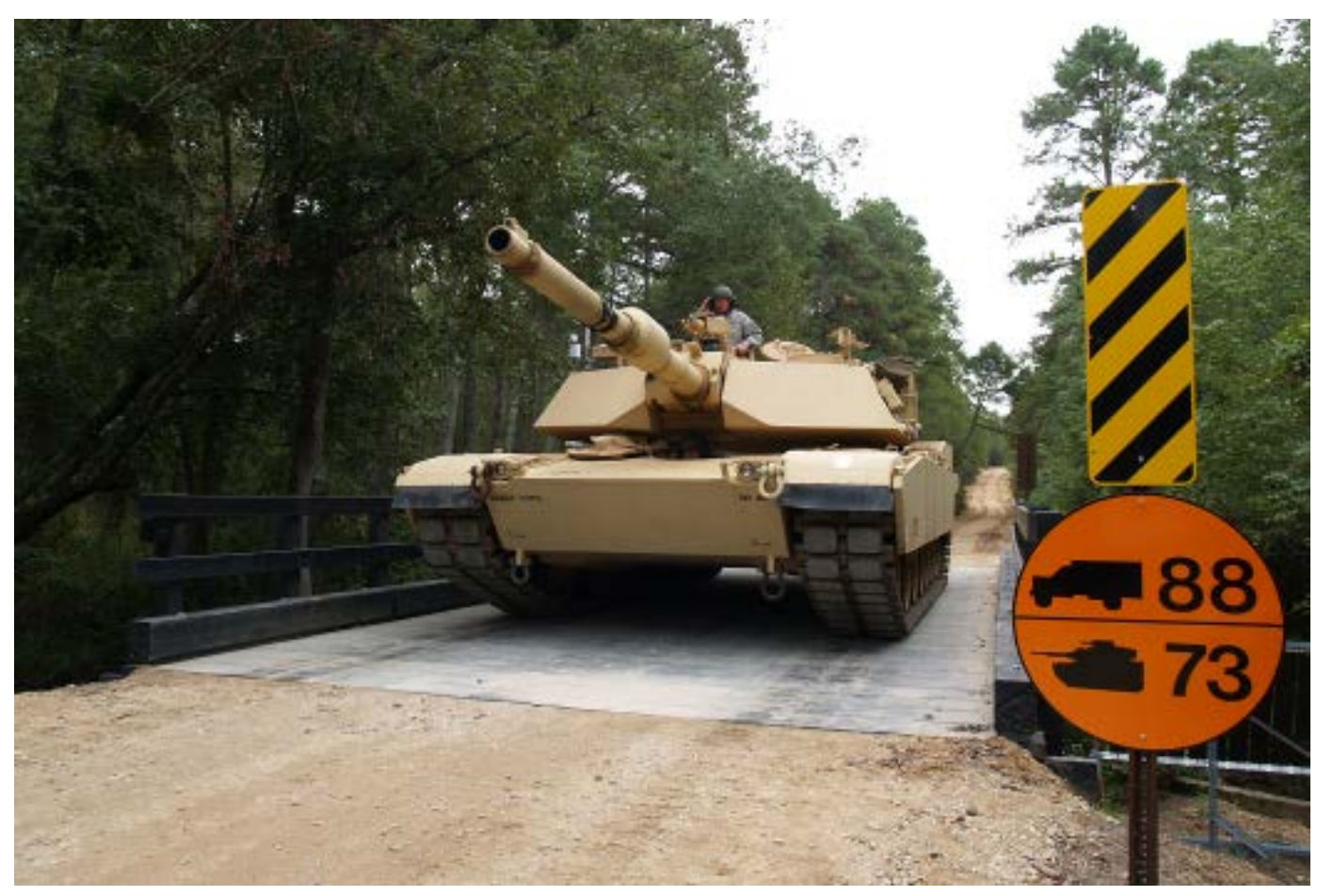

Figure 1. M1A1 Tank crossing thermoplastic bridge. 
As part of ongoing ERDC-CERL research to determine the long-term structural performance of the bridge, a structural performance monitoring (SPM) system was installed to remotely measure the induced strains and deflections in the bridge structure under both moving vehicular (live) loads and static (dead) loads. The purpose of the SPM system is to collect data for use in evaluating how the bridge responds to heavy vehicle loads and thermal (solar) loads. Measurements will be monitored over time to observe for performance changes as the bridge undergoes more load cycles and ages. The response of the bridge under static loading is also of interest to evaluate creep of the thermoplastic composite materials over time.

\subsection{Objective}

The objectives of this project are to design, install, and demonstrate a SPM system in order to assess the material and long-term structural performance of the innovative thermoplastic composite materials and designs used for Bridge T-8518. (See Appendix C for the full text of the Project Management Plan.)

\subsection{Approach}

Because Bridge T-8518 is in a remote location, a fully automated system was needed with enough intelligence to detect and capture the vehicle crossing events that are of interest without operator assistance. The bridge site is also in an undeveloped area with no power or communications facilities. Therefore, the design requirements included using battery power with solar recharge and wireless cellular communications. A comprehensive weather station is also included for evaluating the exposure of the material to weathering, and a video camera is used to capture images of the vehicles that cross the bridge. Data are collected from the site automatically using the cellular communications and loaded into a database that can be viewed in real-time over the web.

The monitoring system collects data for both static and dynamic loading conditions. The dynamic loading data are used for evaluating how the bridge responds to a moving vehicle load, and is read at a frequency of $100 \mathrm{~Hz}$ during crossings by heavy vehicles. Deflection, strain, and temperature data are collected under static loads to evaluate how the bridge responds to seasonal temperature changes and degradation over time. 
The response parameter data for both moving vehicle loading events and static conditions are transmitted from the bridge site using cellular radio modems and are stored in a central project database. A data management and presentation tool was implemented that utilizes a structured query language (SQL) database and web browser interface that allow ERDCCERL personnel to access the data using their existing high-speed internet connections. The data presentation tool provides a graphical interface to the monitoring system data by displaying a clickable site plan of the bridge that allows the users to click on a particular area of the bridge to see plots of the data or to export the data for additional analysis. 


\section{Technical Investigation}

The purpose of the SPM system is to collect the data needed for evaluating the durability and performance of the bridge. The data include deflection of structural elements, strain for use in calculating stress, surface temperatures, images of the heavy vehicles using the bridge, and weather parameters for evaluating material exposure. Specifically, the monitoring system was designed to meet the following criteria:

1. Collect and present vertical deflection, strain, and surface temperature data for girders G3, G4, and G5 at midspan of spans 2 and 3, as shown on the site plan, Figure 2.

2. Collect and present strain and surface temperature data for girders G3, G4, and G5 on the top of the girders at the pile cap 3 support location, as shown on Figure 2.

3. Collect and present vertical displacement and surface temperature data for pile caps 3 and 4, as shown on Figure 2.

4. Collect and present strain and surface temperature data for the bottom of a deck board at one location.

5. Collect and present weather data, including air temperature and relative humidity, wind speed and direction, rainfall, and ultraviolet A (UVA) radiation.

6. Collect the deflection and strain data at a frequency of $100 \mathrm{~Hz}$ during moving vehicle load events of interest. Collect the data once per hour under dead load conditions for evaluating the effect of seasonal temperature fluctuations and long-term creep.

7. Provide a strain threshold that can be adjusted to allow for only capturing deflection and strain data for heavy vehicle loads that are of interest.

8. Record a digital image of the heavy vehicles that are captured as loading events of interest and save the image as a J PEG (J oint Photographic Experts Group) file.

9. Collect the weather station data at a frequency of 15 minutes. 


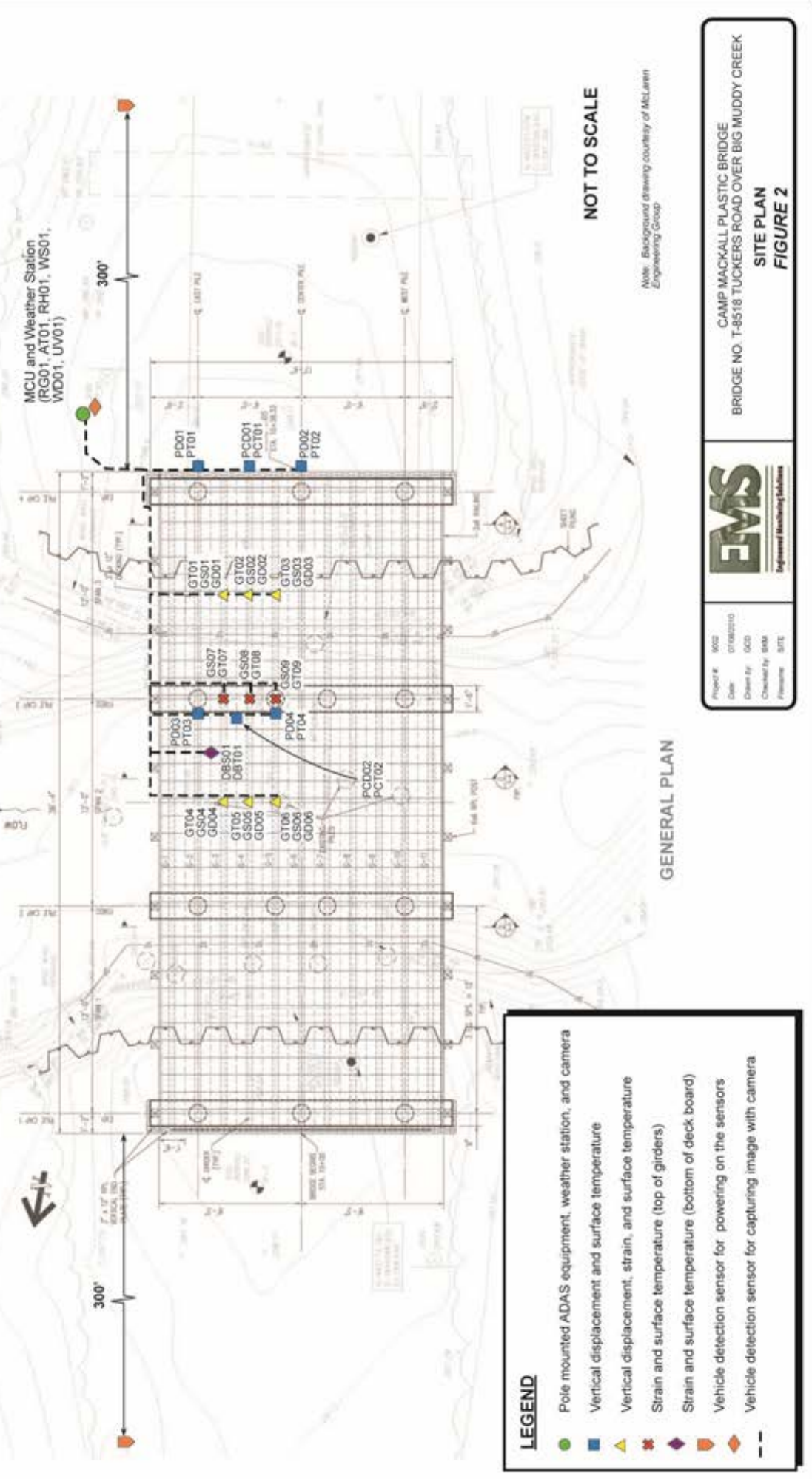

Figure 2. Site plan. 


\subsection{Monitoring system overview}

The monitoring system consists of various sensors and two measurement and control units (MCUs) for data collection. The MCUs read, process, and store data from the various sensors. The processing consists of performing calculations on the raw sensor readings to convert the data from raw units to engineering units. The processed data are then temporarily stored in each MCU until it is forwarded to the data server and web server. The sensors are connected to each MCU using signal cables. The MCUs selected for the system are manufactured by Campbell Scientific and are discussed in more detail in Section 2.2.6. The sensors and MCUs were installed at the locations shown on Figure 2.

Figure 3 presents a dataflow diagram that illustrates how the data are collected and provided to the end users. Both of the MCUs communicate with a data server, which is located off site using a cellular phone modem link. The data server software is configured to contact the MCUs once per day to download any new data that have been collected. The data server is also running MLWeb, by Canary Systems*, a web-enabled data management and presentation software tool. The data server/ web server is hosted by Canary Systems in New Hampshire. The software tool includes a database with a graphical interface that can be accessed over the internet using a web browser such as Microsoft Internet Explorer. The collected data are automatically loaded into the database for simultaneous viewing by multiple users.

\subsection{Installation of the technology}

\subsubsection{Vertical deflections}

Vertical displacements of the piles and vertical deflections of the pile caps and girders are measured using Micro-Epsilon optoNCDT 1300 Laser Sensors. A product data sheet for the sensors is provided in Appendix D. The photoelectric sensor uses a red laser to detect very small changes in distance between the sensor and a reference surface. The sensor can detect movements as small as approximately 0.002 inches under static conditions and 0.01 inches under dynamic loading conditions.

\footnotetext{
* Canary Systems, Inc. 75 Newport Rd, Suite 201, New London, NH 03257.
} 


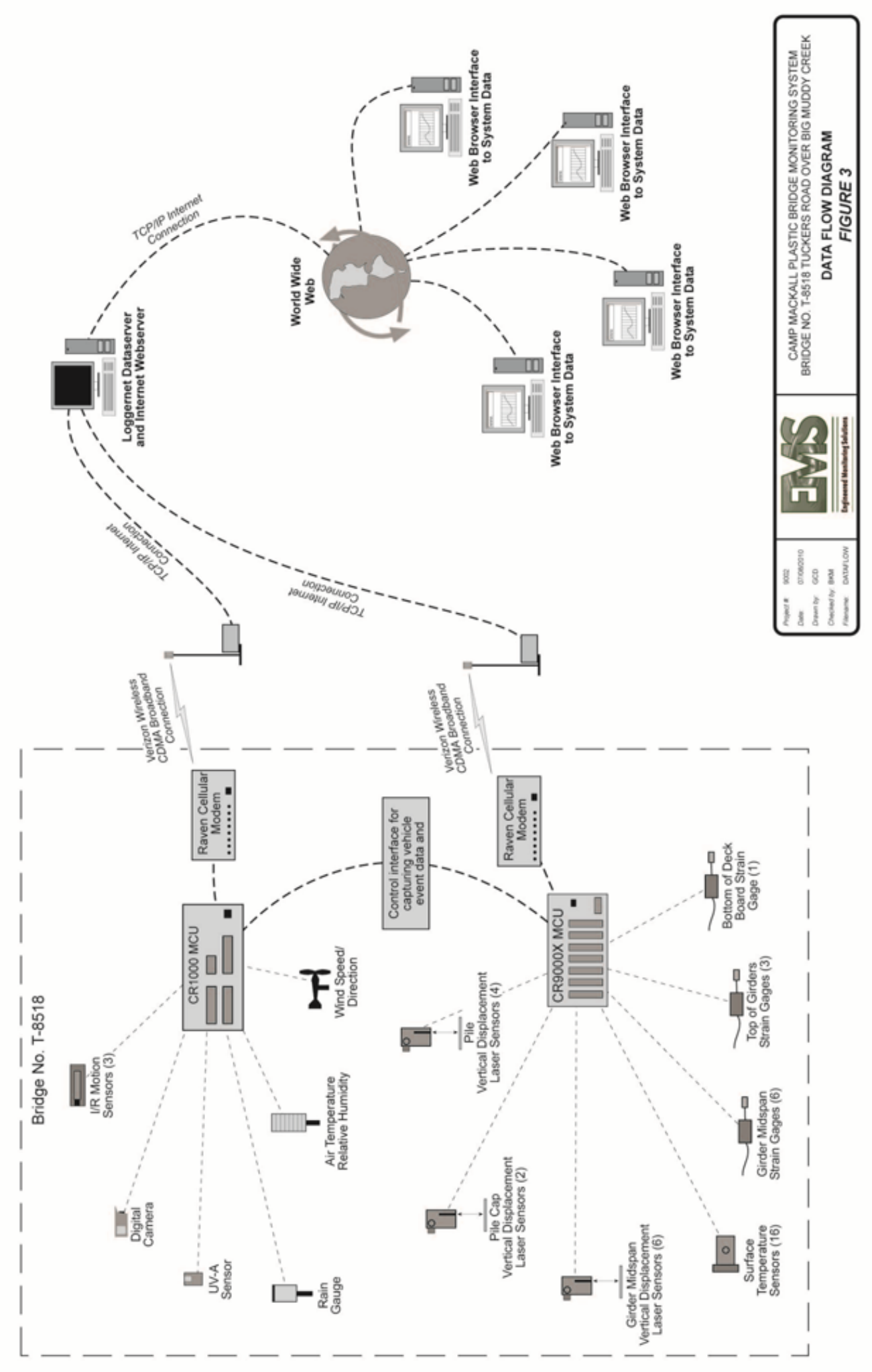

Figure 3. Data flow diagram. 
The sensors are attached to the structural elements in a vertical orientation with the laser aimed downward. The reference surface for the distance measurements is a 2 inch square stainless steel plate that is located approximately 6 inches below the bottom of the sensor. Figure 4 shows a picture of a typical installation at the midspan of span 2 .

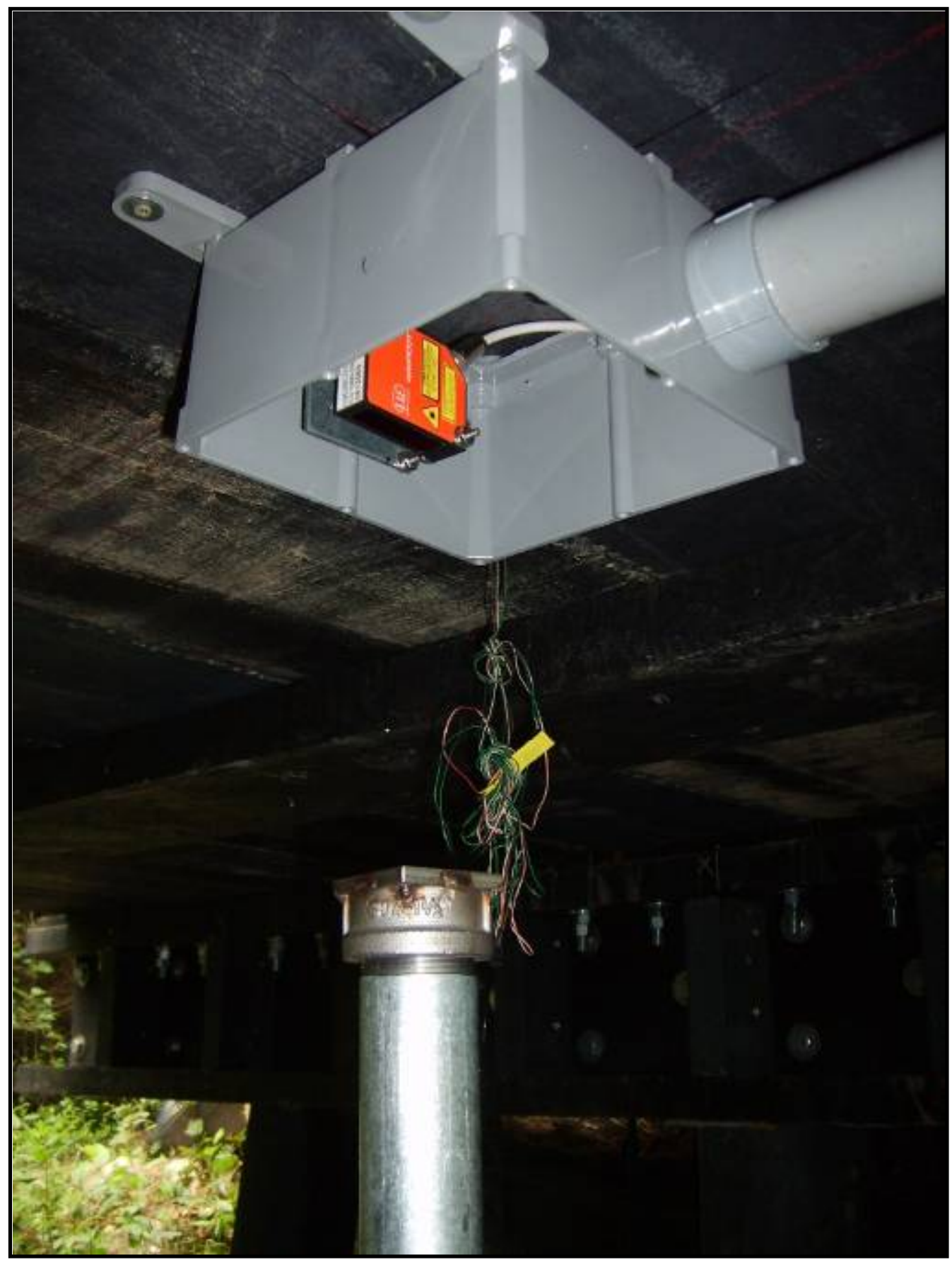

Figure 4. Typical laser sensor installation (midspan of span 2). 
The mounting of the reference surface varies depending upon the location on the bridge. For the girder deflection measurements at the midspan of span 2 and the pile cap and pile displacements on pile cap 3, the reference surfaces are attached to the top of 2 inch diameter galvanized riser pipes that were driven into the stream bed. A steel channel that is attached to the sheet piling and cantilevered into position using angle bracing was installed to provide the reference surface for the girder deflection measurements at the midspan of span 3. For the pile cap and pile displacement measurements on pile cap 4, 12 inch by 12 inch concrete pavers were set in the abutment soil backfill and the 2 inch square steel reference surface was attached to the pavers using a concrete adhesive.

\subsubsection{Strain gages}

The strain measurements are made using Hitec Products, Inc., Model HB full bridge strain gages. A data sheet showing the gage details and specifications is included as Appendix E. The strain gages consist of resistance foil gages that are bonded to a stainless steel shim and encapsulated in a waterproofing compound. The steel shims are attached to the thermoplastic surface using an adhesive made for polyethylene material called Loctite Plastic Bonder. The HB gages include a full Wheatstone bridge with a signal amplifier and excitation voltage regulator. A thin slice of the thermoplastic bridge material was incorporated into the completion resistor block to maintain temperature compensation compatibility with the bridge material. The strain gages are calibrated to provide an output of \pm 5 volts of direct current (VDC) for strain of $\pm 3,000$ microstrain. Figure 5 shows a typical installation of the active strain gage. The shim for the strain gage shown in Figure 5 was bonded to the top of the girder at the location of pile cap 3 and is covered with a black waterproofing compound.

The MCU compares all of the strain gage readings except the deck board sensor to a predetermined threshold value. The deck board strain gage was found to be too responsive to smaller vehicles, so it is not included in the screening for the occurrence of a heavy vehicle crossing event. If any of the strain gage readings exceed the threshold, the MCU captures the strain and deflection data for a period of time starting 8 seconds before the threshold exceedance and ending 8 seconds after the exceedance occurred. The 16 second event captures baseline data from before the vehicle was on the bridge and after the vehicle had passed, along with the dynamic response of the bridge to the moving vehicle load. 


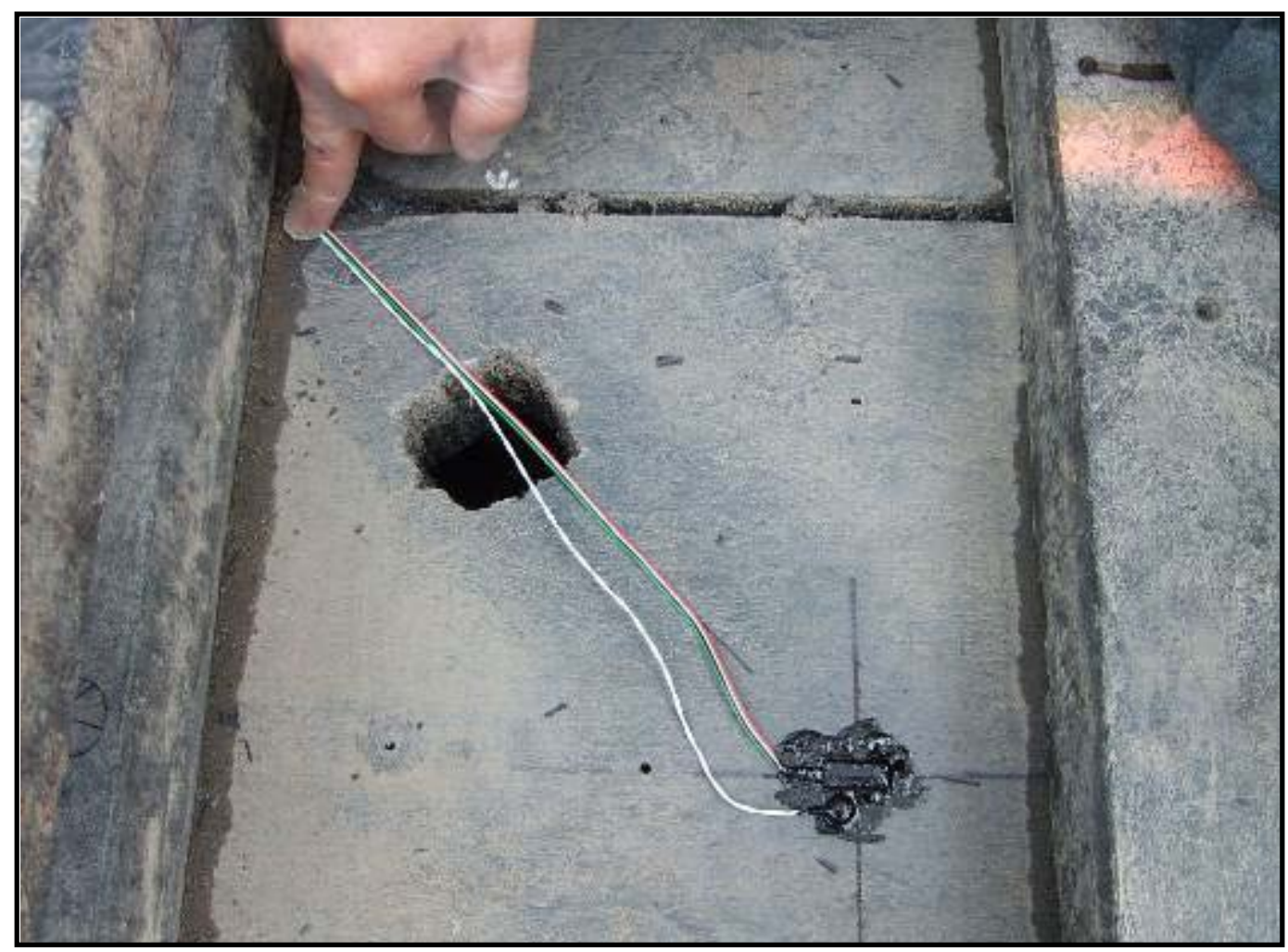

Figure 5. Typical strain gage and surface temperature sensor installation (top of girders at pile cap 3).

\subsubsection{Surface temperatures}

Surface temperature measurements are made using Omega Engineering, Inc., Model ON-909 temperature probe sensors. The surface temperature probe is a thermistor mounted within a narrow plate that is bonded to the surface of the desired bridge component using Loctite Plastic Bonder. The round sensor shown mounted next to the strain gage on Figure 5 is a typical installation for the surface temperature probe. A product data sheet for the sensor is provided as Appendix F.

\subsubsection{Vehicle crossing images}

The images of heavy vehicles crossing the bridge are captured using a Model CC640 digital camera manufactured by Campbell Scientific. The camera is made for operation in harsh locations and is fully integrated with the Campbell Scientific data acquisition equipment. The MCU triggers an image capture when the strain threshold has been exceeded and stores the resultingJ PEG image file for later downloading. The system has also been configured to allow for photographing any vehicle that crosses the bridge. It accomplishes this by monitoring an infrared motion sensor 
that is mounted below the camera and pointing at the bridge. The programming of the MCU provides the ability to either capture an image of every vehicle that triggers the infrared sensor or to only capture images of heavy vehicles that cause the strain threshold to be exceeded. A product data sheet for the camera is provided in Appendix G.

\subsubsection{Weather station}

The MCU that controls the camera also monitors a series of weather station instruments, including a wind monitor, temperature and relative humidity probe, rain gage, and UVA sensor. The wind monitor is an RM Young Model 05103 Wind Monitor. The wind speed sensor is a four-blade propeller that rotates to produce a signal with a frequency directly proportional to wind speed. The wind direction sensor is a vane connected to a potentiometer. When an excitation voltage is applied to both sensors, the output voltage is directly proportional to the wind speed and vane angle, respectively. The wind speed sensor has a range of 0-224 mph with an accuracy of the larger of $\pm 1 \mathrm{mph}$ or $1 \%$ of the reading. The wind direction sensor has an accuracy of \pm 3 angular degrees. A product data sheet for the wind monitor is included in Appendix $\mathrm{H}$.

The temperature and relative humidity probe is an RMYoung Model 41372 Temperature and Relative Humidity Probe. A data sheet for the probe is included in Appendix I. The probe has a humidity sensor and platinum RTD for measuring temperature. The temperature probe has a range of $-50-150{ }^{\circ} \mathrm{F}$ with an accuracy of $\pm 0.1^{\circ} \mathrm{C}\left( \pm 0.2^{\circ} \mathrm{F}\right)$ at $0{ }^{\circ} \mathrm{C}$. The relative humidity probe has a range of $0-100 \%$ relative humidity and an accuracy of $\pm 2 \%$ relative humidity at $20^{\circ} \mathrm{C}$. The probe is intended for use in weather station applications where there is prolonged exposure to outdoor conditions. The probe is installed in a shield to reduce temperature measurement errors arising from direct sunlight on the probe.

The rain gage is an RM Young Model 52202 Tipping Bucket Rain Gage. During a rain event, the bucket is filled to a predetermined amount, tips over, and thus empties the water through the bottom of the instrument. Each time the bucket tips, the instrument sends a signal (count) to the MCU. By counting the number of tips, a calculation of total precipitation is determined. The MCU is programmed to calculate and store the total precipitation for a 24 -hour period. A product data sheet for the rain gage is included as Appendix J . 
A sensor manufactured by the Solar Light Company is installed to measure the intensity of UVA radiation. This sensor was selected to specifically measure UVA radiation because wavelengths in the 320 - 400nm range are known to cause degradation of high-density polyethylene (HDPE), the predominant component of the thermoplastic composite material used to fabricate the bridge. The Model PMA2111 UVA detector provides fast and accurate irradiance measurement in the UVA region. Its spectral response covers the 320 - 400nm range. The detector's enclosure is hermetically sealed and suitable for long-term outdoor operation. A product data sheet for the UVA sensor is included as Appendix K.

Each of the weather station instruments is mounted on the MCU enclosure pole (Figure 6).

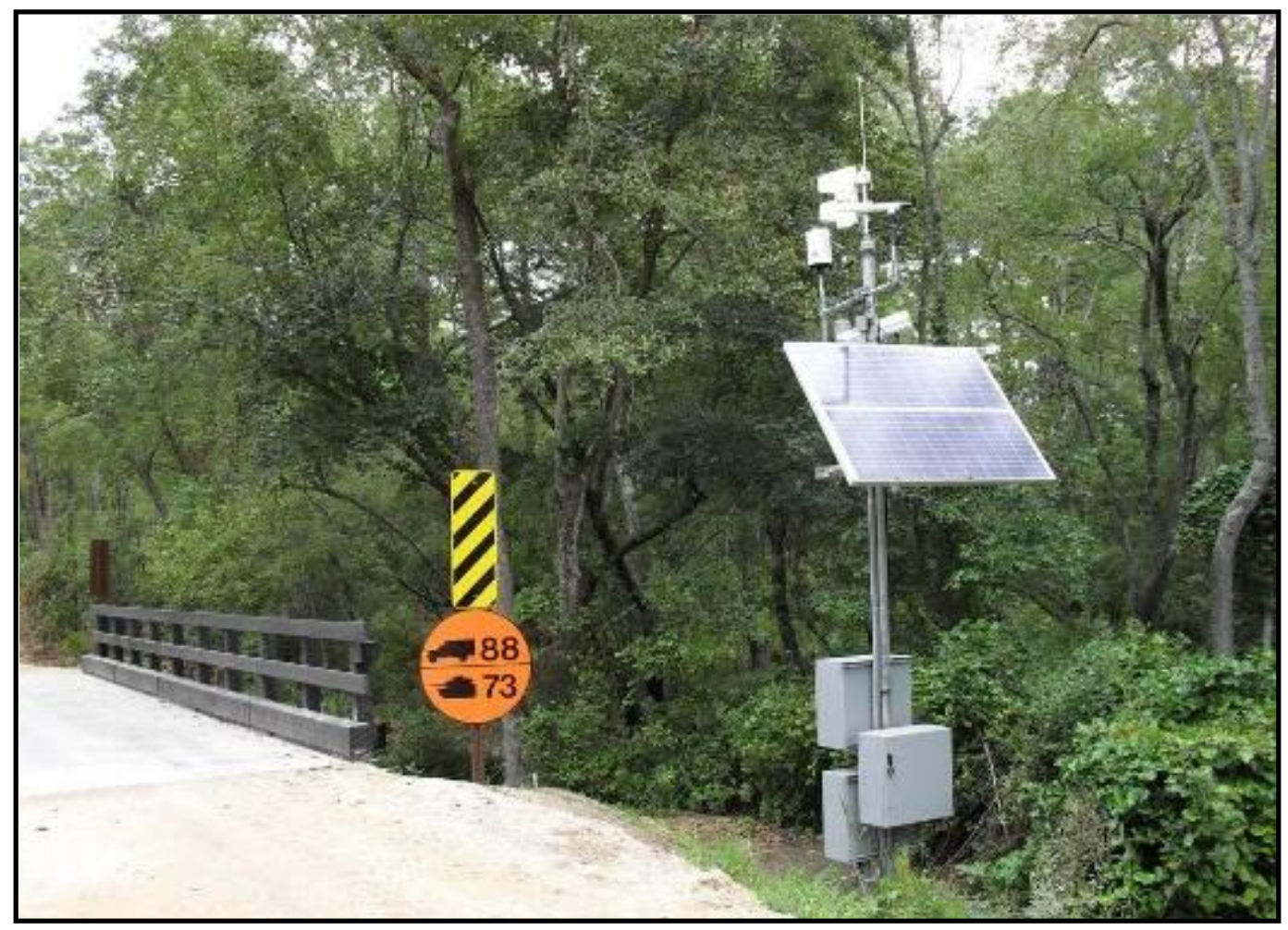

Figure 6. Automated data acquisition equipment installation and weather station sensors.

\subsubsection{Automated data acquisition}

Automated data acquisition is accomplished with the use of two MCUs manufactured by Campbell Scientific. A Model CR9000X is used to perform the measurement, calculations, and temporary storage of data from the deflection, strain, and surface temperature sensors. A Model CR1000 is used to control the operation of the digital camera, and to monitor the 
weather station instruments. The CR1000 also monitors two wireless infrared motion sensors that detect a vehicle approaching the bridge.

Both MCUs are mounted inside a painted gray, steel National Electrical Manufacturers Association NEMA-4-rated enclosure installed on a pole near the south abutment of the bridge, as shown in Figure 6. The CR9000X is programmed to read the deflection, strain, and temperature sensors at the required intervals and perform the necessary calculations to provide the results in engineering units. A product data sheet describing the CR9000X is provided in Appendix L. To evaluate the effects of thermal loading and long-term creep, the CR9000X stores data from the deflection, strain and surface temperature sensors at a frequency of once per hour. In addition, the CR9000X stores deflection and strain data at a frequency of $100 \mathrm{~Hz}$ during a heavy vehicle crossing event.

The CR1000 is programmed to read the weather station sensors every 15 minutes. It also controls the capturing of images from the camera and monitors the status of two infrared motion sensors located 300 feet away from either end of the bridge. The CR1000 monitors the infrared sensors once per second. When the sensors indicate that a vehicle is approaching the bridge, it turns on the power to the laser and strain gage sensors. Because the system uses a stand-alone 12 VDC solar-charged power supply, the sensors are normally off to conserve power. Appendix M provides a product data sheet with details about the CR1000.

Each MCU communicates with the data server using a Raven XT cellular modem. Appendix N includes a product data sheet describing the modem. The LoggerNet software running on the data server is configured to contact the MCUs once a day to download any new data.

The data acquisition equipment is powered using two 160 amp-hour 12VDC batteries recharged by two 140-watt solar panels (see Figure 6).

\subsubsection{Data management and presentation}

Remote monitoring of the system is accomplished from a data server running Campbell Scientific LoggerNet software and the data management and presentation software tool MLWeb, by Canary Systems. A product data sheet providing additional information on LoggerNet is included in Appendix O. MLWeb includes a database that can be accessed over the internet using a web browser. The LoggerNet software contacts the CR9000X 
and the CR1000 once a day to download any new data, which are then automatically loaded into the database for viewing by multiple users. Figure 7 shows a screen capture of the main page of the MLWeb project user interface. Data can be viewed in quick plots or downloaded for analysis using other software tools such as Microsoft Excel, by clicking on the sensor icons or through the use of pull-down menus. A brief summary of the data presentation capabilities of MLWeb is included in Appendix P.

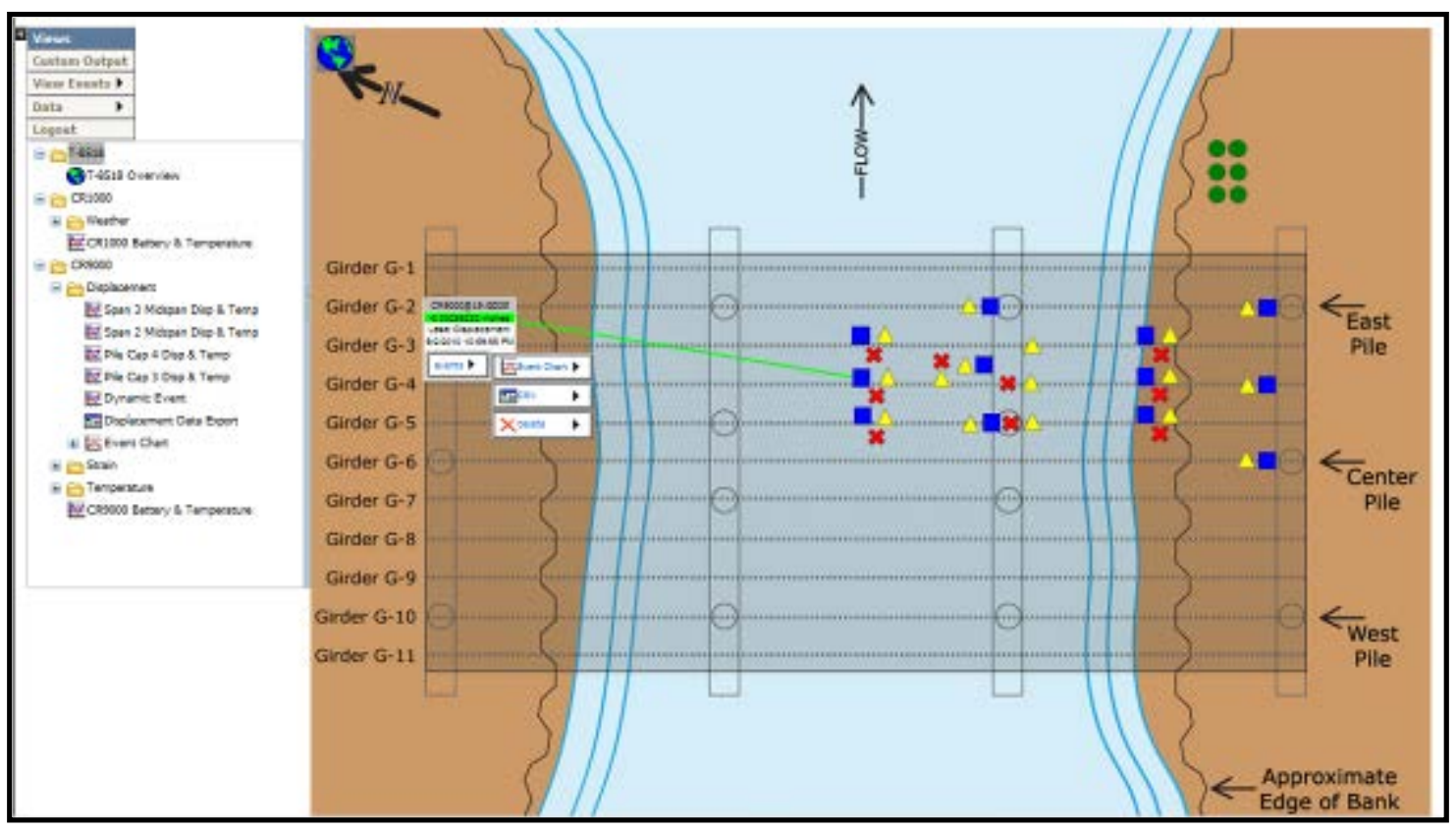

Figure 7. Web-enabled project database interface.

\subsection{Operation and monitoring}

The SPM system was used to collect data for evaluating the performance of Bridge T-8518 under both dynamic and static loading conditions. The dynamic loading response has been obtained both by performing load tests under controlled conditions with heavy vehicles and using the system's automated monitoring functions to capture the response from heavy vehicles that are using the bridge. The static load responses were monitored primarily to track data related to daily and seasonal thermal cycles. The static conditions were also monitored to observe for long-term creep. 


\subsubsection{Load testing}

The objectives of the load testing* were to (1) compare the response of the bridge under heavy loads with the expected performance based on design assumptions and (2) evaluate whether the performance changes over time. To accomplish these objectives, five load tests were performed. The first test was performed in J uly 2009 using an M1089 wrecker as the test vehicle. Figure 8 shows a picture of the M1089, which has a rated gross weight of 34,573 pounds $(15,682 \mathrm{~kg})$.

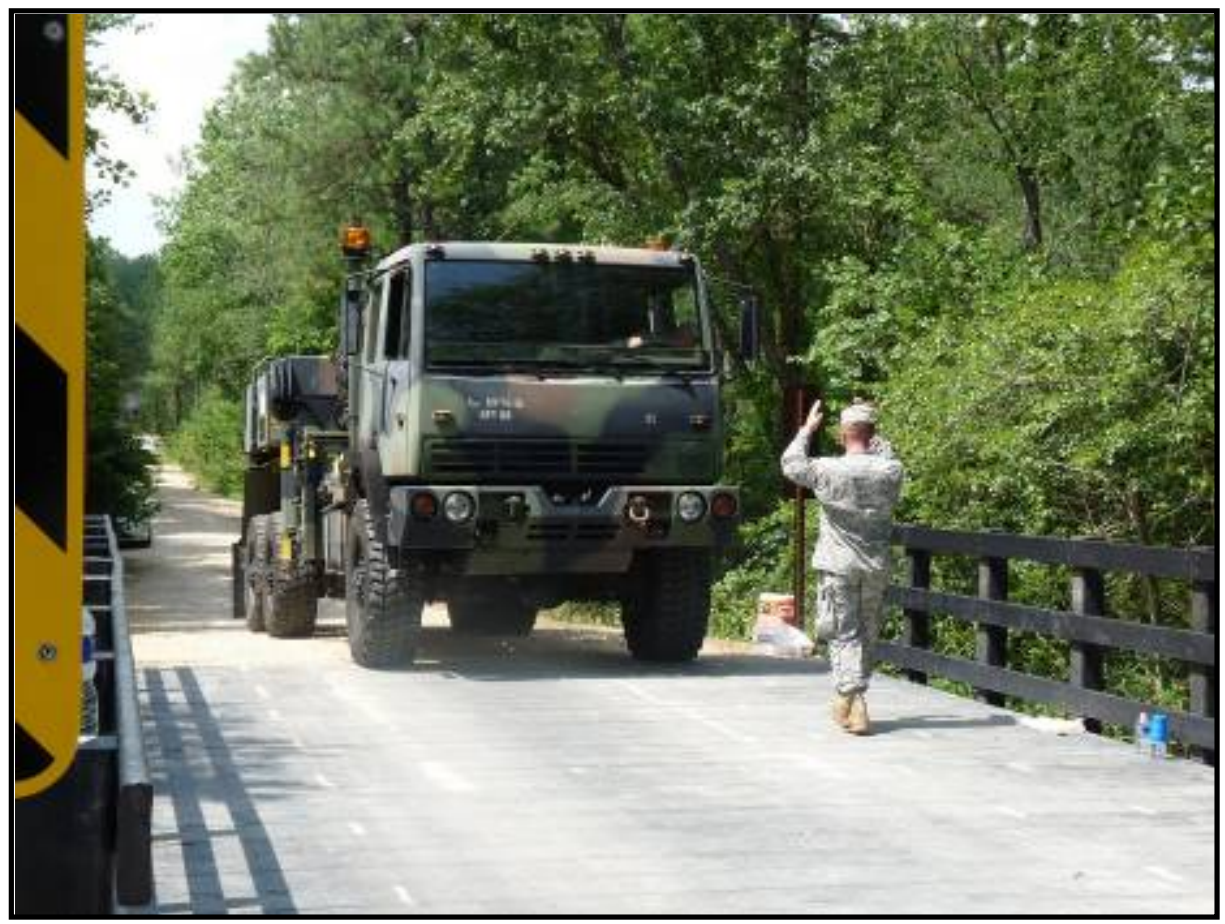

Figure 8. Load test vehicle - M1089 Wrecker.

The testing involved driving the M1089 over the bridge at very slow speeds with the driver-side wheels positioned over girders 3,4 , and 5 . The second part of the test was to position the test vehicle on the bridge at the locations that produced the maximum deflections in sensors GS05 (span 2 midspan) and GS02 (span 3 midspan) for the front and rear wheels. The last part of the test was to drive the vehicle over girder 4 at speeds ranging from 10 - $25 \mathrm{mph}$ to observe the effects of vehicle speed on the bridge response. The plan for load test 1 is presented in Table 1.

\footnotetext{
* Bridge T-8518 was given a load rating classification of 88 tons for wheeled vehicles and 73 tons tracked vehicles based on a load-rating test performed by Bridge Diagnostic, Inc., on 10 June 2009 [5].
} 
Table 1. Test plan for load test 1, July 2009.

\begin{tabular}{|c|c|c|c|}
\hline Test Vehicle & Loading I.D. & Load Location & Vehicle Speed \\
\hline \multirow[t]{9}{*}{ M1089 Wrecker } & A2 & Driver-side front wheel over girder 4 & $\begin{array}{l}\text { Slow as possible, continuously } \\
\text { moving }\end{array}$ \\
\hline & A3 & Driver-side front wheel over girder 3 & $\begin{array}{l}\text { Slow as possible, continuously } \\
\text { moving }\end{array}$ \\
\hline & A4 & Driver-side front wheel over girder 5 & $\begin{array}{l}\text { Slow as possible, continuously } \\
\text { moving }\end{array}$ \\
\hline & A5 & $\begin{array}{l}\text { Driver-side front wheel over deck } \\
\text { board sensor DBS01 }\end{array}$ & $\begin{array}{l}\text { Slow as possible, continuously } \\
\text { moving }\end{array}$ \\
\hline & B1 & $\begin{array}{l}\text { GD05 maximum deflection front } \\
\text { wheel over girder } 4,2-3 / 4 \text { inches } \\
\text { south of GD05. } \\
\text { GD02 maximum deflection front } \\
\text { wheel over girder } 4,6 \text { inches north of } \\
\text { GD02. } \\
\text { GD05 maximum deflection rear } \\
\text { wheel over girder } 4,6 \text { inches south of } \\
\text { GD05. } \\
\text { GD02 maximum deflection rear } \\
\text { wheel over girder 4, 13-1/2 inches } \\
\text { north of GD02. }\end{array}$ & $\begin{array}{l}\text { Finding location of maximum } \\
\text { deflections }\end{array}$ \\
\hline & C1 & Driver-side front wheel over girder 4 & $10 \mathrm{mph}$ \\
\hline & $\mathrm{C} 2$ & Driver-side front wheel over girder 4 & $15 \mathrm{mph}$ \\
\hline & C3 & Driver-side front wheel over girder 4 & $20 \mathrm{mph}$ \\
\hline & $\mathrm{C} 4$ & Driver-side front wheel over girder 4 & $25 \mathrm{mph}$ \\
\hline
\end{tabular}

The second load test was performed in September 2009. The purpose was to perform additional testing with the M1089 at varying speeds over girders 3 and 5, and to perform testing with a much heavier M1A1 tank (Figure 9). The test plan for both vehicles is presented in Table 2. For the M1A1, the maximum deflections were evaluated as well as the effects of vehicle speeds. Because of the width of the tank, the driver-side track could only be placed over girder 4 . 


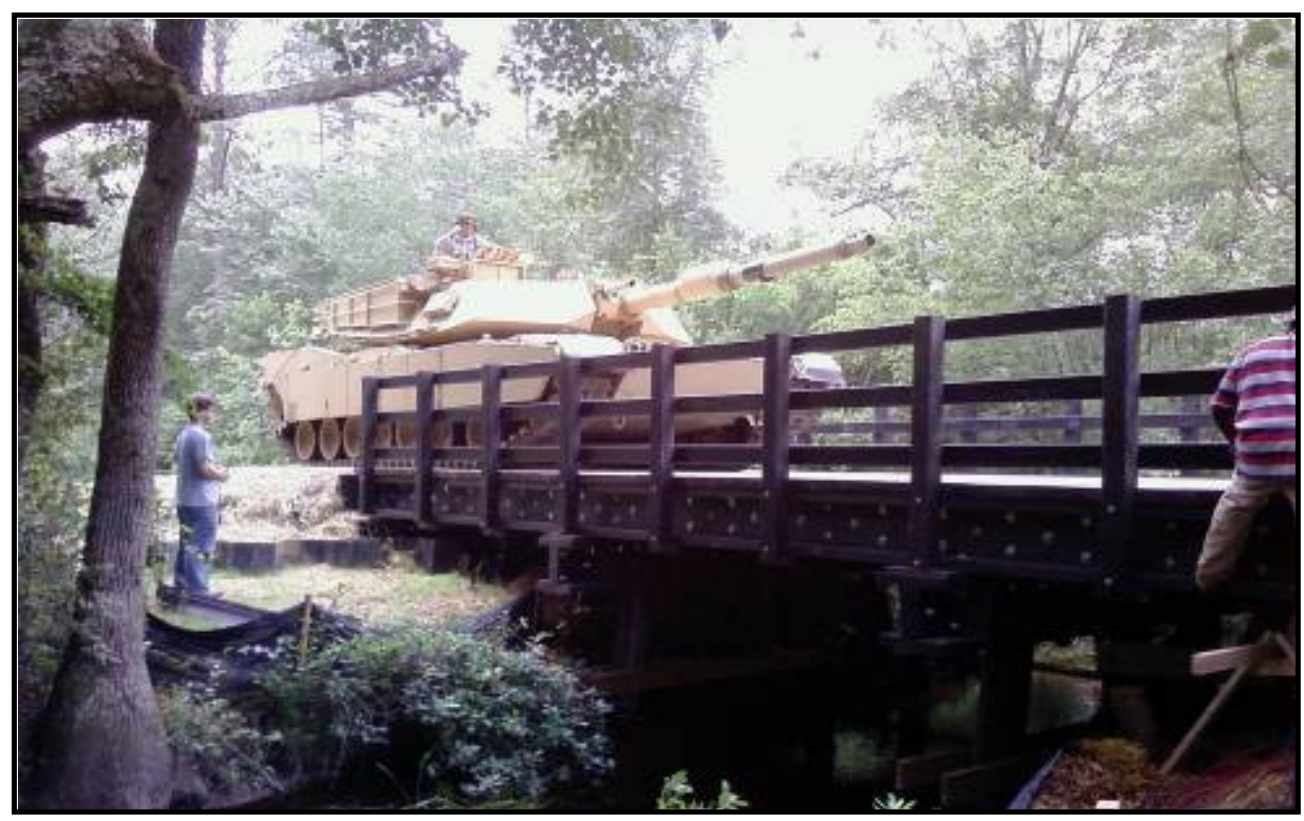

Figure 9. Load test vehicle - M1A1 main battle tank.

Table 2. Test plan for load test 2, September 2009.

\begin{tabular}{|c|c|c|c|}
\hline Test Vehicle & Loading I.D. & Load Location & Vehicle Speed \\
\hline \multirow[t]{6}{*}{ M1089 Wrecker } & D1 & Driver-side front wheel over girder 3 & $15 \mathrm{mph}$ \\
\hline & D2 & Driver-side front wheel over girder 3 & $20 \mathrm{mph}$ \\
\hline & D3 & Driver-side front wheel over girder 3 & $25 \mathrm{mph}$ \\
\hline & G1 & Driver-side front wheel over girder 5 & $15 \mathrm{mph}$ \\
\hline & G2 & Driver-side front wheel over girder 5 & $20 \mathrm{mph}$ \\
\hline & G3 & Driver-side front wheel over girder 5 & $25 \mathrm{mph}$ \\
\hline \multirow[t]{8}{*}{ M1 Tank } & E1 & $\begin{array}{l}\text { GD04 maximum deflection left track over } \\
\text { girder } 3 \text {. }\end{array}$ & $\begin{array}{l}\text { Finding location of maximum } \\
\text { deflections }\end{array}$ \\
\hline & E2 & $\begin{array}{l}\text { GD01 maximum deflection left track over } \\
\text { girder } 3 .\end{array}$ & $\begin{array}{l}\text { Finding location of maximum } \\
\text { deflections }\end{array}$ \\
\hline & E3 & Left track over girder 3 & $\begin{array}{l}\text { Slow as possible, continuously } \\
\text { moving }\end{array}$ \\
\hline & E4 & Left track over girder 4 & $\begin{array}{l}\text { Slow as possible, continuously } \\
\text { moving }\end{array}$ \\
\hline & F1 & Left track over girder 3 & $10 \mathrm{mph}$ \\
\hline & $\mathrm{F} 2$ & Left track over girder 3 & $15 \mathrm{mph}$ \\
\hline & F3 & Left track over girder 3 & $20 \mathrm{mph}$ \\
\hline & $\mathrm{F} 4$ & Left track over girder 3 & $25 \mathrm{mph}$ \\
\hline
\end{tabular}

In J anuary 2010 the third load test was performed. An M978A2R1 tanker filled with 2,000 gallons of diesel fuel was used as the test vehicle. The M978A2R1 has a curb weight of 37,300 pounds (16,918 kg), and 2,000 gallons of diesel fuel weights approximately 14,200 pounds $(6,441 \mathrm{~kg})$. The 
total weight of the tested vehicle is 51,500 pounds (23,360 kg). Figure 10 shows a picture of the M978A2R1. The test plan is presented as Table 3. The testing included loading girders 3,4 , and 5 ; finding the locations of the maximum deflections; and evaluating the effects of vehicle speed on the three girders.

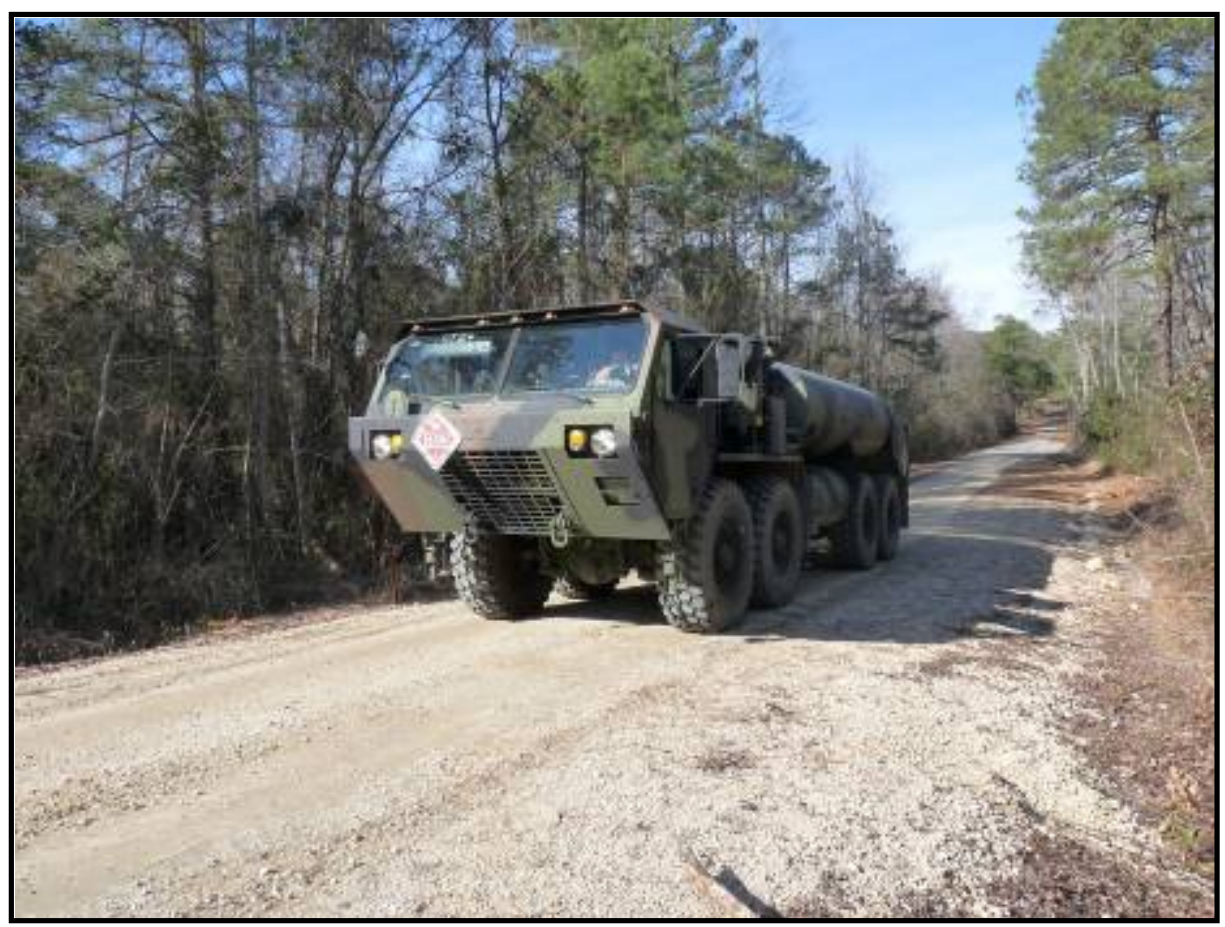

Figure 10. Load test vehicle - M978A2R1 tanker.

Table 3. Test plan for load test number 3, January 2010.

\begin{tabular}{|l|l|l|l|}
\hline Test Vehicle & Loading I.D. & Load Location & Vehicle Speed \\
\hline $\begin{array}{l}\text { M978A2R1 } \\
\text { tanker (loaded } \\
\text { with 2,000 } \\
\text { gallons of diesel } \\
\text { fuel) }\end{array}$ & A2A & Driver-side front wheel over girder 4 & $\begin{array}{l}\text { Slow as possible, continuously } \\
\text { moving }\end{array}$ \\
\cline { 2 - 4 } & A4A & Driver-side front wheel over girder 3 & $\begin{array}{l}\text { Slow as possible, continuously } \\
\text { moving }\end{array}$ \\
\cline { 2 - 4 } & A5A & Driver-side front wheel over girder 5 & $\begin{array}{l}\text { Slow as possible, continuously } \\
\text { moving }\end{array}$ \\
\cline { 2 - 4 } & B1A & $\begin{array}{l}\text { Driver-side front wheel over deck board sensor } \\
\text { DBS01 }\end{array}$ & $\begin{array}{l}\text { Slow as possible, continuously } \\
\text { moving }\end{array}$ \\
\cline { 2 - 4 } & $\begin{array}{l}\text { GD05 maximum deflection front wheel over } \\
\text { girder 4, 11-1/2 inches south of GD05. } \\
\text { GD02 maximum deflection front wheel over } \\
\text { girder 4, 5-1/2 inches south of GD02. } \\
\text { GD05 maximum deflection rear wheel over } \\
\text { girder 4, 4-1/2 inches north of GD05. } \\
\text { GD02 maximum deflection rear wheel over } \\
\text { girder 4, 3 inches north of GD02. }\end{array}$ & $\begin{array}{l}\text { Finding location of maximum } \\
\text { deflections }\end{array}$ \\
\hline
\end{tabular}




\begin{tabular}{|l|l|l|l|}
\hline Test Vehicle & Loading I.D. & Load Location & Vehicle Speed \\
\hline & C1A & Driver-side front wheel over girder 4 & $10 \mathrm{mph}$ \\
\cline { 2 - 4 } & C2A & Driver-side front wheel over girder 4 & $15 \mathrm{mph}$ \\
\cline { 2 - 4 } & C3A & Driver-side front wheel over girder 4 & $20 \mathrm{mph}$ \\
\cline { 2 - 4 } & C4A & Driver-side front wheel over girder 4 & $25 \mathrm{mph}$ \\
\hline & D1A & Driver-side front wheel over girder 3 & $15 \mathrm{mph}$ \\
\hline & D2A & Driver-side front wheel over girder 3 & $20 \mathrm{mph}$ \\
\cline { 2 - 4 } & D3A & Driver-side front wheel over girder 3 & $25 \mathrm{mph}$ \\
\cline { 2 - 4 } & G1A & Driver-side front wheel over girder 5 & $15 \mathrm{mph}$ \\
\cline { 2 - 4 } & G2A & Driver-side front wheel over girder 5 & $20 \mathrm{mph}$ \\
\cline { 2 - 4 } & G3A & Driver-side front wheel over girder 5 & $25 \mathrm{mph}$ \\
\hline
\end{tabular}

The fourth load test was performed in August 2010. The test vehicles included an M1089 and an M88 Recovery Vehicle. The M88 is a very heavy track mounted vehicle that weighs 140,000 pounds. The testing plan is presented as Table 4. The purpose of the testing for the M1089 was to repeat the tests from 2009 for comparison to evaluate for changes in performance with time. The M88 was used as a heavier load to test the response of girder \#3.

Table 4. Test plan for load test 4, August 2010.

\begin{tabular}{|c|c|c|c|}
\hline Test Vehicle & Loading I.D. & Load Location & Vehicle Speed \\
\hline \multirow[t]{10}{*}{ M1089 Wrecker } & A2B & Drivers side front wheel over Girder \#4 & $\begin{array}{l}\text { Slow as possible, continuous- } \\
\text { ly moving }\end{array}$ \\
\hline & A3B & Drivers side front wheel over Girder \#3 & $\begin{array}{l}\text { Slow as possible, continuous- } \\
\text { ly moving }\end{array}$ \\
\hline & A4B & Drivers side front wheel over Girder \#5 & $\begin{array}{l}\text { Slow as possible, continuous- } \\
\text { ly moving }\end{array}$ \\
\hline & B1B & $\begin{array}{l}\text { GD05 maximum deflection front wheel over } \\
\text { Girder \#4, 2-3/4 inches south of GD05. } \\
\text { GD02 maximum deflection front wheel over } \\
\text { Girder \#4, } 6 \text { inches north of GD02. } \\
\text { GD05 maximum deflection rear wheel over } \\
\text { Girder \#4, } 6 \text { inches south of GD05. } \\
\text { GD02 maximum deflection rear wheel over } \\
\text { Girder \#4, 13-1/2 inches north of GD02. }\end{array}$ & $\begin{array}{l}\text { Finding location of maximum } \\
\text { deflections }\end{array}$ \\
\hline & C1B & Drivers side front wheel over Girder \#4 & $10 \mathrm{mph}$ \\
\hline & C4B & Drivers side front wheel over Girder \#4 & $25 \mathrm{mph}$ \\
\hline & $\mathrm{H} 1$ & Drivers side front wheel over Girder \#3 & $10 \mathrm{mph}$ \\
\hline & $\mathrm{H} 2$ & Drivers side front wheel over Girder \#3 & $25 \mathrm{mph}$ \\
\hline & G4 & Drivers side front wheel over Girder \#5 & $10 \mathrm{mph}$ \\
\hline & G3B & Drivers side front wheel over Girder \#5 & $25 \mathrm{mph}$ \\
\hline
\end{tabular}

The fifth and final load test was performed in October 2011 using the M1089. This test was for comparison with the 2009 and 2010 testing to 
identify changes in performance due to aging of the structure. Table 5 shows the testing plan.

Table 5. Test plan for load test 5, October 2011.

\begin{tabular}{|c|c|c|c|}
\hline Test Vehicle & Loading I.D. & Load Location & Vehicle Speed \\
\hline \multirow[t]{10}{*}{ M1089 Wrecker } & $\mathrm{A} 2 \mathrm{C}$ & Drivers side front wheel over Girder \#4 & $\begin{array}{l}\text { Slow as possible, continuously } \\
\text { moving }\end{array}$ \\
\hline & $\mathrm{A} 3 \mathrm{C}$ & Drivers side front wheel over Girder \#3 & $\begin{array}{l}\text { Slow as possible, continuously } \\
\text { moving }\end{array}$ \\
\hline & A4C & Drivers side front wheel over Girder \#5 & $\begin{array}{l}\text { Slow as possible, continuously } \\
\text { moving }\end{array}$ \\
\hline & B1C & $\begin{array}{l}\text { GD05 maximum deflection front wheel over } \\
\text { Girder \#4, 2-3/4 inches south of GD05. } \\
\text { GD02 maximum deflection front wheel over } \\
\text { Girder \#4 at GD02. } \\
\text { GD05 maximum deflection rear wheel over } \\
\text { Girder \#4, } 6 \text { inches south of GD05. } \\
\text { GD02 maximum deflection rear wheel over } \\
\text { Girder \#4 at GD02. }\end{array}$ & $\begin{array}{l}\text { Finding location of maximum } \\
\text { deflections }\end{array}$ \\
\hline & C1C & Drivers side front wheel over Girder \#4 & $10 \mathrm{mph}$ \\
\hline & $\mathrm{C} 4 \mathrm{C}$ & Drivers side front wheel over Girder \#4 & $25 \mathrm{mph}$ \\
\hline & $\mathrm{H} 1 \mathrm{~A}$ & Drivers side front wheel over Girder \#3 & $10 \mathrm{mph}$ \\
\hline & $\mathrm{H} 2 \mathrm{~A}$ & Drivers side front wheel over Girder \#3 & $25 \mathrm{mph}$ \\
\hline & G4A & Drivers side front wheel over Girder \#5 & $10 \mathrm{mph}$ \\
\hline & G3C & Drivers side front wheel over Girder \#5 & $25 \mathrm{mph}$ \\
\hline
\end{tabular}

\subsubsection{Captured heavy vehicle crossing events}

Data were collected for heavy vehicles that cross the bridge to document the various types of heavy vehicles that use the bridge, their estimated speeds, and the dynamic response of the bridge under these loads. The data also will be used to identify relative changes in bridge performance over time for certain vehicle types. Examples documented by the digital camera setup are shown in Figure 11 through Figure 14. 


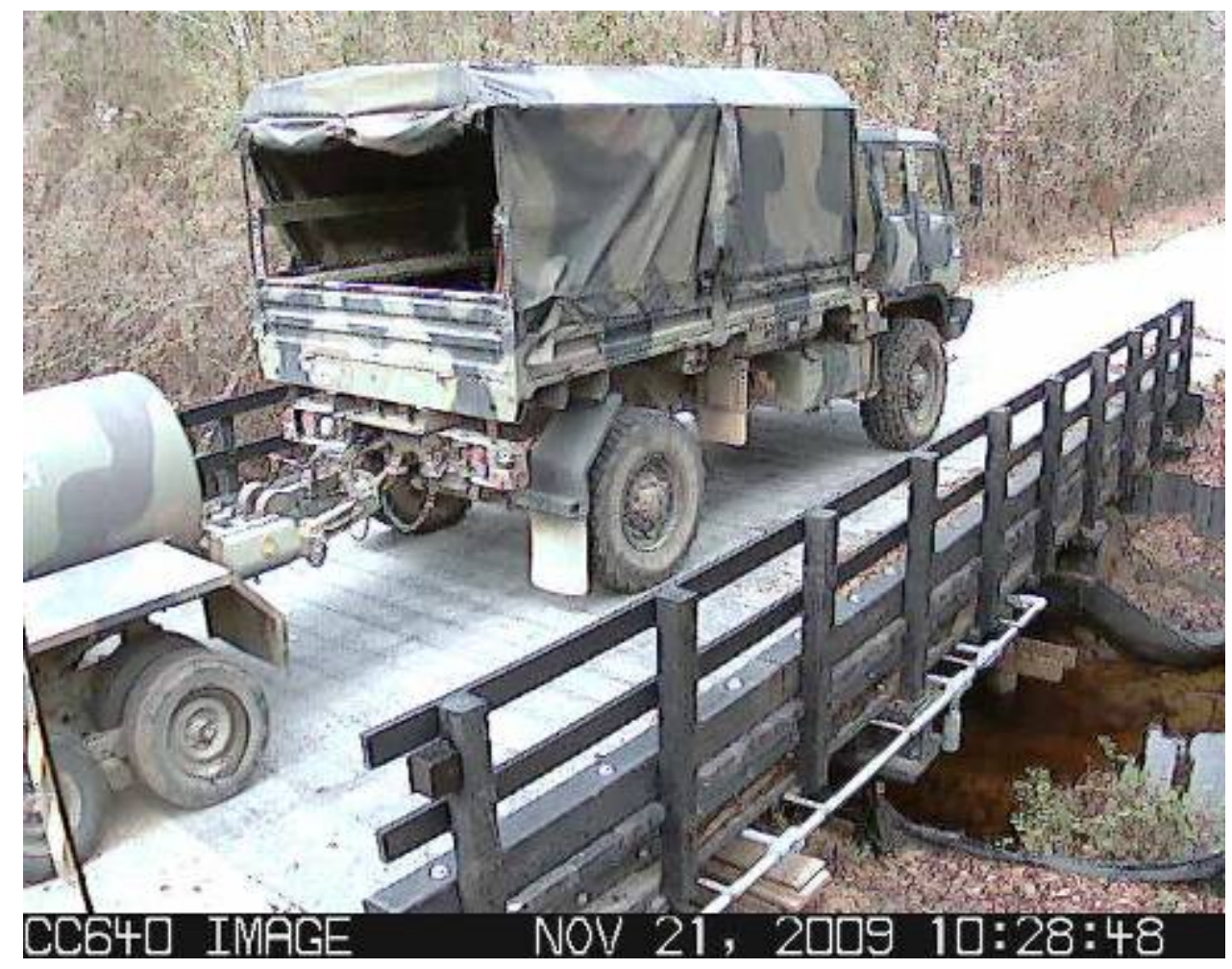

Figure 11. Captured heavy vehicle crossing - M1078.

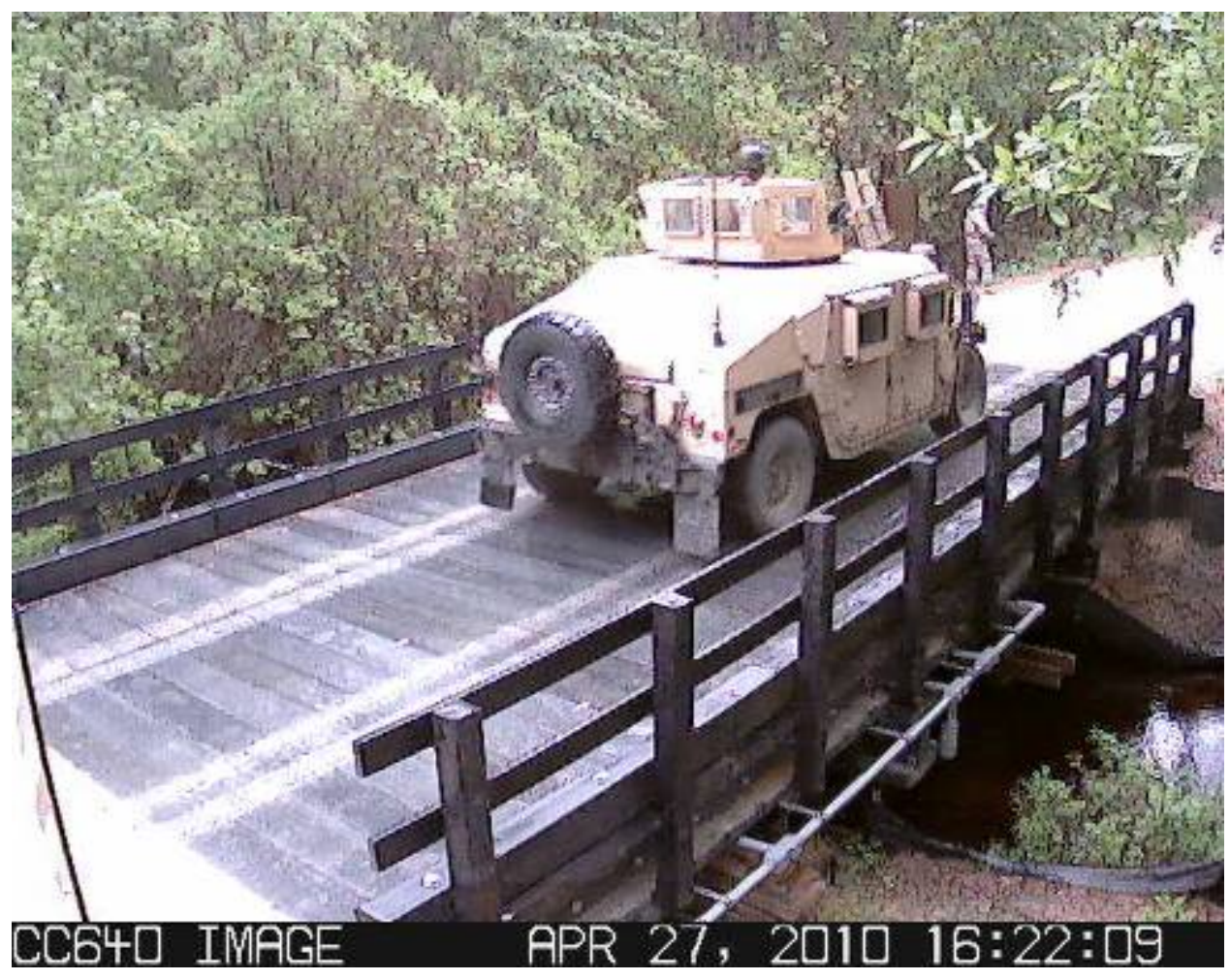

Figure 12. Captured heavy vehicle crossing - armored HMMWV. 


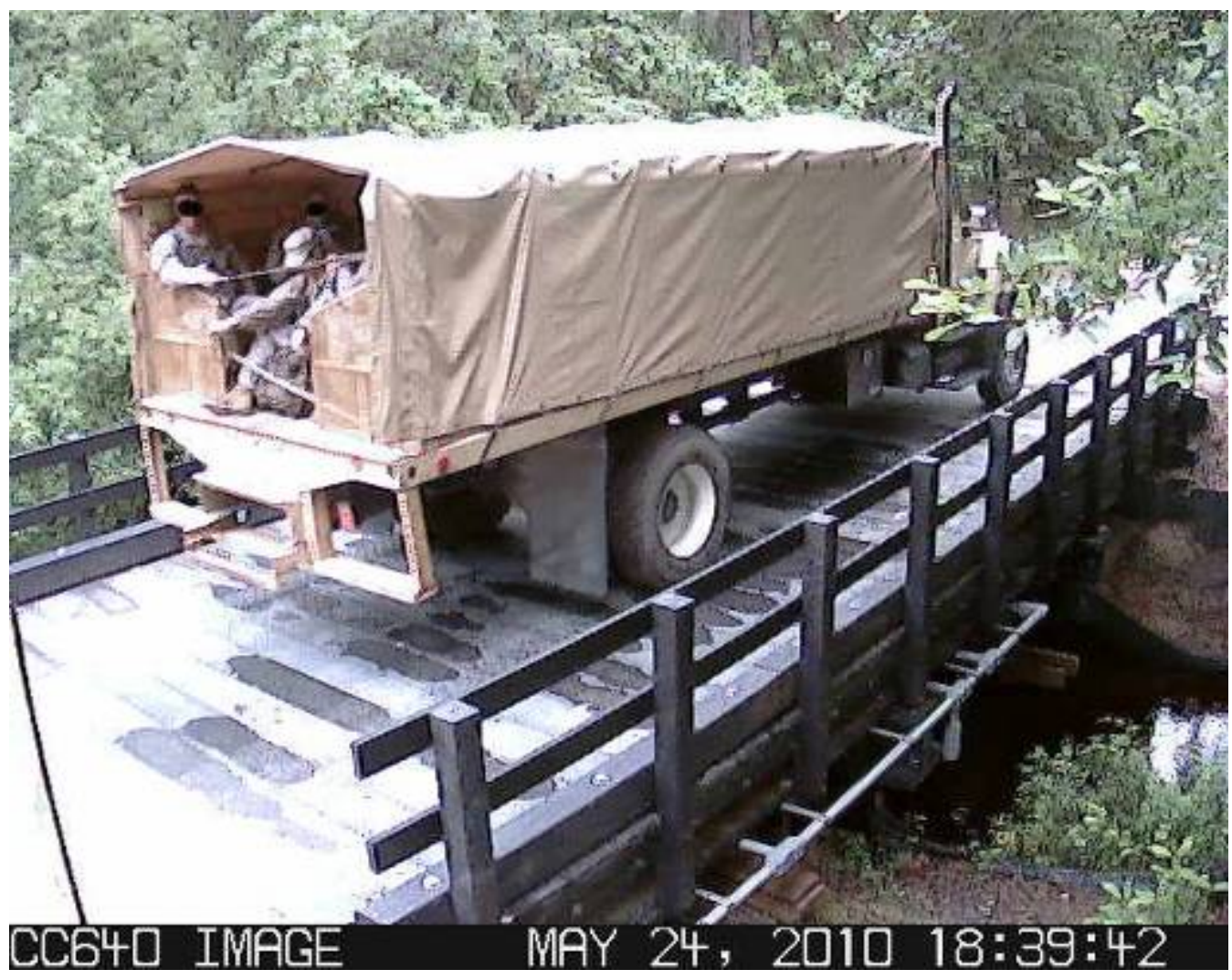

Figure 13. Captured heavy vehicle crossing - 2 axle cargo truck.

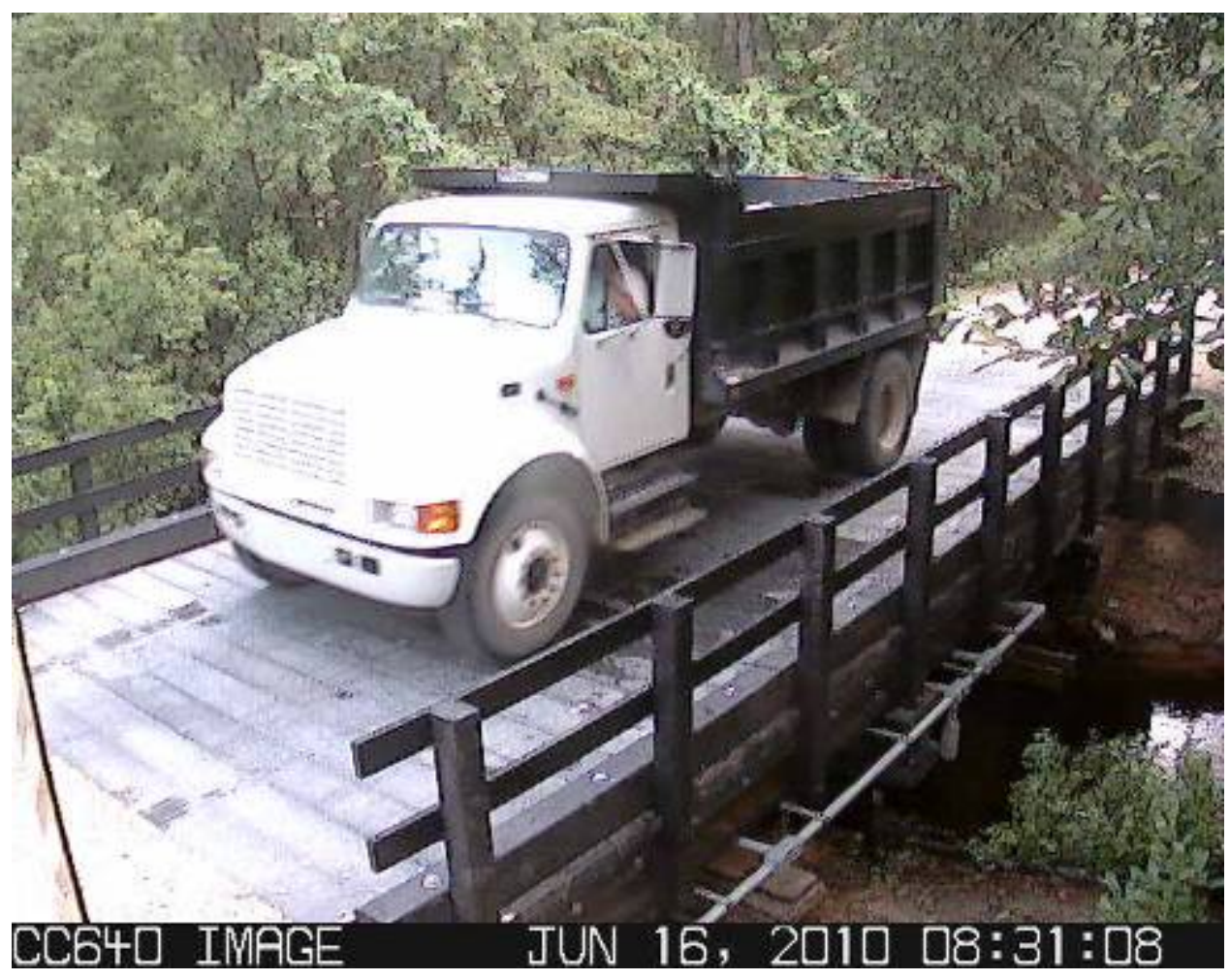

Figure 14. Captured heavy vehicle crossing - 2 axle dump truck. 
The types of heavy vehicles captured include the M1078 armored HMMWV, 2-axle cargo truck, 2-axle dump truck, concrete truck, road grader, backhoe, fire truck, dozer with disc implement, and a boom truck. The criterion used to identify a heavy vehicle is a load that produces a change in strain exceeding a threshold value of 90 microstrain. Setting the threshold lower than that value resulted in capturing smaller vehicles such as pickup trucks. For reference, the M1078 produces a change in strain of 110 to 150 microstrain and an armored HMMWV is in the range of 90 120 microstrain.

\subsubsection{Response to static (dead) loads}

Displacement, strain, and surface temperature data were collected hourly and downloaded to the project database. The data were evaluated to observe how the bridge responds to daily and seasonal temperature cycles, and to determine if creep of the material or permanent structural deformations has occurred.

\subsection{Materials exposure and testing}

\subsubsection{Atmospheric corrosion rate measurement}

In order to characterize the environmental conditions at the test site, a rack containing metallic coupons was mounted to the bridge (Figure 15). The rack contained four sets of six coupons, with each set including one coupon each fabricated of silver, copper, 1010 steel, 2024 T3 aluminum, $6061 \mathrm{~T} 6$ aluminum, and $7075 \mathrm{~T} 6$ aluminum. 


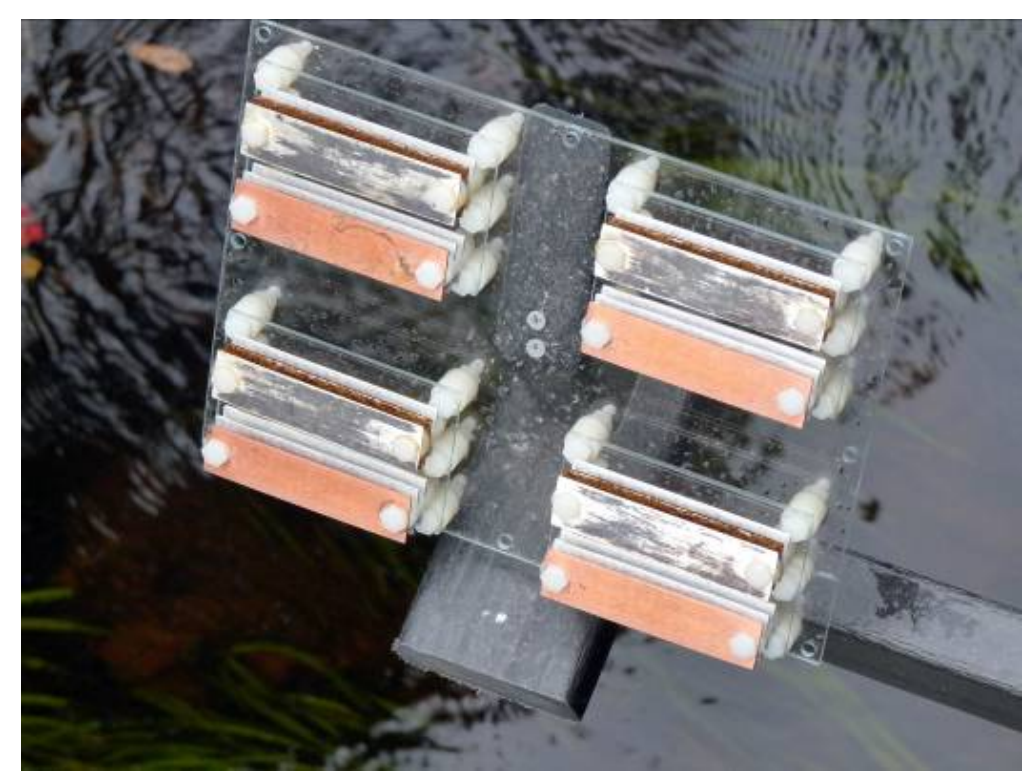

Figure 15. Atmospheric corrosion coupons mounted on bridge.

Coupon sets were removed and sent to a laboratory for testing at 3 month intervals. Coupons were analyzed for mass loss in accordance with ASTM G1, Standard Practice for Preparing, Cleaning, and Evaluating Corrosion Test Specimens [6]. The coupon surfaces were analyzed for chlorides in accordance with ASTM B825, Standard Test Method for Coulometric Reduction of Surface Films on Metallic Test Samples [7].

\subsubsection{Thermoplastic material exposure testing}

In order to evaluate the thermoplastic material for property changes due to UVA exposure, nominal two-by-four boards each 36 inches long were prepared in accordance with ASTM D6662, Standard Specification for Olefin-Based Plastic Lumber Decking Boards, paragraph 6.3.2 [8]. Fifteen boards were set aside for baseline testing and 20 were mounted at the bridge site (Figure 16). Five boards were removed and tested after 6 months of exposure, and five were removed and tested after 12 months of exposure. The remaining 10 boards were left at the bridge site for continued exposure and future testing. 


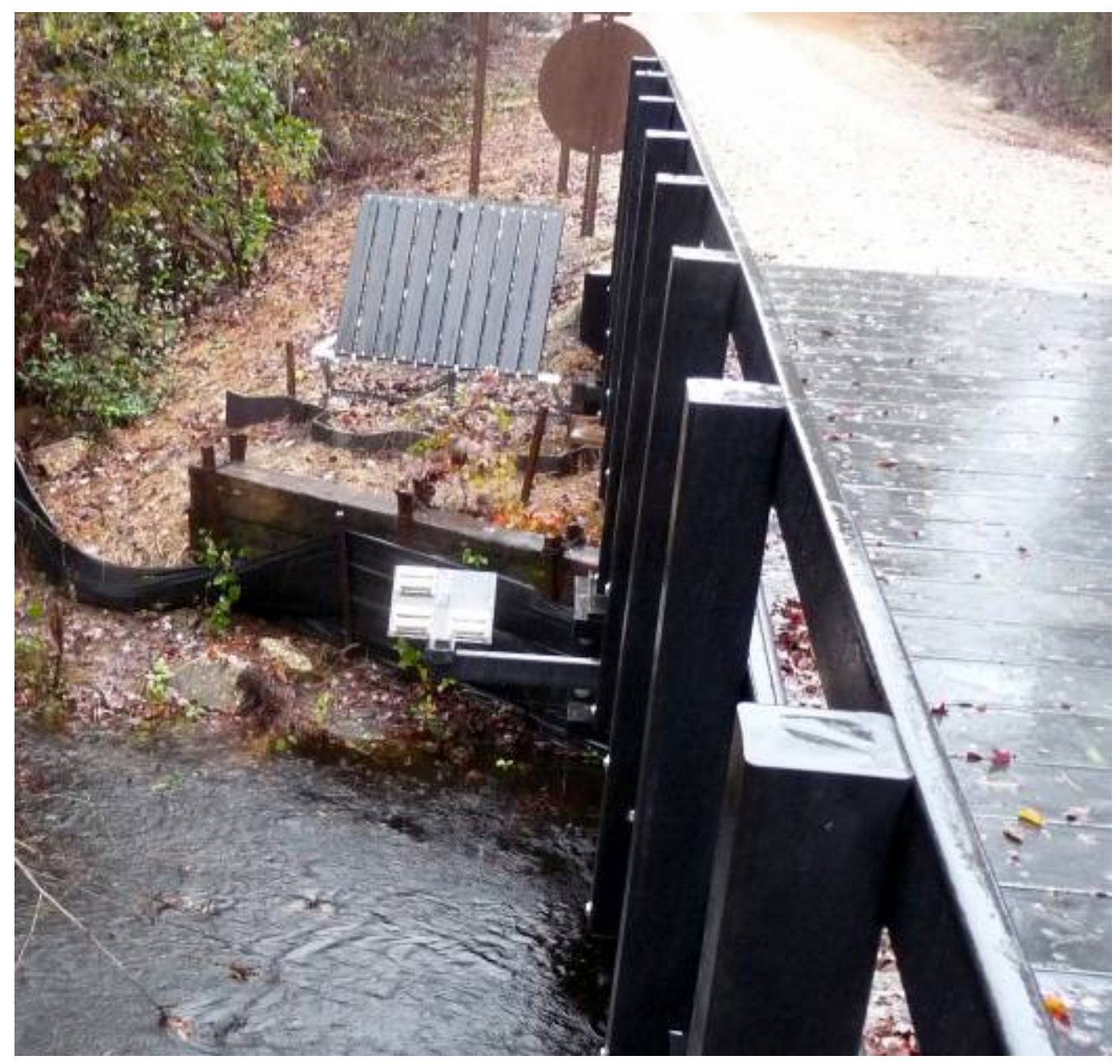

Figure 16. Nominal $2 \times 4$ thermoplastic specimens mounted at bridge site. 


\section{Discussion}

Data were collected from J uly 2009 to October 2011 to assist in evaluating long-term bridge performance. This chapter provides a discussion about the design and performance of the SPM system and the results of the data evaluation.

\subsection{Design and performance of SPM system}

High-speed data acquisition equipment was needed to collect data at a fast enough rate to see the dynamic response of the bridge to moving vehicles. The data collection rate of $100 \mathrm{~Hz}$ ( 100 data points per second) has provided very good resolution for observing the response of the bridge to moving vehicles. The top speed of the vehicle events captured to date has been 25 miles per hour, and the responses to the different vehicle axles are easily discernible at these speeds (Figure 17).

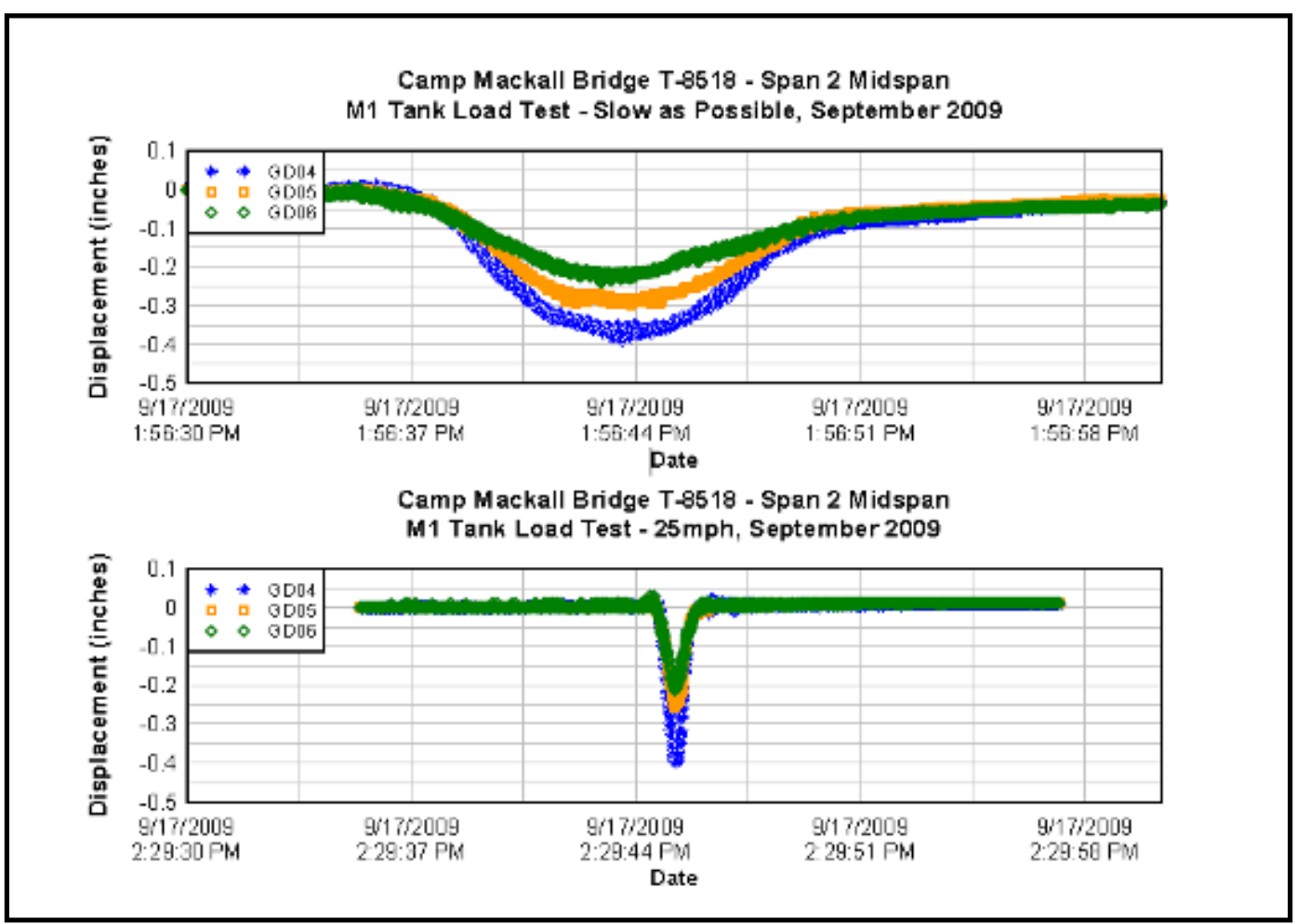

Figure 17. Example of results from load testing with M1 Tank (bridge response at different vehicle speeds).

The requirement for high-speed data acquisition at a remote site provided some challenges in system design. High-speed data acquisition equipment 
generally needs more power to operate and can produce large volumes of data. The battery power supply and solar recharge array was significant for this project, as discussed in section 2.2.6, but it was a manageable size. The two $160 \mathrm{amp}-\mathrm{hr}$ batteries were contained in a 24 inch by 24 inch enclosure, and both the enclosure and two 140-watt solar panels could be mounted on the pole with the data acquisition equipment. However, to reliably operate with this power supply through the winter months required that the system be designed for minimal power use. The methods used to conserve power include powering down the sensors when measurements are not being made, using a slower (and lower-power) data acquisition unit to measure the weather instruments, and powering the cellular modems for only 1 hour each day to allow for data downloading and remote communications. The system still had to meet the performance requirement of detecting and capturing vehicle crossing events, which could not be done with the sensors powered down. To meet this requirement, wireless infrared sensors were installed as discussed in section 2.2.6 to detect an approaching vehicle with enough time to power on the sensors. The data acquisition equipment is always on and monitoring for a contact closure from the vehicle detection sensors. This system has worked very well and because the bridge does not have a lot of traffic, it conserves a significant amount of power by keeping the sensors powered down most of the time.

When sampling at $100 \mathrm{~Hz}$, a significant amount of data can be generated in a small amount of time. Managing data collection so that only valuable information is saved is very important. This is helpful for both the user who is working with the data, and to keep communications needed for data downloading to a minimum because transmitting information uses a lot of power. Therefore, the system was designed to evaluate the response of the bridge as the vehicle is crossing it and to decide whether the event is worth saving. When the data acquisition equipment sees a change in strain on any of the strain gages that exceeds the threshold value, then it logs (or saves) the data for 8 seconds before the trigger occurred and 8 seconds after. Events that do not exceed the threshold value are not logged. The threshold value is programmed as a variable so that it can be changed remotely by the system user. In this way, the user has control over what events are being collected. For the hourly data that are used to evaluate thermal loading responses, the data acquisition equipment powers up the sensors based on its internal clock, takes a running average reading of the sensors, logs the data, and turns the sensors back off again. Logic in the 
programming allows for both a vehicle event and hourly readings to be recorded correctly if they occur at the same time.

\subsection{Evaluation of load testing data}

The results of load tests 1 and 2 were used to compare the response of the bridge under heavy loads with the expected performance based on design assumptions. This evaluation was performed by the bridge designer, McLaren Engineering Group. The results of their evaluation are documented in a report dated 17 December 2010, which is included as Appendix Q. The general conclusion was that the bridge performed as expected under the heavy vehicle loads.

The second objective of the load testing was to evaluate if the performance changes with time as a result of material or structural degradation. Load tests 4 and 5 were performed for this purpose. Table 6 shows a comparison of the resulting peak deflections from load tests 1, 2, 4, and 5 for the M1089. The following observations are made from these results:

1. The measured deflections are slightly larger for Span 3 than Span 2. This is likely because the south end of Span 3 (Pile Cap 4) is not pinned and is free to move.

2. The deflections are generally less at faster vehicle speeds.

3. The deflections appear to be affected by temperature more than time (aging). In general, the maximum deflections are similar between the 2009 and 2010 load tests. There is a slight increase in 2010 from 2009 for some of the loading conditions. However, the deflections are less for the 2011 load test. The surface temperature of the bottom of the girders was 84 degrees Fahrenheit for both the 2009 and 2010 load tests and 68 degrees Fahrenheit for the 2011 load test. Loading condition G3 was performed in September of 2009 and the surface temperature was 76 degrees Fahrenheit. Generally, the bridge appears to be stiffer at colder temperatures as would be expected given the materials of construction.

Based on these results it does not appear that there has been any degradation that has produced a noticeable difference in the structural performance under heavy vehicle loads. 
Table 6. Maximum Deflections Measured for the M1089 for Load Tests 1, 2, 4, and 5.

\begin{tabular}{|c|c|c|c|c|c|}
\hline $\begin{array}{l}\text { Loading } \\
\text { I.D. }\end{array}$ & Load Location & Vehicle Speed & 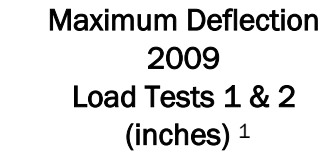 & $\begin{array}{c}\text { Maximum Deflection } \\
2010 \\
\text { Load Test } 4 \\
\text { (inches) }^{1}\end{array}$ & $\begin{array}{c}\text { Maximum Deflection } \\
2011 \\
\text { Load Test } 5^{5} \\
\text { (inches) }^{1}\end{array}$ \\
\hline $\mathrm{A} 2, \mathrm{~B}, \mathrm{C}$ & $\begin{array}{l}\text { Drivers side front wheel over } \\
\text { Girder \#4 }\end{array}$ & $\begin{array}{l}\text { Slow as possible, con- } \\
\text { tinuously moving }\end{array}$ & $\begin{array}{l}\text { GD02: } 0.100 \\
\text { GD05: } 0.104\end{array}$ & $\begin{array}{l}\text { GD02: } 0.104 \\
\text { GD05: } 0.090\end{array}$ & $\begin{array}{l}\text { GD02: } 0.091 \\
\text { GD05: } 0.077\end{array}$ \\
\hline$A 3, B, C$ & $\begin{array}{l}\text { Drivers side front wheel over } \\
\text { Girder \#3 }\end{array}$ & $\begin{array}{l}\text { Slow as possible, con- } \\
\text { tinuously moving }\end{array}$ & $\begin{array}{l}\text { GD01: } 0.118 \\
\text { GD04: } 0.090 \\
\end{array}$ & $\begin{array}{l}\text { GD02: } 0.097^{3} \\
\text { GD04: } 0.091^{2} \\
\end{array}$ & $\begin{array}{l}\text { GD01: } 0.100 \\
\text { GD04: } 0.082\end{array}$ \\
\hline $\mathrm{A} 4, \mathrm{~B}, \mathrm{C}$ & $\begin{array}{l}\text { Drivers side front wheel over } \\
\text { Girder \#5 }\end{array}$ & $\begin{array}{l}\text { Slow as possible, con- } \\
\text { tinuously moving }\end{array}$ & $\begin{array}{l}\text { GD03: } 0.109 \\
\text { GD06: } 0.089\end{array}$ & $\begin{array}{l}\text { GD03: } 0.105 \\
\text { GD06: } 0.110 \\
\end{array}$ & $\begin{array}{l}\text { GD03: } 0.094 \\
\text { GD06: } 0.066\end{array}$ \\
\hline $\mathrm{B} 1, \mathrm{~B}, \mathrm{C}$ & $\begin{array}{l}\text { GD05 maximum deflection } \\
\text { front wheel over Girder \#4. } \\
\text { GD02 maximum deflection } \\
\text { front wheel over Girder \#4. } \\
\text { GD05 maximum deflection rear } \\
\text { wheel over Girder \#4. } \\
\text { GD02 maximum deflection rear } \\
\text { wheel over Girder \#4. }\end{array}$ & $\begin{array}{l}\text { Finding location of } \\
\text { maximum deflections }\end{array}$ & $\begin{array}{l}\text { Front Wheel } \\
\text { GD02: } 0.109 \\
\text { GD05: } 0.088 \\
\text { Rear Wheel } \\
\text { GD02: } 0.128 \\
\text { GD05: } 0.123\end{array}$ & $\begin{array}{l}\text { Front Wheel } \\
\text { GD02: } 0.107 \\
\text { GD05: } 0.113 \\
\text { Rear Wheel } \\
\text { GD02: } 0.146 \\
\text { GD05: } 0.131\end{array}$ & $\begin{array}{l}\text { Front Wheel } \\
\text { GD02: } 0.079 \\
\text { GD05: } 0.069 \\
\text { Rear Wheel } \\
\text { GD02: } 0.101 \\
\text { GD05: } 0.088\end{array}$ \\
\hline C1, B, C & $\begin{array}{l}\text { Drivers side front wheel over } \\
\text { Girder \#4 }\end{array}$ & $10 \mathrm{mph}$ & $\begin{array}{l}\text { GD02: } 0.083 \\
\text { GD05: } 0.085\end{array}$ & $\begin{array}{l}\text { GD02: } 0.098 \\
\text { GD05: } 0.091\end{array}$ & $\begin{array}{l}\text { GD02: } 0.087 \\
\text { GD05: } 0.066\end{array}$ \\
\hline $\mathrm{C} 4, \mathrm{~B}, \mathrm{C}$ & $\begin{array}{l}\text { Drivers side front wheel over } \\
\text { Girder \#4 }\end{array}$ & $25 \mathrm{mph}$ & $\begin{array}{l}\text { GD02: } 0.081 \\
\text { GD05: } 0.083\end{array}$ & $\begin{array}{l}\text { GD02: } 0.092 \\
\text { GD05: } 0.087\end{array}$ & $\begin{array}{l}\text { GD02: } 0.077 \\
\text { GD05: } 0.059\end{array}$ \\
\hline $\mathrm{H} 1, \mathrm{~A}$ & $\begin{array}{l}\text { Drivers side front wheel over } \\
\text { Girder \#3 }\end{array}$ & $10 \mathrm{mph}$ & NM & $\begin{array}{l}\text { GD02: } 0.089^{3} \\
\text { GD04: } 0.082 \\
\end{array}$ & $\begin{array}{l}\text { GD01: } 0.099 \\
\text { GD04: } 0.099\end{array}$ \\
\hline $\mathrm{H} 2, \mathrm{~A}$ & $\begin{array}{l}\text { Drivers side front wheel over } \\
\text { Girder \#3 }\end{array}$ & $25 \mathrm{mph}$ & NM & $\begin{array}{l}\text { GD02: } 0.081^{3} \\
\text { GD04: } 0.078 \\
\end{array}$ & $\begin{array}{l}\text { GD01: } 0.085 \\
\text { GD04: } 0.093 \\
\end{array}$ \\
\hline G4, A & $\begin{array}{l}\text { Drivers side front wheel over } \\
\text { Girder \#5 }\end{array}$ & $10 \mathrm{mph}$ & NM & $\begin{array}{l}\text { GD03: } 0.087 \\
\text { GD06: } 0.094\end{array}$ & $\begin{array}{l}\text { GD03: } 0.081 \\
\text { GD06: } 0.052\end{array}$ \\
\hline G3, B, C & $\begin{array}{l}\text { Drivers side front wheel over } \\
\text { Girder \#5 }\end{array}$ & $25 \mathrm{mph}$ & $\begin{array}{l}\text { GD02: } 0.0922^{2} \\
\text { GD05: } 0.067\end{array}$ & GD03: 0.092 & $\begin{array}{l}\text { GD03: } 0.080 \\
\text { GD06: } 0.039\end{array}$ \\
\hline
\end{tabular}

Notes:

1. Surface temperatures on the bottom of girders were $84^{\circ} \mathrm{F}$ for the July 2009 and August 2010 load tests and $68^{\circ} \mathrm{F}$ for the October 2011 load test.

2. Loading condition G3 was performed in September 2009 when the surface temperature was $76{ }^{\circ} \mathrm{F}$. The maximum deflections were measured with sensors GD02 and GD05

indicating that the test vehicle was actually driving over Girder \#4 rather than Girder \#5 as planned. 


\subsection{Evaluation of captured heavy vehicle crossings}

The data from the captured vehicle crossing events were used to evaluate the relative demand placed on the bridge by the different types of heavy vehicles that are using it. Figure 18 and Figure 19 show example comparisons of the deflection response of span 3 and strain response of span 2, respectively, under the loading of an M1078 versus a concrete truck. Peak values for the deflections and strains, and estimated vehicle speeds were interpreted from the data. These values are plotted by vehicle type as shown on Figure 20 through Figure 22. In the future, displacement data could be collected again for a period of time and compared with the existing measured response to evaluate if degradation has occurred with time.

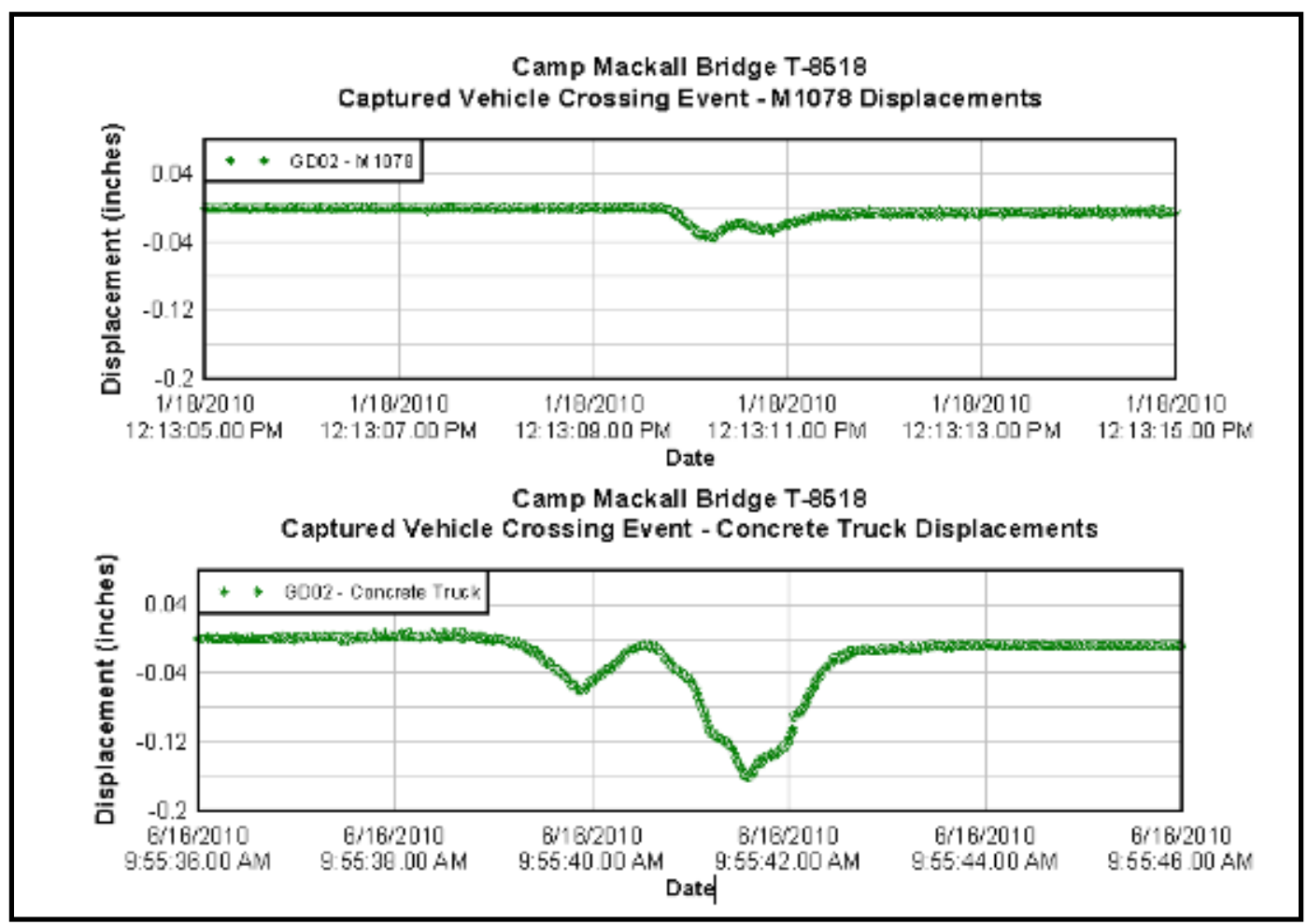

Figure 18. Displacement response of the bridge to an M1078 as compared to a concrete truck. 


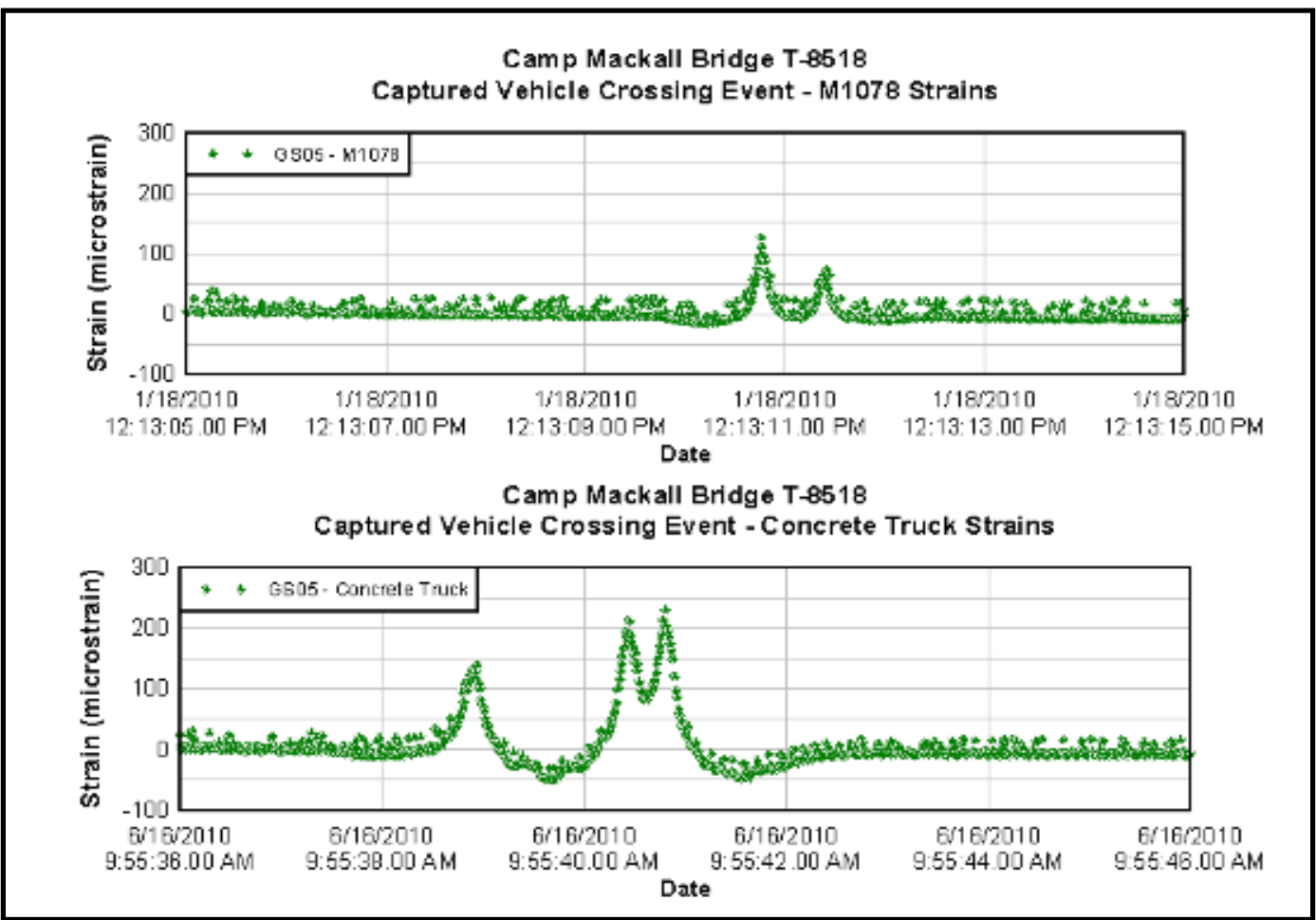

Figure 19. Strain response of the bridge to an m1078 as compared to a concrete truck.

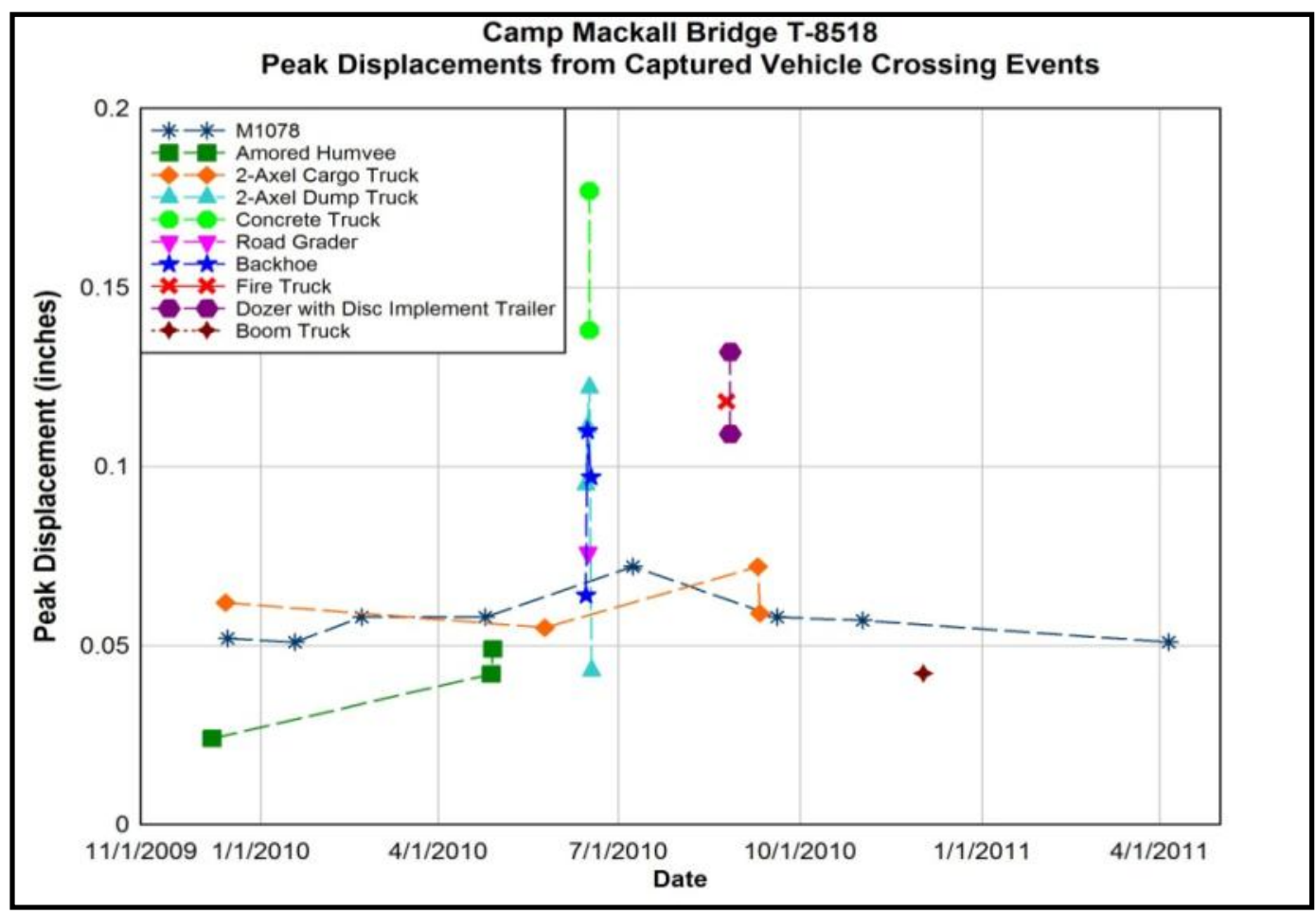

Figure 20. Comparison of peak displacements from captured heavy vehicle crossings. 


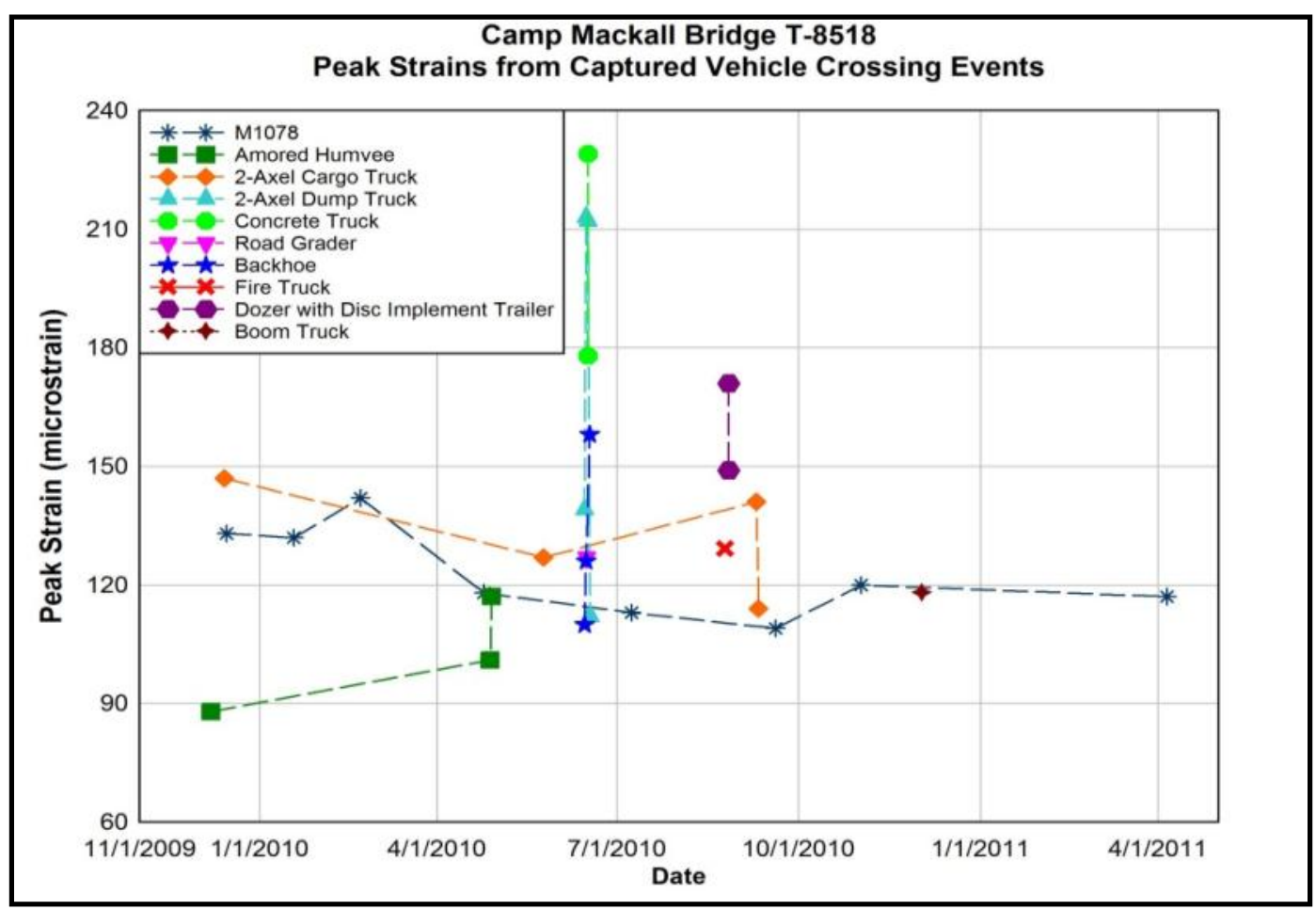

Figure 21. Comparison of peak strains from captured heavy vehicle crossings.

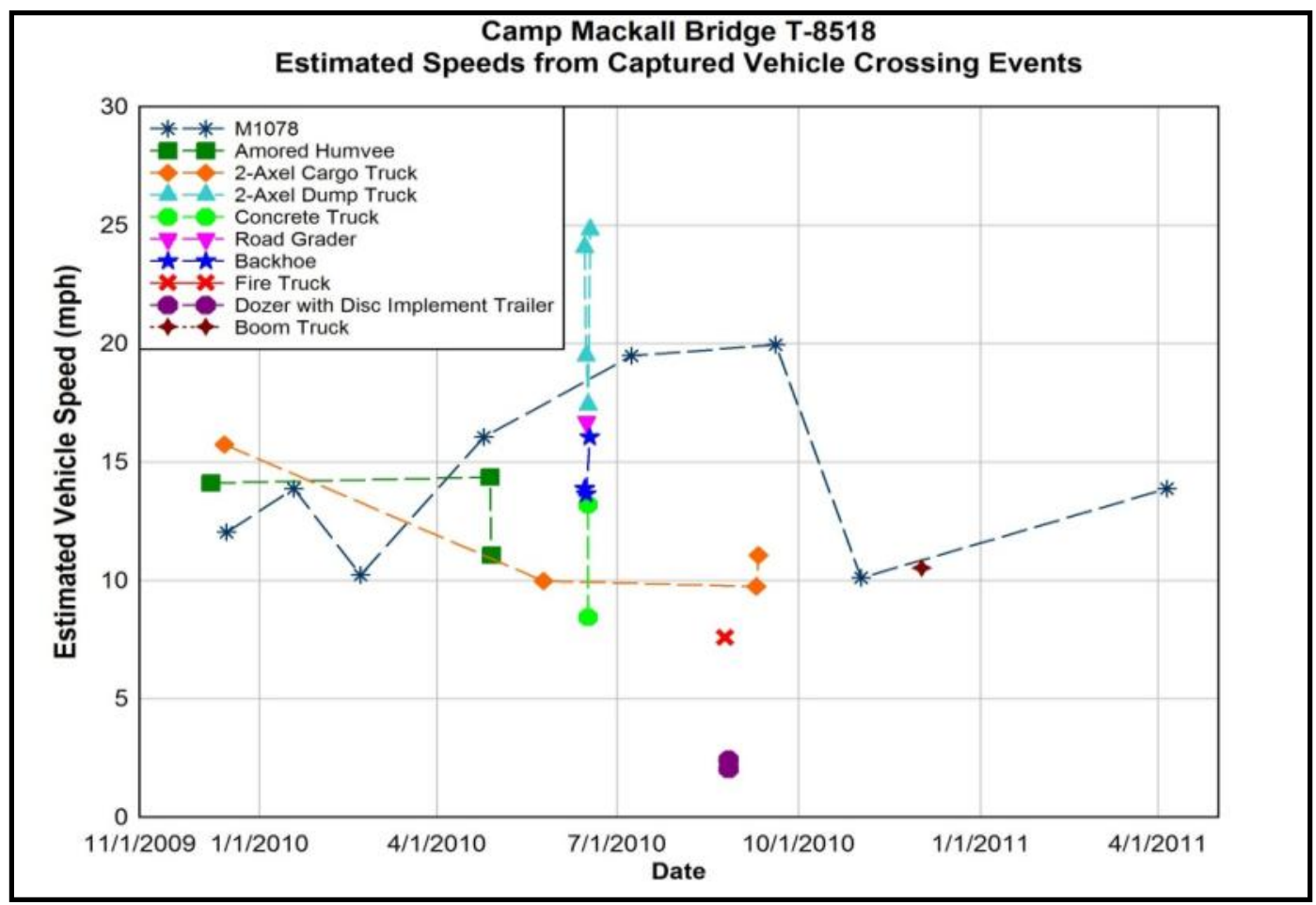

Figure 22. Estimated vehicle speeds from captured heavy vehicle crossing events. 


\subsection{Evaluation of the response to static loads}

The response of the bridge to thermal loading and creep under its own (dead) weight was evaluated using the hourly displacement, strain, and surface temperature data. The results of the measured displacements for span 2 and for pile cap 3 are presented in Figure 23 and Figure 24. The plots shows the 2 years of data that were collected. Observation of the plots indicates a very strong correlation with temperature changes on both the daily and seasonal cycles. For the 2 years of data, neither location appears to be showing any indication of creep; the displacements have continued to return to the values measured under similar temperatures).

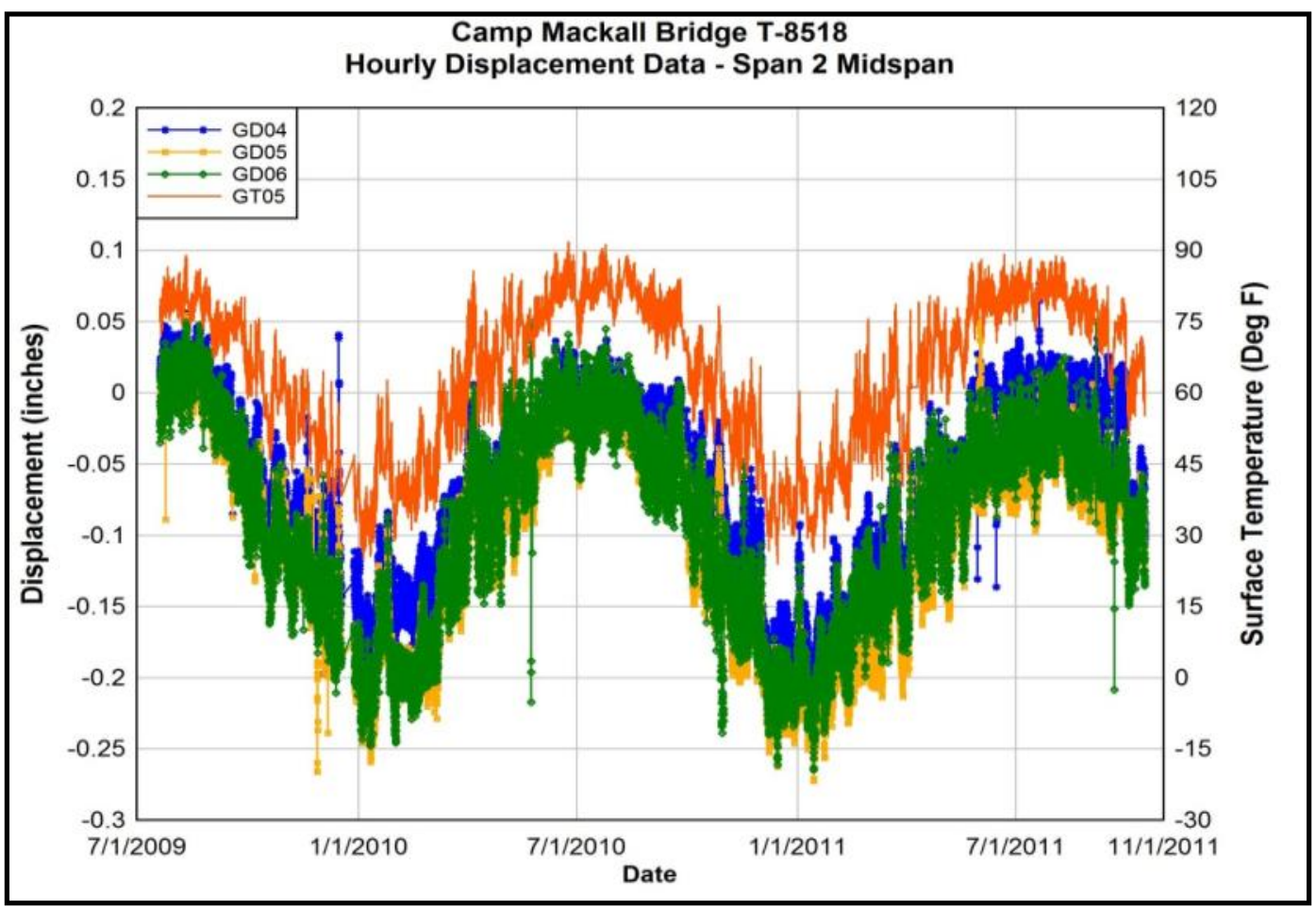

Figure 23. Example of bridge response to thermal loading (displacements at span 2 midspan). 


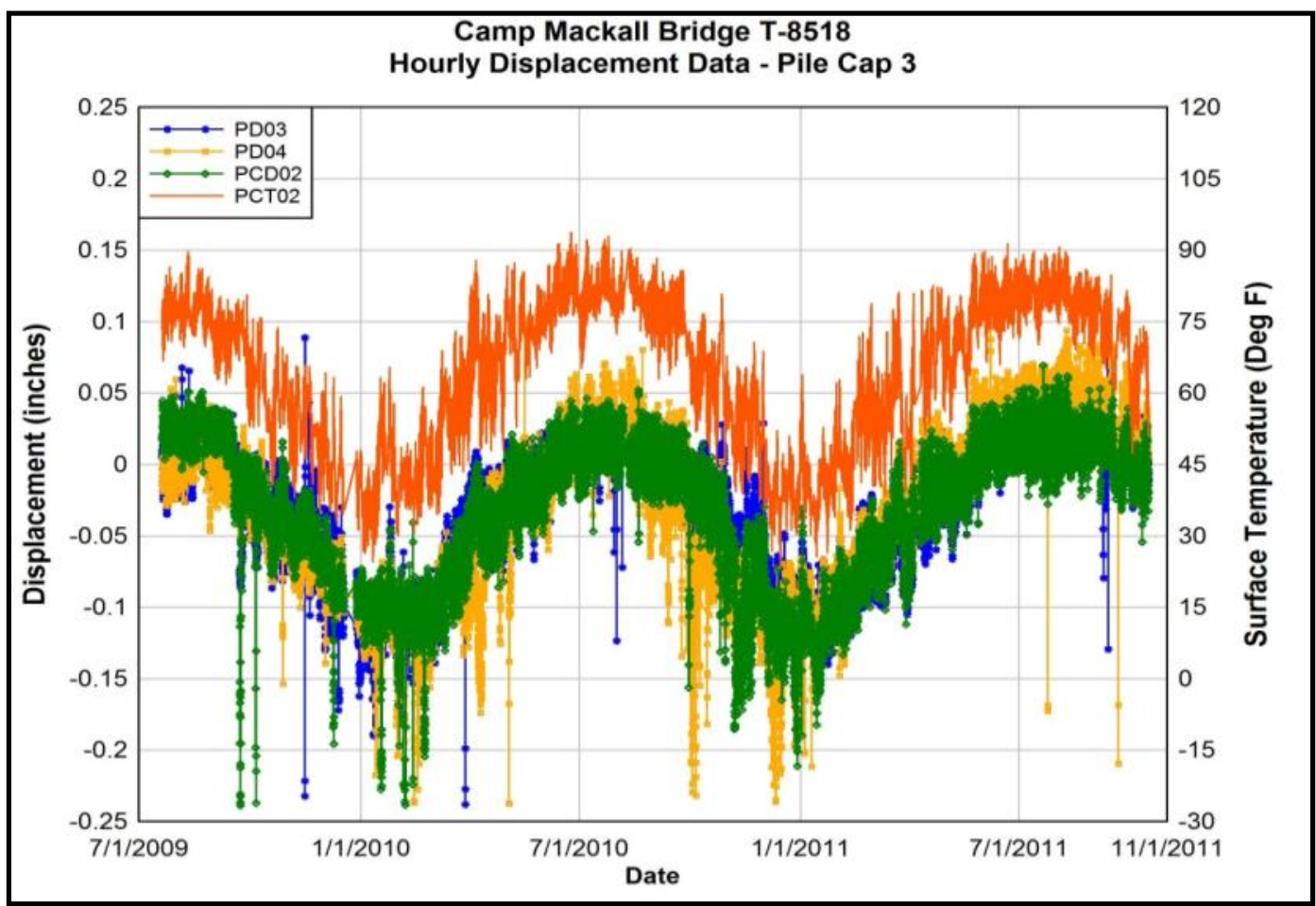

Figure 24. Example of bridge response to thermal loading (displacements at pile cap 3).

\subsubsection{Atmospheric corrosion rate measurement}

The average temperature at the Camp Mackall site is $61.4^{\circ} \mathrm{F}$, with an average rainfall of 48.6 inches per year. Results of the atmospheric corrosion rate measurements are shown in Table 7 through Table 12. From an atmospheric perspective, this location is considered to be mildly corrosive to metals.

Table 7. Atmospheric corrosion data, silver.

\begin{tabular}{|l|l|l|l|}
\hline Exposure Time (months) & Mass Loss $(\mathrm{g})$ & Mass Loss (\%) & Corrosion Rate (mils/year) \\
\hline 3 & 0.0027 & 0.02 & $<0.1$ \\
\hline 6 & 0.0077 & 0.05 & $<0.1$ \\
\hline 9 & 0.0167 & 0.11 & $<0.1$ \\
\hline 12 & 0.0242 & 0.16 & $<0.1$ \\
\hline
\end{tabular}


Table 8. Atmospheric corrosion data, 2024-T2 aluminum.

\begin{tabular}{|l|l|l|l|}
\hline Exposure Time (months) & Mass Loss $\mathbf{( g )}$ & Mass Loss $(\%)$ & Corrosion Rate (mils/year) \\
\hline 3 & 0.0003 & 0 & $<0.1$ \\
\hline 6 & 0.0037 & 0.04 & $<0.1$ \\
\hline 9 & 0.0013 & 0.01 & $<0.1$ \\
\hline 12 & 0.0014 & 0.01 & $<0.1$ \\
\hline
\end{tabular}

Table 9. Atmospheric corrosion data, 6061-T6 aluminum.

\begin{tabular}{|l|l|l|l|}
\hline Exposure Time (months) & Mass Loss $(\mathbf{g})$ & Mass Loss $(\%)$ & Corrosion Rate (mils/year) \\
\hline 3 & 0.0013 & 0.01 & $<0.1$ \\
\hline 6 & 0.0045 & 0.05 & $<0.1$ \\
\hline 9 & 0.0029 & 0.03 & $<0.1$ \\
\hline 12 & 0.0025 & 0.03 & $<0.1$ \\
\hline
\end{tabular}

Table 10. Atmospheric corrosion data, 7075-T6 aluminum.

\begin{tabular}{|l|l|l|l|}
\hline Exposure Time (months) & Mass Loss $(\mathrm{g})$ & Mass Loss $(\%)$ & Corrosion Rate (mils/year) \\
\hline 3 & 0.003 & 0.03 & $<0.1$ \\
\hline 6 & 0.0107 & 0.11 & $<0.1$ \\
\hline 9 & 0.0064 & 0.06 & $<0.1$ \\
\hline 12 & 0.0142 & 0.14 & $<0.1$ \\
\hline
\end{tabular}

Table 11. Atmospheric corrosion data, C1010 steel.

\begin{tabular}{|l|l|l|l|}
\hline Exposure Time (months) & Mass Loss (g) & Mass Loss (\%) & Corrosion Rate (mils/year) \\
\hline 3 & 0.1007 & 0.035 & 0.4 \\
\hline 6 & 0.1549 & 0.54 & 0.3 \\
\hline 9 & 0.2219 & 0.76 & 0.3 \\
\hline 12 & 0.3663 & 1.25 & 0.3 \\
\hline
\end{tabular}

Table 12. Atmospheric corrosion data, CDA101 copper.

\begin{tabular}{|l|l|l|l|}
\hline Exposure Time (months) & Mass Loss (g) & Mass Loss (\%) & Corrosion Rate (mils/year) \\
\hline 3 & 0.0082 & 0.02 & $<0.1$ \\
\hline 6 & 0.0227 & 0.07 & $<0.1$ \\
\hline 9 & 0.0328 & 0.1 & $<0.1$ \\
\hline 12 & 0.0362 & 0.11 & $<0.1$ \\
\hline
\end{tabular}




\subsubsection{Thermoplastic material exposure testing}

Bending tests were conducted by PFS Corporation, Cottage Grove, Wisconsin on five of the original fifteen boards that were never exposed to the elements as well as the five boards each removed after 6 months and 12 months outdoor exposure at the bridge site (see Appendix R). All of the boards were tested in bending per ASTM D6109, Standard Test Methods for Flexural Properties of Unreinforced and Reinforced Plastic Lumber and Related Products [9].

The specimens were loaded at a uniform cross head speed of 0.71 in per minute until the specimen was no longer able to sustain increasing load. A typical failure consisted of excessive deflections. None of the specimen boards ruptured. The results are shown in Table 13.

Table 13. Strength and modulus of elasticity (stiffness) versus time of outdoor exposure.

\begin{tabular}{|l|l|l|}
\hline Months of Exposure & Average Bending Strength (psi) & $\begin{array}{l}\text { Average Modulus of Elasticity } \\
\text { (Secant @ 1\% Strain) (psi) }\end{array}$ \\
\hline 0 & 4,150 & 202,705 \\
\hline 6 & 4,284 & 207,182 \\
\hline 12 & 4,217 & 203,674 \\
\hline
\end{tabular}

The average strength in bending was 4,200 psi and the average modulus of elasticity, E, in bending was $205 \mathrm{ksi}$. Within experimental error, the results of the boards after 6 and 12 month exposures were the same as the unexposed specimens. Specimens removed from the exposure rack at the bridge site at 6 months and 12 months showed no visible signs of degradation, such as fading or discoloration, compared to the baseline, unexposed specimens. No mechanical or physical degradation is indicated as a result of exposure of the materials to the conditions at Camp Mackall. 


\section{Economic Summary}

This demonstration project indicates that remotely monitoring a system of sensors for measuring structural performance and environmental conditions at the bridge site, combined with periodic on-site testing is a costeffective means of learning about the performance characteristics of the recycled plastic bridge materials and designs. The projected return on investment (ROI) is presented based on the provided costs and assumptions.

\subsection{Costs and assumptions}

Because the economic value of the data obtained from the system is difficult to quantify, this analysis is based on the assumption that this type of structural performance monitoring is necessary to provide verification that the bridge is performing as intended prior to wide-scale implementation of this bridge technology.

The economic benefits of the bridge material and design are assumed to be the costs required to design and construct and maintain bridges made from recycled thermoplastic composite materials compared to traditional, chemically treated timbers.

Net present value costs for timber bridges has been calculated at $\$ 981$ per square foot over the life of the bridge [3]. A value of $\$ 675$ per square foot was calculated for the thermoplastic composite bridges. Both of these values include annual maintenance costs over the respective 15 and 50 year life expectancy of the bridge.

The analysis calculations shown in Table 14 assumes a replacement of 2 bridges per year at Fort Bragg over a 10 year period. Each bridge is assumed to be 15 feet wide by 45 feet long. The thermoplastic composite bridge will not need to be replaced over the 30 year analysis period and will require negligible maintenance due to materials degradation. A wood timber bridge will need to be replaced after 15 years of service. The biannual inspection costs are ignored since both types of bridges would require such inspections and the costs are considered to be the same for either type. 
Table 14. ROI calculation for plastic bridge performance without remote SPM system.

\section{Return on Investment Calculation}

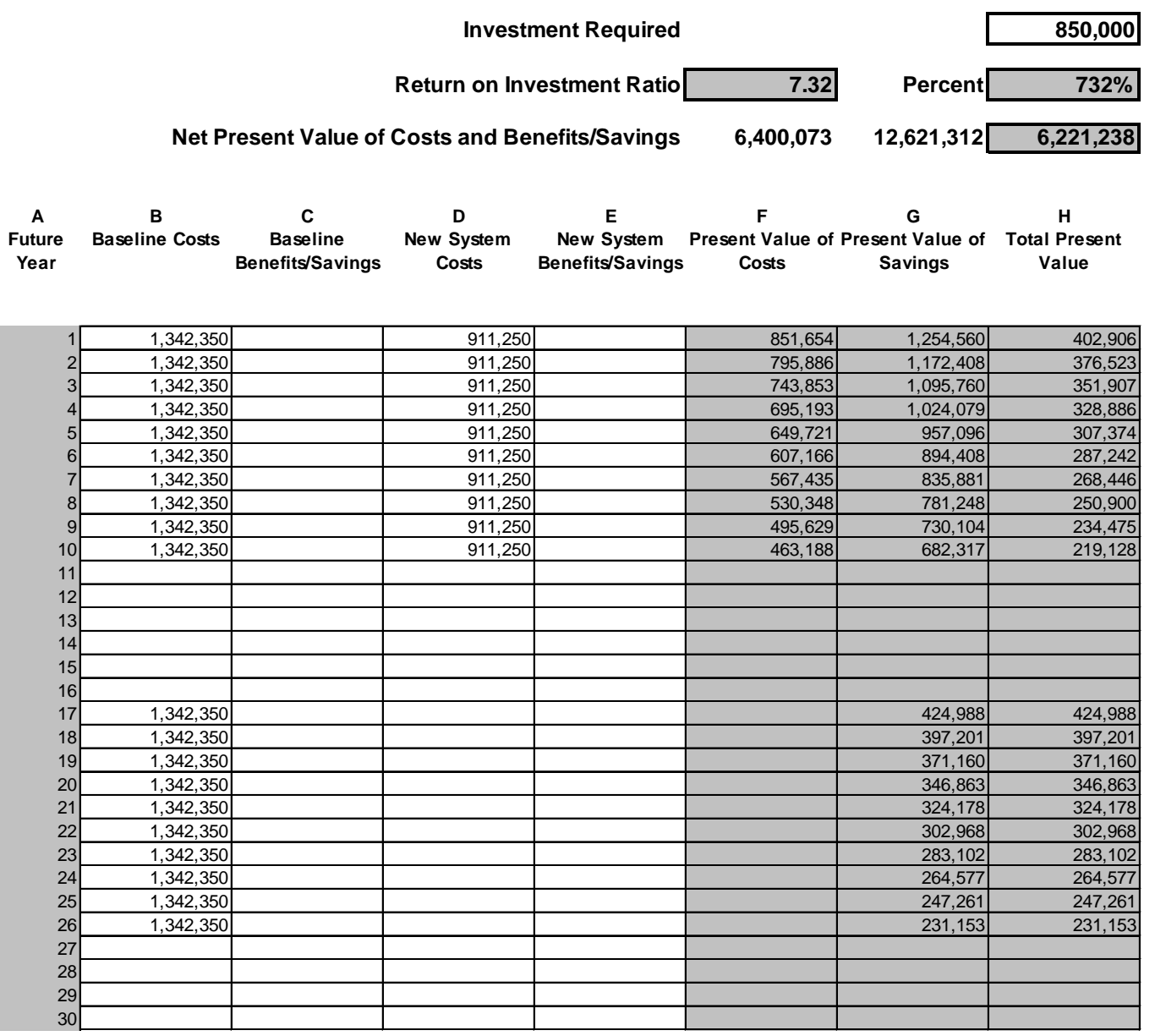

A further analysis was conducted considering the potential benefits of the remote structural performance monitoring system as installed on Bridge $\mathrm{T}-8518$ versus the current practice of biannual on-site inspections.

The initial cost of the monitoring system as installed on Bridge T-8518 was $\$ 304,100$. This includes procurement of the hardware, its installation, one year's worth of monitoring, and the performance of three guided on-site load tests. An annual cost of $\$ 20,000$ is assumed for remotely monitoring of the bridge as well as conducting one guided on-site load test. In addition to the recurring annual cost for monitoring, a recurring annual cost of $\$ 12,000$ is assumed to allow for any maintenance, troubleshooting, or repair that may become necessary. A cost of $\$ 20,000$ is assumed for site inspection of each wooden bridge. Each wooden bridge is inspected biannually. In the analysis shown in Table 15, it is assumed that the remote monitoring system on the thermoplastic composite bridges eliminates the 
need for the biannual site inspections. (While not currently the situation, one day, such SPM and SHM systems may achieve the sophistication and reliability to eliminate the current practice of biannual on-site inspections.)

Table 15. ROI calculation for plastic bridge with remote SPM system.

\section{Return on Investment Calculation}

\begin{tabular}{crrr|} 
Investment Required & & 850,000 \\
Return on Investment Ratio & 0.70 & & Percent \\
\cline { 4 - 4 } & & & $70 \%$ \\
Net Present Value of Costs and Benefits/Savings & $14,061,606$ & $14,659,372$ & 597,766 \\
\hline
\end{tabular}

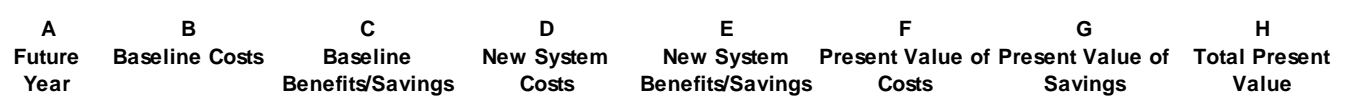

\begin{tabular}{|c|c|c|c|c|c|}
\hline 1[ & \begin{tabular}{|l|}
$1,342,350$ \\
\end{tabular} & \begin{tabular}{|l|}
$1,519,450$ \\
\end{tabular} & $1,420,078$ & $1,254,560$ & $-165,518$ \\
\hline 2 & $\begin{array}{l}1,342,350 \\
\end{array}$ & $1,559,450$ & $1,362,024$ & $1,172,408$ & $-189,615$ \\
\hline 3 & $\begin{array}{l}1,382,350 \\
\end{array}$ & $\begin{array}{l}1,611,450 \\
\end{array}$ & $1,315,427$ & $1,128,412$ & $-187,014$ \\
\hline 4 & $1,382,350$ & $\begin{array}{l}1,651,450 \\
\end{array}$ & $1,259,891$ & $1,054,595$ & $-205,296$ \\
\hline 5 & $1,422,350$ & \begin{tabular}{l|}
$1,691,450$ \\
\end{tabular} & $1,206,004$ & $1,014,136$ & $-191,868$ \\
\hline 6 & $1,422,350$ & $\begin{array}{l}1,731,450 \\
\end{array}$ & $1,153,665$ & 947,712 & $-205,953$ \\
\hline 7 & $1,462,350$ & $\begin{array}{l}1,771,450 \\
\end{array}$ & $1,103,082$ & 910,605 & $-192,477$ \\
\hline 8 & $1,462,350$ & $1,811,450$ & $1,054,264$ & 851,088 & $-203,176$ \\
\hline 9 & $1,502,350$ & $1,851,450$ & $1,007,004$ & 817,128 & $-189,875$ \\
\hline 10 & $1,542,350$ & $1,891,450$ & 961,424 & 783,977 & $-177,448$ \\
\hline 11 & 325,000 & 412,000 & 195,741 & 154,408 & $-41,334$ \\
\hline 12 & 325,000 & 412,000 & 182,928 & 144,300 & $-38,628$ \\
\hline 13 & 325,000 & 412,000 & 170,980 & 134,875 & $-36,105$ \\
\hline 14 & 325,000 & 412,000 & 159,774 & 126,035 & $-33,739$ \\
\hline 15[ & 325,000 & 412,000 & 149,309 & 117,780 & $-31,529$ \\
\hline 16[ & 325,000 & 412,000 & 139,544 & 110,078 & $-29,467$ \\
\hline 17 & $1,627,350$ & 412,000 & 130,439 & 515,219 & 384,780 \\
\hline 18[ & $\begin{array}{l}1,627,350 \\
\end{array}$ & 412,000 & 121,911 & 481,533 & 359,622 \\
\hline 19 & $1,627,350$ & 412,000 & 113,918 & 449,962 & 336,044 \\
\hline 20 & $1,627,350$ & 412,000 & 106,461 & 420,507 & 314,046 \\
\hline 21 & $1,627,350$ & 412,000 & $\begin{array}{l}99,498 \\
\end{array}$ & 393,005 & 293,507 \\
\hline 22 & $1,502,350$ & 412,000 & 92,988 & 339,080 & 246,092 \\
\hline 23 & $1,502,350$ & 412,000 & 86,891 & 316,846 & 229,955 \\
\hline 24 & $1,502,350$ & 412,000 & 81,205 & 296,113 & 214,908 \\
\hline 25 & $1,502,350$ & 412,000 & 75,890 & 276,733 & 200,842 \\
\hline 26 & $1,502,350$ & 412,000 & 70,946 & 258,705 & 187,758 \\
\hline 27 & 325,000 & 412,000 & 66,291 & 52,293 & $-13,998$ \\
\hline 28 & 325,000 & 412,000 & 61,965 & 48,880 & $-13,085$ \\
\hline 29 & 325,000 & 412,000 & 57,927 & 45,695 & $-12,232$ \\
\hline 30 & 325,000 & 412,000 & 54,137 & 42,705 & $-11,432$ \\
\hline
\end{tabular}

\subsection{Projected return on investment (ROI)}

Given the above assumptions and ignoring the costs of the monitoring system, an ROI of 7.3 is calculated for thermoplastic composite bridges. The results are shown in Table 14. This 7.3 ROI is based on the replacement of only 20 bridges. In fact, this number could be at least 30 times that amount for the Army alone. This would result in an even larger ROI.

The calculated ROI of 0.7 as shown in Table 15 indicates that the remote monitoring system as used on Bridge T-8518 would not be an economical 
investment on every new thermoplastic composite bridge the Army may construct. However, it is clear that the SPM system provided the needed performance data for the materials and design of the new thermoplastic composite bridge. Because the SPM system effectively provides timely structural performance data, the benefits of using this technology to monitor mission-critical bridges in remote locations may be considerable irrespective of the ROI figure. 


\section{Conclusions and Recommendations}

\subsection{Conclusions}

The remote SPM system accomplished the design objective of providing the data needed for ongoing evaluation of the long-term performance of the bridge. The SPM system allows for remote monitoring to be accomplished with minimal labor effort, and it is intelligent enough to identify and capture the dynamic loading events of interest as they occur. The system is also self sufficient in its power supply and communications and is fully integrated with the project database. Data are collected and loaded into the database automatically on a schedule and is available in real-time to the data users over the internet.

The SPM system has been used to collect a baseline of dynamic response data under both controlled load tests and unplanned vehicle crossings. This data can be used to compare with future data for evaluating changes in performance of the bridge structure with time. The response of the bridge to thermal loading has also been measured for two complete seasons. The data do not indicate any permanent displacements of the structure at this time. Measured displacements that do not correlate with the temperature response measured to date, may indicate creeping of the material or loosening of structural connections. To date the bridge has been performing per the original design with no indication of material or structural degradation.

\subsection{Recommendations}

\subsubsection{Applicability}

The automated SPM system has worked well in meeting the data collection needs of the project. Although the remote SPM system would not be costeffective for monitoring the condition of all new thermoplastic bridges, it is recommended that the system be considered for use on new missioncritical thermoplastic composite bridges located in remote areas. Bridges erected in close proximity to one another may be wirelessly linked to utilize a single data collection and transmission system to reduce hardware and operational costs. The SPM system could also be engineered with preset limits that would trigger warnings if values were exceeded and thus become a more traditional structural health monitoring (SHM) system. Such 
a SHM system could extend the time between periodic site inspections, which can be costly to perform in remote locations.

\subsubsection{Implementation}

\subsubsection{Long-term monitoring program}

The SPM system was designed and installed with the intent that it will be used for long-term monitoring. After 2 years of data collection, the system was taken off line in October 2011. The current plan is to leave the sensors and data collection equipment installed, but powered down and not collecting data. The SPM system can then be reactivated in the future for collecting data to compare with the current data for evaluating degradation with time. This future data collection could include repeating the load testing with the M1089, capturing heavy vehicle crossing events, and measuring the response under static loading conditions. Because the dynamic loading events (load testing and captured heavy vehicle crossings) are a measure of the relative change in deformations and strain, the future data should be comparable as long as the sensors continue to function properly. The static loading conditions may not be directly comparable over the period of time that the system was not collecting data if the sensor zero conditions change. For the displacements, this could be a change in the location of the targets due to a physical impact or settlement/ overturning of the pipe supports in the stream channel. The strain gages should not experience a zero drift as long as they stay properly bonded to the bridge material. Continuous monitoring is typically used to identify these sudden changes so that the data can be corrected. Without the continuous monitoring, a change in the sensor zero condition may go undetected.

To activate the SPM system in the future will require replacing the station batteries and the batteries in the infrared motion sensors. The system can then be powered on and startup testing performed to assure that it is functioning properly. The air temperature/ relative humidity and wind sensors should also be sent to the manufacture for recalibration.

\subsubsection{Engineering guidance documentation}

To best utilize the structural performance monitoring (SPM) system and the thermoplastic composite bridge design and materials as used on Bridge T-8518, the following engineering guidance needs to be developed: 
- Design and Use of Structural Health Monitoring Systems for Bridges (Steel Truss* and Thermoplastic Composite Bridges)

- Design, Construction, Inspection, and Maintenance \& Repair of Thermoplastic Composite Timber Bridges.

While both of these should eventually be developed and published as Unified Facility Criteria documents, an interim step would be to develop both as an Engineer Technical Letter (ETL). Development of the needed guidance was beyond the resources of this funded project.

* This guidance would pertain to the demonstration of SHM systems on the Government Bridge at the Rock Island Arsenal and the I-20 Bridge at Vicksburg, Mississippi, as the second part of CPC Project F08AR13. 


\section{References}

[1] Lampo, Richard G., S. Sweeney, J . Wilcoski, V. Hock, , V. Chiarito, H. Diaz-Alvarez, and T. Nosker, "Thermoplastic Composites as Degradation-Resistant Material Systems for Timber Bridge Designs," proceedings 2009 DoD Corrosion Conference, Washington DC, August 2009.

[2] Larsen, Kathy, "Corrosion-Resistant Thermoplastic Timber is Constructed of Recycled MilkJ ugs and Automobile Bumpers - US Army Builds First Thermoplastic Timber Bridge Capable of Bearing the Weight of a Battle Tank," Materials Performance, NACE International, Houston, TX, J anuary 2010.

[3] Lampo, Richard G., J . Wilcoski, V. Hock, S. Nemeth, H. Diaz-Alvarez, and T. Nosker, "US Army Builds Degradation Resistant Bridges," AMMTIAC Quarterly, Rome, Ney York, Volume 5, Number 4, December 2010.

[4] Lampo, Richard, T. Nosker, G. Nagle, S. Nemeth, K. Palutke, and L. Clark, "Demonstration of Thermoplastic Composite I-Beam Design Bridge at Camp Mackall, NC," Draft ERDC-CERL technical report, Engineer Research \& Development Center, Construction Engineering Research Laboratory, Champaign, IL.

[5] Commander, Brett, H. Diaz-Alvarez, "Field Testing and Load Rating Repoprt, Thermoplastic Bridge T-8518, Camp Mackall, NC," Technical Report ERDC/GSL TR-10-19, J une 2010, Engineer Research \&Development Center, Geotechnical and Structures Laboratory, Vicksburg, MS.

[6] ASTM Standard G1, 2003, "Standard Practice for Preparing, Cleaning, and Evaluating Corrosion Test Specimens," ASTM International, West Conshohocken, PA, 2003, DOI: 10.1520/G0001-03, www.astm.org.

[7] ASTM Standard B825, 2008, "Standard Test Method for Coulometric Reduction of Surface Films on Metallic Test Samples," ASTM International, West Conshohocken, PA, 2008, DOI: 10.1520/ B0825-02R08, www.astm.org.

[8] ASTM Standard D6662, 2009, "Standard Specification for Polyolefin-Based Plastic Lumber Decking Boards," ASTM International, West Conshohocken, PA, 2009, DOI: 10.1520/ D6662-09, www.astm.org.

[9] ASTM Standard D6109, 2010, "Standard Test Methods for Flexural Properties of Unreinforced and Reinforced Plastic Lumber and Related Products," ASTM International, West Conshohocken, PA, 2010, DOI: 10.1520/D6109-10, www.astm.org. 


\section{Appendix A: Bridge T-8518 Drawings and Specifications}

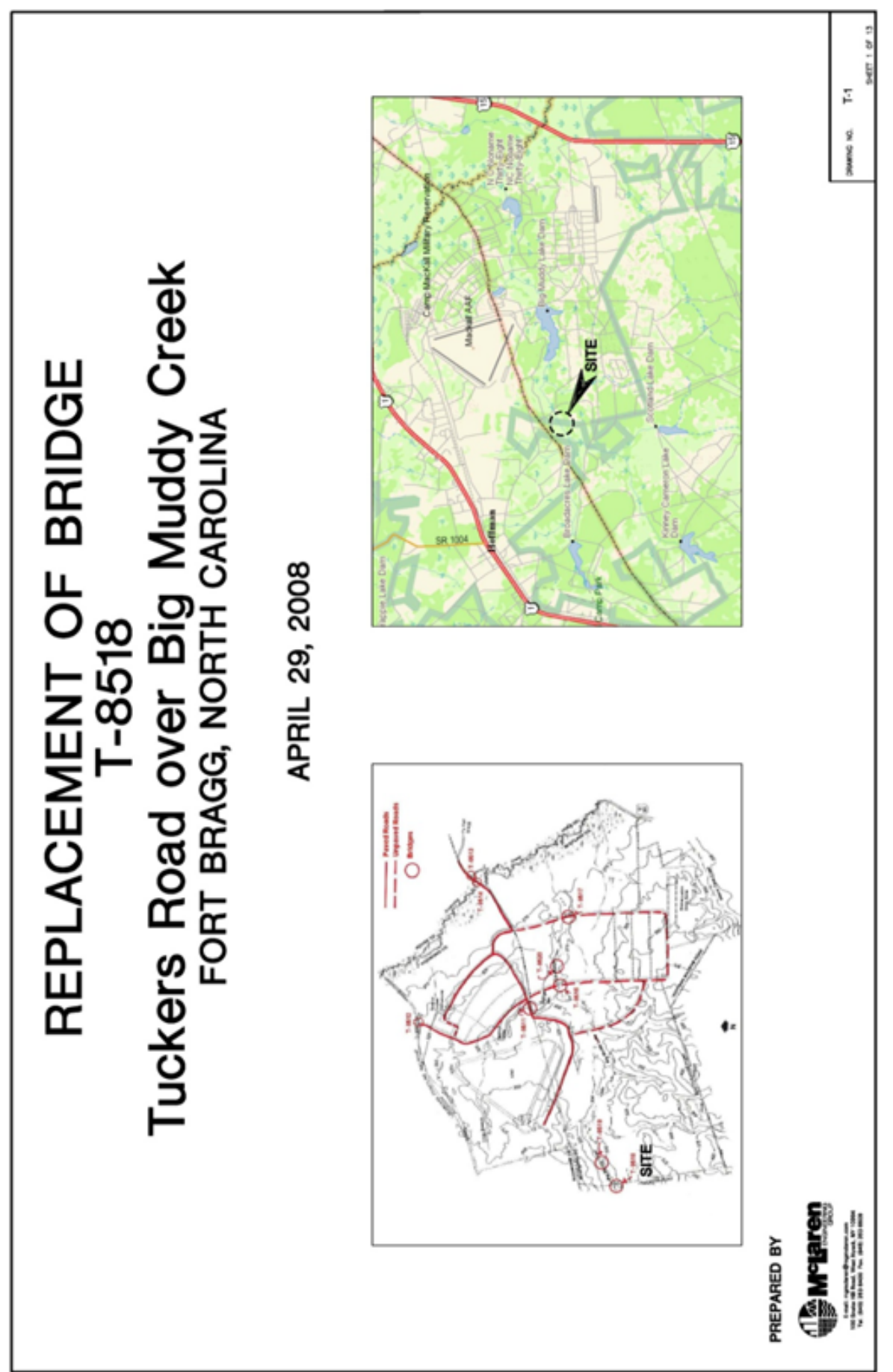




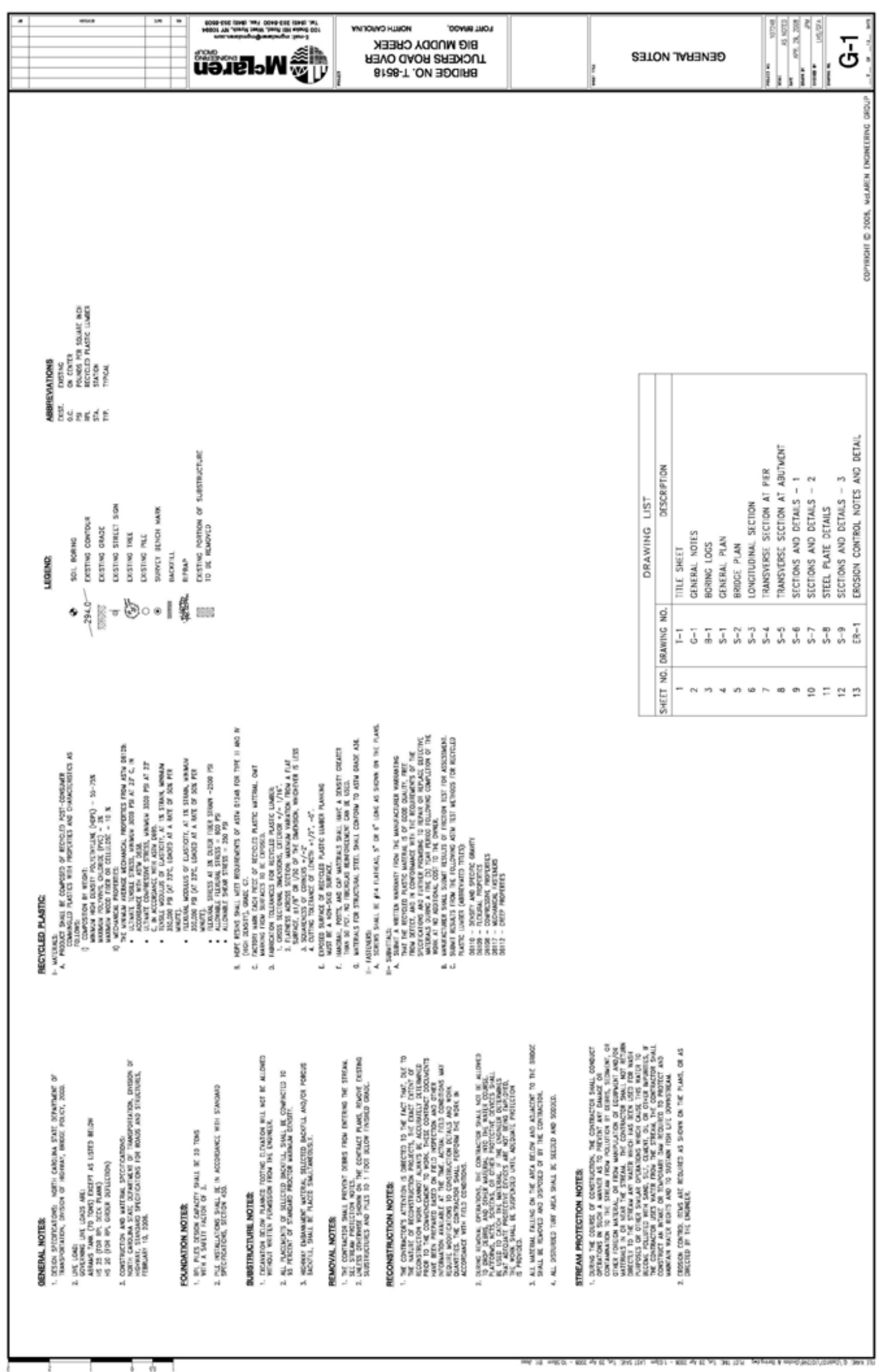




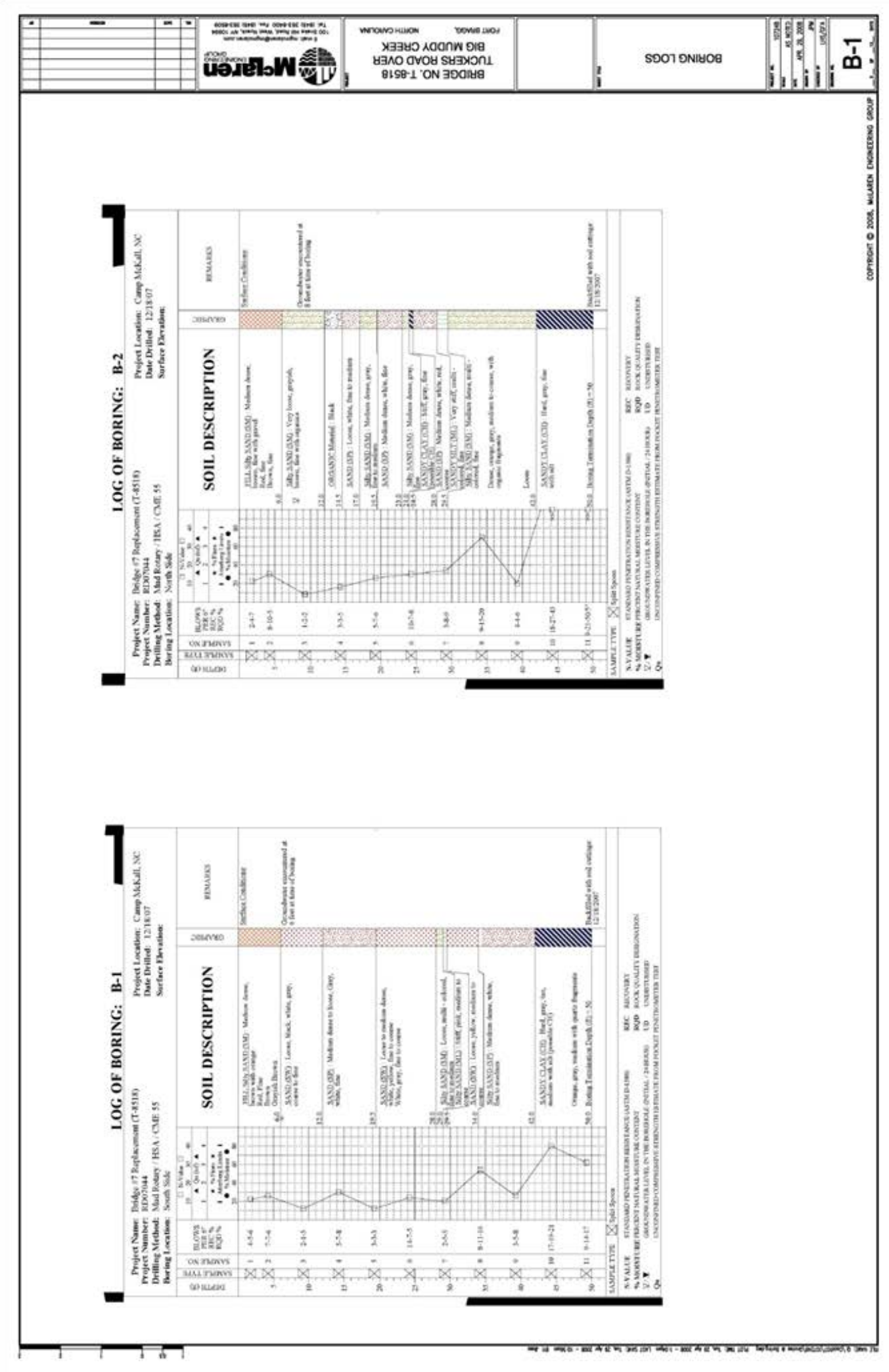




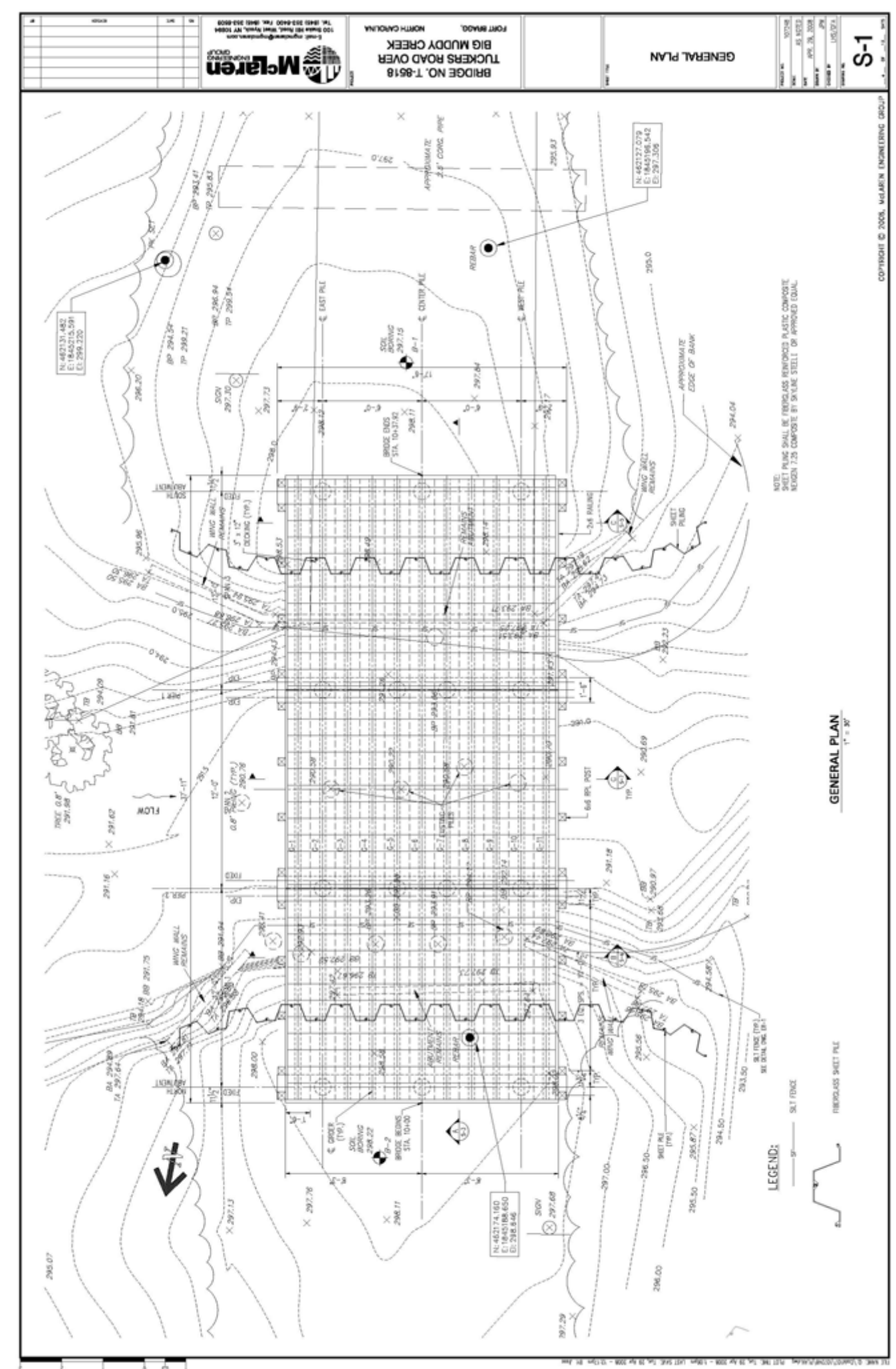




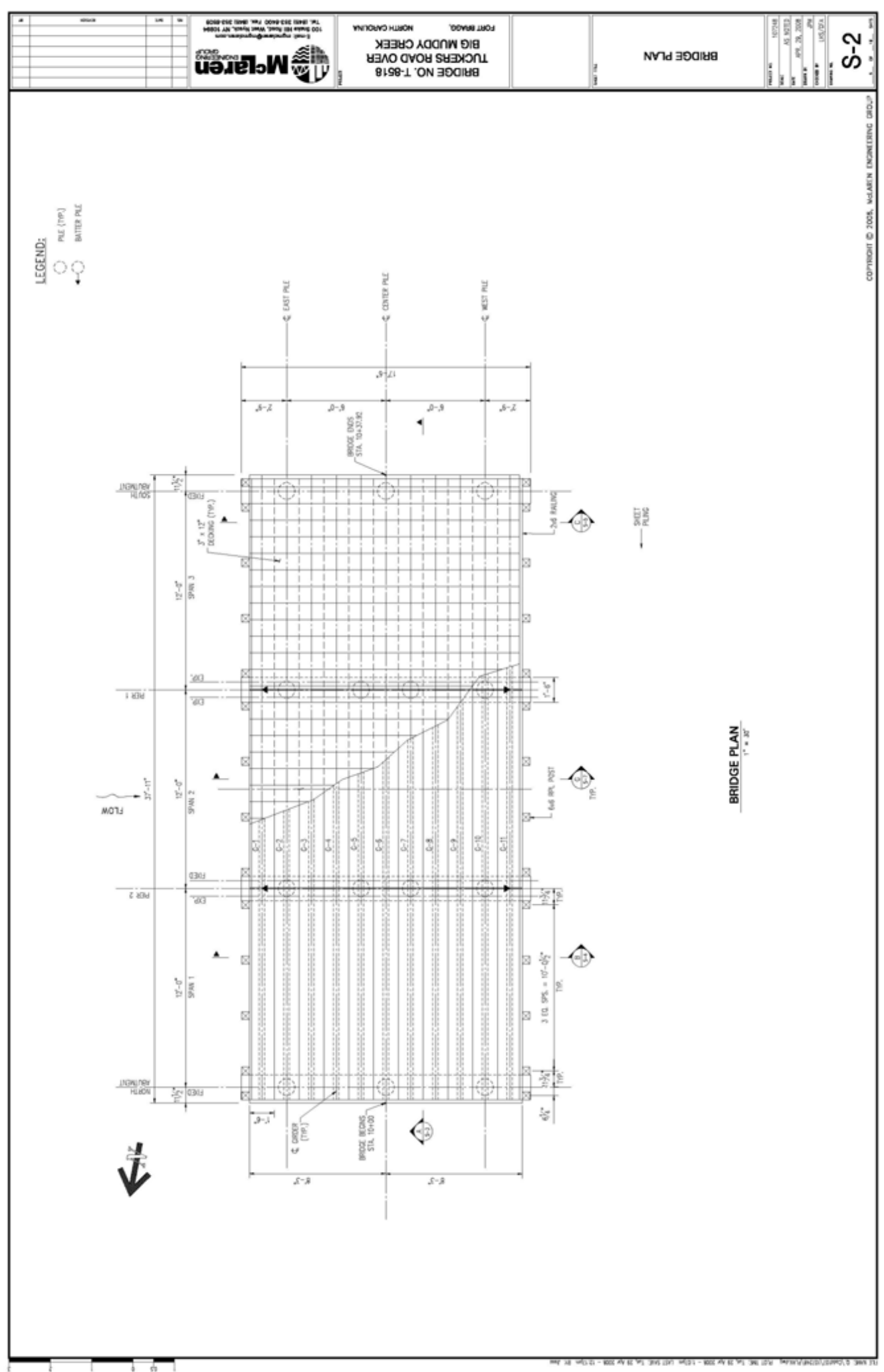




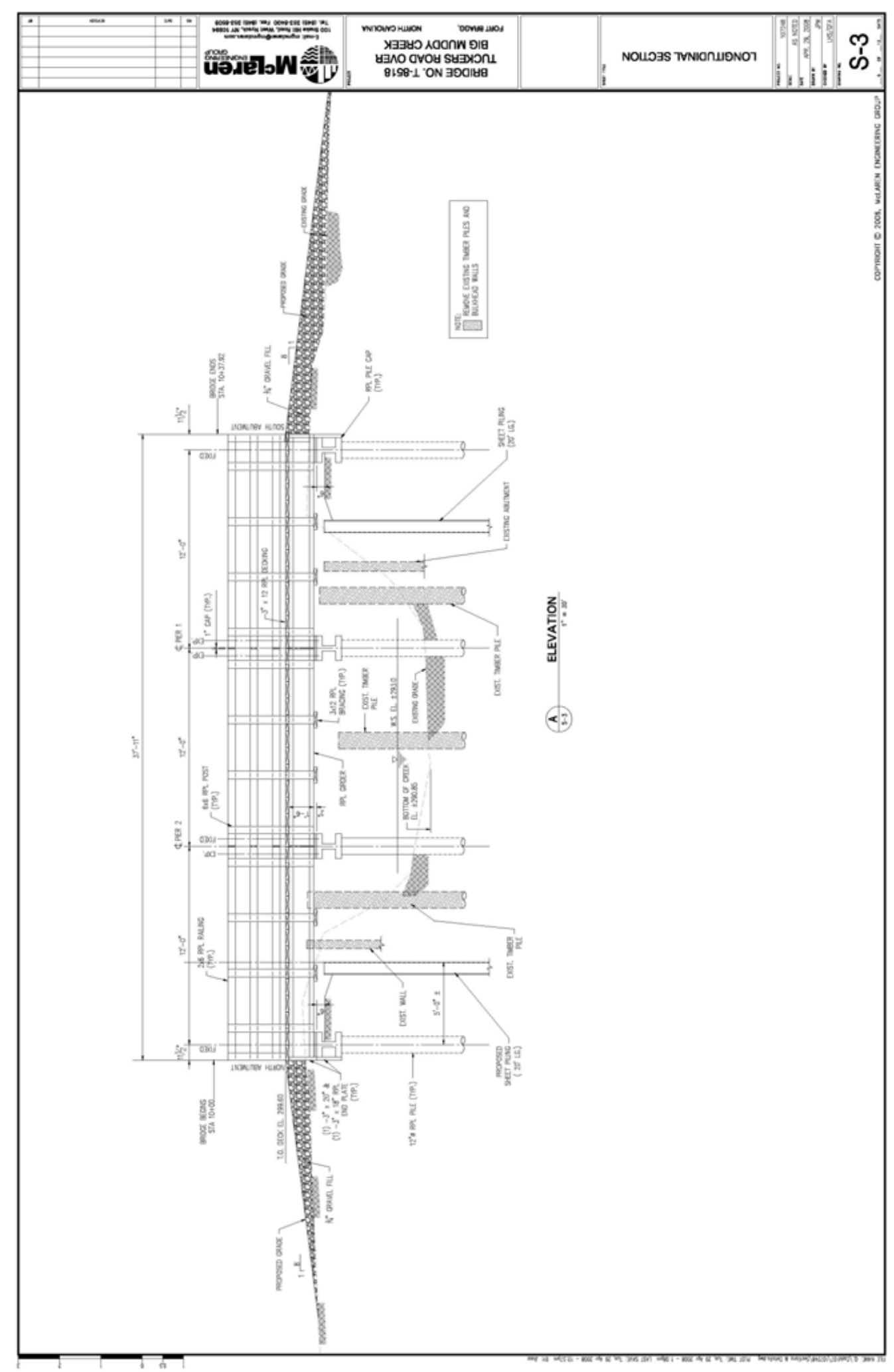




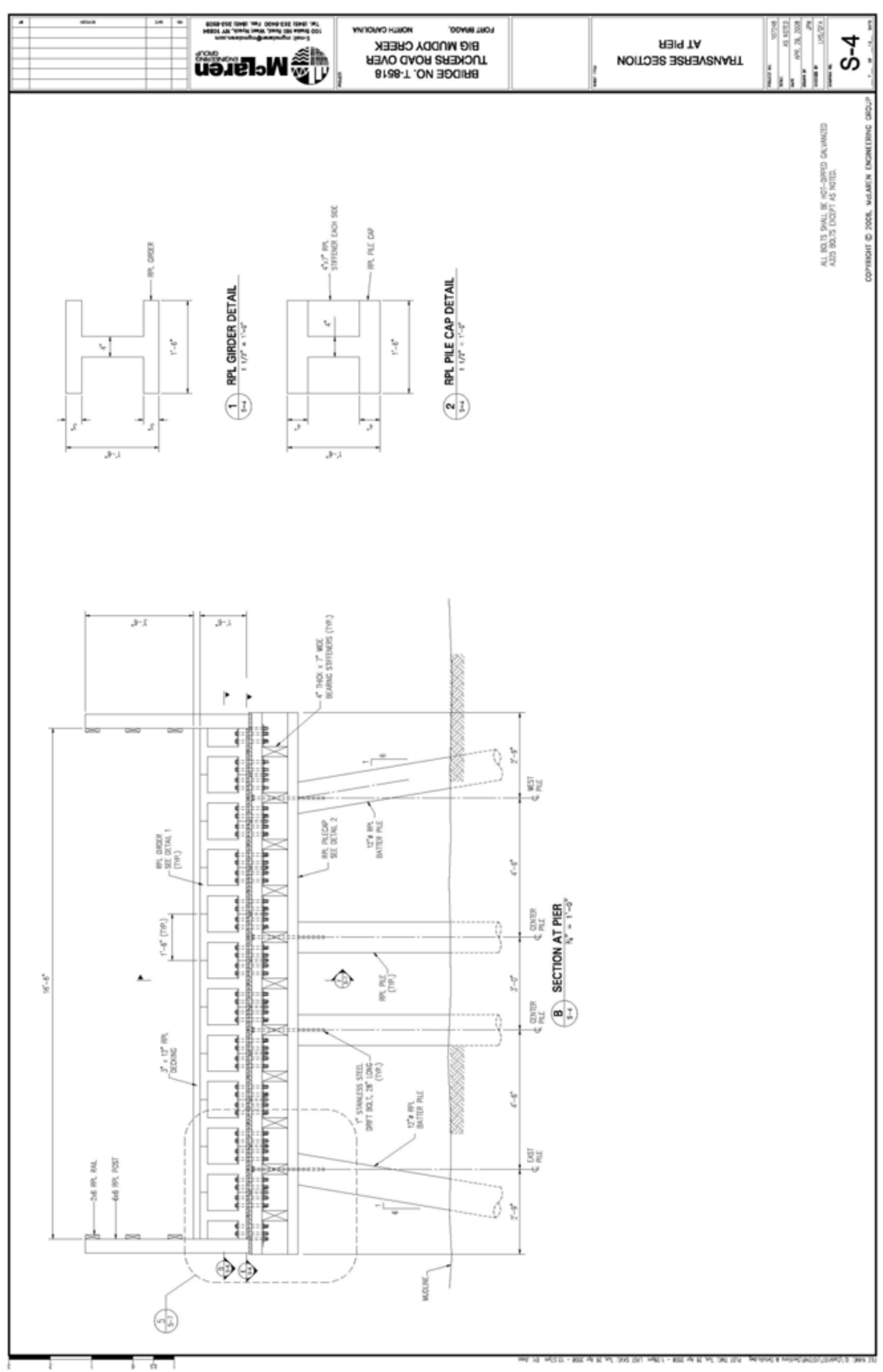




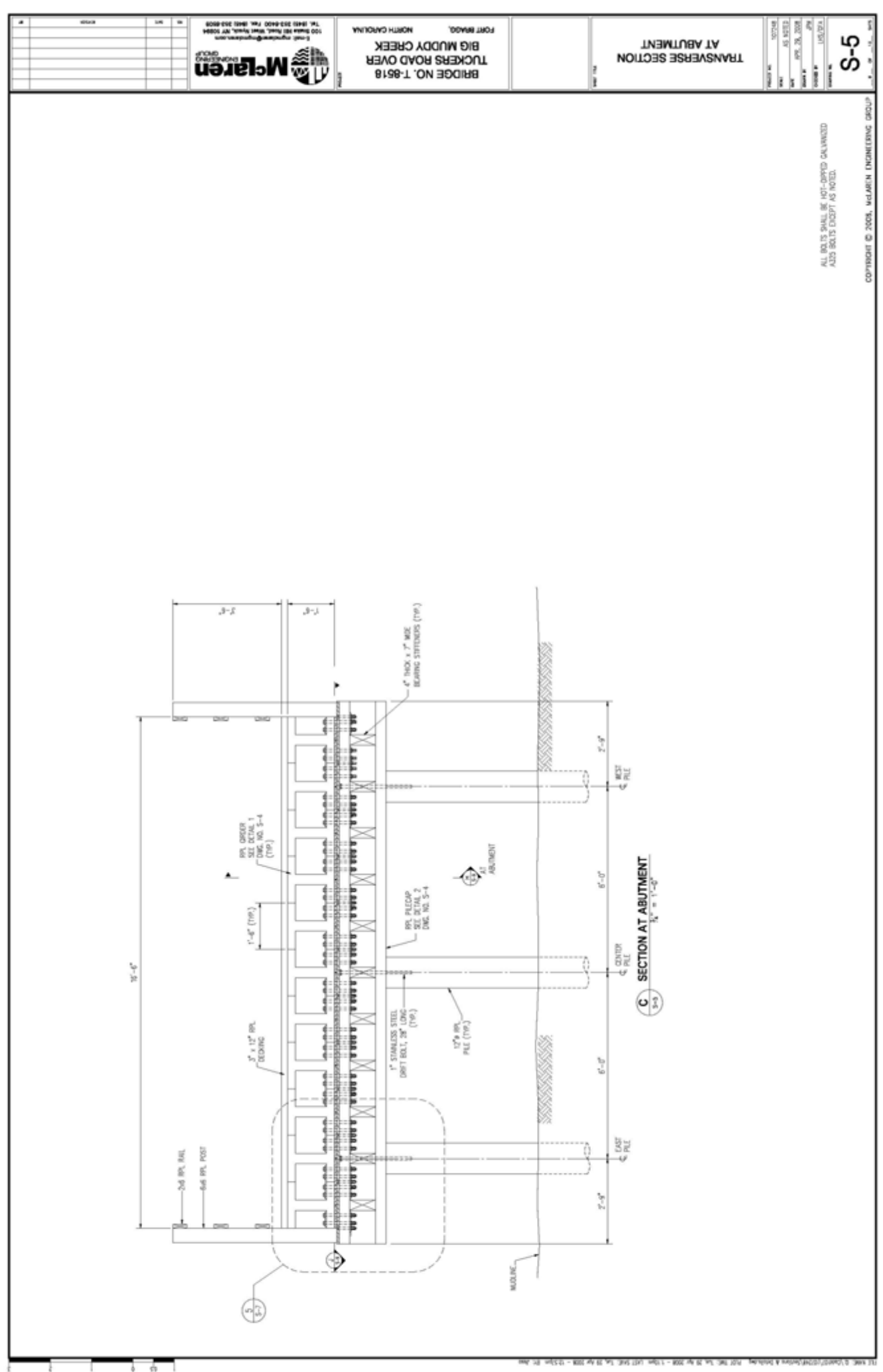




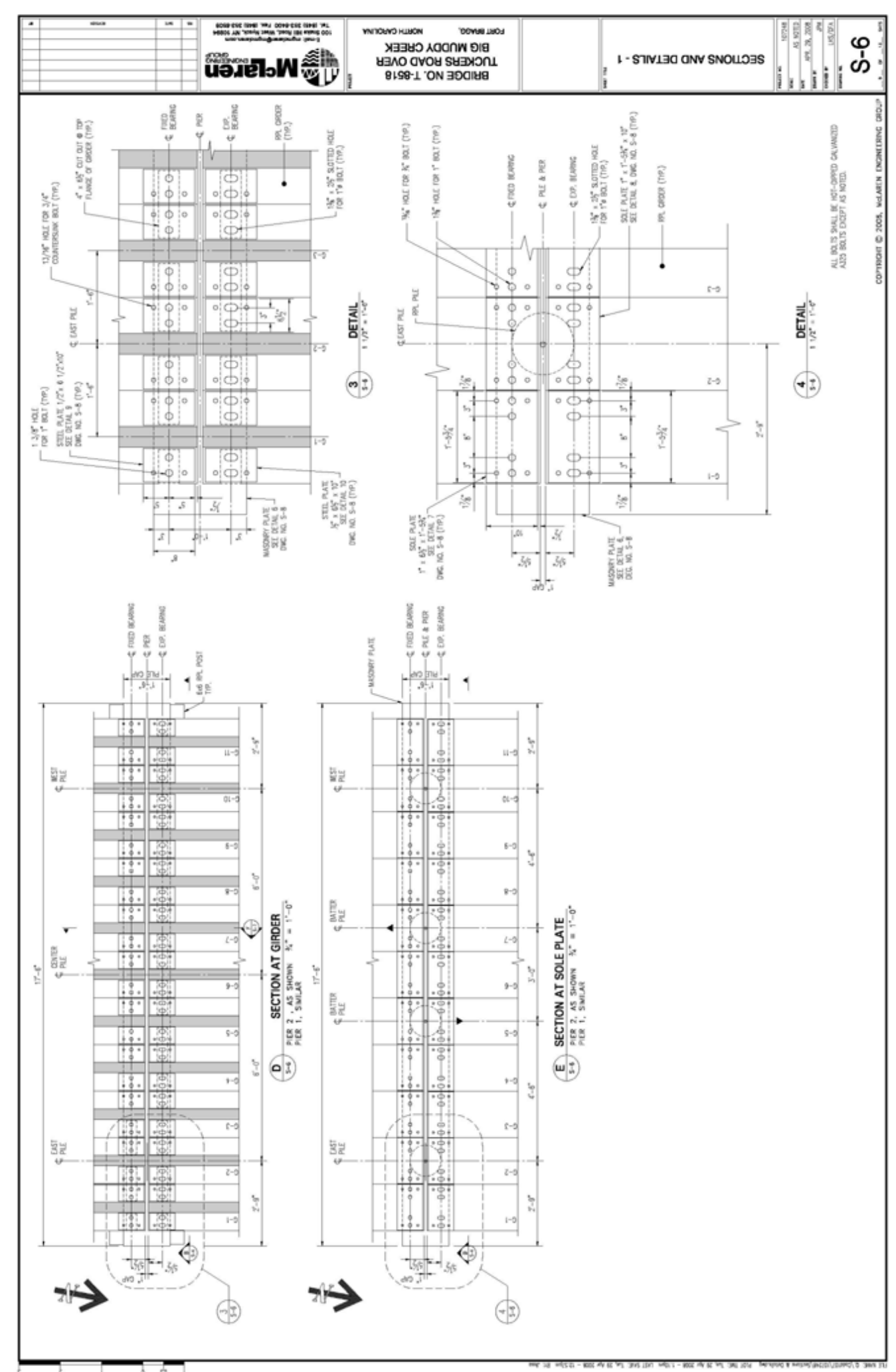




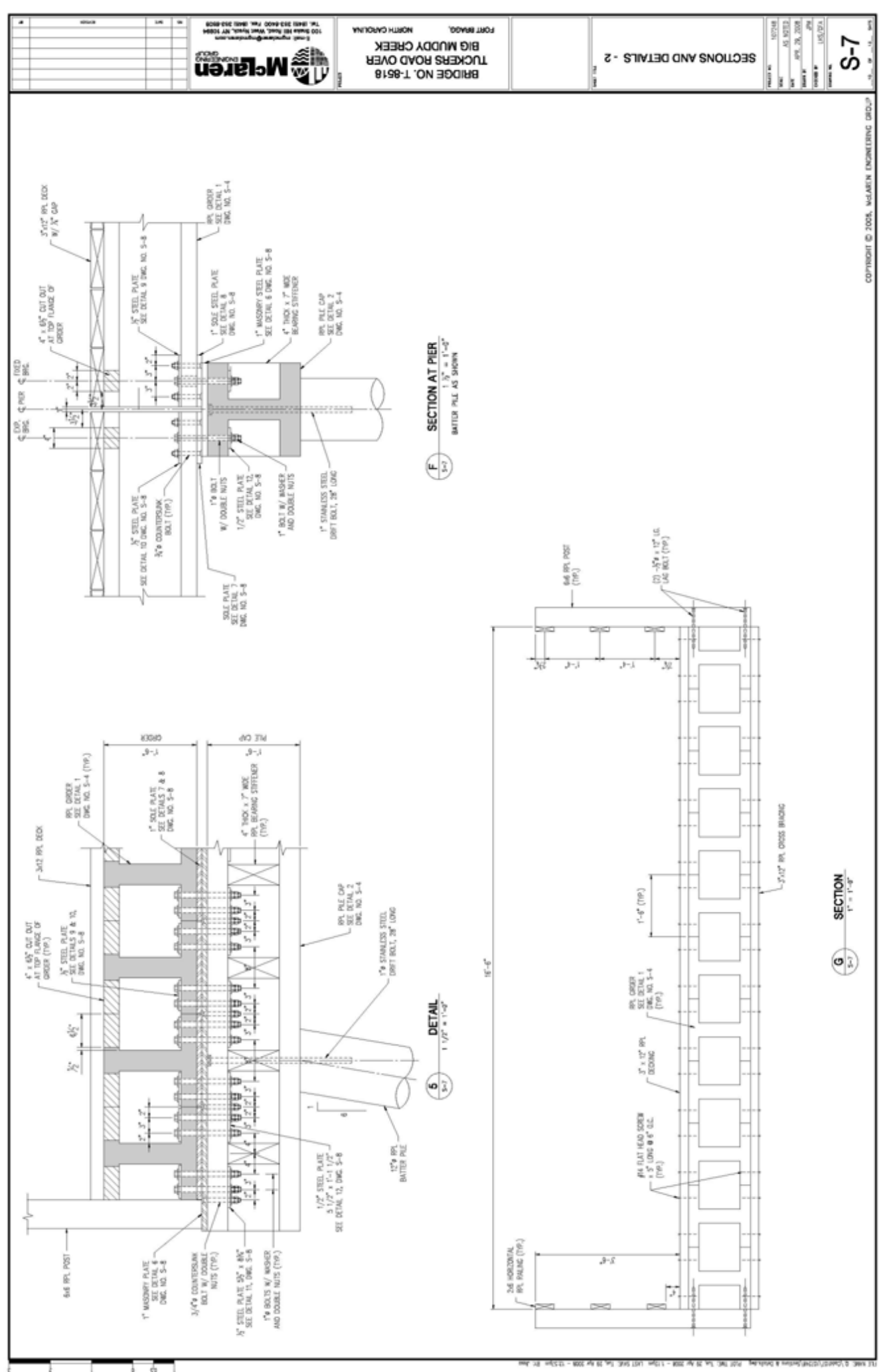




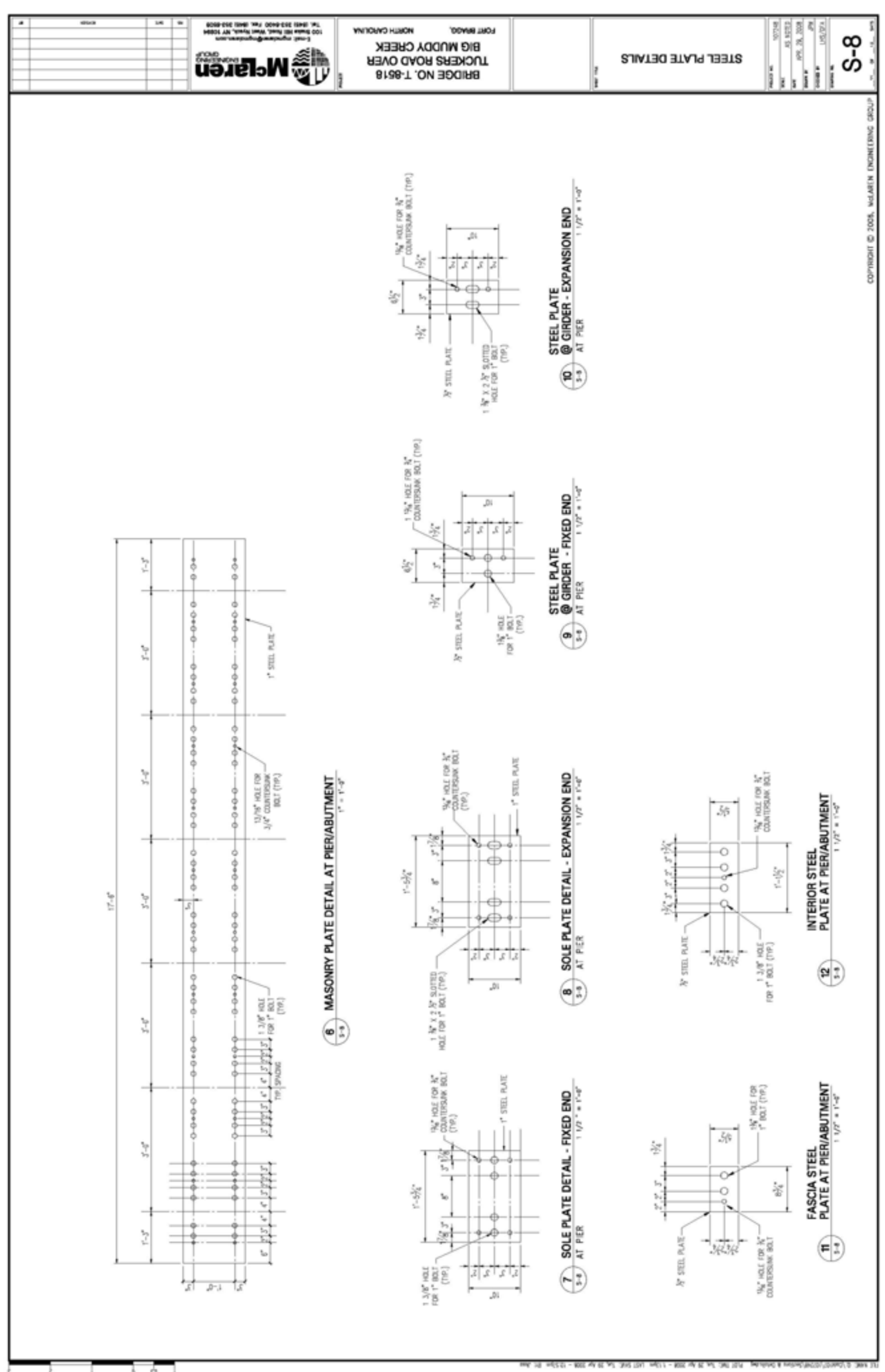




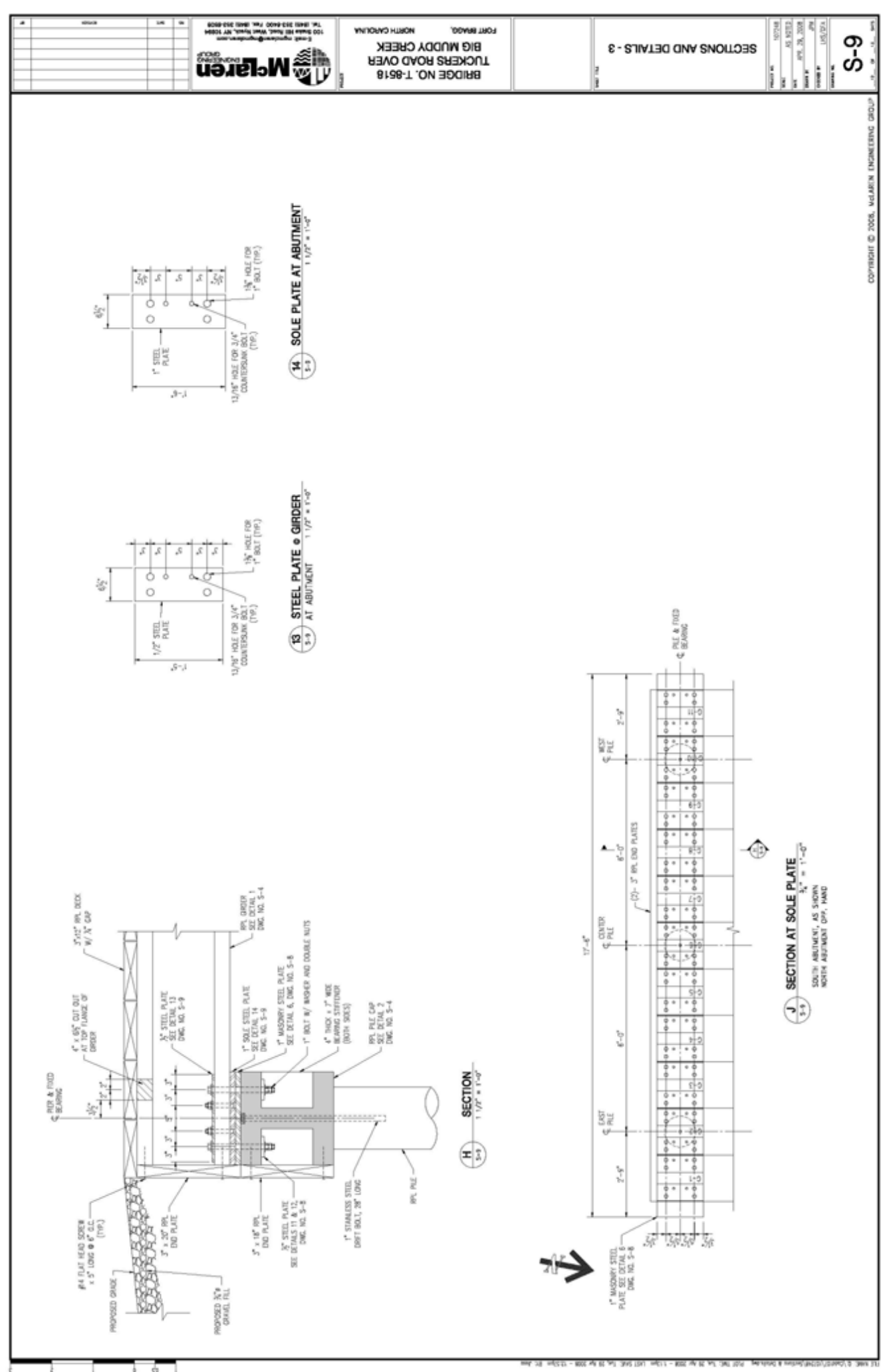




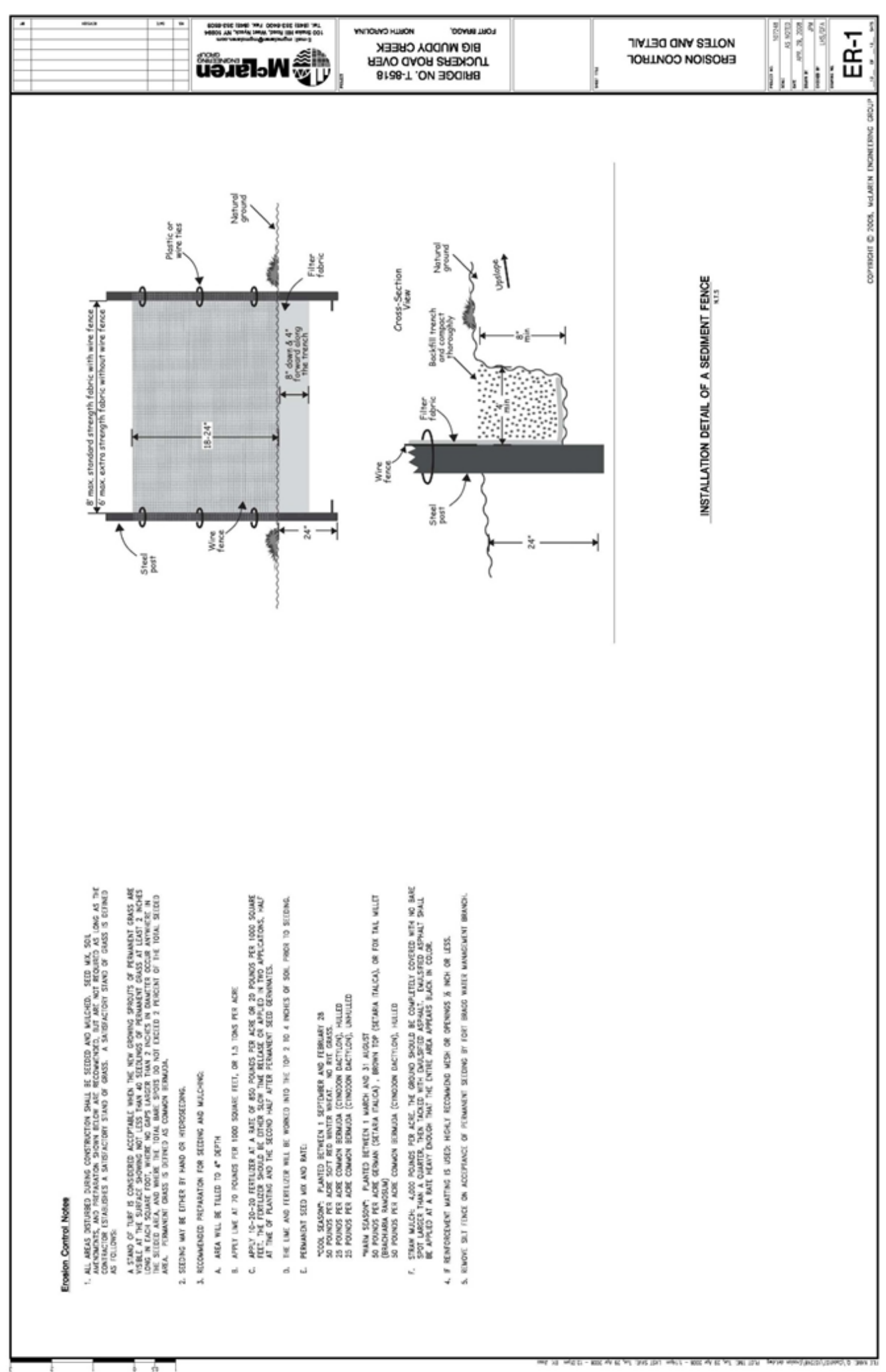




\section{Appendix B: Design, Construction, and Inspection of Bridge T-8518}

\section{B.1 Design}

The bridge was designed by M.G. McLaren Consulting Engineers, West Nyack, New York, using traditional timber bridge design methodology but with slightly lower allowable stresses for the thermoplastic composite materials. The material properties utilized in the design are shown in Table B1.

Table B1. Design values for thermoplastic composite bridge.

\begin{tabular}{|l|l|}
\hline Elastic modulus for live load (short duration) & $E=\quad 350 \mathrm{ksi}(2,400 \mathrm{MPa})$ \\
\hline Ultimate compression parallel to grain* & $\mathrm{f}^{\prime} \mathrm{c}=3,500 \mathrm{psi}(24 \mathrm{MPa})$ \\
\hline Allowable compression parallel to grain* & $\mathrm{f}^{\prime} \mathrm{c}=1,000 \mathrm{psi}(6.89 \mathrm{MPa})$ \\
\hline Ultimate flexural strength & $\mathrm{F}^{\prime} \mathrm{b}=2,300 \mathrm{psi}(15.9 \mathrm{MPa})$ \\
\hline Allowable flexural strength & $\mathrm{F}^{\prime} \mathrm{b}=600 \mathrm{psi}(4.1 \mathrm{MPa})$ \\
\hline Ultimate shear strength parallel to grain* & $\mathrm{F}^{\prime} \mathrm{v}=1,100 \mathrm{psi}(7.58 \mathrm{MPa})$ \\
\hline Allowable shear strength parallel to grain* & $\mathrm{F}^{\prime} \mathrm{v}=350 \mathrm{psi}(2.4 \mathrm{MPa})$ \\
\hline Self weight & $\omega p=0.032 \mathrm{pci}(8,686 \mathrm{~N} / \mathrm{m} 3)$ \\
\hline Coefficient of thermal expansion & $\varepsilon=0.000052 /{ }^{\circ} \mathrm{F}\left(2.88889 \mathrm{E}-05 /{ }^{\circ} \mathrm{C}\right)$ \\
\hline $\begin{array}{l}\text { * For the flow-molded thermoplastic composite members, grain is considered to be the direction of material } \\
\text { flow in the mold during fabrication. }\end{array}$ \\
\hline
\end{tabular}

The design incorporates heavy-duty I-beam members up to $46 \mathrm{~cm}$ (18 in.) high. The piles are made from the same glass-fiber-reinforced polymer material as the I-beams and decking. Stainless steel and other corrosion resistant bolts and screw fasteners were used in the bridge construction.

\section{B.2 Construction}

Thermoplastic composite lumber expands and contracts to a greater extent with changes in temperature than does wood or steel. Design features were, therefore, incorporated to allow the plastic lumber bridge structure to move differentially relative to the steel members and the bridge abutments during such changes in temperature. These features included slotted connections between the plastic lumber joists and the steel girder to which they were attached to accommodate side-to-side movement, and a 
floating deck at the bridge abutments to accommodate end-to-end movement.

Thermoplastic composite materials can be drilled and cut with saws much like natural wood. However, due to the glass fiber reinforcement, carbidetipped drills and saw blades are recommended.

\section{B.3 Inspection}

The following inspection checklist is will help assure a trouble-free structure with minimal maintenance in the long-term.

1. As described above, the thermoplastic composite lumber materials expands and contracts to a greater extent with changes in temperature than does wood or steel. It is imperative that the features designed to accommodate these movements are incorporated during construction and free to function. For example, components with slotted connections must be free to move with fasteners not over-tightened.

2. Cracking: During a visual inspection, the focus should be put on any appearance of cracks or splits . This includes cracking at and around the fastening points and at the apex of the beams. In the case of the $18 \mathrm{in.} \mathrm{I-}$ beams, it is not uncommon to find small gaps at the point of where the two bases of the T-beams meet (Figure B1). The T-beams are molded individually, then glued and bolted together to make the I-beam. These gaps represent the slight variation in the web depth of each T-beam during the manufacturing process. The presence of these gaps does not affect the structural capability of the I-beam. Although the appearance of cracking does not necessarily indicate mechanical failure, it should be photographed and appropriately documented for future monitoring.

3. Unusual or excessive movement of the piles and/ or deck during vehicle crossing shall be documented.

4. Lateral shifting of the structure, with regard to abutment shifting shall be documented.

5. Determine that specified corrosion-resistant hardware and fasteners were used. Also verify that manufacturer's recommended torque specifications are maintaining initial settings. 


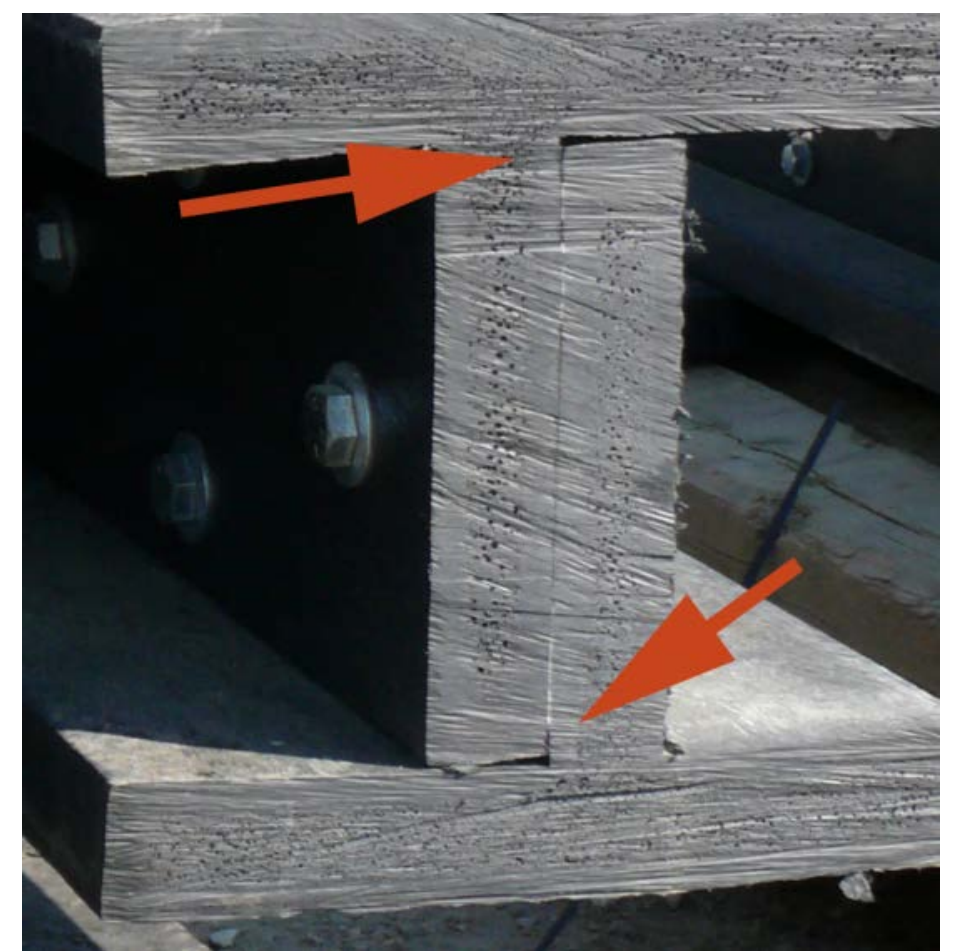

Figure B1. Gaps at the point of contact between the two T-beams. 


\section{Appendix C: Project Management Plan}

Reclama

F08AR13

OSD CORROSION PREVENTION AND CONTROL (CPC) PROGRAM

FY08 TRISERVICE I ARMY FACILITIES CPC PROJECT MANAGEMENT PLAN

Remote Monitoring of Degradation of Reinforced Thermoplastic Composite Bridges (RDT\&E)

3 August 2007

Updated 13 December 2010

Submitted By:

$\underline{\text { Vincent Hock }}$

U.S. Army Engineer Research \& Development Center (ERDC)

Construction Engineering Research Laboratory (CERL)

Comm: $217-373-6753$

F08AR13

This Project was pre-selected in FY07 as a candidate project for FY08 
F08AR13 Remote Monitoring of Degradation of Reinforced Thermoplastic Composite Bridges (RDT\&E)

\section{IMPORTANT PROGRAM CONSIDERATIONS:}

This project addresses Contributors to Total Corrosion Costs that are below the Top 25 as identified in Appendix Table N-1 in the draft 2007 Facilities Cost of Corrosion report. Number 25 , as listed by Facility Analysis Category (FAC), shows a total annual corrosion cost of \$16M and a total annual maintenance cost of \$76M. Vehicular Bridges (FAC \#8513) has an annual cost of corrosion of $\$ 321 \mathrm{~K}$ and a total annual maintenance cost of $\$ 2.1 \mathrm{M}$. Using the eight categories identified in Table 3-4 "Total Maintenance Corrosion Cost by Craft" of the subject draft report, Vehicular Bridges would fall under Roads and Grounds which typically has a low cost of corrosion index. However, as identified by the Bridge Program Managers at ACSIM and IMCOM and the respective DPW's, Fort Bragg NC, and Fort Leonard Wood, MO, have over three dozen failed or near failing timber bridges in their training areas. Fort Polk is another Army Installation with known deteriorated bridges, especially in their training areas. Materials durability is therefore having a significant negative impact on the Army's training mission.

This proposed FY08 Facilities Corrosion Prevention and Control (CPC) Project does not duplicate any past (FY05-07) funded CPC Projects by the Army, Air Force or the Navy relative to the type of sensors being used to monitor the performance degradation of the thermoplastic polymer materials being analyzed as part of this project. Also consider that while this proposed project is focusing on the use of remote wireless sensors, it will also be validating the performance durability (corrosion resistance) and economic viability of the subject thermoplastic composite materials for use in structural applications.

Fort Bragg DPW has given a commitment to fund the construction of a thermoplastic composite bridge in FY08 in coordination with this proposed OSD project.

On 1 August, the Interstate 35W Bridge collapsed into the Mississippi River in Minneapolis with corrosion and fatigue likely contributors to the catastrophe. The Army and the rest of DoD have a number of fracture critical design bridges within their infrastructure. At the request of OSD, the scope of proposed project FO8AR13 was to be broadened to include remote monitoring of degradation of steel bridges. This version is before that expansion of scope and involves just the original focus for the monitoring of a thermoplastic composite bridge.

\section{STATEMENT OF NEED}

PROBLEM STATEMENT: Roads are an essential part of any military installation whether they are on the main part of the Post or the more remote training areas. These roads provide a means for the transportation of people and things and are critical for the safety and security of the Installation as well as its mission. And, wherever there are roads, there will be bridges to transverse rivers, streams, and gulleys that are just a part of the natural terrain. Most of these bridges are small wood or steel structures that, like many of our Nation's infrastructure bridges, are in dire need of major repairs or replacement due to corrosion and materials degradation. 
As corrosion degradation progresses, the bridge load rating (the safe weight capacity of the bridge) will be lowered to ensure continued safe use. As the deterioration advances further without major repair, the bridge may be taken out of service altogether. At best, this means considerable more time and distance to get around natural barriers. In times of medical emergency or fire, a delay could have significant consequences by forcing the ambulance or fire truck to go the "long-way around."

Budget constraints equate to limited repairs on just the most critical structures. Many bridges have deteriorated to a point in which the cost of needed repairs exceeds the cost of replacement. If the bridge is using the same materials, the degradation cycle just starts all over again.

The materials degradation problem associated with wood bridges is also observed in other large outdoor wooden or steel structures such as decks, docks, boardwalks, observation towers, etc. The latest generation, treated-wood products are also suspected to cause accelerated corrosion of steel-based fasteners due to the presence of copper (copper compounds being added in quantities sufficient to limit biological-induced degradation but supposedly low enough to not be a human health hazard).

A material system and design is needed that is corrosion resistant (both chemically-induced and biologically-induced degradation) and cost beneficial compared to current treated-wood bridges and other similar loadbearing structures. A means to remotely monitor and validate the durability performance of these thermoplastic composite materials in load-bearing applications is also needed.

IMPACT STATEMENT: Reducing the load capacity or losing a bridge from use altogether can have serious effects on the everyday mission operations of the Installation. Such loss can be especially critical for emergency and security situations as well as loss of training capability. The small bridges on most Army Installations are showing significant deterioration and need of major repair or replacement. If this project is not funded, bridges will continue to be repaired or replaced using material systems that require high maintenance and replacement costs. The proposed corrosion resistant and virtually maintenance-free innovative thermoplastic composite system will assure long-term operation at full capacity at a lower first- and lifecycle cost compared to traditional treated-wood and steel designs. Remote sensor capabilities are needed to monitor and validate the performance of the thermoplastic composite materials being used in critical, high-stress applications. The modeling and degradation data developed from the execution of this proposed CPC project on thermoplastic composites will link directly to the ongoing 6.2 Program funded research being conducted at ERDC-CERL on the Degradation of Advanced Materials. This ongoing 6.2 effort is developing and validating models for the degradation of fiber-reinforced composites in infrastructure applications and is mainly focused on thermoset composites. The CPC-funded project will provide additional data to help test the validity of the models being developed and how they relate and may be used to predict the degradation of thermoplastic composites as well. 
F08AR13 Remote Monitoring of Degradation of Reinforced Thermoplastic Composite Bridges (RDT\&E)

\section{PROPOSED SOLUTION}

TECHNICAL DESCRIPTION: Over the last twenty years, Industry has been developing thermoplastic lumber products as alternatives to treated-wood materials (Ref. 1). Over the last ten years, these products have been developed into engineered products for structural applications. In 1998, a vehicular "plastic lumber" bridge was built at Fort Leonard Wood, MO, using structural-grade thermoplastic lumber elements (Figure 1) (Ref. 2, 3). This plastic bridge replaced a wood structure, which had significantly deteriorated after $50 \%$ of its estimated design life, using conventional wood designs for the plastic bridge replacement (the original steel support stringers were retained). The bridge has had no maintenance to date and looks like new nine (9) years later.

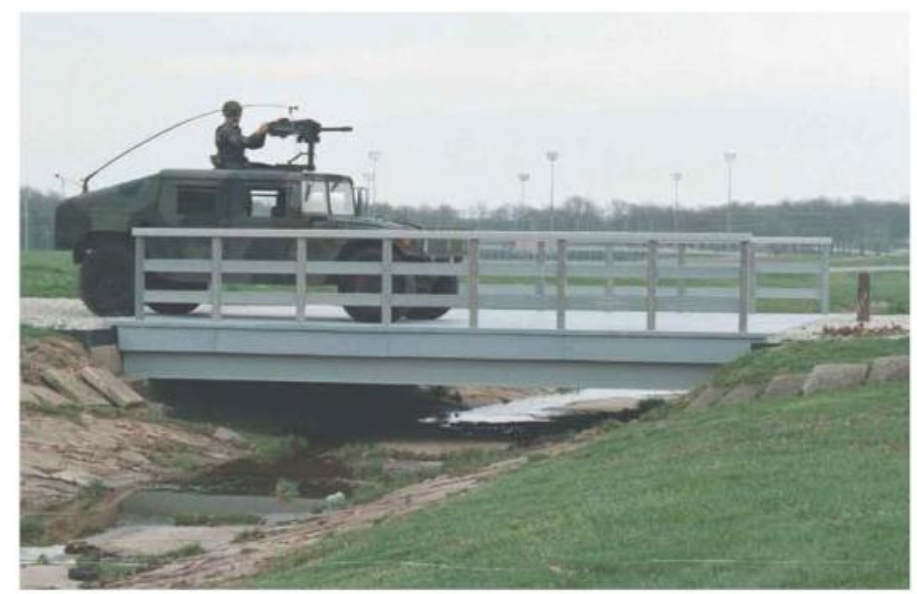

Figure 1. Thermoplastic composite lumber bridge at Fort Leonard Wood, MO.

The initial materials costs were approximately two times greater for this bridge than if replaced with a treated-wood structure like the original. However, a lifecycle costs analysis showed the thermoplastic bridge would pay for itself in less than eight (8) years, mainly through the lowmaintenance requirements compared to a wooden structure. And with a fifty (50) year plus expected lifetime, the lifecycle cost savings are very significant. Still the first costs were higher and represents a barrier for more routine use of this alternative thermoplastic material technology regardless of the lifecycle benefits. Note that since this thermoplastic bridge is now nine (9) years old and has had no maintenance over that lifetime, it has now paid for itself on a lifecycle basis.

In 2000, another thermoplastic bridge was built in a State Park in New York using an arch-truss design (Ref. 4). This all-plastic bridge has a 15,000 lb load capacity and the arch-truss design further reduced the first costs, as compared to an all-wood structure, but was still not as low as desired. 
Then, in 2003, an innovative thermoplastic I-beam design was used to build a Class 20 bridge (designed to carry a 75,000lb load and still not be in the stress level that causes creep) on an access road within the Wharton State Forest in New Jersey (Figure 2) (Ref. 5). Because of the load capabilities of the I-beam members and the construction efficiencies of interlocking beams, not only does the design promise low lifecycle costs but lower first costs (as compared to more conventional design) as well.

It is this innovative I-beam technology that may provide the Army (and other DoD) a corrosion resistant alternative for bridges (and other large outdoor structures otherwise made using treatedwood) that is cost effective, sustainable (recyclable), and environmentally friendly (uses recycled waste plastics and containing no added chemical treatments - biocides). However, all past constructions using these thermoplastic composite materials were for structures with intermittent, overall low traffic density. The durability of these materials in a higher traffic density, which would equate to a higher accumulated stress level, is unknown.

Fort Bragg, NC, has several small wooden bridges needing extensive repair or replacement (Figure 3). The Fort Bragg DPW will use the innovative thermoplastic I-beam (or T-beam) technology to replace one of these bridge structures in early 2008 to coincide with this proposed CPC project (i.e., instrumentation will be done during or just after construction). The bridge will be an all-plastic structure as the piles, structural support members, decking, and guard rails will all be made from corrosion-resistant recycled-thermoplastic materials. This bridge, made from thermoplastic structural lumber and design, will then be instrumented with state-of-the-art wireless, miniature sensors (Figure 4) to remotely measure and record the vehicular loadings and induced deflections to help determine any progression of deterioration due to loading and/or environmental exposures. The data will not only assure that the bridge is safe to use but will aid in modeling the durability of the thermoplastic materials. The benefits will be an up-grade in the load capacity of the bridge a projected almost maintenance-free material system over its fifty (50)-plus year life.

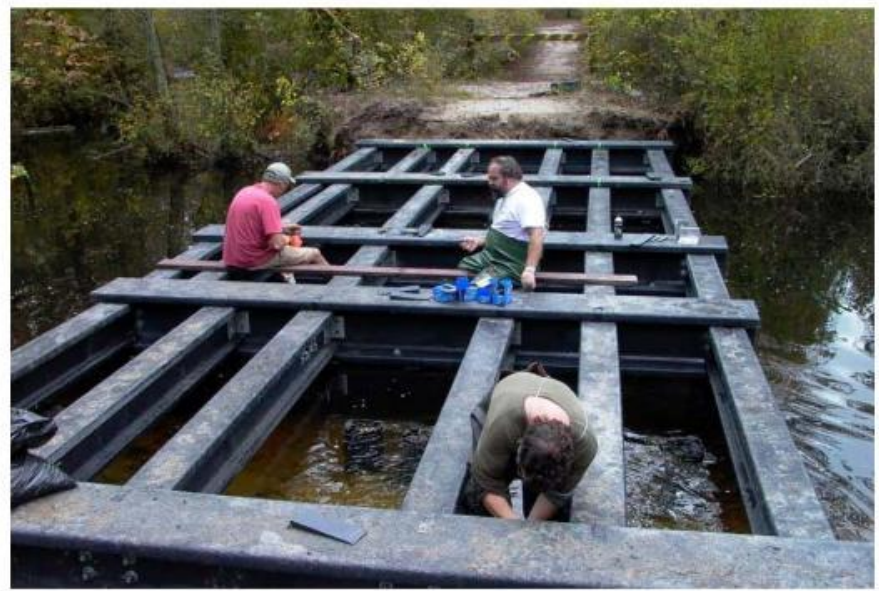

Figure 2. Interlocking thermoplastic I-beam design for bridge construction. 


\section{F08AR13 Remote Monitoring of Deqradation of Reinforced Thermoplastic Composite Bridges (RDT\&E)}

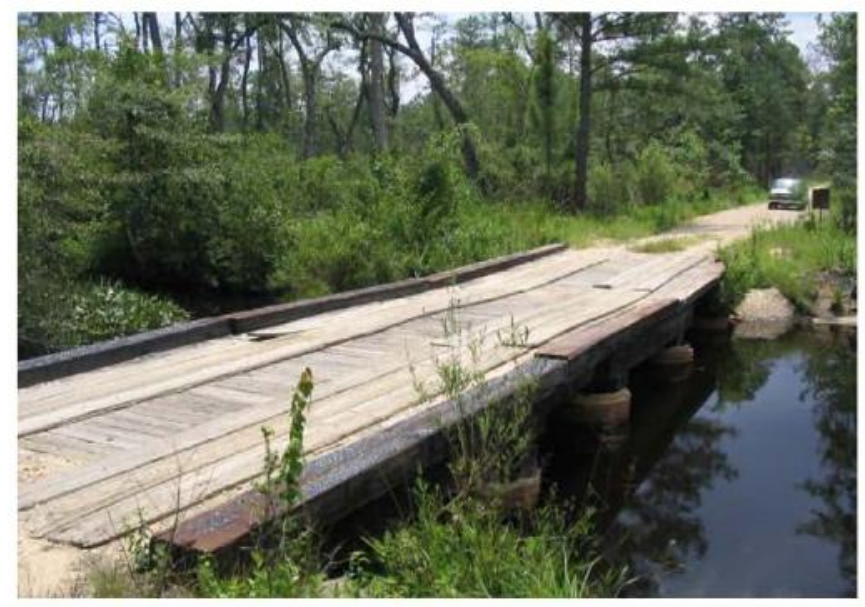

Figure 3. Deteriorated wood bridge being replaced with thermoplastic bridge by Bragg DPW.

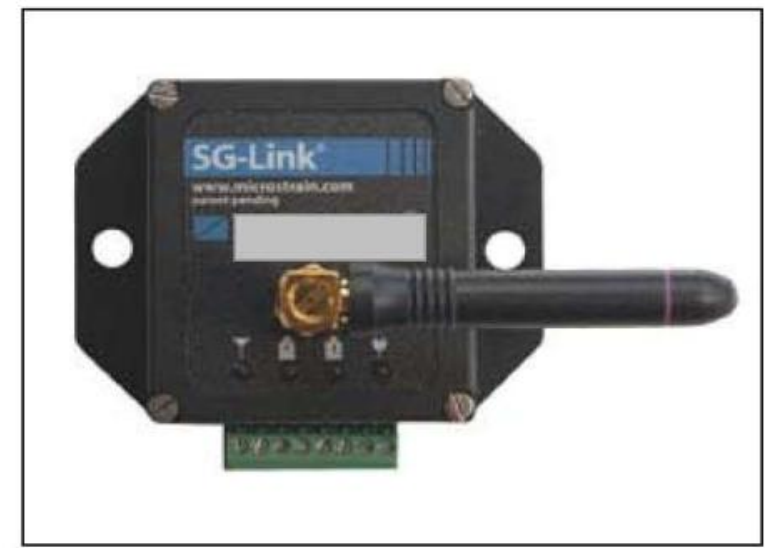

Figure 4. Example of a wireless strain sensor for durability performance monitoring of the bridge structure.

Implementation of this technology (that is, the thermoplastic lumber using the remote sensors) at Fort Bragg is projected to have an ROI of 14.9, and a total savings of \$12.6M.

\section{Technology Maturity:}

Thermoplastic lumber products are readily available from a number of manufacturers across the U.S. While the concepts behind an I-beam design are not new, it wasn't until recently that such 
F08AR13 Remote Monitoring of Deqradation of Reinforced Thermoplastic Composite Bridges (RDT\&E)

thermoplastic I-beam products were made and used in such structural applications. The ability to design and construct a vehicular bridge using this innovative material system and design was proven in the construction of the New Jersey bridge (Figure 5). What are not well documented to date, however, are the complete cost benefits that the technology can offer. A primary objective of the proposed project is to demonstrate the capabilities of the thermoplastic I-beam design and verify and document the corrosion resistance (durability and low maintenance requirements), economic (first and lifecycle costs) and the environmental (sustainable and "green") benefits to the Army and the rest of DoD through the use of wireless sensors to measure durability performance. This will be accomplished through laboratory tests and monitoring, field sensors and monitoring, and field load testing of materials and bridge structure.

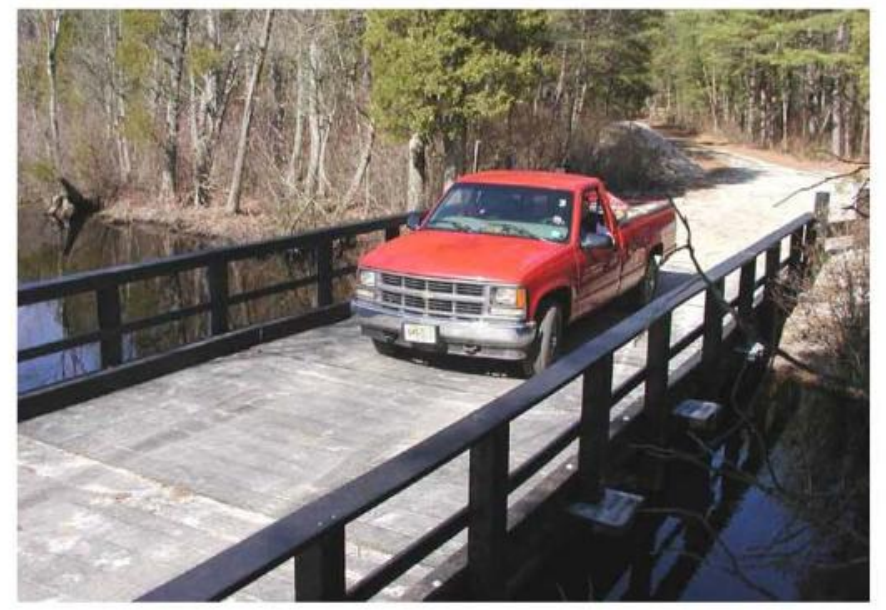

Figure 5. Completed Thermoplastic I-Beam Bridge at Wharton State Forest, NJ.

RISK ANALYSIS: This is a low-risk project as the remote sensors and the thermoplastic composite structural materials being monitored are commercially available, and have been successfully used or field tested in similar applications (e.g., the thermoplastic lumber in the New Jersey Bridge, see Figures 2 and 5). The site and plans for implementation of this project at Fort Bragg have been coordinated with Mr. Gregory Bean, Chief, Fort Bragg DPW and his Staff responsible for bridges on Post. Fort Bragg DPW has given a commitment to fund the construction of a thermoplastic composite bridge in FY08 in coordination with this proposed OSD project. The project will not be parsed into phases.

EXPECTED DELIVERABLES AND RESULTS/OUTCOMES: Using a minimum load Class 20 thermoplastic lumber bridge in the training area at Fort Bragg, NC, wireless sensors will be installed to monitor performance degradation of the thermoplastic materials. Not only will the success of the wireless sensors to monitor performance and life-performance predictions will also be documented but the economics and performance benefits of the I-beam design will be analyzed and documented as well. Data developed in this project will directly relate to 
F08AR13 Remote Monitoring of Degradation of Reinforced Thermoplastic Composite Bridges (RDT\&E)

ongoing 6.2-funded research on the Degradation of Advanced Materials. The project design and benefits analyses will be used to develop engineering guidance (e.g., Unified Facilities Guide Specifications - UFGS and Unified Facilities Criteria - UFC) for the use of the remote sensors as well as the design and construction of thermoplastic I-beam structures for outdoor applications (e.g., bridges, decks, docks, etc.). Lessons-learned and guidance developed as part of this project will be implemented in ACSIM's Installation Design Standards Process. A final report describing the details of the project will be developed and placed on the OSD Corrosion Exchange website under "Specs \& Standards" and "Facilities SIG." In addition, the draft documents will be posted on the ERDC-CERL Corrosion Control Technology Program (CCTP) website.

PROGRAM MANAGEMENT: The Project Manager will be: Mr. Vincent Hock (ERDCCERL Senior Researcher and Materials Engineer). The Associate Project Manager will be: Mr. Richard Lampo. Mr. Steven Sweeney is the ERDC-CERL Branch Chief. The stakeholders will be: Mr. Gregory Bean (Fort Bragg DPW), Ms. Kristen Thomas (IMCOM-SERO), Mr. Paul Volkman (HQ-IMCOM), Mr. David Purcell (HQ-ACSIM), as well as Tri-services WIPT representatives, Mr. Dan Zarate (NFESC), and Mr. Mike Zapata (AFCESA/CESM). The initial customer is: Mr. Gregory Bean, Chief, DPW, Fort Bragg, NC. The technology has been requested by Fort Bragg to help reduce their maintenance and replacement costs of their many small bridges.

\section{Project Team Roles and Responsibilities:}

a. Fort Bragg DPW / USAES Roles and Responsibilities: Fort Bragg DPW will replace an existing wooden bridge with a plastic lumber bridge on which to implement the technologies to be demonstrated and validated by this project. Mr. Darryl Butler and Mr. Ted Kientz, Fort Bragg DPW will provide technical and logistical support. The Army Engineer School (USAES) has expressed an interest in both the structural use of the thermoplastic materials that will be used in the bridge and the monitoring methods and results that will be part of the technology validation. LTC Robert Tucker, USAES, will provide supplemental engineering and design support and act as the liaison between ERDC-CERL and the USAES concerning the project results.

c. ERDC-CERL Roles and Responsibilities: Overall project management and technical oversight of the on-site work will be provided by ERDC-CERL. Mr. Richard Lampo has this primary responsibility of overall project management and technical oversight. ERDC-CERL will develop and contract for the implementation the sensors on the subject bridge. Mr. Lampo will coordinate the laboratory testing and investigations as part of this project. All Contractor deliverables (including monthly progress reports) shall be submitted through and approved by Mr. Lampo (in coordination and approval of Fort Bragg DPW) before concurrence will be given for payment of incremental invoices. On all OSD funded Corrosion Prevention and Control Projects, ERDC-CERL is responsible for providing Progress Reports (in the form of quad charts) on a bi-monthly basis to OSD. ERDC-CERL will coordinate with the Fort Bragg DPW before these Bimonthly's are submitted to OSD. Mr. Lampo will immediately inform the Fort Bragg DPW of any problem that arises in the performance of this project. ERDC-CERL will 
F08AR13 Remote Monitoring of Degradation of Reinforced Thermoplastic Composite Bridges (RDT\&E)

coordinate with the Fort Bragg DPW and the USA Engineer School when preparing the final project ROIs and Technical Report.

\section{Contact Information for Key Personnel}

\begin{tabular}{|l|l|l|l|}
\hline Name & Organization & Phone \# & E-Mail \\
\hline Richard Lampo & ERDC-CERL & $217-373-6765$ & r-lampo@cecer.army.mil \\
\hline Gregory Bean & Chief, DPW & $\mathbf{9 1 0 - 3 9 6 - 4 0 0 9}$ & gregory.g.bean $@$ us.army.mil \\
\hline Darryl Butler & Bragg DPW & $\mathbf{9 1 0 - 9 0 7 - 1 7 6 0}$ & darryl.m.butler@us.army.mil \\
\hline Ted Kientz & COE / DPW & $\mathbf{9 1 0 - 3 9 6 - 1 6 1 9}$ & theodore.kientz@us.army.mil \\
\hline LTC Robert Tucker & USAES & $573-563-5142$ & robert.tucker2@ us.army.mil \\
\hline
\end{tabular}

Fort Bragg DPW will provide funds to construct the thermoplastic lumber bridge in FY08. Matching funds (\$275K) to the OSD share will be provided through HQ-IMCOM (See Memorandum from ACSIM Director for Facilities and Housing in Appendix 2). Coordination with the Army Corrosion Program Office will be through Mr. Hilton Mills (HQ-AMC).

This is a Tri-service Project. Funds have been requested for travel of Air Force and Navy representatives to participate in the evaluation of technology implementations.

\section{REFERENCES:}

(1) Lampo, R. and T. Nosker, "Development and Testing of Plastic Lumber Materials for Construction Applications," USACERL Technical Report 97/95.

(2) Gregorski, T., ed., October 1998, "Bridge Advances Plastic Lumber Use," Roads \& Bridges, Des Plaines, IL: Scranton Gillette Communications, p 58.

(3) Lampo, R., T. Nosker, and M. McLaren, "Demonstration Installations of RecycledPlastic Lumber for Bridges, Marine Pilings, and Railroad Ties," Proceedings of R' $20005^{\text {th }}$ World Congress, Toronto, Canada, June 2000.

(4) Krishnaswamy, P. and R. Lampo, "Recycled-Plastic Lumber Standards: From Waste Plastics to Markets for Plastic Lumber Bridges," winner 2001 World Standards Day paper competition, Standards Engineering Society, Miami, FL.

(5) Lampo, R., "Site Development and Management - What's New in Building Materials," Proceedings of 2004 Watchable Wildlife Conference, Dubuque, IA, October 2004. 
F08AR13 Remote Monitoring of Degradation of Reinforced Thermoplastic Composite Bridges (RDT\&E)

\section{COST/BENEFITS ANALYSIS}

a. Funding (\$K):

$\begin{array}{lccc} & & & \text { Fort Bragg } \\ \text { Funding Source } & \text { OSD } & \text { IMA } & \text { DPW Matching* } \\ \text { Labor } & 100 & 110 & - \\ \text { Contracts } & \mathbf{7 5} & \mathbf{7 5} & \mathbf{1 0 0} \\ \text { Lab Materials \& Misc. } & \mathbf{4 0} & \mathbf{4 0} & \mathbf{2 0 0} \\ \text { Travel } & 20 & 25 & -- \\ \text { Report } & \mathbf{2 5} & \mathbf{2 5} & -- \\ \text { Air Force/Navy Participation } & 15 & -- & - \\ \text { TOTAL (\$K) } & \mathbf{2 7 5} & \mathbf{2 7 5} & \mathbf{3 0 0} \\ \text { * Relative to providing the thermoplastic lumber bridge on which to } & \end{array}$

\section{Development Project Budget}

The $\$ 550 \mathrm{~K}$ budget (not including the $\$ 300 \mathrm{~K}$ from Fort Bragg to build the bridge) is realistic and adequate for the scope of the project. This budget has been based on a needs assessment of the candidate bridge at Fort Bragg. ERDC-CERL has extensive previous experience with the thermoplastic lumber products including the innovative I-beams to be used in this demonstration and the use of wireless sensors to monitor materials durability performance.

\section{b. Return-On-Investment Computation:}

Using the required OMB spreadsheet, and in accordance with OMB Circular A-94, a return-on-investment (ROI) of $\mathbf{1 4 . 9}$ was calculated (see Appendix 1 below for assumptions made in this calculation). The associated savings were \$12.6M. This ROI value is based on current best practices, as well as projected maintenance and rehabilitation practices and costs.

\section{c. Mission Criticality:}

Bridges are a critical element for lines of communication for the Installation to be able to carry out its mission. This is especially true for bridges in the more remote training areas. If a bridge is taken out of service for component failure, it can have a major impact on daily operations forcing users of the bridge to go many miles out of the way to get to the desired location. Reduced access can not only jeopardize daily operational routines but can negatively impact base security and emergency response. At the very least, implementing this technology for Installation bridges will lower dollars otherwise spent on maintenance activities and periodic bridge replacement. 
F08AR13 Remote Monitoring of Degradation of Reinforced Thermoplastic Composite Bridges (RDT\&E)

\section{SCHEDULE}

\section{MILESTONE CHART}

\section{EVENT}

Site Visit to Survey Existing Bridge and Begin Design for Sensor System

Award Contract to Install Sensors

Complete Laboratory Testing \& Evaluations

Complete Field Data Collection and Analysis

Complete ROI Validation

Complete Interim Technical Report
TIME

(months after

receipt of funds)

a. Note: If project is approved, bi-monthly status reports will be submitted (i.e. starting the first week of the second month after contract award and every two months thereafter until final report is completed). This report will be submitted to the DoD CPC Policy \& Oversight office. Report will include project number, progress summary (and/or any issues), performance goals and metrics and upcoming events.

b. Examples of performance goals and metrics: include achieving specific milestones, showing positive trend toward achieving the forecasted ROI, reaching specific performance quality levels, meeting test and evaluation parameters, and/or successfully demonstrating a new system.

\section{Development Project Schedule}

This project to install wireless sensors and monitor the durability performance of a thermoplastic composite I-bean bridge will be completed, including an interim technical report, within 24 months. A final report will be completed after a 2-year performance monitoring cycle. The goals of the project are, through the use of remote wireless sensors, to demonstrate and validate the corrosion resistant material system for use in large outdoor structures otherwise made from treated wood or steel. Performance, economic, and environmental benefits will be documented. Engineering guidance documents will be developed to enable others to design and use the thermoplastic composite systems and the use of remote sensors. ERDC-CERL will provide overall management, technical guidance, contract monitoring, and provide bi-monthly progress reports. The schedule has been coordinated with Fort Bragg DPW. Project milestones are shown in the Table above. Potential contractors have been identified.

\section{IMPLEMENTATION}

a. Transition approach: The project design and benefits analyses will be used to develop engineering guidance (e.g., Unified Facilities Guide Specifications - UFGS and Unified Facilities Criteria - UFC) for the design and construction of thermoplastic I-beam structures for outdoor applications (e.g., bridges, decks, docks, etc.). A final report describing the details of the project will be developed and placed on the OSD Corrosion Exchange website under "Specs \& Standards" and "Facilities SIG." Lessons-learned 
F08AR13 Remote Monitoring of Degradation of Reinforced Thermoplastic Composite Bridges (RDT\&E)

and guidance developed as part of this project will be implemented in ACSIM's Installation Design Standards Process. In addition, the draft documents will be posted on the ERDC-CERL Corrosion Control Technology Program (CCTP) website. Coordination with potential users will be an essential part of the transition of the technology. Guidance for the use of the thermoplastic materials and the monitoring system to be implemented and evaluated in this project will be incorporated into guidance used by ACSIM's Army Transportation Infrastructure Program, Bridges.

b. ROI validation. Potential ROI will be validated by comparison of replacement of conventional wood timber bridge design at the site location. The calculated ROI for this project, which is based on current best practices, projected maintenance and rehabilitation cost, has the potential to increase over the multiple year implementation due to the reduction in down time, which will result in increased indirect savings. Third party validation will be used to document the ROI savings performance of this project. This validation work will be performed by an impartial and technically qualified individual.

\section{c. Final Report:}

An interim report will be written 60 days after the project is completed. The report will reflect the project plan format as implemented and will include lessons learned.

\section{Projected Benefits}

The thermoplastic I-beam design for bridges (and other similar outdoor loadbearing structures) will provide virtually maintenance-free facilities for the fifty (50)-plus years of service life as validated by the wireless monitoring of durability performance. In addition, the replacement bridges will have a greater load capacity than most of the bridges they are replacing. This thermoplastic I-beam design would likely be beneficial for construction by units in theater, especially in locations of high corrosivity and materials degradation. The wireless sensors could find a multitude of future beneficial applications for the performance monitoring of materials and structures in remote locations or even in inaccessible locations on the structure.

\section{Management Support}

This project is supported by the Director, Fort Bragg DPW Office as well as the IMCOMSERO Region (see coordination sheet signatures). In addition, the Army (HQ-IMCOM and HQACSIM) have reviewed this project and provided matching funds for FY08. See associated Memorandum from ACSIM Director for Facilities and Housing in Appendix 2. 
F08AR13 Remote Monitoring of Degradation of Reinforced Thermoplastic Composite Bridges (RDT\&E)

6. COORDINATION SHEET

\section{ORGANIZATION}

Associate Project Manager

Project Manager

ERDC-CERL Branch Chief, CF-M

Fort Bragg DPW

Installation Support, Savannah District

IMCOM SERO

HQ IMCOM

HQ ACSIM

HQ AMC

Tri-Service Facilities WIPT Chair
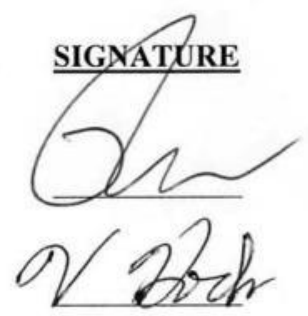

$\underline{\text { DATE }}$

$6 / 21 / 07$

$6 / 21 / 07$

$6121 / 07$

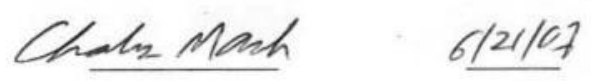

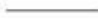
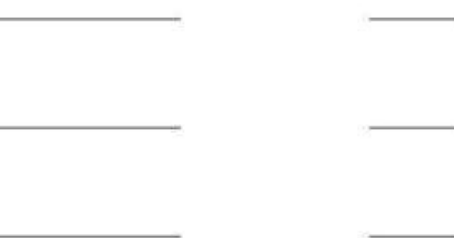
F08AR13 Remote Monitoring of Degradation of Reinforced Thermoplastic Composite Bridges (RDT\&E)

\section{APPENDICES}

APPENDIX 1: Return on Investment (ROI) Calculations based on OMB Circular A-94

\section{Assumptions:}

a. The projected ROI is based not directly on the application of the wireless sensors, but on the durability performance of the thermoplastic materials and bridge structure the sensors will be monitoring and validating the performance thereof. Used the cost (matching from Fort Bragg) to construct the bridge in the project total.

b. Assume implementation of the thermoplastic composite lumber and sensors on nineteen (19) additional bridges at Fort Bragg. Bridge sizes (and thus replacement costs) vary but estimate a replacement cost of $\mathbf{\$ 3 0 0 K}$ average per bridge. Replacement is needed immediately. Timber bridges of the type at Fort Bragg would normally be replaced every 15 years.

c. Based on projections from existing plastic lumber bridges and other large plastic lumber structures at least 30 -years old, the thermoplastic I-beam bridge will have a virtually maintenance-free life over the thirty years (See documentation of durability in references listed in Statement of Need above.)

d. The timber bridges require annual inspection and repair with the repair costs increasing as the age of the bridge increases. (Inspection of all bridges is done annually by the Installation and equal for either material type - that is, wood or plastic. Inspection costs are shown for both bridge types at $\$ 2,000$ per year total.) Repair costs are assumed to be $\$ 2,500$ per bridge per year starting the first year after construction, $\$ 3,500$ per bridge per year starting the third year after construction, and $\$ 4,500$ per bridge per year starting the ninth year until replacement at fifteen (15) years. Because of the increased durability of the thermoplastic lumber, repair costs are assumed to be negligible over the thirty years.

e. The thermoplastic I-beams are made from recycled waste plastics which gives a benefit for diverting these wastes from landfill (new system savings).

f. Even with routine maintenance, failures of the timber bridges will still occur due to materials degradation with a direct (detours and emergency repairs) and indirect (loss of mission capability) cost impact $(\$ 125 \mathrm{~K})$ figured on a periodic basis of every three years.

g. The ROI is likely greater than $\mathbf{1 4 . 9}$ since a thermoplastic bridge is actually expected to have a service life exceeding fifty (50) years with little or no maintenance over that time span. In the time from thirty (31) to fifty (50) years, a treated wood bridge would have to be replaced at least two more times. While the lifecycle cost benefits have been known before, it has been the higher first costs that have been a barrier to more common use of this type material. However, the innovative I-beam designs being demonstrated in this project will show the first costs for the thermoplastic I-beam system to be even lower than a conventional treated-wood structure. In addition, with the technologies to be demonstrated applicable to many other bridges within the Army and DoD, the ultimate ROI would be higher still. 
F08AR13 Remote Monitoring of Degradation of Reinforced Thermoplastic Composite Bridges (RDT\&E)

\section{Return on Investment Calculation}

Investment Required

Return on Investment Ratio 14.88

Net Present Value of Costs and Benefits/Savings $\quad 5,352,037$

Percent $1488 \%$

$17,997,837 \square \quad 12,645,800$

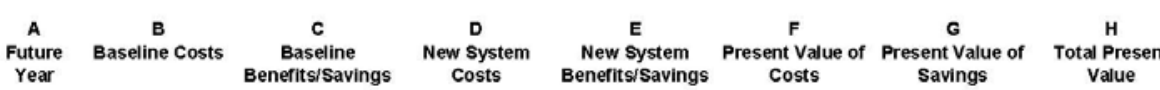

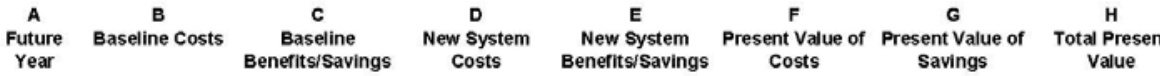

\begin{tabular}{r|r|r|r|r|r|r|}
\hline \\
\cline { 2 - 8 }
\end{tabular}


F08AR13 Remote Monitoring of Degradation of Reinforced Thermoplastic Composite Bridges (RDT\&E)

APPENDIX 2. IMA Matching Funds Letter:

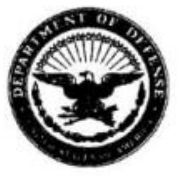

DAIM-FD

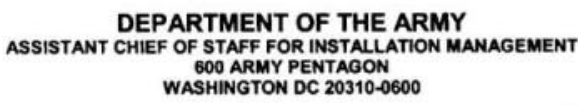

DEPARTMENT OF THE ARMY ASSISTANT CHIEF OF STAFF FOR INSTALLATION MANAGEMENT

600 ARMY PENTAGON

WASHINGTON DC 20310-0600

JUN 20 2UU7

S: 1 Nov 2007

MEMORANDUM FOR DEPUTY COMMANDER, INSTALLATION MANAGEMENT COMMAND, 2511 JEFFERSON DAVIS HIGHWAY, ARLINGTON VA 22202-3926

SUBJECT: FY 08 Corrosion Prevention and Control (CPC) Program

1. Reference Department of Defense, Office of Corrosion Policy and Oversight, Corrosion Prevention and Mitigation Strategic Plan, November 2004.

2. The purpose of this memorandum is to request Headquarters, Installation Management Command (HQ IMCOM) earmark funds for the FY08 CPC program.

3. OSD has allocated funding for implementation and augmentation of corrosion prevention and control projects in FY 08. To take advantage of this funding augmentation, Army must commit to providing matching funds for projects that obtain approval from OSD. The target is to obtain $\$ 5 \mathrm{M}$ from OSD and match that with $\$ 5 \mathrm{M}$ of Army funding for a total FY08 program of $\$ 10 \mathrm{M}$ in facility related projects.

4. The enclosed list of prioritized Army projects will be presented to OSD on 22 June 2007 . Final project approval is pending and the commitment represented by this memorandum will assist in obtaining maximum OSD support for Army facility projects.

5. Request $\mathrm{HQ} I M C O M$ support this program by earmarking $\$ 5 \mathrm{M}$ in matching $\mathrm{FY} 08$ funds. Further instructions on the actual distribution of funds will follow.

6. POC for this action is Mr. David N. Purcell, or (703) 601-0371, David.Purcell@hqda.army.mil.

FOR THE ASSISTANT CHIEF OF STAFF FOR INSTALLATION MANAGEMENT

Encl

as

CF:

ACSIM

DACSIM

DAIM-ZR

DAIM-ZXA

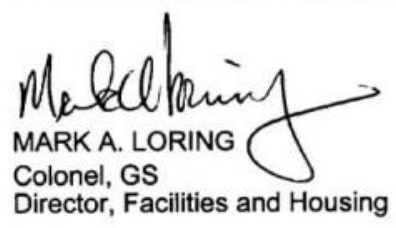

Colonel, GS
Director, Facilities and Housing 
F08AR13 Remote Monitoring of Degradation of Reinforced Thermoplastic Composite Bridges (RDT\&E)

\section{METRICS / TRACKING}

Costs for replacement of the different bridges using traditional treated lumber and timbers will be developed and compared to the actual costs to implement the thermoplastic composite bridge. Comparisons will also include indirect costs associated with environmental benefits or negatives, as appropriate. Typical costs for maintenance of the wooden brides will be collected from the DPW. Maintenance costs (although, none expected) for the thermoplastic composite bridge will also be compared, by an independent third-party, and used to develop a projection of long-term benefits and corrosion-resistant performance of the materials that will be documented in the Final report. 


\section{Appendix D: Micro-Epsilon optoNCDT 1300 Laser Sensor Data Sheet}

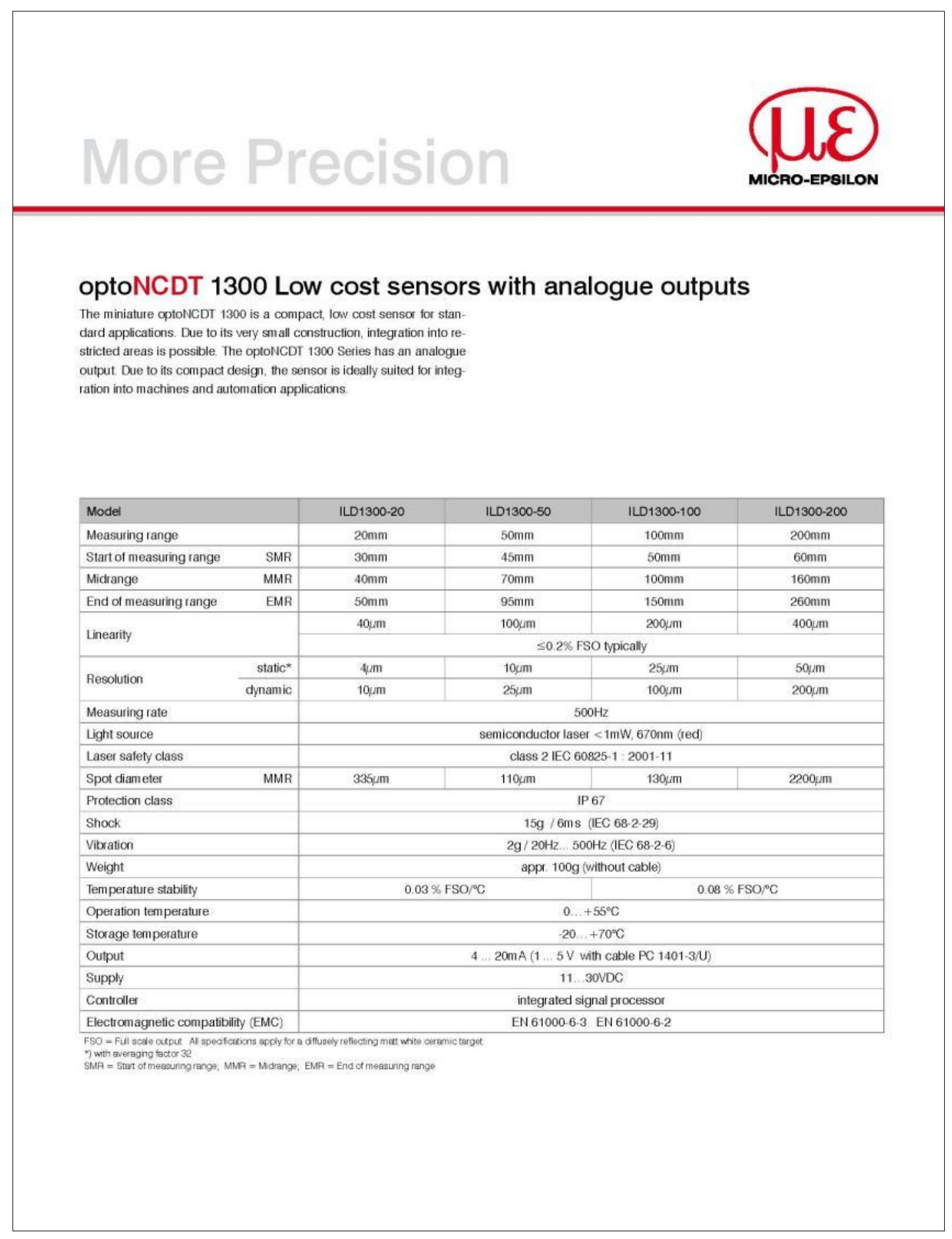




\section{optoNCDT 1300 Dimensions and Accessories}

optoNCDT 1300

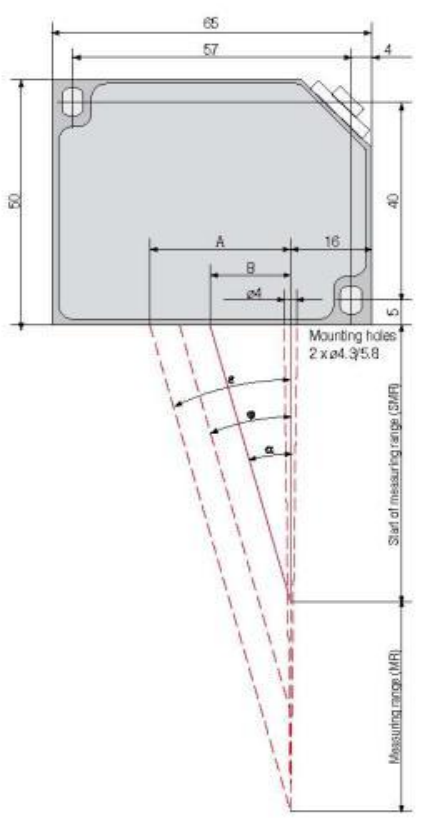

Accessories optoNCDT 1300

Supply and output cable (all cables available in $90^{\circ}$ version) PC 1401-3/I (3 m)

PC 1401-6/ (6 m)

$P C 1401-3 / \mathrm{U}(3 \mathrm{~m}$, with integral resistance, output $1 \ldots 5 \mathrm{VDC})$

PC 1401-6/U (6 m, with integral resistance, output $1 . .5$ VDC $)$

Protective housing

SGH 1800

Power supply

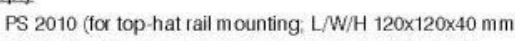
Input 115 / 230 VAC selectable; output 24 VDC / 2.5 A)

\begin{tabular}{|c|c|c|c|c|c|c|}
\hline MR & SMR & $\alpha$ & $\varphi$ & $\varepsilon$ & A & $B$ \\
\hline 20 & 30 & $286^{\circ}$ & $271^{\circ}$ & $264^{\circ}$ & 24.8 & 16.3 \\
\hline 50 & 45 & $244^{\circ}$ & $198^{\circ}$ & $168^{\circ}$ & 286 & 21.4 \\
\hline 100 & 50 & $243^{\circ}$ & $15.0^{\circ}$ & $114^{\circ}$ & 303 & 22.6 \\
\hline 200 & 60 & $211^{\circ}$ & $9.6^{\circ}$ & 6.8 & 308 & 23 \\
\hline
\end{tabular}

(Dimensions in mm, not to scale)
Connector axial

Article Number: 0323142

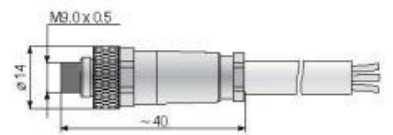

Connector radial Article Number: 0323203

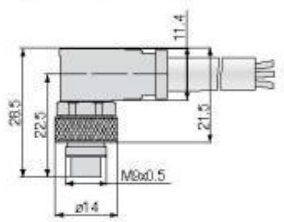

\begin{tabular}{l} 
7-pin-connector \\
(view on solder termination \\
side of male inserts) \\
\begin{tabular}{|c|c|c|}
\hline \\
Pin assignment vottage $7 \times 1 \times 014$ \\
\hline Pin-Nr & Function & Cable colors \\
\hline 1 & Error & green \\
\hline 2 & Laser on/oft & yellow \\
\hline 3 & n.c & \\
\hline 4 & n.c & \\
\hline 5 & $4.20 \mathrm{~mA}$ & grey \\
\hline 6 & GND & brown \\
\hline 7 & Supply 11 (3) $30 \mathrm{VDC}$ & white \\
\hline
\end{tabular} \\
\hline
\end{tabular}

\section{Micro-Epsilon}

info@micro-epsilon.com wrwmicro-epsilon.com info@micro-epsilon.couk wuw.micro-epsilon co uk info@micro-epsilon.us wunmicro-epsilon us certified DIN EN ISO $9001: 2000$ modifications reserved / Y9761187-A0300980GO C 


\section{Appendix E: Hitec Products Inc. HB Full Bridge Strain Gage Data Sheet}

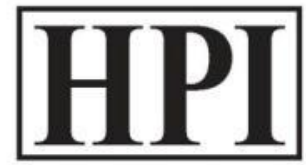

\section{HITEC PRODUCTS, INC.}

P.O. Box 790 - Ayer, MA 01432 USA

Tel: 978-772-6963 - Fax: 978-772-6966

www.hitecprod.com

\section{WELDABLE STRAIN TRANSDUCER FOR FIELD MEASUREMENTS \\ Full Bridge - Unique Design}

\section{FEATURES:}

- SIMPLE! Easy to install and use. Install with portable spot welder

- NO PREVIOUS STRAIN GAGE EXPERIENCE NECESSARY

- Four Arm Bridge for OUTSTANDING STABILITY \& TEMPERATURE COMPENSATION

- ELIMINATES LEAD WIRE ERRORS - even with long cable lengths

- DOUBLE OUTPUT of a standard gage for HIGH SENSITIVITY

- COMPLETELY PRE-WIRED \& WATERPROOFED. 100\% Water Immersion Tested

- INSTALL IN INCLEMENT WEATHER - Wind, Rain or Snow

- Units available to CONFORM TO A FLAT SURFACE OR ANY RADIUS

- Units made SPECIFICALLY FOR INSTALLATION ON RE-BAR available

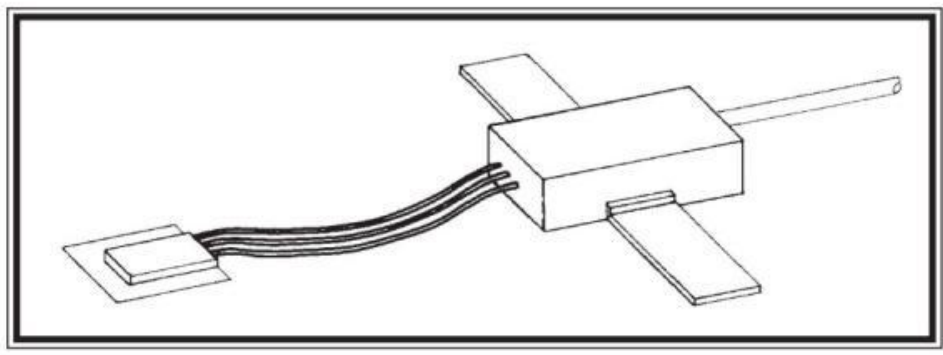

\section{APPLICATIONS:}

- Bridge Load Monitoring

- Ship Hull Monitoring and Testing

- Overload Frequency Recording

- Overload Sensing and Alarm Triggering

- Tunnel and Structural Monitoring \& Testing

- Useable Before, During, or After Structural Construction

- Vehicle Weighing

- Roof Load Monitoring

- Concrete Pile Testing 


\section{WELDABLE STRAIN GAGES}

Hitec Products weldable gages are precision foil strain gages bonded to stainless steel shim, pre-wired and waterproofed. The waterproofing material is a molded compound used for under sea cable connections. These specially constructed gages are capable of operation under adverse conditions and at temperatures to $180^{\circ} \mathrm{F}$ making them ideal for application on ship hulls, offshore drill rigs, power plant structures, railroad cars and tracks, and anywhere that an installation must be protected from the elements. HBW strain gages are available in a number of configurations designed to reduce installation costs. Detailed description of HBW models as well as pricing information is available from the factory.

\section{HBW CABLE DESIGNATIONS:}

GP: General purpose 3 or 4 conductor shielded vinyl jacketed (\#22 AWG)

HP: 4 conductor heavy duty shielded vinyl jacket ( $\$ 22$ AWG)

VR: 3 or 4 conductor vinyl ribbon (\#26 or \#30 AWG)

TR: 3 or 4 conductor teflon ribbon ( $\# 26$ or \#30 AWG)

UP: 4 conductor polyurethane ( $\# 22$ AWG) sheilded jacket

$\mathrm{VH}: 4$ conductor teflon shielded jacket (\#26 AWG) with thick wall rubber
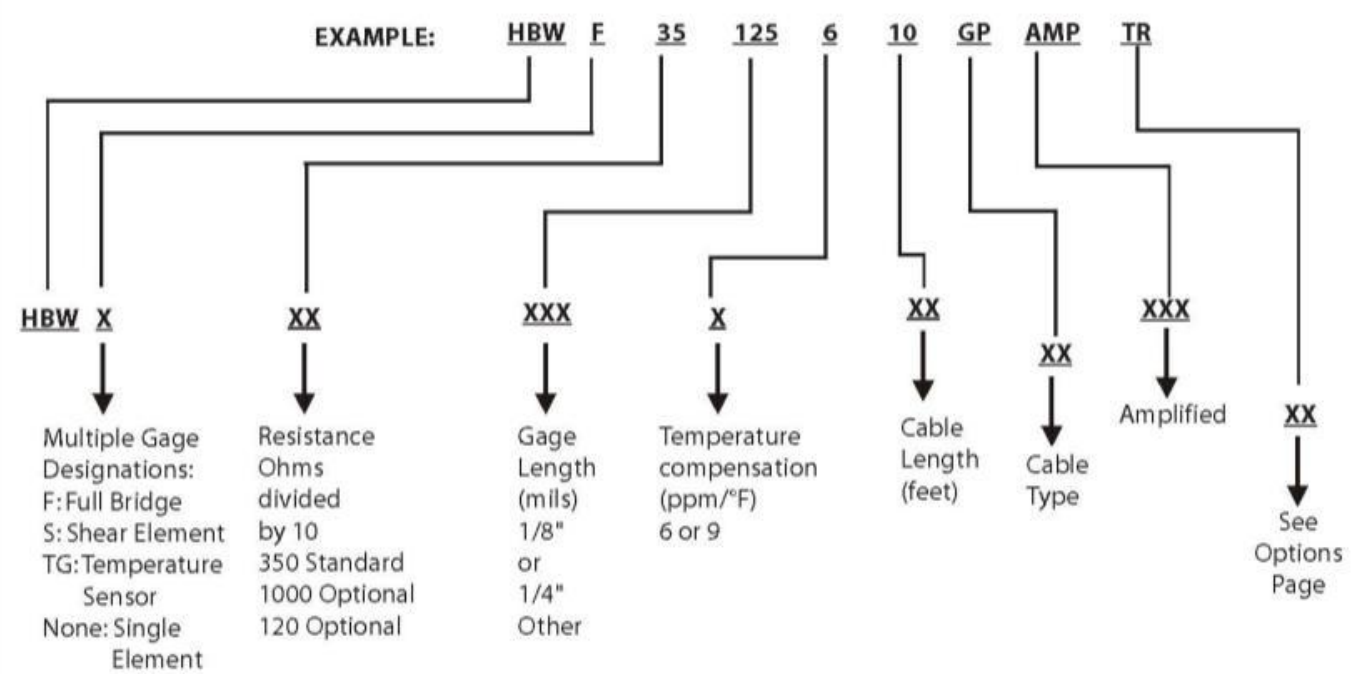

Most configurations are also available in custom configurations including mounting on a polyimide "shim" for installation with conventional adhesives. Consult factory for more information on these HBP gages. 


\section{HPI HIIEC PRoDUCIS, NNC. \\ P.O.Box 790 - Ayer, MA 01432 USA \\ Tel: $978-772-6963 \cdot$ Fax: 978-772-6966 \\ www.hitecprod.com}

PRODUCT DATA SHEET

Integral Amplified and Bridge Voltage Option

An amplifier and voltage regulator can be incorporated into almost all full bridge weldables available. This option provides precision bridge voltage regulation and 100 times the normal signal output. Excellent signal to noise ratio, direct data acquisition, or direct voltage measurements of strain, and low power consumption are a few advantages gained when using this strain measuring transducer system.
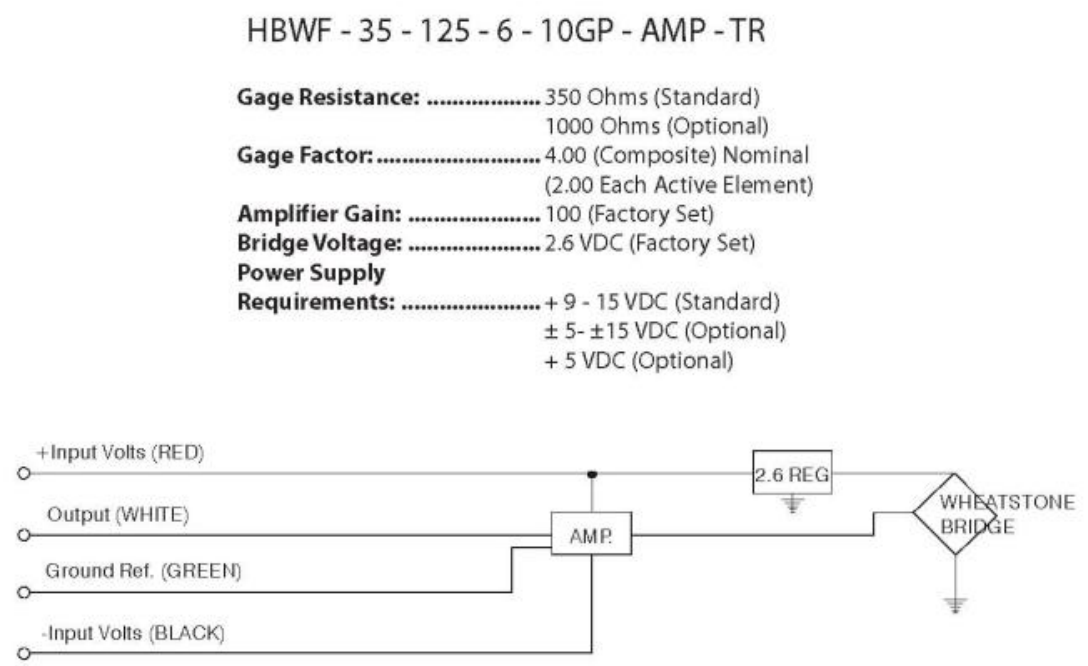

Notes: - Please consult factory for specific option wiring diagrams.

- A virtual ground connection can be supplied for voltage splitting applications. Consult factory for details.

- The -Input Volts and Ground Reference wires can both be connected as Ground if tension only measurements are to be made. 


\section{Appendix F: Omega Model ON-909 Surface Temperature Sensor Data Sheet}

\section{Precision Thermistor Sensor For Surface Temperature Measurements}

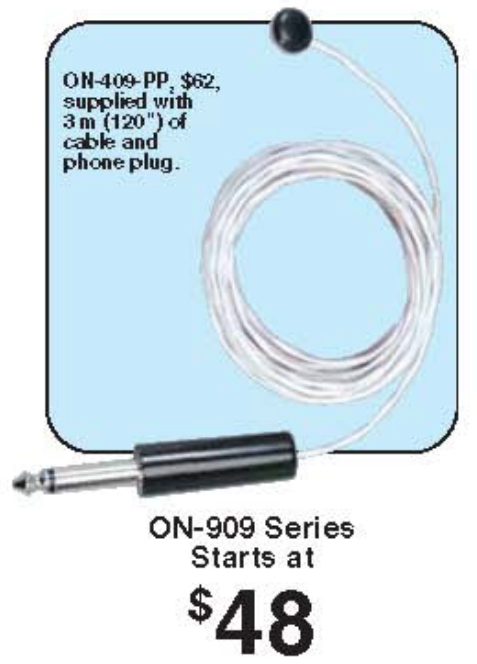

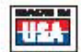

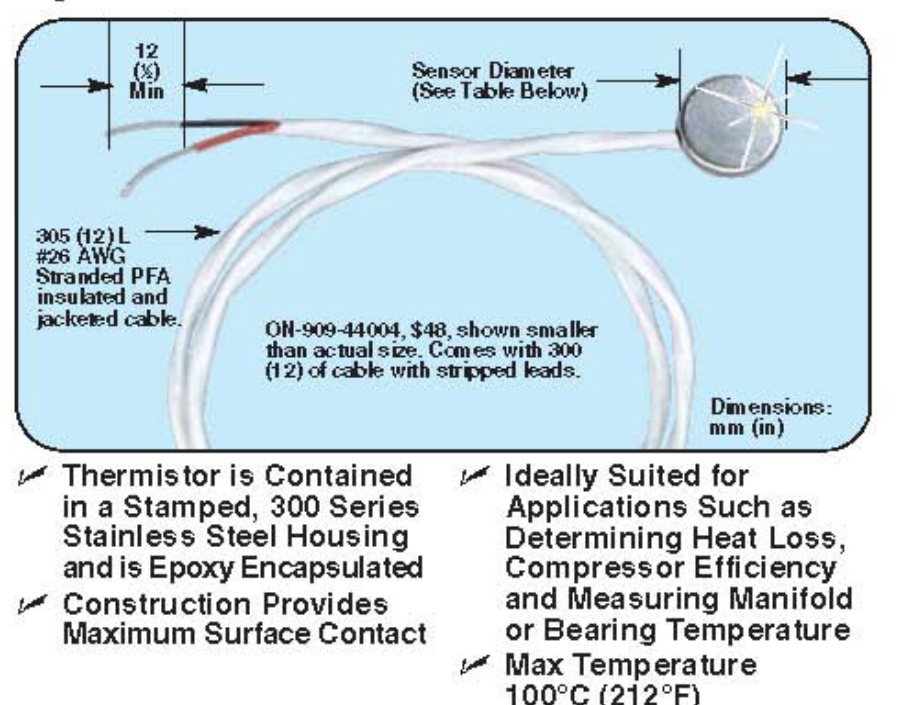

MOST POPULAR MODELS HGHUGHED!

To Order (Specify Model Number)

\begin{tabular}{|c|c|c|c|c|c|c|c|}
\hline $\begin{array}{l}\text { Whodel } \\
\text { Number }\end{array}$ & Price & $\begin{array}{c}\text { Resistance } \\
\text { @ } 25^{\circ} \mathrm{C}\end{array}$ & $\begin{array}{c}\text { Interchangeability } \\
\text { @ } 0 \text { to } 70^{\circ} \mathrm{C}\end{array}$ & $\begin{array}{l}\text { Max } \\
\text { Temp }\end{array}$ & $\begin{array}{c}\text { Tip Dia. } \\
\text { (in) }\end{array}$ & $\begin{array}{l}\text { Cable } \\
\text { Length }\end{array}$ & $\begin{array}{c}\text { Cable } \\
\text { Termination }\end{array}$ \\
\hline ON-409-PP & $\$ 62$ & $2252 \Omega$ & $\pm 0.1^{\circ} \mathrm{C}$ & $100^{\circ} \mathrm{C}\left(212^{\circ} \mathrm{F}\right)$ & $0.44^{\prime \prime}$ & $3 m\left(120^{\prime \prime}\right)$ & Phone plug \\
\hline ON-909-44004 & 48 & $2252 \Omega$ & $\pm 0.2^{\circ} \mathrm{C}$ & $100^{\circ} \mathrm{C}\left(212^{\circ} \mathrm{F}\right)$ & $0.38 "$ & $300 \mathrm{~mm}\left(12^{\prime \prime}\right)$ & Stripped \\
\hline ON-909-44005 & 48 & $3000 \Omega$ & $\pm 0.2^{\circ} \mathrm{C}$ & $100^{\circ} \mathrm{C}\left(212^{\circ} \mathrm{F}\right)$ & $0.38 "$ & $300 \mathrm{~mm}\left(12^{\prime \prime}\right)$ & Stripped \\
\hline ON-909-44007 & 48 & $5000 \Omega$ & $\pm 0.2^{\circ} \mathrm{C}$ & $100^{\circ} \mathrm{C}\left(212^{\circ} \mathrm{F}\right)$ & $0.38 "$ & $300 \mathrm{~mm}\left(12^{\prime \prime}\right)$ & Stripped \\
\hline ON-909-44006 & 48 & $10000 \Omega$ & $\pm 0.2^{\circ} \mathrm{C}$ & $100^{\circ} \mathrm{C}\left(212^{\circ} \mathrm{F}\right)$ & $0.38 "$ & $300 \mathrm{~mm}\left(12^{\prime \prime}\right)$ & Stripped \\
\hline ON-909-44008 & 48 & $30000 \Omega$ & $\pm 0.2^{\circ} \mathrm{C}$ & $100^{\circ} \mathrm{C}\left(212^{\circ} \mathrm{F}\right)$ & $0.38 "$ & $300 \mathrm{~mm}\left(12^{\prime \prime}\right)$ & Stripped \\
\hline ON-909-44004-40 & 49 & $2252 \Omega$ & $\pm 0.2^{\circ} \mathrm{C}$ & $100^{\circ} \mathrm{C}\left(212^{\circ} \mathrm{F}\right)$ & $0.38 "$ & $1 \mathrm{~m}\left(40^{\prime \prime}\right)$ & Stripped \\
\hline ON-909-44005-40 & 49 & $3000 \Omega$ & $\pm 0.2^{\circ} \mathrm{C}$ & $100^{\circ} \mathrm{C}\left(212^{\circ} \mathrm{F}\right)$ & $0.38^{\prime \prime}$ & $1 \mathrm{~m}\left(40^{\prime \prime}\right)$ & Stripped \\
\hline ON-909-44007-40 & 49 & $5000 \Omega$ & $\pm 0.2^{\circ} \mathrm{C}$ & $100^{\circ} \mathrm{C}\left(212^{\circ} \mathrm{F}\right)$ & $0.38 "$ & $1 \mathrm{~m}\left(40^{\prime \prime}\right)$ & Stripped \\
\hline ON-909-44006-40 & 49 & $10000 \Omega$ & $\pm 0.2^{\circ} \mathrm{C}$ & $100^{\circ} \mathrm{C}\left(212^{\circ} \mathrm{F}\right)$ & $0.38 "$ & $1 \mathrm{~m}\left(40^{\prime \prime}\right)$ & Stripped \\
\hline ON-909-44008-40 & 49 & $30000 \Omega$ & $\pm 0.2^{\circ} \mathrm{C}$ & $100^{\circ} \mathrm{C}\left(212^{\circ} \mathrm{F}\right)$ & $0.38^{\prime \prime}$ & $1 \mathrm{~m}\left(40^{\prime \prime}\right)$ & Stripped \\
\hline
\end{tabular}

Notes: For addition al cable length, add reguired length (in inches) to end of the model number and $\$ 0.80$ ftit to the price. For a phone plug, add "Pp" to the model number and $\$ 7$ to the price. For tighter interchange ability, substitute the thermistor part number from the table below and add the price isted to the sensor price.

Ordering Examples: ON-909-44004-40-pp, surtace thermistor sensor with a resistance of $2252 \Omega$ at $25^{\circ} \mathrm{C}$ and an interchangeability of $\pm 0.2^{\circ} \mathrm{C}$, $1 \mathrm{~m}\left(400^{\circ}\right)$ of cable and a phone plug connector, $\$ 49+\$ 7=\$ 56$. ON-909-44032-40-PP, surtace thermistor sensor with a resistance of $30000 \Omega$ at $25^{\circ} \mathrm{C}$ and an interchangeability of $\pm 0.1^{\circ} \mathrm{C}, 1 \mathrm{~m}\left\langle 40^{\circ}\right)$ of oable and a phone plug connector, $\$ 49+11+\$ 7^{\circ}=\$ 67$.

\section{Optional Thermistors}

\begin{tabular}{|c|c|c|c|c|c|}
\hline $\begin{array}{c}\text { Model } \\
\text { Number }\end{array}$ & $\begin{array}{c}\text { Adcitional } \\
\text { Price }\end{array}$ & $\begin{array}{c}\text { Resistance } \\
\left(25^{\circ} \mathrm{C}\right. \\
(\Omega)\end{array}$ & $\begin{array}{c}\text { Maximum } \\
\text { Working } \\
\text { Temp }\end{array}$ & $\begin{array}{c}\text { Interchangeability } \\
\text { O to } 70^{\circ} \mathrm{C}\end{array}$ & $\begin{array}{c}\text { Storage and Working } \\
\text { Temp for Best } \\
\text { Stability }\end{array}$ \\
\hline $\mathbf{4 4 0 3 3}$ & $\mathbf{\$ 1 1}$ & 2252 & $75^{\circ} \mathrm{C}\left(165^{\circ} \mathrm{F}\right)$ & $\pm 0.1^{\circ} \mathrm{C}$ & -80 to $75^{\circ} \mathrm{C}\left(-110\right.$ to $\left.165^{\circ} \mathrm{F}\right)$ \\
$\mathbf{4 4 0 3 0}$ & $\mathbf{1 1}$ & 3000 & $75^{\circ} \mathrm{C}\left(165^{\circ} \mathrm{F}\right)$ & $\pm 0.1^{\circ} \mathrm{C}$ & -80 to $\left.75^{\circ} \mathrm{C}\right\}-110$ to $\left.165^{\circ} \mathrm{F}\right\}$ \\
$\mathbf{4 4 0 3 4}$ & $\mathbf{1 1}$ & 5000 & $75^{\circ} \mathrm{C}\left(165^{\circ} \mathrm{F}\right)$ & $\pm 0.1^{\circ} \mathrm{C}$ & -80 to $\left.75^{\circ} \mathrm{C}\right\}-110$ to $\left.165^{\circ} \mathrm{F}\right\}$ \\
$\mathbf{4 4 0 3 1}$ & $\mathbf{1 1}$ & 10,000 & $75^{\circ} \mathrm{C}\left(165^{\circ} \mathrm{F}\right.$ & $\pm 0.1^{\circ} \mathrm{C}$ & -80 to $\left.75^{\circ} \mathrm{C}\right\}-110$ to $\left.165^{\circ} \mathrm{F}\right\}$ \\
$\mathbf{4 4 0 3 2}$ & $\mathbf{1 1}$ & 30,000 & $75^{\circ} \mathrm{C}\left(165^{\circ} \mathrm{F}\right)$ & $\pm 0.1^{\circ} \mathrm{C}$ & -80 to $75^{\circ} \mathrm{C}\left(-110\right.$ to $\left.165^{\circ} \mathrm{F}\right\}$ \\
\hline
\end{tabular}

D-18 


\section{omega.com ${ }^{6}$}

Your One-Stop Source for Process Measurement and Control!

One Omega Drive |Stamfond, CT 06907 | 1-886-TC-OMEGA (1-888-826-6342)| info@omegacom

\section{wWW.omega.com}

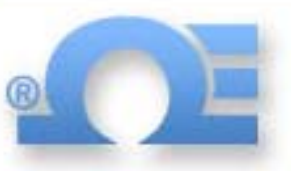

UNITED STATES

wwomega.com

1-800-TC OMEGA

Stamford, CT.

CANADA

whwomedaca

Laval(Quebec)

1.800-TC-OMEGA

GERMANY

wow.omeqa.de

Deckenptronn, Germany

$0800-8266342$
UNITED KINGDOM

whus omega,couk

Mlanchester, England $0800-488488$

FRANGE wow.omeqa.ti

Guyancourt, France

$088 \cdot 465-342$

CZECH REPUBLIC www omegaeng.c工 Kanvină, Crech Republic $595-311.899$

BENELUX whwomega.n. Amstelveen, NL $0800-099-33-44$

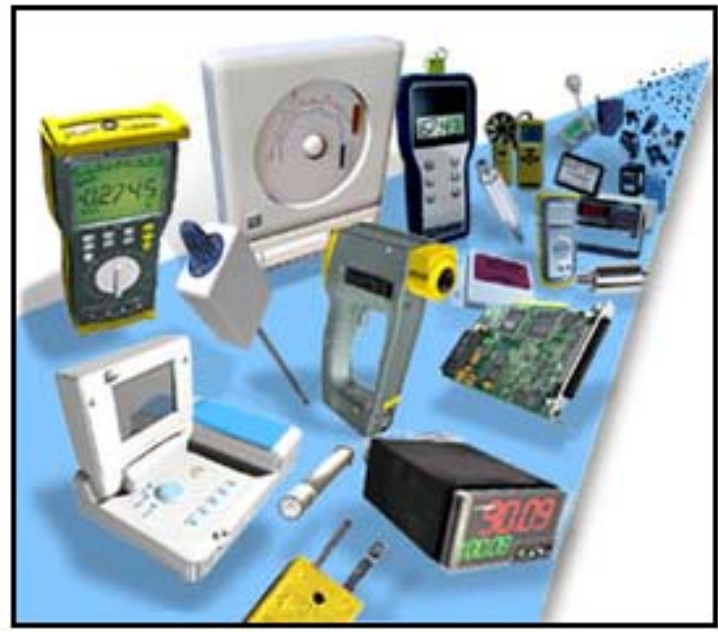

\section{More than 100,000 Products Avallable!}

\section{- Temperature}

Ca librators, Connectors, Genera I Testa a nd fuleasurement Instrument $s_{r}$ Glass Bulb Thermometers, Handheld Instruments forTemperature Mea surement, ke Point References, Indicating Labels, Crayons, Cements and Lacquers, Infared Temperature fileasurement Instruments, Recorders Relative Humidity (Weasurement Instrument s. RTD Probes, Elements and Assemblies, Temperature\& Process (Wheters, Timers and Counters, Temperature and Process Controllers and Power Switching Devices, Thermistor Elements, Probes and A ssemblies, Themooouples Themowells and Head and Miell Assemblies, Transmitters, Wire

\section{- Flow and Level}

Air'Vebcity Indicators, Doppler Flowmeters, Level Measurement, Nutgnetic Flowmeters, Nuass Fowmeters. Pitot Tubes, Pumps, Botameters, Tutine and Paddle Wheel Flowmeters, Ultrasonic Flowmeters, Valves, Variable Area Fbwmeters, Vortex Shedding Howmeters

\section{- $\mathrm{pH}$ and Conductivity}

Conductivity Instrumentation, Dissolved Oxygen Instrumentation. Emuironmental Instrumentation, $\mathrm{pH}$ Electrodes and Instruments, Waterand SoilAnalysis Instrumentation

\section{- Data Acquisition}

Auto-Dialers and Alarm Mionitoring Systems, Communication Productsand Converters, Data Acquisition and Analysis Software. Data Loggers Plug-in Card s, SignalConditioners, USE, RS232, RS485 and Parallel Port Data Acqu isition Systems, Wireless Transmittersand Receivers

\section{- Pressure, Strain and Force}

Displacement Transducers, Dynamic fuleasurement Fore Sensors, Instrumentation for Pressure and Stra in Measurements, Load Cells, Pressure Gauges, Pressure Reference Section, Pressure Switches, Pressure Transducers, Proximity Transducers, Regulators,

Stra in Gages, Torque Transducers, valves

\section{- Heaters}

Band Heaters, Cartidge Heaters, Cirulation Heaters, Comfort Heaters, Controllers, Mleters and Switching Devices, Flexible Heaters, GeneralTest and Mleasurement Instruments, Heater Hook-up Wire. Heating Cable System s, Immersion Heaters, Process A ir and Duct. Heaters, Radiant Heaters, Strip Heaters, Tubutar Heaters

\section{- click here to go to the omega.com home page}




\section{Appendix G: Campbell Scientific CC640 Digital Camera Data Sheet}

\section{CC640}

\section{Digital Camera for Harsh Environments}

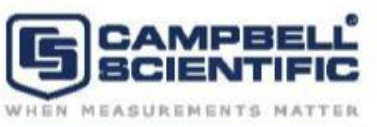

The CC640 Digital Camera, manufactured by Campbell Scientific Canada, works in harsh, remote locations. It operates at temperatures as low as $-40^{\circ} \mathrm{C}$, while using minimal power. Three communications ports (RS-232, RS-485, CS I/O) facilitate transfer of images to a datalogger.

Our dataloggers trigger image acquisitions by applying a 5 to $12 \mathrm{~V}$ signal. The CC640 also has a stand-alone mode that allows the camera to store images on a CompactFlash $^{\circ}$ card-without the use of a datalogger. In this mode, image acquisitions are triggered by the camera’s precision real-time clock.

The CC640 can store JPEG images on a CompactFlash card or in the datalogger's memory. To send images to the datalogger's memory, the datalogger must have the $\mathrm{PAKBUS}^{\circ}$ communication protocol and at least 2 Mbytes of memory. Compatible dataloggers include our CR800, CR850, CR10X-2M-PB,

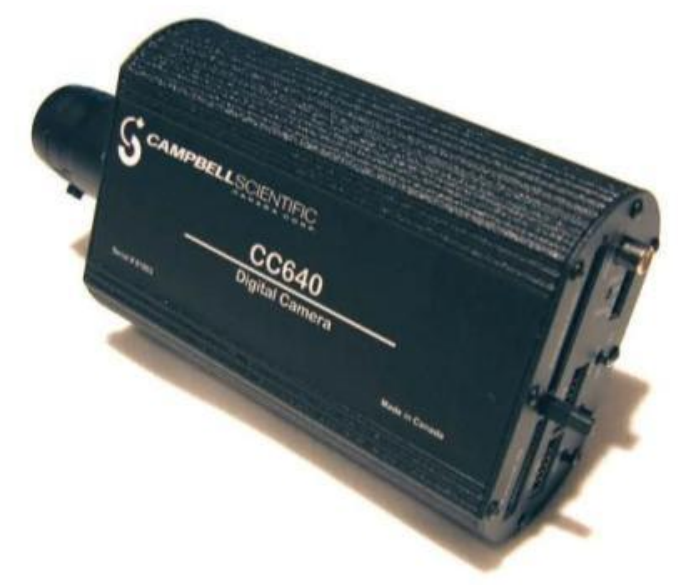
CR1000, and CR3000.

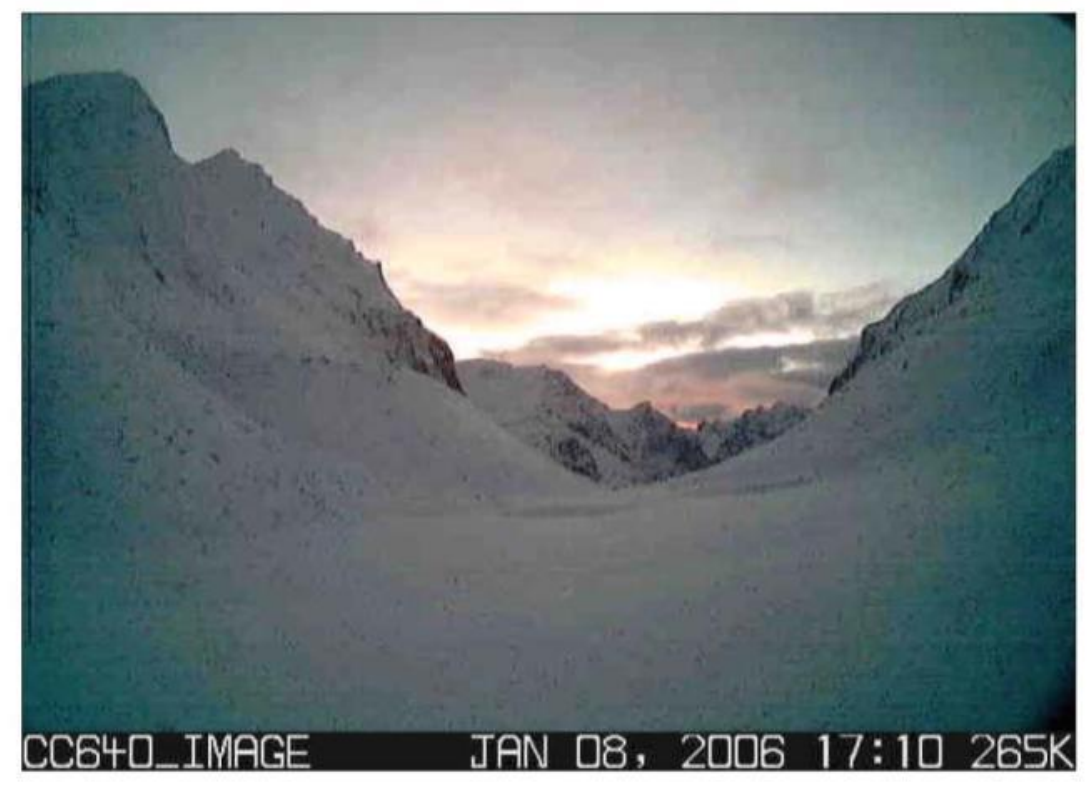




\section{Datalogger Connection}

If the distance between the camera and datalogger is less than 25 feet, the CC 640 typically connects to the datalogger via the COMCBL1 cable. When Campbell Scientific's MD 485 Multidrop Interface is used, the camera and datalogger can be at a distance of up to 4000 feet. Our MD 485 interface connects to the camera via a three-twisted pair, shielded cable, such as the 9721 .

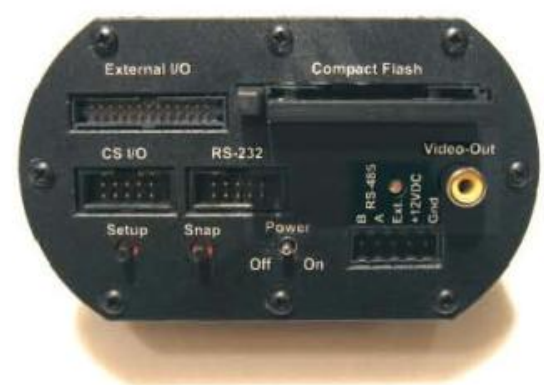

The communication ports, video output, Compact lash card slot, and power switch are located on the back of the camera. The video output connector provides an analog video signal for the purpose of focusing and targeting the camera.

\begin{tabular}{|l|l|}
\hline \multicolumn{2}{|c|}{ Ordering Information } \\
\hline CC640 & Digital Camera \\
\hline $\mathbf{1 8 5 4 3}$ & $\begin{array}{l}\text { Enclosure that houses and protects the } \\
\text { CC640; a window in the enclosure all ows } \\
\text { the CC640 to take photographs while the } \\
\text { Camera is housed inside the enclosure }\end{array}$ \\
\hline $\mathbf{1 8 5 5 4}$ & $\begin{array}{l}\text { 120V defrost kit for the enclosure's window } \\
\mathbf{1 8 5 4 9}\end{array}$ \\
\hline $\mathbf{C O M C B L 1 - L}$ & $\begin{array}{l}\text { RS-232 cable that terminates in pigtails for } \\
\text { Connection to the COM ports on a CR800, } \\
\text { CR850, CR1000, or CR3000 datalogger. Enter } \\
\text { lead length, in feet, after the L }\end{array}$ \\
\hline $\mathbf{1 9 5 0 4}$ & $\begin{array}{l}\text { Pigtail-to-9pin Connector Converter Kit } \\
\text { allows the COMCBL1 to be connected to } \\
\text { the RS-232 or CS VO port on a datalogger. }\end{array}$ \\
\hline $\mathbf{9 7 2 1}$ & $\begin{array}{l}\text { Three-twisted pair, shielded cable that con- } \\
\text { nects the MD485 to the CC640 }\end{array}$ \\
\hline
\end{tabular}

\section{Specifications}

Lens Description:

F1.43.5 to $8 \mathrm{~mm}$ Varifocal Lens with Electronic Iris

Image Type: JPEG

Resolution:

$640 \times 480(307,200$ pixels);

$604 \times 504$ (with time stamp)

Current Drain:

Operating: $250 \mathrm{~mA}$ maximum

Quiescent: $250 \mu$ A typical

Communication Ports:

RS-232, CS I/O, RS-485 (labeled external I/O),

Maximum Baud Rate:

230 kbps (RS-232, RS-485),

$76.8 \mathrm{kbps}(\mathrm{CS} \mathrm{H} / \mathrm{O})$

CS I/O CSDC Addresses: 7 or 8

Video Output: NTSC, PAL

Operating Temperature: $-40^{\circ}$ to $+70^{\circ} \mathrm{C}$

External Input Signal:

Logic Low Level: 0 to $0.7 \mathrm{Vdc}$

$(-12 \mathrm{Vdc}$ absolute minimum)

Logic High Level: 4 to $15 \mathrm{Vdc}$

(15 Vdc absolute maximum)

Memory Card:

Type: CompactFlash

File System: FAT16

Storage: 2 Gigabytes or less

Clock Accuracy: \pm 1 minute/year $\left(0^{\circ}\right.$ to $\left.40^{\circ} \mathrm{C}\right)$; \pm 4 minute/year $\left(-40^{\circ}\right.$ to $\left.70^{\circ} \mathrm{C}\right)$

Dimensions: 8.5 " $\times 2.6 " \times 4.3$ " $(21.5 \times 6.5 \times 11.0 \mathrm{~cm})$

Weight: $1.1 \mathrm{lbs}(500 \mathrm{~g})$

Power: 9 to $15 \mathrm{Vdc}$ 


\section{Appendix H: RM Young Model 05103 Wind Monitor Data Sheet}

High Performance Wind Sensor

\section{ㄸind}

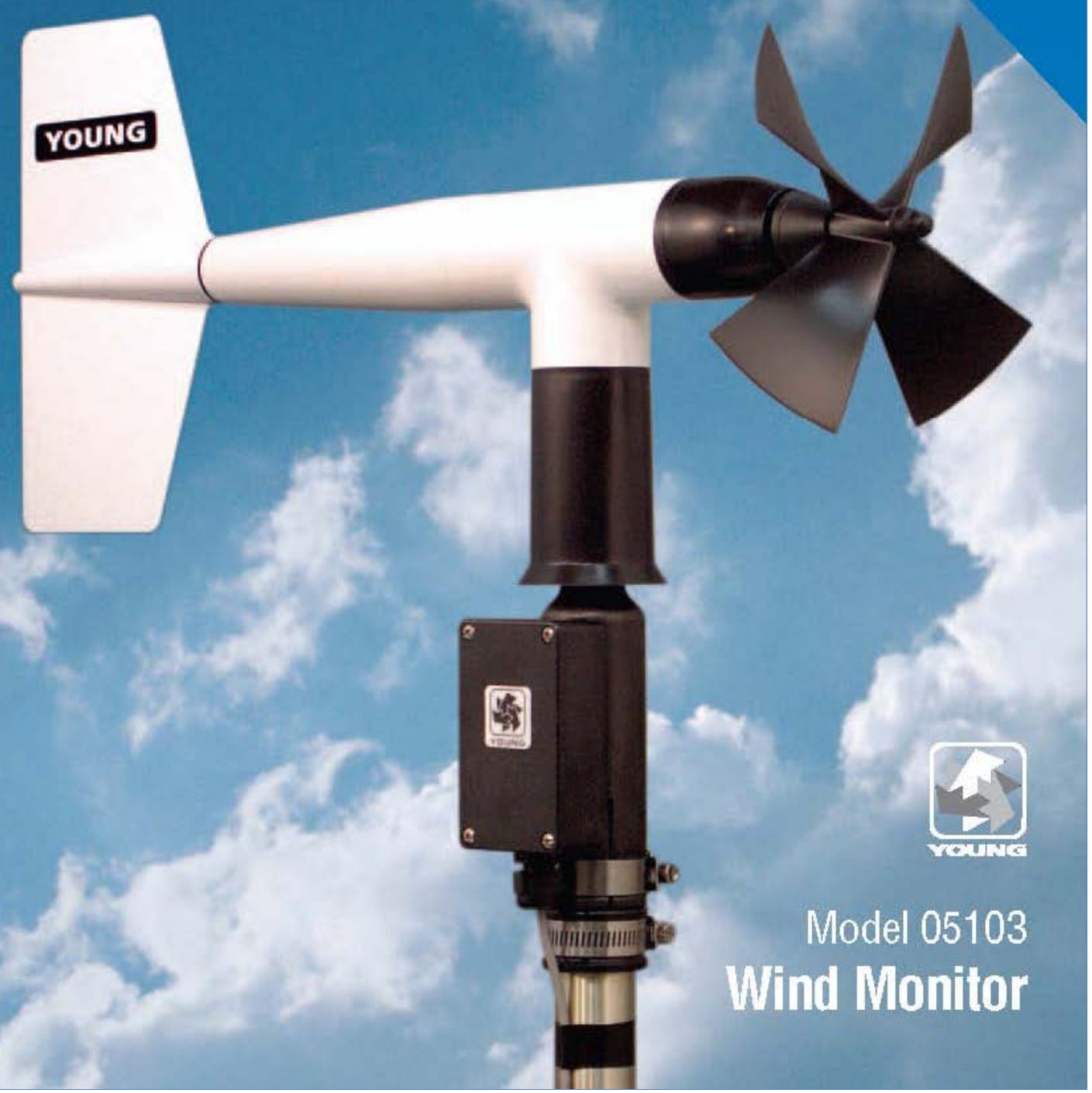


The Whd Monitoris a high performance, rugged wind sensor. its simplicity and comosion-resistant construction make it idealfor a wide rangeof wind measufIng applicatons.

The wind speed sensor is a four blade helicoid propeller. Propeller rotation produces an $\mathrm{AC}$ sine wave voltage signal with frequency directly proportional to wind speed. Slip ring s and brushes are eliminated for increased reliability.

The wind direction sensor is a rugged yet lightweight vane with a sufficiently low aspect ratio to assure good fidelity in fluctuating wind

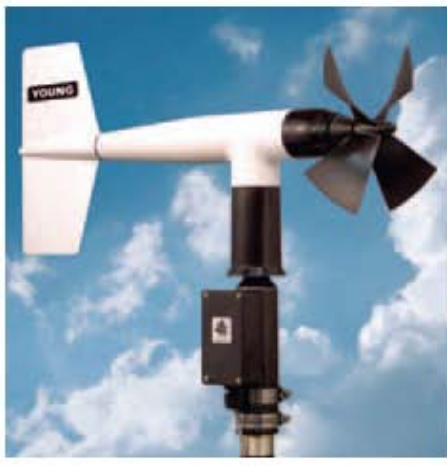
conditions. Vane angle is sensed by a precision potentiometer housed in a sealed chamber. With a known excitation voltage applied to the potentiometer, the output voltage is directly proportional to vane angle. A mounting orientation ring assures correct realignment of the wind direction reference when the instrument is removed for maintenance.

The instrument is made of LV stabilized plastic with stainless steel and anodized aluminum fittings. Precision grade, stainless steel ball bearings are used. Transient protection and cable terminations are in a corvenient junction box. The instrument mounts on standard 1 inch pipe.

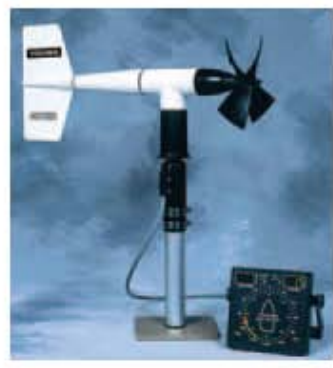

For offshore and marine use, Model 05105, Wind Monltor-mA teatures special waterproof bearing lubricant and a sealed, heawy duty cable pigtail in place of the standard junction box. Separate signal conditioning for voltage or current outputs is available.

The Wind Monitor is avalable with two additional output signal options. Model 05103V ofters calibrated 0-5 VDC outputs, convenient for use with many dataloggers. Model 05103L provides a calibrated 4-20 mA current signal for each channel, useful in high noise areas or for long cables (up to several Kilometers). Signal conditioning electronics are integrated into the sensor junction box
Ordering information

MODEL

WIND MONITOR . 05103

WIND MONITOR 0.5 VDC OUTPUTS

$05103 \mathrm{~V}$

WIND MONITOR 4-20 MH OUTPUTS

$5103 \mathrm{~L}$

WIND MONITOR - MA (MARINE MODEL)

05106

WIIND SENSOR INTERFACE (FOR USE WITH (05T 106 ] $0.5 \mathrm{VOC}$

$05603 \mathrm{C}$

WIND LINE DRIVER (FOR USE WTH 15106 ) $4-20 \mathrm{~m}$.

\section{Speciffications}

Range:

Wind speed: 0-100 mis $224 \mathrm{mph}$;

Azimutt: $360^{\circ}$ mechanical, $355^{\circ}$ electrical $\left(5^{\circ}\right.$ open) Accuracy:

Wind speed: $\pm 0.3 \mathrm{~ms}(0.6 \mathrm{mph})$ or $1 \%$ of regding Wind direction: \pm 3 degress

Threshold: ${ }^{\star}$

Propeller: $10 \mathrm{mis} 22 \mathrm{mph}$

$1.1 \mathrm{~m} / \mathrm{s}(2.4 \mathrm{mph}) 05106$

vane: 1.1 ms $(2.4$ mohi 05100

Dynamic Response:

Propeller distance constant (63\% recovery) $2.7 \mathrm{~m}$ (8.9 ț Wane delay distance $(50 \%$ recovery) $13 \mathrm{~m}$ (43 ft) Damping ratio: 03

Damped natural ugivelengtt: $7.4 \mathrm{~m}$ (24.3 ft) Unda moed natural wevelength: $72 \mathrm{~m}$ (23.6 tt)

\section{Signal 0ulput:}

Wind speed: magnetically induced ac wottage, 3 pulsee per revolution. $1800 \mathrm{rm}(00 \mathrm{~Hz})=8.8 \mathrm{~m} / \mathrm{s}(197 \mathrm{mph}$ Az imutt: analog DC woltage from conductive plastic potentiometer - res istance $10 \mathrm{~K} \Omega$, linearity $025 \%$ life expectency -50 million resolutions

Power Requirement

Potentiometerexcitation: 15 VOC maximum

\section{Dimensions:}

Overall teight $37 \mathrm{~cm}$ (146 in)

Overall length: $55 \mathrm{~cm}(21.7 \mathrm{in})$

Propeller: $18 \mathrm{~cm}(7$ in) diameter

Mounting: $34 \mathrm{~mm}(1.34$ in) diametr(standard 1 inch pipe) Weight:

Sensorweight: $1.0 \mathrm{~kg}(22$ |ts

Shipping weight: $2.3 \mathrm{~kg}(5 \mathrm{lbs})$

"Nowinal welues, determined in accordance with AS Tw standaro orocediures.

\section{MODEL 051 03Y 0.5 YDC outputs}

Power Requirement: $8-24 \mathrm{VDC}(5 \mathrm{mR} \otimes 12 \mathrm{VDC})$

operaling Temoeralure: 50 to $50^{\circ} \mathrm{C}$

0ulput Signals:

$0-5$ CovoC full scak

\section{MODEL 05103L 4-20 mA outpuls}

Power Requirement

8-30 VOC (40 mA max.)

0peraling Temerature:

-50 to $50^{\circ} \mathrm{C}$

0ulput Signals:

4-20 mi full scak

cє

Compries with applicatre CE directives. Specifications subject to change without notice. 


\section{Appendix I: RM Young Model 41372 Temperature and RH Probe Data Sheet}

\section{YOUNG}

\author{
Model 41382 Relative Humidity / Temperature Probe
}

Model 41342 Temperature Probe

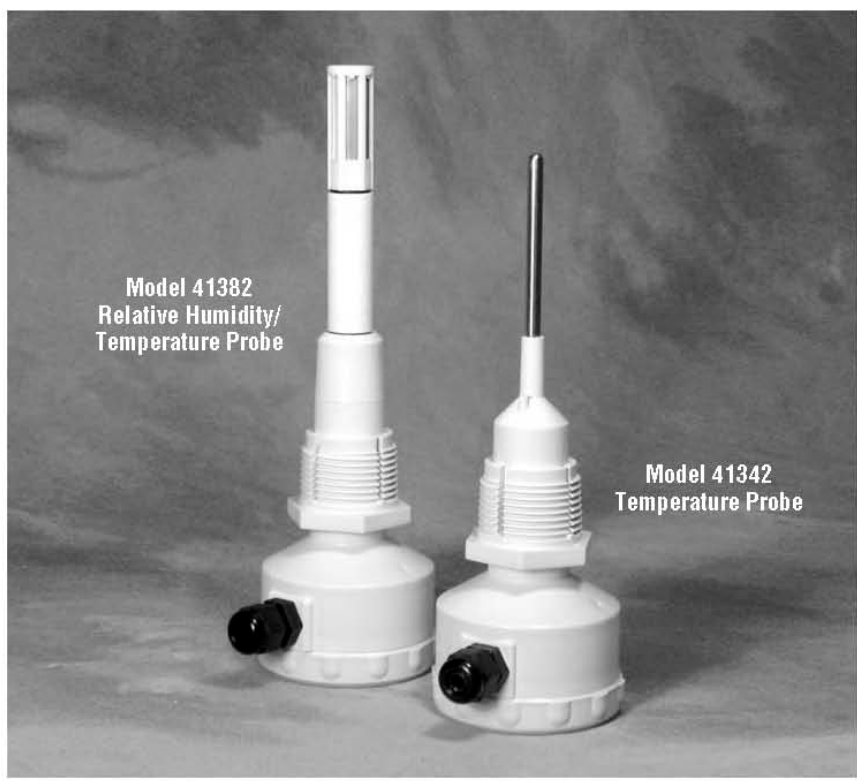

The Model 41382 Relative Humidity/Temperature Probe combines a high accuracy, capacitance type humidity sensor and precision Platinum RTD temperature sensor in one probe. This probe offers a choice of $0-1$ VDC or 4-20 mA outputs for T and RH. Model 41342 Temperature Probe offers accurate temperature-only measurement. Three output options are available: $0-1$ VDC, $4-20 \mathrm{~mA}$, and 4 wire RTD. Probes are easily installed in YOUNG naturally ventilated (multi-plate) and aspirated radiation shields. A junction box is provided for cable terminations.

\section{Ordering Information}

SENSOR CABLE MODEL

RELATIVE HUMIDITY/TEMP PROBE 4-20 mA output..

18723. $.41382 L^{*}$

RELATIVE HUMIDITY/TEMP PROBE 0-1 VDC output.

8446 $41382 V^{*}$

TEMPERATURE PROBE 4 wire RTD output 41342 TEMPERATURE PROBE 4-20 mA output TEMPERATURE PROBE 0-1 VDC output 18443 $41342 V^{*}$

\section{Specifications}

Voption: $10-28$ VDC $8 \mathrm{~mA} \quad 5 \mathrm{~mA}$

Loption: 10-28 VDC $40 \mathrm{~mA} \quad 20 \mathrm{~mA}$

RELATIVE HUMIDITY: (41382)

Measuring Range: $0-100 \% \mathrm{RH}$

Accuracy at $20^{\circ} \mathrm{C}: \pm 2 \% \mathrm{RH}$

Stability: Better than $\pm 1 \%$ RH per year

Response Time: 10 seconds (without filter)

Sensor Type: Rotronic Hygromerm

Output Signal: Voption: 0-1 VDC

Loption: 4-20 mA

TEMPERATURE: $(41382,41342)$

Calibrated Measuring Range:

-50 to $50^{\circ} \mathrm{C}$ (suffix C)

-50 to $150^{\circ} \mathrm{F}$ (suffix $\mathrm{F}$ )

Response Time: 10 seconds (without filter)

Accuracy at $0{ }^{\circ} \mathrm{C}: \pm 0.3^{\circ} \mathrm{C}^{* *}$

$\pm 0.1^{\circ} \mathrm{C}$ (optional) with NIST traceable calib ration

Sensor Type: Platinum RTD

Output Signal: V Option: 0-1 VDC

Loption: 4-20 mA, 4 wire RTD (41342 only)

\section{Recommended Radiation Shields:}

Model 41003P Multi-Plate Radiation Shield

Model 43408P Aspirated Radiation Shield

*toitterential measurement recommended with V voption 


\section{Appendix J: RM Young Model 52202 Tipping Bucket Rain Gauge Data Sheet}

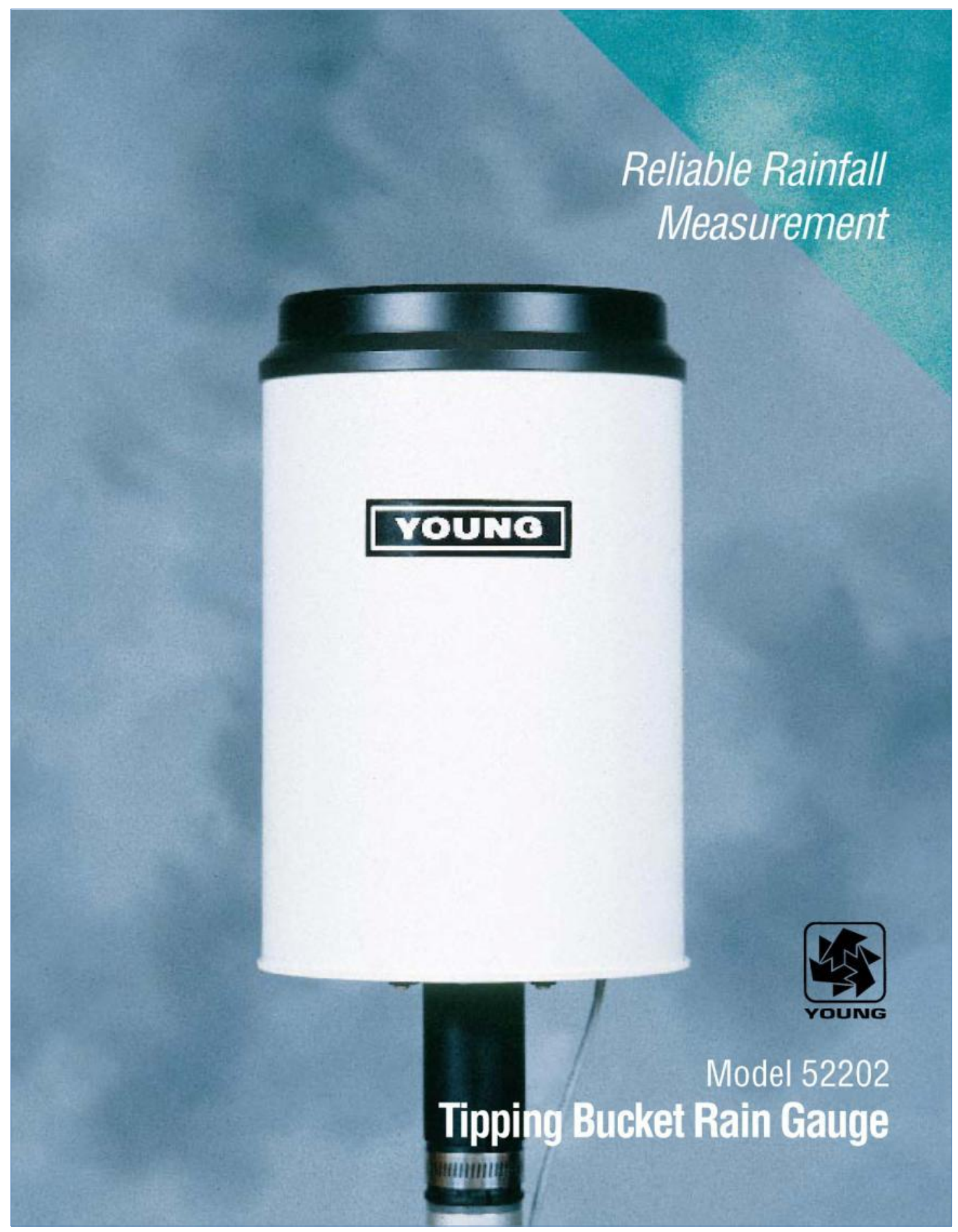




\section{YOUNG}

\section{Model 52202 Tipping Bucket Rain Gauge}

The YOUNG Tipping Bucket Rain Gauge meets the specifications of the World Meteorological Organization (WMO).

The design uses a proven tipping bucket mechanism for simple and effective rainfall measurement. The bucket geometry and material are specially selected for maximum water release, thereby reducing contamination and errors.

Catchment area of $200 \mathrm{~cm}^{2}$ and measurement resolution of $0.1 \mathrm{~mm}$ meet the recommendations of the WMO. Extensive use of molded thermo-

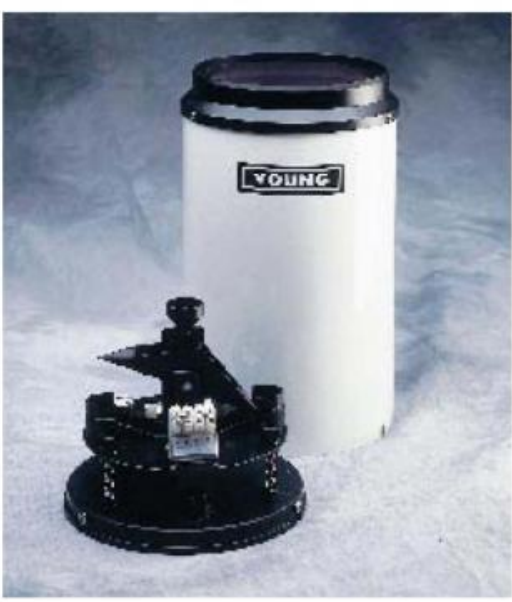

plastic components ensures maximum performance and value. Leveling screws and bullseye level are built-in for easy and precise adjustment in the field. Measured precipitation is discharged through a collection tube for verification of total rainfall. Model 52202 is heated for operation in cold temperatures. An unheated version, 52203 , is available for use in moderate climates.

\section{Specifications}

Size:

$18 \mathrm{~cm}$ dia $\times 30 \mathrm{~cm}$ high, (39 cm high with mounting base) Catchment Area:

$200 \mathrm{~cm}^{2}$

Resolution:

$0.1 \mathrm{~mm}$ per tip

Accuracy:

$2 \%$ up to $25 \mathrm{~mm} / \mathrm{hr}$

$3 \%$ up $1050 \mathrm{~mm} / \mathrm{hr}$

Oulput:

Magnetic reed switch (N.0). rating 24VACIOC 500mA

Operating Temperature:

$-20^{\circ} \mathrm{C}$ to $+50^{\circ} \mathrm{C}$ (heated)

Power:

18 Watts tor heater only

Mountling:

Clamp for $11^{*}\left(1.34^{*}\right.$ dia) iron pipe

or 3 bolts on $160 \mathrm{~mm}$ dia. circle

other

Leveling adjustment

thermostatic control tor heater

intake screen 


\section{Appendix K: Solar Light Model PMA1111 UVA Detector Data Sheet}

\section{PMA 2111 UVA Detector for Outdoor Installation}

The PMA2111 UVA detector provides fast and accurate irradiance measurement in the UVA region. Its spectral response covers the 320 to $400 \mathrm{~nm}$ range. The detector's enclosure is hermetically sealed and suitable for permanent outdoor operation.

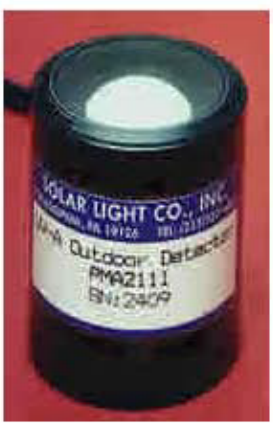

\section{Features:}

- High sensitivity

- Wide dynamic range

- Excellent long term stability

- Cosine corrected

- NIST traceable calibration

- Radiometric units

- Weatherproof

Analog version of this detector $c$ an be used with anv 0 to $5 \mathrm{VDC}$ or 4 to $20 \mathrm{~mA}$ recor ding device

\section{Applications:}

- high pressure mercury and metal halide lamps

- high pressure xenon lamps

- sunlight

- Source of UV

- low pressure florescent lamps

The Teflon diffuser assures an angular response close to a cosine function (Lambertian response) making the detector suitable for measuring diffused radiation or radiation from extended sources.

The PMA2111 detector is ideal for measuring mercury, xenon, metal halide or fluorescent lamps, commonly used for studies in the UVA region, as well as sunlight. The measured irradiance is displayed in $\mathrm{mW} / \mathrm{cm}^{2}$ or W/m $\mathrm{m}^{2}$, user selectable.

Consequently, the integrated dose is shown in Joules $/ \mathrm{cm}^{2}$ or $\mathrm{kJ}$ oules $/ \mathrm{m}^{2}$. The PMA2111 
has a resolution of $0.001 \mathrm{~mW} / \mathrm{cm}^{2}$ and a full scale of $200 \mathrm{~mW} / \mathrm{cm}^{2}$ allowing measurement of very week and very strong signals with the same detector. The effect of stray light is negligible.

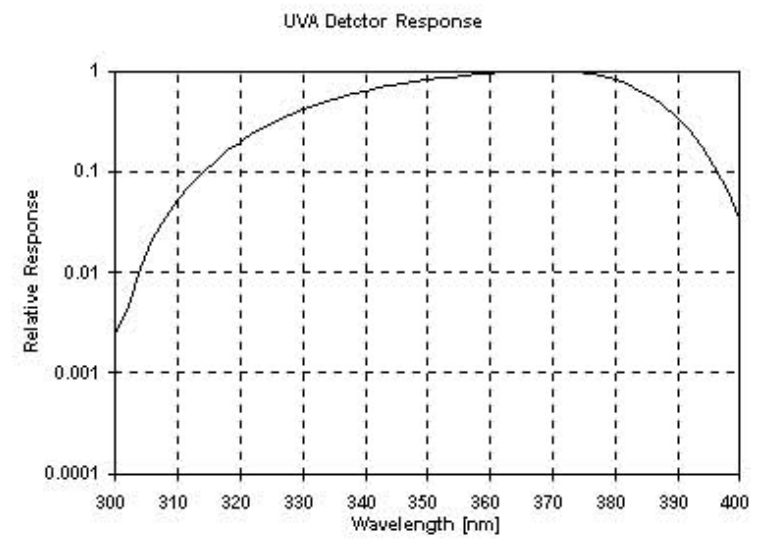

\section{Specifications:}

- Spectral response 320-400nm, figure 1

- Angular response $5 \%$ for angles $<50^{\circ}$

- Range $200\left[\mathrm{~mW} / \mathrm{cm}^{2}\right]$ or $2000\left[\mathrm{~W} / \mathrm{m}^{2}\right]$

- Display resolution $0.001\left[\mathrm{~mW}^{\mathrm{W}} / \mathrm{cm}^{2}\right], 0.01\left[\mathrm{~W} / \mathrm{m}^{2}\right]$

- Operating environment -40 to $120^{\circ} \mathrm{F}\left(-40\right.$ to $\left.+50^{\circ} \mathrm{C}\right)$ outdoors

- Temperature coefficient $<0.1 \% /{ }^{\circ} \mathrm{C}$

- Cable 50ft

- Diameter 1.6" (40.6 mm)

- Height 1.8" (45.8 $\mathrm{mm})$

- Weight $7.1 \mathrm{oz}$. (200 grams) 


\section{Appendix L: Campbell Scientific Model CR9000X Datalogger Data Sheet}

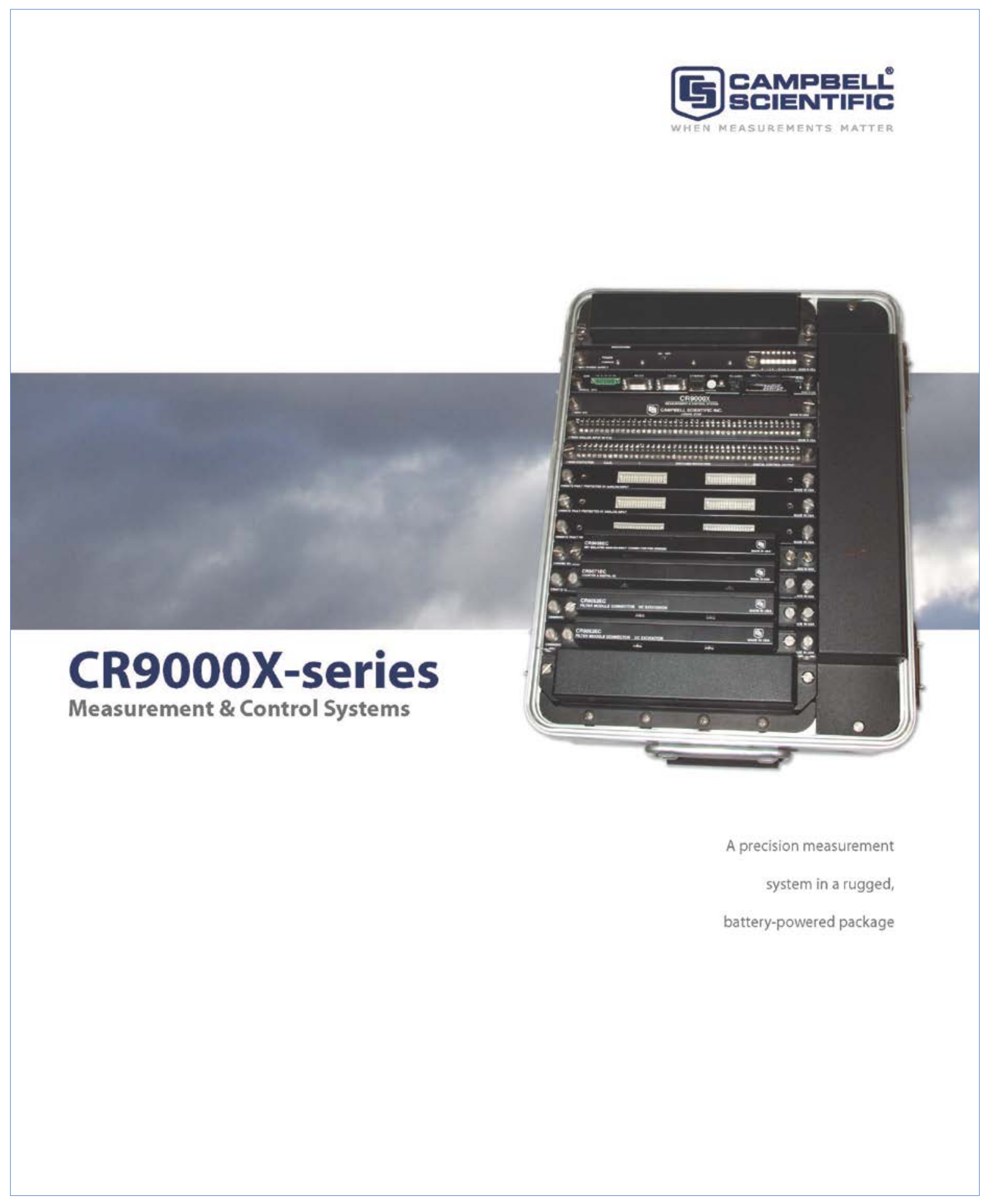




\section{CR9000X \& CR9000XC}

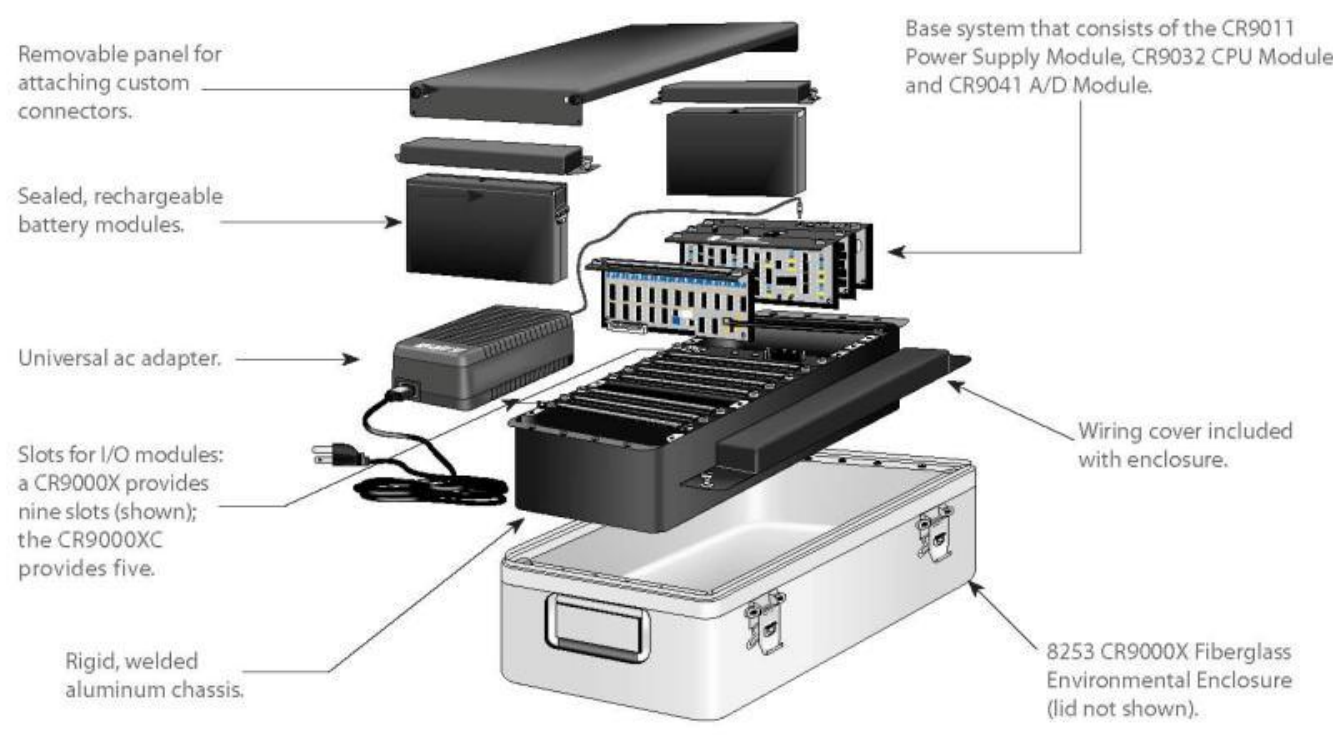

\section{Design Features}

- Modular system that consists of a base system and a chassis with $\mathrm{I} / \mathrm{O}$ module slots. Up to nine user-selected modules insert in the CR9000X or five user-selected modules in the CR9000XC

- Measurement rate of up to $100 \mathrm{~K}$ samples/second

- 16-bit resolution with programmable gain

- Powerful instruction set that supports measurement of most sensor types, on-board processing, data reduction, and intelligent control

- 128 Mbytes of internal SDRAM for data and program storage

- Expandable memory using a PCMCIA card or a CompactFlash card through the use of an adapter

- Robust ESD protection

- CE compliant

- Low power, $12 \mathrm{Vdc}$ operation

- Data values stored in tables with a time stamp and record number

- Operating temperature range of $-25^{\circ}$ to $+50^{\circ} \mathrm{C}$; extended range of $-40^{\circ}$ to $+70^{\circ} \mathrm{C}$ available

- $180 \mathrm{MHz}$ clock speed

\section{Base System}

CR9032 CPU Module

The CR9032 is a 32-bit CPU module that provides system control, data processing, and communications. The module features a clock speed of $180 \mathrm{MHz}$ and 128 Mbytes of internal SDRAM for data and program storage. It also includes an RS-232 port, 10 base T/100baseT port, CS I/O port, and a PC-card slot. The CS I/O port supports communications with our DSP4 Heads-Up Display or our SDM device at rates up to 115,200 bps. The PC-card slot accepts one Type I, Type II, or Type III PCMCIA card. CompactFlash cards are supported with an adapter. Industrial grade CompactFlash cards offered by Campbell Scientific store 64 Mbytes, 256 Mbytes, 1 Gbyte, or 2 Gbytes of data.

\section{Power Supply}

The power supply consists of the sealed rechargeable battery module, universal ac adapter, and CR9011 Power Supply Module. The battery module has a $14 \mathrm{Ahr}$ rating for the CR9000X and a $7 \mathrm{Ahr}$ rating for the CR9000XC. The batteries are recharged using the universal ac adapter, a dc input, or another external source.

The CR9011 module controls the current flowing to the charging source. A relay included in the CR9011 allows the datalogger to turn the power on and off. This conserves power and increases the battery's life. 
CR9041 A/D and Amplifier Module

The CR9041 provides signal conditioning and 16-bit, $100 \mathrm{kHz}$ A/D conversions.

\section{CR9000XC}

The CR9000XC is a compact version of the CR9000X The CR9011 Power Supply Module, CR9032 CPU Module, CR9041 A/D and Amplifier Module, five I/O module slots, one $7 \mathrm{Ahr}$ sealed rechargeable battery, and an environmental enclosure are included with the purchase of the CR9000XC.

\section{Transient Protection}

Rugged gas tubes protect all terminal block inputs and outputs from electrical transients. The CR9000X series is CE compliant under the European Union's EMC Directive, meeting ESD, EMC, Fast Transient standards.

\section{I/O Modules}

A mix of $\mathrm{I} / \mathrm{O}$ modules is selected based on the measurements required for the application. Individual I/O modules can be "swapped out", allowing the system to be reconfigured if requirements change. $\mathrm{I} / \mathrm{O}$ modules whose model numbers end in an " $\mathrm{E}$ " (e.g., CR9051E, CR9055E) and the CR9052DC include an "Easy Connector" module.

\section{CR9050 and CR9051E Analog Input Modules}

The CR9050 and CR9051E provide 14 differential (28 single-ended) input channels for measuring voltages up to $\pm 5 \mathrm{~V}$. Resolution is $1.6 \mu \mathrm{V}$ on the most sensitive range. Both modules have an on-board reference PRT and connectors for precise thermocouple measurements. The CR9051E channels are fault protected to $+50 \mathrm{~V} /-40 \mathrm{~V}$. This prevents overvoltage on one channel from corrupting measurements on other channels. The CR9051E channels become open circuits when the datalogger is powered down so sensors are not loaded.

\section{CR9052DC and CR9052IEPE Anti-Alias Filter and} Spectrum Analyzer Modules

The CR9052DC is a high-performance anti-alias filter and Fast Fourier Transform (FFT) spectrum analyzer with dc excitation. The CR9052IEPE module provides excitation and signal conditioning for IEPE-type (Integral Electronic Piezo Electric) accelerometers, microphones, and pressure transducers. Detailed information and specifications are available in the CR9052DC and CR9052IEPE brochure.
CR9055 or CR9055E 50-Volt Analog Input Module The CR9055(E) has 14 differential (28 single-ended) programmable input channels for measuring voltages up to $\pm 50 \mathrm{~V}$. Resolution to $16 \mu \mathrm{V}$ is available.

\section{CR9058E Isolation Module}

The CR9058E provides 10 isolated differential channels for measuring thermocouples or other low level voltage measurements that are at an elevated voltage plane. Each channel has its own isolated ground for shielded cable connection, and its own 24-bit A/D converter that supplies input isolation for up to $\pm 60 \mathrm{Vdc}$. An on-board digital signal processor provides digital noise filtering that is automatically maximized for the specified integration time. For precise thermocouple measurements, the CR9058E includes an on-board reference PRT.

\section{CR9060 Excitation Module}

The CR9060 provides six continuous analog outputs (CAOs), 10 switched excitation channels, and eight digital control outputs. The CAOs have individual digital-to-analog converters for proportional control, waveform generation, and excitation. Each CAO sources up to $50 \mathrm{~mA}$ between $\pm 5 \mathrm{~V}$. The excitation channels provide precision voltages for bridge measurements. The digital outputs control external devices.

\section{CR9071E Timer/Pulse Input Module}

The CR9071E provides 16 digital I/O and 12 pulse counting channels. Four pulse channels count switch closures; the other eight channels count low-level ac signals. All of the pulse channels can measure highlevel frequencies up to $1 \mathrm{MHz}$. The digital I/O channels are used for digital control, communications, output triggering, and pulse counting. The CR9071E supports interval timing and pulse width duration.

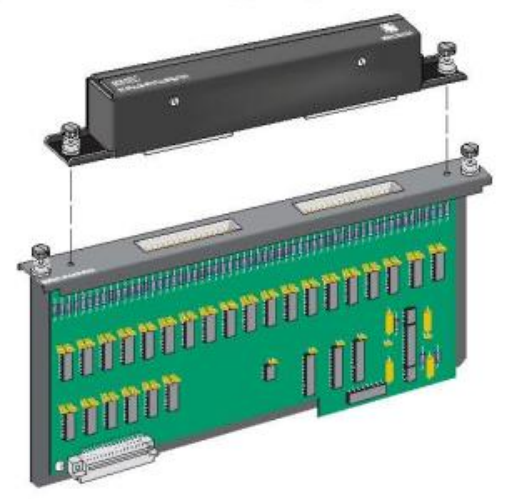

Easy Connector module allows sensor wiring to remain connected while the input module's measurement electronics and the rest of the datalogger system are used elsewhere. 


\section{Enclosures}

8253 Fiberglass Environmental Enclosure The environmental enclosure is designed for field applications where the endosure will be exposed to the elements. A CR $9000 \mathrm{X}$ housed in this enclosure is protected from water, dust, and most environmental pollutants.

\section{Lab Enclosure}

The Lab Enclosure is for applications where the CR9000X will reside inside a building.

\section{CR9000XC Envirommental Enclosure}

The CR9000XC includes a non-corrosive, sealed, aluminum enclosure that provides protection from water, dust, and most environmental pollutants.

\section{Measurement and Control Peripherals}

The following peripherals expand the capabilities of the CR9000X series:

- AM25T Multiplexer increases the number of thermocouples/voltages that can be measured Combinations of both can be made on each AM25T.

- SDM-CAN Interface allows the datalogger to sample data directly from a CANbus network.

- SDM-INT8 Eight Channel Interval Timer expands the number of pulse channels in the system and outputs period, pulse width, frequency, counts, and interval time.

- SDM-SIO4 Serial Input/Output Module provides four configurable serial RS-232 ports for connecting our GPS sensor or other devices that transfer data in a serial manner.

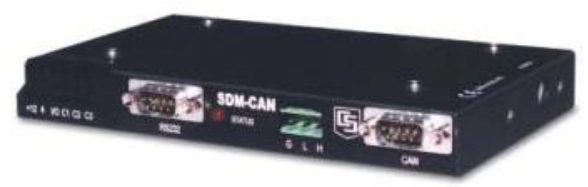

The SDM-CAN allows a vehicle's on-board diagnostic system to output standardized data streams that are synchronized with other measurements and stored in the CR9000X.

Although the following peripherals do not support the maximum measurement rate, the CR9000X series is also compatible with:

- SDM-CD16AC 16-Channel AC/DC Relay Controller

- SDM-CVO4 4-Channel Current/Voltage Output Module

- AM16/32B Multiplexer

\section{Data Storage and Retrieval}

Data storage and retrieval options commonly used with the CR9000X series include:

\section{- PCMCIA Cards or CompactFlash ${ }^{\circ}$ (CF) Cards} can be used to augment the datalogger's storage capacity or to transport data or programs from the datalogger to a PC.

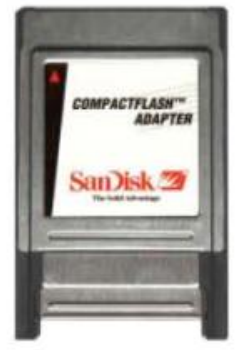

The CF 1 adapter allows the PCMCIA slot in the CR9000X datalogger to receive CF cards. Only industrial-grade CF cards with a storage capacity of 2 Gbytesor less should be used with our products.

- Ethernet Cables connected to the on-board 10baseT/100baseT port transmit data to a PC with an Ethernet port via a local network or the Internet

- Direct Links use an SC12 cable connected to the on-board RS-232 port to communicate with a laptop or desktop computer.

- DSP4 Heads up Display is primarily intended for vehicle test applications. The DSP4 permits dashboard mounting in a variety of vehicles without obstructing the view of the driver.

Although the following peripherals do not support the maximum measurement rate, the $\mathrm{CR} 9000 \mathrm{X}$ series is also compatible with:

- Telephone modems (landline and cellular)

- Spread spectrum radios

\section{Operating System/Logic Control}

The on-board operating system includes measurement, processing, and output instructions for programming the datalogger The programming language, CRBASIC, uses a BASIC-like syntax. Measurement instructions specific to bridge configurations, voltage outputs, thermocouples, and pulse/frequency signals are included. Processing instructions support algebraic, statistical, and transcendental functions for on-site processing, Output instructions process data over time and control external devices. These instructions include averages, maximums, minimums, standard deviation, histograms, rainflow histograms, level crossings, and FFTs. 


\section{Sof tware}

One copy of RTDAQ Real-Time Data Acquisition Software is shipped with each CR9000X-series datalogger. The CR9000X is also compatible with most of the other software packages offered by Campbell Scientific. Additional information is provided in the Software Overview brochure and the brochures for the individual software packages.

RTDAQ Real-Time Data Acquisition Sofiware RTDAQ is an ideal solution for industrial and real-time users desiring to use reliable data collection software over a single telecommunications medium, and who do not rely on scheduled data collection. RTDAQ's strength lies in its ability to handle the display of high speed data.

Tools bundled with RTDAQ include Short Cut, ProgGen, and CRBasic for creating datalogger programs; RTMC for graphically displaying data; View Pro and Split for working with data files; and LogTool and PakBus Graph for troubleshooting communications.

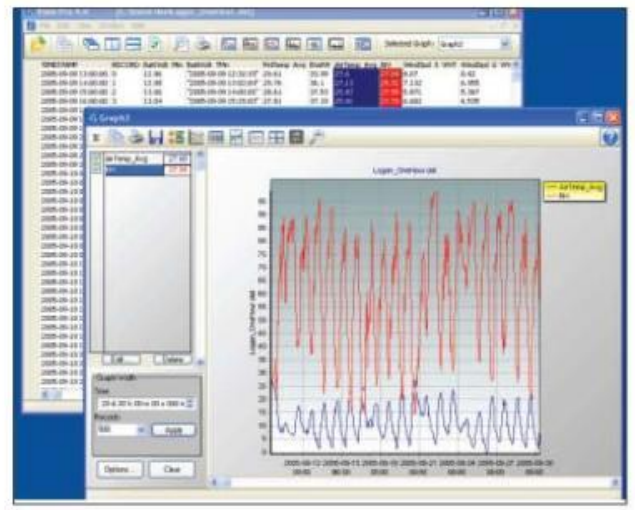

Using View Pro, you can display historical data in a tabular or graphical format.

Features/Benefits:

- Provides non-invasive field calibration of sensorsincorporating the appropriate multipliers and offsets into the datalogger program

- Monitors real-time data using the Graph, Fast Graph (similar to PC9000's virtual oscilloscope), Histogram Viewer, Fast Fourier Transform (FFT) Viewer, Rainflow Viewer, Table Monitor (similar to the PC9000 Field Monitor), and XY Plot Viewer

- Displays historical data files including specialized engineering data such as FFTs and histograms

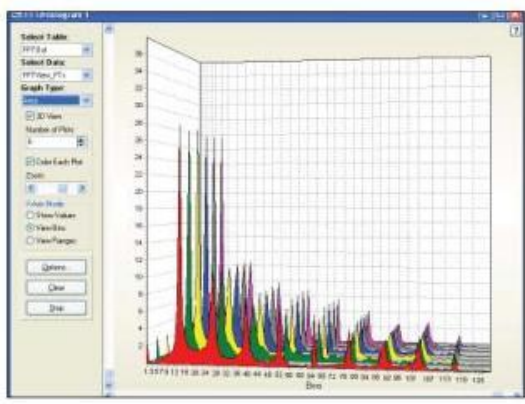

The FFT is an example of the many real-time data displays offered by RTDAQ that allow you to view the measurements instantly.

\section{Other Compatible Software}

- Short Cut (SCWin)-generates straight-forward CR9000X programs in four easy steps. Short Cut can be downloaded, at no charge, from our Web site at: www.campbellsci.com/downloads

- PC200W-intended for first-time users or users with simple data collection needs. PC200W can be downloaded, at no charge, from our Web site at: www.campbellsci.com/downloads

- PC400 - supports a variety of telecommunication options, manual data collection, and data display. It does not support combined communication options (e.g., phone-to-RF), PAKBUS routing, or scheduled data collection.

- LoggerNet-allows you to write datalogger programs, transfer those programs to the datalogger, collect the data, and analyze the data. Combined communication options (e.g., phone-to-RF), PAKBUs routing and scheduled data collection are supported.

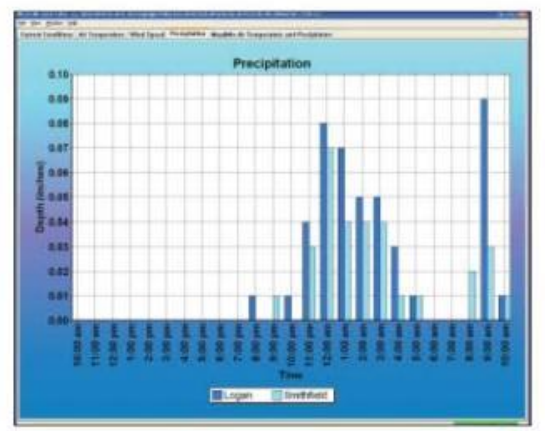

RTMC is bundled with RTDAQ and LoggerNet. Users who want additional capabilities and more flexibility can purchase RTMC Pro - an enhanced version of RTMC 


\section{Applications}

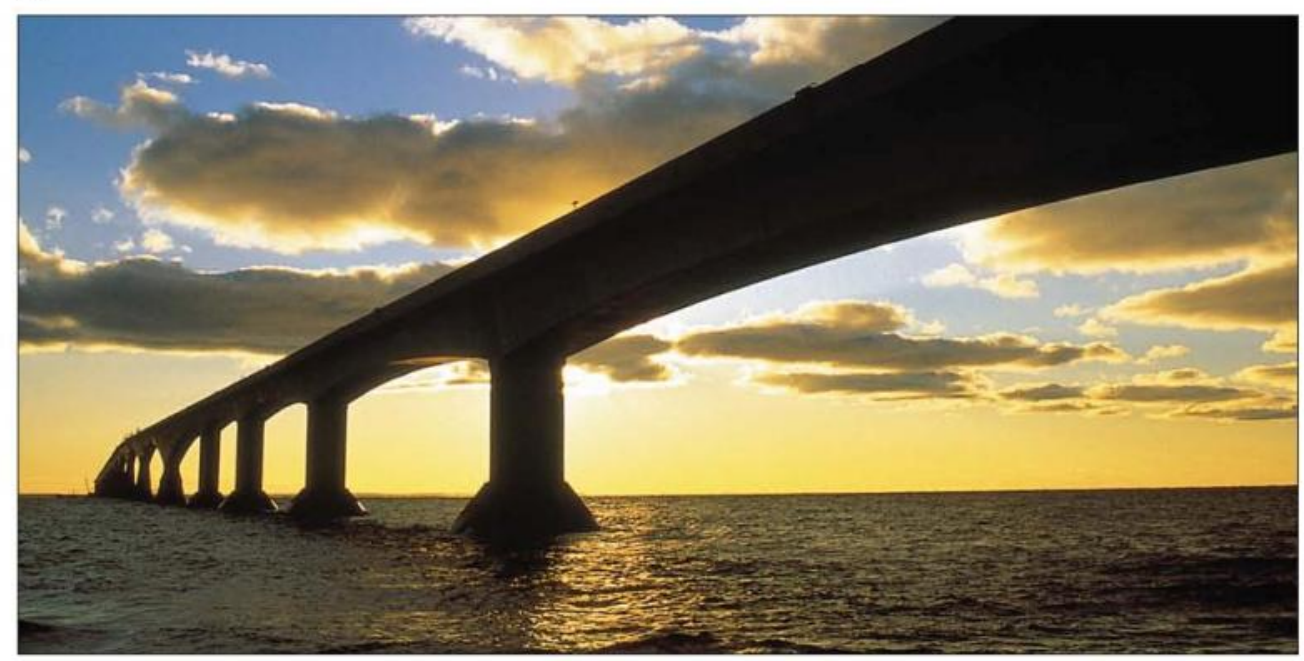

Our dataloggers have been used over the years to monitor many prominent bridges. Whether bridges are large or small, Campbell Scientific is committed to providing quality instrumentation and support to help maintain their safety.

\section{Structural and Seismic Monitoring}

The rapid sampling rate and large number of high resolution channels provided by the CR9000X-series dataloggers make them ideal for structural and seismic monitoring. These dataloggers can be used in applications ranging from simple beam fatigue analysis, to structural mechanics research, to continuous monitoring of large, complex structures.

The on-board instruction set supports many algorithms and math functions that are useful for structural and seismic monitoring. The datalogger can store data as rainflow or level crossing histograms. The rainflow and level crossing algorithms can be processed for extended periods of time, not just a finite number of cycles. The instruction set also supports triggered output with pre-trigger data capture capability. Triggers can be based on sensor output, time, and/or user control.

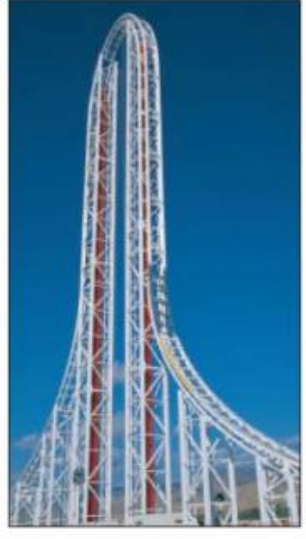

The CR9000X can provide remote, unattended monitoring of high-way overpasses, amusement park rides, roads, bulldings, and retaining walls.
For example, if an overpass or bridge is being monitored, data collection can be triggered:

(1) by a sensor detecting the approach of a car or an earthquake,

(2) at pre-programmed times, or

(3) by pushing a button.

The datalogger's control functions allow it to activate alarms, actuate electrical devices, or shut down equipment based on time or measured conditions.

Typical sensors used for structural and seismic monitoring include:

- Carlson strain meters

- Foil strain gages (set up in quarter, half, or full bridge strain configurations)

- Inclinometers

- Crack and joint sensors

- Tilt sensors

- Piezoresistive accelerometers

- Piezoelectric accelerometers

- Capacitive accelerometers

- Borehole accelerometers

- Servo force balance accelerometers 
Vehicle Monitoring and Testing

The versatile, rugged design and low power requirements of the CR9000X-series dataloggers make them well suited for vehicle monitoring. They excel in cold and hot temperature, high altitude, off-highway, and crosscountry performance testing. The CR9000X series is compatible with our SDM-CAN interface and DSP4 Heads Up Display.

Compatible sensors often used for vehicle monitoring and testing include thermocouples, pressure transducers, GPS receivers, pulse pick-ups, flow transducers, potentiometers, strain gages, load cells, digital switches, accelerometers, LVDTs, and tilt sensors. Most sensors connect directly to the datalogger, eliminating costly external signal conditioning.

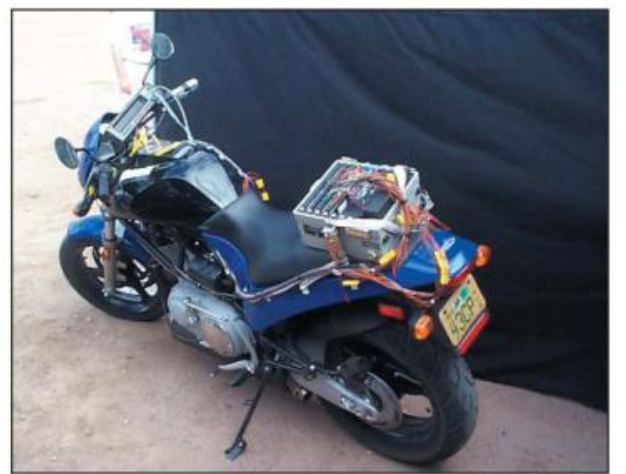

Vehicle monitoring includes not only passenger cars but locomotives, airplanes, helicopters, tractors, buses, heavy trucks, drilling rigs, race cars, ATVs, and motorcycles.

Common measurements include:

- Suspension-strut pressure, spring force, travel, mounting point stress, deflection, ride

- Fuel system-line and tank pressure, flow, temperature, injection timing

- Comfort control-ambient and supply air temperature, solar radiation, fan speed, blower currents, ac on/off, refrigerant pressures, time-to-comfort

- Brakes-line pressure, pedal pressure and travel, $\mathrm{ABS}$, fluid and pad temperature

- Engine-pressure, temperature, crank position, RPM, time-to-start, oil pump cavitation

- General vehicle-chassis monitoring, road noise, NVH, traction, payload, vehicle position/ speed, steering, air bag, hot/cold soaks, wind tunnels, CANbus, wiper speed/current, vehicle electrical loads
Other Applications

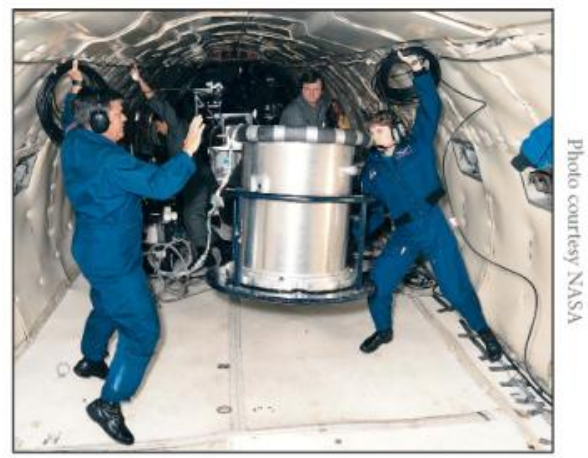

Our dataloggers measured the effects of gravity on a test structure aboard a NASA low-gravity flight.

- Aerospace/aviation-can endure the rigors of space travel and provided acceleration, structural, and equipment performance measurements.

- Geotechnical-measures tilt, convergence, displacement, geographic position, strain, load, vibration, overburden, level, flow, creep, and force for slope stability, subsidence, seismicity studies, structural restoration, or site assessment applications.

- Mining-monitors mine ventilation, slope stability, convergence, and equipment performance.

- Machinery testing-provides temperature, pressure, RPM, velocity, power, acceleration, position, torque, and strain measurements.

- Laboratory-can serve as a monitoring device to record parameters over time and can also be used to regulate and control test conditions.

\section{Compatibility with Retired Products}

Customers can add CR9000X-series dataloggers to networks containing the older CR9000-series dataloggers. 1/O modules other than the CR9080 can be used with either the CR9000 series or CR9000X series. The NL105, BLC100, and TL925 communication interfaces are retired because they were used exclusively with the CR9000 series; the PLA100 will not be available once our inventory has been depleted. RTDAQ software is not compatible with the retired CR9000 series. Customers can upgrade a CR9000 or CR9000C to a CR9000X or CR9000XC by replacing their CR9031 CPU module with a CR9032 CPU module. 


\section{CR9000X \& CR9000XC Specifications}

Electrical specifications are valid over $\mathrm{a}-25^{\circ}$ to $+50^{\circ} \mathrm{C}$ range unless othenwise specified; extended testing over $-40^{\circ}$ to $+70^{\circ} \mathrm{C}$ range available as an option, excluding batteries. Non-condensing environment is required. To maintain specifications, Campbell Scientific recommends recalibrating dataloggers every two years. We recommend that you confirm system configuration and critical specifications with Campbell Scientific before purchase.

\section{CR9032 CPU MODULE}

PROCESSORS: $180 \mathrm{MHz}$ Hitachi $8 \mathrm{H}-4$

MEMORY 128 Mbyles of interna SDRAM tor program and fata storage. Expanded data storage with PCMCIA type I, SERIAL INTERFACES: A8-232 9-pin interface for computer ERIAL INTERFACES: AS-232 9-pin interface for computer
or modem. CS vO \%-pin interface for CSI peripherals and
SDM devices.

ETHERNET INTERFACE 10 baseTH100baseT port bor commu nications over a local network or the Intemet

\section{CR9O11 POWER SUPPLY MODULE}

\section{VOLTAGE 9.61018 Vdo}

TYPICAL OURRENT DRAIN. Base syslem with no modules is

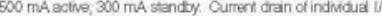
modies varies. Fieter io specilications for each 10 modis to specific values. Power supply module can place the system in

DC CHARGING 9.6 to 18 Vdo input charges internal betteries tf up to $2 \mathrm{~A}$ rate Charging arouit ncludes termperature

INTERNAL BAT TERIES: Sealed techargeable with 14 Ahr (7) Anr for the CR9000XC) capacity per charge

EXTERNAL BATTEFIES: Edemal $12 \mathrm{~V}$ berlenes can be connected. CR904I A/D and AMPLFIER MODUE

AD Conversions: 16 -bil, $100 \mathrm{kHz}$

CR9050 and CR9051E ANALOG INPUT MODUE with RTD INPUT CHANNELS PER MODULE 14 Diflerential (diti) or 28 single-ended (SE)

RANGE, RESOLUTION, AND INPUT NOISE

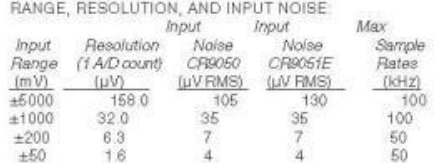

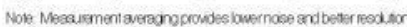

ADCURACY OF VOLTAGE MEASUREMENTS: Single-ended \& Differential

$2007 \%$ of reading +4 AND colns $)-25^{\circ}$ to $+50 \%$

Dual Difterertial (two meesurements with irpul polanty Erersed)

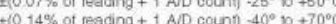

COMMON MODE RANGE: $\pm 5 \mathrm{~V}$

DC COMMON MODE REJECTION: $>120 \mathrm{~dB}$

INPUT RESISTANCE: 25 gigaohms tyoicas

MAXIMUM INPUT VOLTAGE WITHOUT DAMAGE

T20 V CR955 - 40 to + 50 V C C $9051 \mathrm{E}$

TYPICAL CURRENT DRAIN: 25 MA aCTNE

Resistance \& Conductivity Measurements (also requires CR9060 Excetation Module)

ACCUAACY: $\pm(0.04 \%$ of reading +2 ADD counns $)$ limited by accuracy of exle mal bridoe resistors

MEASUREMENT TYPES. 6-wire and 4-wire full bndge, 4-wire, 3 -wire, and 2-wre halr bidge Uses excutation reversal to remove thermal EMF error:

\section{CR9052DC ANTI-ALIAS FILTER MODULE}

Reter to the $\mathrm{CR} 9052 \mathrm{DC}$ documentation

CR9055(E) 50 V-ANALOG INPUT MODULE

INPUT CHANNELS PER MODULE. 14 ditt or $28 \mathrm{SE}$. RANGE AND RESOLUTION

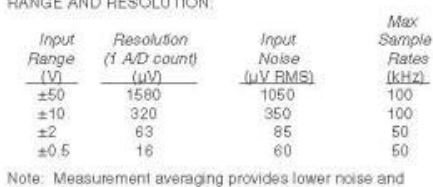

Note: Measurement averagng provides lower noise and better resolution
ACCURACY OF VOLTAGE MEASUREMENTS: Single-Ended $\&$ Ditterential $\pm\left(0.1 \%\right.$ of reading +4 AV counts) $25^{\circ} 10+50^{\circ} \mathrm{C}$ $\pm(0.2 \%$ of reading $+4 A D$ counts $)-40^{\circ}$ to $+70^{\circ}$ Dual Ditterentia:

(two measurements with inout polarity reversed)

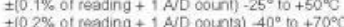

COMMON MODE RANGE: $\pm 50 \mathrm{~V}$

DC COMMON MOOE REJECTION $>62 \mathrm{~dB}$

NPUT RESISTANCE $100 \mathrm{kohms} \mathrm{typics}$

MAXIMUM INPUT YOLTAGE WITHOUT DAMAGE: $\pm 150 \mathrm{~V}$

TYPICAL CURRENT DRAIN $15 \mathrm{~mA}$ aotive

\section{CR9058E ISOLATION MODULE}

NPUT CHANNELS PER MODULE 10 isolated, ditterentiat

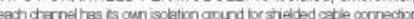
RANGE, RESOLUTION, AND INPUT RESISTANCE

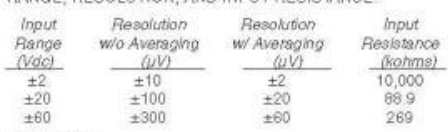

ACCURACY

Gain Error: $\pm 0.02 \%$ of reading $\left(-40^{\circ} 10+50^{\circ} \mathrm{C}, \pm 0.07 \%\right.$ of Gain Error: $40.02 \%$ of reading
reading $\left(-40^{\circ}\right.$ to $\left.+70^{\circ} \mathrm{C}\right)$

Otser Emor $\pm 0.01 \%$ of $F S R\left(-40^{\circ}\right.$ to $\left.+50^{\circ} \mathrm{C}\right), \pm 0.01 \%$ of FSR $\left(-40^{\circ} 10+70^{\circ} \mathrm{C}\right)$

INPUT TO SYSTEM OROUND CMRR dL:

input Riange
Nodel

\pm 0
\pm 2
\pm 20
$\pm \infty 0$

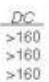

$\frac{60 \mathrm{~Hz}}{93.3}$
991
94.6

$\frac{300 \mathrm{~Hz}}{81.0}$
88.8
85.3

$2 \mathrm{kHz}$
70.7
7116
667

INPUT TO INPUT CAOSSTALK OL

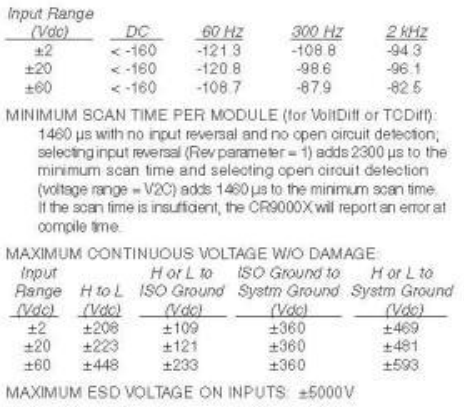

TYPICAL CURRENT DRAIN: 360 mA operating. 5 mA standby

\section{CR9060 EXCITATION MODULE}

TYPIOAL CURPENT DRAIN. 108 mA aviescent, 125 mA active

\section{Analog Outputs}

ANALOG OUTPUTS PER MODULE: 10 sumched, 6 continuous SWITCHED Provides excitation for resistance measurements Hy one outpul cen be active al a fime.

CONTINUOUS. All ouputs can be active simulteneousy

RANGE $\pm 5 \mathrm{~V}$

ACCUARACY $\pm(0.2 \%$ of output $\pm 4 \mathrm{mV})$

RESOLUTION 12-bit AV $(2,4 \mathrm{mV}$

OUTPUT CURRENT: $\pm 50 \mathrm{MA}$

Digital Control Outputs

CONTROL CHANNELS PER MODULE. A

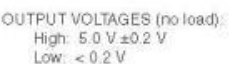

\section{CR907IE COUNTER \& DIGITAL. I/O MODULE}

Counter Channels

COUNTER CHANNELS PER MODULE: 12

MAXMUUM COUNTS PER INTERVAL: $2^{32}$ Max counts per Anterval will never be reacheo because win a maximiur input frequency of $1 \mathrm{MHz}$, the 32 -bit counter will go 71.58 minules betore it rolls over. The misamum

SWITCH CLOSURE MODE (4 channels) Minmum switch closed time: $5 \mathrm{ma}$ Maximim bounce time $1 \mathrm{~ms}$ spen wifnout being counted

HIGH FREGUENCY MOOE (all channels) Minimum pusa width $500 \mathrm{~ns}$ Maximum inout frequency $1 \mathrm{MHz}$ Tresholds. Pulse counted on transition trom below $15 \mathrm{~V}$ to above $3.5 \mathrm{~V}$,

Nole: Because of the pulse channess input tiliter with a (a) larger input transioons.

LOW LEVEL AC MODE (8 channels) input hysteresis to mV Masimum input voltage $+20 \mathrm{~V}$ Frequency range:

$\frac{\text { IMV RMS) }}{25} \quad \frac{\text { BANGE (HZ) }}{11010,000}$ $\begin{array}{ll}25 & 11010,000 \\ 250 & 0.51020,000\end{array}$

TYPICAL CURARENT DRAIN $35 \mathrm{~mA}$

Digital Inputs/Outputs O CHANNELS PER MODULE 18

OUTPUT VOLTAGES (no load) High $5.0 \mathrm{~V} \neq 0.2 \mathrm{~V}$

OUTPUT RESISTANCE: $320 \mathrm{ohms}$ INPUT STATE:

Hign: 3.5 to $5 \mathrm{~V}$
Low: -0.5 to $1.2 \mathrm{~V}$ INPUT RESISTANCE $100 \mathrm{kOhm}$

Interval Measurement

vo CHANNELS: Resclution is the soan rate

PULSE CHANNELS Maximum interval 1 mirute
Resclution 40 ns

TRANSIENT PROTECTION

Al analog and digtal inpuls and ouputs use gas discharge tubes and transient filters to protect against high-voltage tran-
sients Digital los also have over- voltage protection diampiny

\section{PHYSICAL}

Size

AAB ENCLOQSURE $1575 \mathrm{~L} \times 975 \mathrm{~W} \times 8 \mathrm{O}(40 \times 248 \times 203 \mathrm{~cm})$ FIBEFGLLASS ENVIRONMENTAL ENCLOSURE: CA9000XC: $10^{\circ} \mathrm{L} \times 11 \mathrm{~W} \times 9^{*} \mathrm{D}(25.4 \times 27.9 \times 22.9 \mathrm{~cm})$

Weight

LAB ENCLOSUFE $30 \mathrm{lbs}$ induding modues (13.6 kg) FIBERGLASS ENVIRONMENTAL ENCLOSURE 42 lbsincluding modules (19.1 kg)

CR9000XC. 27 Ibs insluding modules ( $(12.3 \mathrm{~kg})$ REPLACEMENT BATTERIES: $6.4 \mathrm{lbs}(2.9 \mathrm{~kg})$ ADOITIONAL MODULES: $1 \mathrm{lb}$ each $\langle 0.5 \mathrm{~kg})$

WARRANTY

Three years agansi delects in materials and workmanship 


\section{Appendix M: Campbell Scientific Model CR1000 Datalogger Data Sheet}

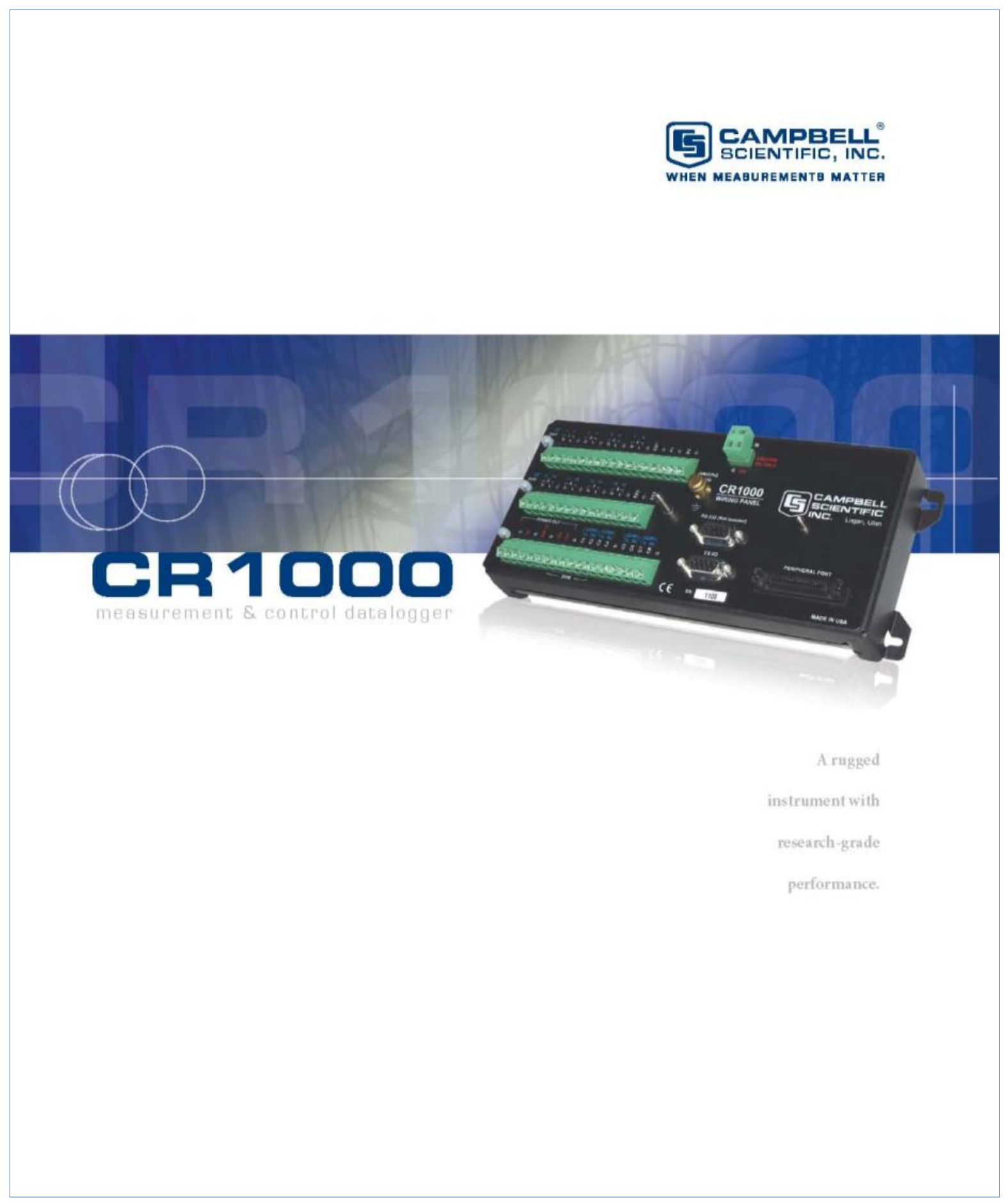




\section{CR1000}

\section{Measurement \& Control System}

The CR 1000 provides precision measurement capabilities in a rugged, battery-operated package. It consists of a measurement and control module and a wiring panel. Standard operating range is $-25^{\circ}$ to $+50^{\circ} \mathrm{C}$ an optional extended range of $-55^{\circ}$ to $+85^{\circ} \mathrm{Cis}$ available.

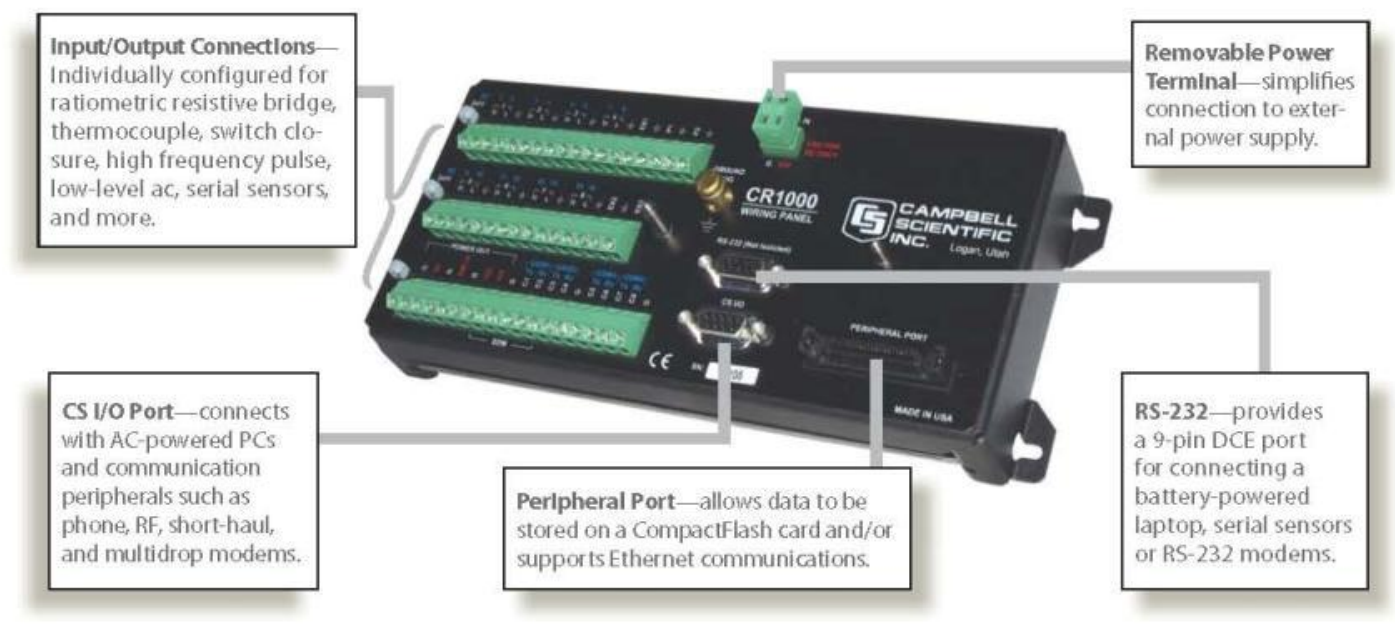

\section{Features}

- 4 Mbyte memory*

- Program execution rate of up to $100 \mathrm{~Hz}$

- CS I/O and RS-232 serial ports

-13-bit analog to digital conversions

- 16-bit H8S Renesas Microcontroller with 32-bit internal CPU architecture

- Temperature compensated real-time clock

- Background system calibration for accurate measurements over time and temperature changes

- Single DAC used for excitation and measurements to give ratio metric measurements

- Gas Discharge Tube (GDT) protected inputs

- Data values stored in tables with a time stamp and record number

- Battery-backed SRAM memory and clock ensuring data, programs, and accurate time are maintained while the CR1000 is disconnected from its main power source

- Serial communications with serial sensors and devices supported via I/O port pairs

- PAKBus, Modbus, and DNP3 protocols supported

\section{Measurement and Control Module}

The module measures sensors, drives direct communications and telecommunications, reduces data, controls external devices, and stores data and programs in on-board, non-volatile storage. The electronics are RF shielded and glitch protected by the sealed, stainless steel canister. A battery-backed clock assures accurate timekeeping. The module can simultaneously provide measurement and communication functions. The on-board, BASIC-like programming language supports data processing and analysis routines.

\section{Wiring Panel}

The CR1000WP is a black, anodized aluminum wiring panel that is compatible with all CR 1000 modules. The wiring panel includes switchable $12 \mathrm{~V}$, redistributed analog grounds (dispersed among analog channels rather than grouped), unpluggable terminal block for $12 \mathrm{~V}$ connections, gas-tube spark gaps, and $12 \mathrm{~V}$ supply on pin 8 to power our COM-series phone modems and other peripherals. The control module easily disconnects from the wiring panel allowing field replacement without rewiring the sensors. A description of the wiring panel's input/output channels follows.

* Originally, the standard CR1000 had $2 \mathrm{Mbytes}$ of data/program storage, and an optional version, the CR1000-4M, had $4 \mathrm{Mbytes}$ of memory. In September 2007, the standard CR1000 started having 4 Mbytes of memory, making the CR1000-4M obsolete. Dataloggers that have a module with a serial number greater than or equal to 11832 will have a 4 Mbyte memory. The 4 Mbyte dataloggers will also have a sticker on the canister stating " $4 M$ Memory". 
Analog Inputs

Eight differential (16 single-ended) channels measure voltage levels. Resolution on the most sensitive range is $0.67 \mu \mathrm{V}$.

\section{Pulse Counters}

Two pulse channels can count pulses from high level (5 V square wave), switch closure, or low level AC signals.

\section{Switched Voltage Excitations}

Three outputs provide precision excitation voltages for resistive bridge measurements.

\section{Digital I/O Ports}

Eight ports are provided for frequency measurements, digital control, and triggering. Three of these ports can also be used to measure SDM devices. The I/O ports can be paired as transmit and receive. Each pair has 0 to $5 \mathrm{~V}$ UART hardware that allows serial communications with serial sensors and devices. An RS232-tologic level converter may be required in some cases.

\section{CSI/O Port}

$\mathrm{AC}$-powered $\mathrm{PCs}$ and many communication peripherals connect with the $\mathrm{CR} 1000$ via this port. Connection to an $\mathrm{AC}$-powered $\mathrm{PC}$ requires either an $\mathrm{SC} 32 \mathrm{~B}$ or $\mathrm{SC}$-USB interface. These interfaces isolate the PC's electrical system from the datalogger, thereby protecting against ground loops, normal static discharge, and noise.

\section{RS-232 Port}

This non-isolated port is for connecting a batterypowered laptop, serial sensor, or RS-232 modem. Because of ground loop potential on some measurements (e.g., low level single-ended measurements), AC-powered PCs should use the CS I/O port instead of the RS-232 port (see above).

\section{Peripheral Port}

One 40-pin port interfaces with the NL115 Ethernet Interface \& CompactFlash Module, the NL120 Ethernet Interface, or the CFM100 CompactFlash ${ }^{\circ}$ Module.

\section{Switched 12 Volt}

This terminal provides unregulated $12 \mathrm{~V}$ that can be switched on and off under program control.

\section{Storage Capacity}

The CR1000 has 2 Mbyte of FLASH memory for the Operating System, and 4 Mbytes of battery-backed SRAM for CPU usage, program storage, and data storage. Data is stored in a table format. The storage capacity of the CR 1000 can be increased by using a CompactFlash card.

\section{Communication Protocols}

The CR1000 supports the PAKBus, Modbus, and DNP3 communication protocols. With the PAKBus protocol, networks have the distributed routing intelligence to continually evaluate links. Continually evaluating links optimizes delivery times and, in the case of delivery failure, allows automatic switch over to a configured backup route.

The Modbus RTU protocol supports both floating point and long formats. The datalogger can act as a slave and/or master.

The DNP3 protocol supports only long data formats. The dataloggers are level 2 slave compliant, with some of the operations found in a level 3 implementation.

\section{Power Supplies}

Any 12 Vdc source can power the CR1000; a PS100 or BPALK is typically used. The PS100 provides a 7-Ahr sealed rechargeable battery that should be connected to a charging source (either a wall charger or solar panel). The BPALK consists of eight non-rechargeable D-cell alkaline batteries with a 7.5-Ahr rating at $20^{\circ} \mathrm{C}$.

Also available are the BP12 and BP24 battery packs, which provide nominal ratings of 12 and 24 Ahrs, respectively. These batteries should be connected to a regulated charging source (e.g., a CH100 connected to a unregulated solar panel or wall charger).

\section{Enclosure/Stack Bracket}

A CR1000 housed in a weather-resistant enclosure can collect data under extremely harsh conditions. The enclosure protects the CR1000 from dust, water, sunlight, or pollutants.

The 17565 Stack Bracket allows a small peripheral to be placed under the mounting bracket, thus conserving space. With the bracket, the CR1000 can be attached in a "horizontal" orientation in an $\mathrm{ENC10/12} \mathrm{enclosure} \mathrm{(i.e.,} \mathrm{the} \mathrm{long} \mathrm{axis} \mathrm{of} \mathrm{the}$ CR1000 spanning the short axis of the enclosure).

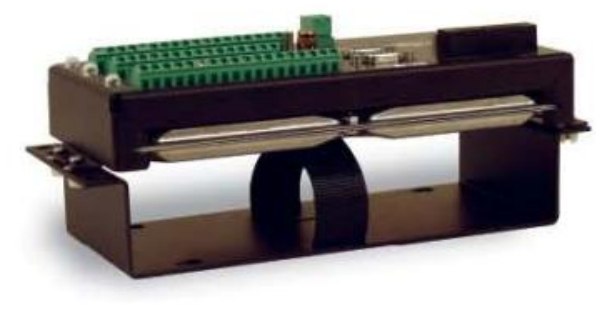

Above shows a side view of the stack bracket. The CR1000 fastened to the bracket via Velcro straps. 


\section{Data Storage and Retrieval Options}

To determine the best option for an application, consider the accessibility of the site, availability of services (e.g., cellular phone of satellite coverage), quantity of data to collect, and desired time between data-collection sessions. Some communication options can be combined -increasing the flexibility, convenience, and reliability of the communications.

\section{Radios}

Radio frequency (RF) communications are supported via narrow-band UHF, narrow-band VHF, spread spectrum, or meteor burst radios. Lineof-sight is required for all of our RF options.

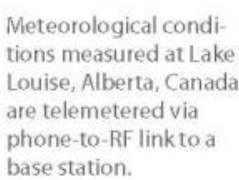

Meteorological conditions measured at Lake Louise, Alberta, Canada are telemetered via phone-to-RF link to a base station.

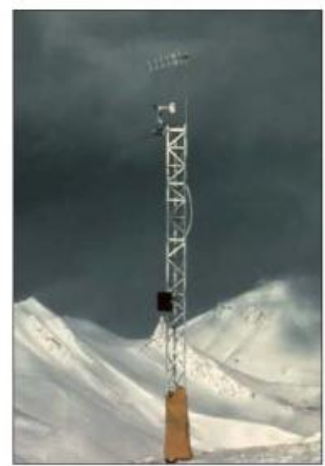

Telephone Networks

The CR1000 can communicate with a PC using landlines, cellular CDMA, or cellular GPRS transceivers. A voice synthesized modem enables anyone to call the CR1000 via phone and receive a verbal report of realtime site conditions.

\section{Multidrop Interface}

The MD485 intelligent RS-485 interface permits a $\mathrm{PC}$ to address and communicate with one or more dataloggers over the CABLE3CBL cable. Distances up to 4000 feet are supported.

\section{Short Haul Modems}

The SRM-5A RAD Short Haul Modem supports communications between the CR1000 and a PC via a fourwire unconditioned line (two twisted pairs).

\section{Direct Links}

AC-powered PCs connect with the datalogger's CS $1 / O$ port via an SC32B or SC-USB interface. These interfaces provide optical isolation. A battery-powered laptop can be attached to the CR 1000 's RS- 232 port via an RS-232 cable; no interface required.

\section{Keyboard Display}

The CR1000KD can be used to program the CR1000, manually initiate data transfer, and display data. The CR 1000 KD displays 8 lines $\times 21$ characters $(64 \times 128$ pixels) and has a 16-character keyboard. Custom menus are supported allowing customers to set up choices within the datalogger program that can be initiated by a simple "toggle" or "pick list".

\section{Ethernet}

Use of an NL120, NL115, or NL100 interface enables the CR 1000 to communicate over a local network or a dedicated Internet connection via TCP/IP. The NL115 can also store data on a CompactFlash card.

\section{CD295 DataView II Display}

This two-line, 32-character LCD displays one real-time value, a description, and units. It is typically mounted in an enclosure lid, which allows customers to view the CR1000's data on-site without opening the enclosure.

\section{CompactFlash $^{\circ}$}

A CFM100 or NL115 module attached to a CR1000 can store data on a CompactFlash (CF) card. The PC reads the $\mathrm{CF}$ card using either the $\mathrm{CF} 1$ CompactFlash Adapter or a 17752 USB Reader/Writer. Please note that the CF card should be industrial-grade with a storage capacity of 2 Gbytes or less.

\section{PDAs}

Customers can set the CR1000's clock, monitor realtime data, retrieve data, graph data, and transfer CR 1000 programs via a PDA. PDAs with a Palm ${ }^{\mathrm{TM}}$ OS require PConnect software (purchased separately); PDAs with a Windows ${ }^{\circ}$ Pocket $\mathrm{PC} / \mathrm{W}$ indows Mobile OS require PConnectCE software (purchased separately).

\section{Satellite Transmitters}

Our NESDIS-certified GOES satellite transmitter provides one-way communications from a Data Collection Platform (DCP) to a receiving station. We also offer an Argos transmitter that is ideal for highaltitude and polar applications and a METEOSAT transmitter for European applications.

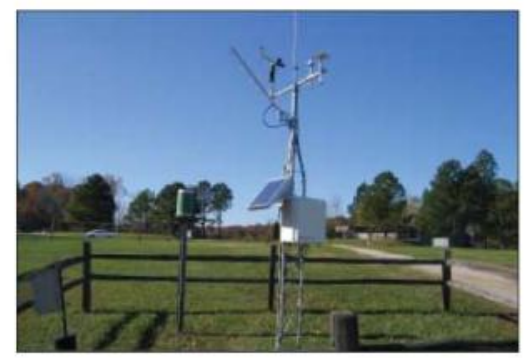

This station for the National Estuarine Research Reserve (NERR) in Virginia transmits data via our GOES satellite transmitter. 


\section{Channel Expansion}

Synchronous Devices for Measurement (SDMs) SDMs are addressable peripherals that expand the CR1000's measurement and control capabilities. For example, SDMs are available to add control ports, analog outputs, pulse count channels, interval timers, or even a CANbus interface to the system. Multiple SDMs, in any combination, can be connected to one CR1000 datalogger.

\section{Multiplexers}

Multiplexers increase the number of sensors that can be measured by a CR1000 by sequentially connecting each sensor to the datalogger. Several multiplexers can be controlled by a single CR1000. The CR1000 is compatible with the AM16/32B and AM25T.

\section{4-Channel Low Level AC Module}

The LLAC4 is a small peripheral device that allows customers to increase the number of available lowlevel ac inputs by using control ports. This module is often used to measure up to four anemometers, and is especially useful for wind profiling applications.

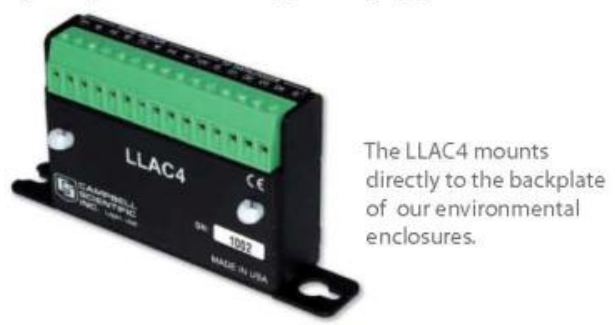

\section{Software}

Starter Software

Our easy-to-use starter software is intended for first time users or applications that don't require sophisticated communications or datalogger program editing. SCWin Short Cut generates straight-forward CR1000 programs in four easy steps. PC200W allows customers to transfer a program to, or retrieve data from a CR1000 via a direct communications link.

At www.campbellsci.com/downloads you can download starter software at no charge. Our Resource CD also provides this software as well as PDF versions of our brochures and manuals.

\section{Datalogger Support Software}

Our datalogger support software packages provide more capabilities than our starter software. These software packages contains program editing, communications, and display tools that can support an entire datalogger network.

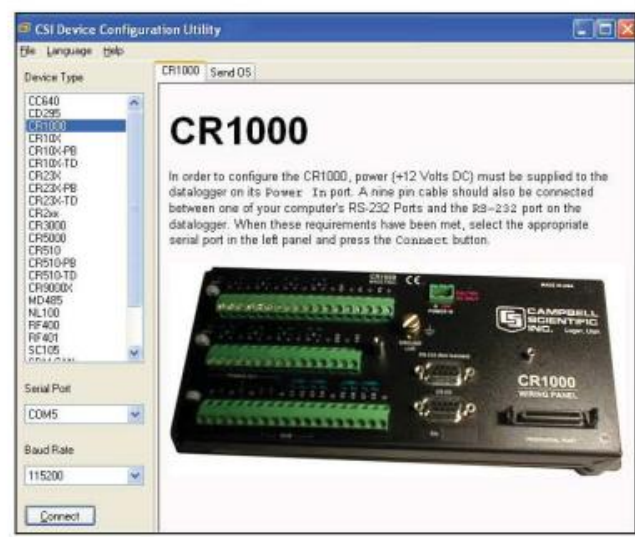

Our device configuration (DevConfig) utility is bundled with PC400, LoggerNet, and RTDAQ and can be downloaded, at no charge, from our Web site. DevConfig allows you to send new operating systems to the CR1000.

PC400, our mid-level software, supports a variety of telemetry options, manual data collection, and data display. For programming, it includes both Short Cut and the CRBasic program editor. PC400 does not support combined communication options (e.g., phone-to-RF), PakBus routing, or scheduled data collection.

LoggerNet is Campbell Scientific's full-featured datalogger support software. It is referred to as "fullfeatured" because it provides a way to accomplish almost all the tasks you'll need to complete when using a datalogger. It supports combined communication options (e.g., phone-to-RF), PakBus* routing, or scheduled data collection.

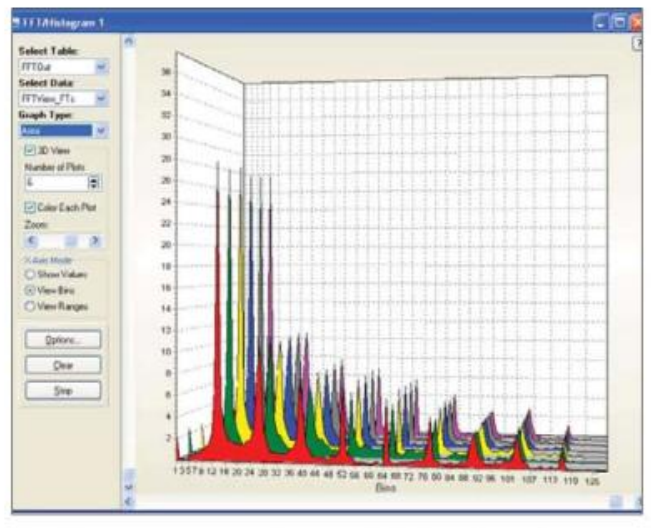

The CR1000 is also compatible with RTDAQ Real-Time Data Acquisition Software.. FFT is an example of the many real-time data displays offered by RTDAQ that allow you to view the measurements instantly. 


\section{Applications}

The measurement predision, flexiblility, long-term reliability, and economical price of the CR1 000 make it ideal for scientific, commercial, and industrial applications.

\section{Meteorology}

The CR1000 is used in long-term climatological monitoring, meteorological research, and routine weather measurement applications.

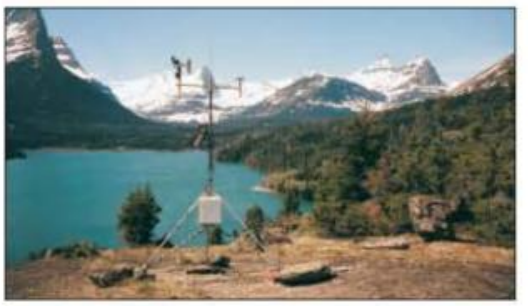

Our rugged, reliable weather station measures meteorological conditions at St Mary's Lake, Glacier National Park, MT:

Sensors the CR1000 can measure include:

- cup, propeller, and sonic anemometers

- tipping bucket rain gages

- wind vanes

- pyranometers

- ultrasonic ranging sensor

Agriculture and Agricultural Research

The versatility of the CR1000 allows measurement of agricultural processes and equipment in applications such as:

- plant water research

- canopy energy balance

- machinery performance

- plant pathology

- crop management decisions

- food processing/storage

- frost prediction

- irrigation scheduling

- integrated pest management
- thermistors, RTDs, and thermocouples

- barometric pressure sensors

- RH sensors

- cooled mirror hygrometers

\section{Wind Profiling}

Our data acquisition systems can monitor conditions at wind assessment sites, at producing wind farms, and along transmission lines. The CR1000 makes and records measurements, controls electrical devices, and can function as PLCs or RTUs. Because the datalogger has its own power supply (batteries, solar panels), it can continue to measure and store data and perform control during power outages.

Typical sensors for wind assessment applications include, but are not limited to:

- sonic anemometers

- three-cup and propeller anemometers (up to 10 anemometers can be measured by using two LI.AC4 peripherals)

- wind vanes

- temperature sensors

- barometric pressure

- wetness

- solar radiation

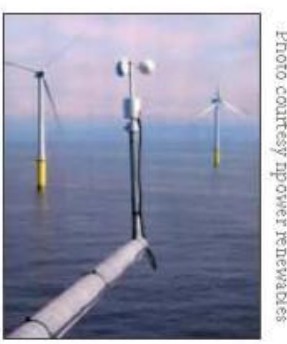

A. Campbell Scientific systern monitors an offshore wind farm in North Wales.
For turbine performance applications, the CR1000 monitors electrical current, voltage, wattage, stress, and torque.

\section{Soil Moisture}

The CR1000 is compatible with the following soil moisture measurement technologies:

- Soil moisture blocks are inexpensive sensors that estimate soil water potential.

- Matric water potential sensors also estimate soil water potential but are more durable than soil moisture blocks.

- Time-Domain Reflectometry Systems (TDR) use a reflectometer controlled by a CR1000 to accurately measure soil water content. Multiplexers allow sequential measurement of a large number of probes by one reflectometer, reducing cost per measurement.

- Self-contained water content reflectometers are sensors that emit and measure a TDR pulse.

- Tensiometers measure the soil pore pressure of irrigated soils and calculate soil moisture. 


\section{Air Quality}

The CR1000 can monitor and control gas analyzers, particle samplers, and visibility sensors. It can also automatically control calibration sequences and compute conditional averages that exclude invalid data (e.g., data recorded during power failures or calibration intervals).

\section{Road Weather/RWIS}

Our fully NTCIP-compliant Environmental Sensor Stations (ESS) are robust, reliable weather stations used for road weather/RWIS applications. A typical ESS includes a tower, CR1000, two road sensors, remote communication hardware, and sensors that measure wind speed and direction, air temperature, humidity, barometric pressure, solar radiation, and precipitation.

\section{Water Resources/Aquaculture}

Our CR1000 is well-suited to remote, unattended monitoring of hydrologic conditions. Most hydrologic sensors, including SDI-12 probes, interface directly to the CR1000. Typical hydrologic measurements:

- Water level is monitored with incremental shaft encoders, double bubblers, ultrasonic ranging sensors, resistance tapes, strain gage pressure transducers, or vibrating wire pressure transducers. Vibrating wire transducers require an AVW200series or another vibrating wire interface.

- Ionic conductivity measurements use one of the switched excitation ports from the CR1000.

- Samplers are controlled by the CR1000 as a function of time, water quality, or water level.

- Alarm and pump actuation are controlled through digital I/O ports that operate external relay drivers.

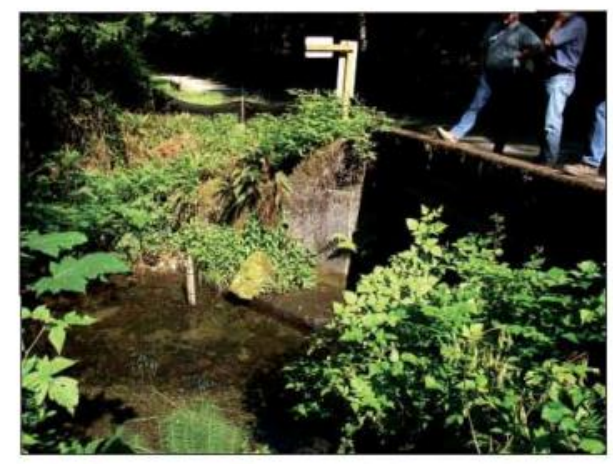

A turbidity sensor was installed in a tributary of the Cedar River watershed to monitor water quality conditions for the city of Seattle, Washington.

\section{Vehicle Testing}

This versatile, rugged datalogger is ideally suited for testing cold and hot temperature, high altitude, off-highway, and cross-country performance. The CR1000 is compatible with our SDM-CAN interface and GPS16X-HVS receiver.

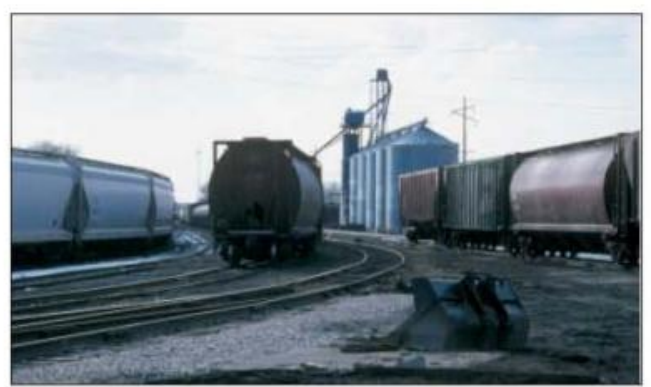

Vehicle monitoring includes not only passenger cars, but airplanes, locomotives, helicopters tractors, buses, heavy trucks, drilling rigs, racecars, and motorcycles.

The CR1000 can measure:

- Suspension-strut pressure, spring force, travel, mounting point stress, deflection, ride

- Fuel system-line and tank pressure, flow, temperature, injection timing

- Comfort control-ambient and supply air temperature, solar radiation, fan speed, ac on and off, refrigerant pressures time-to-comfort, blower current

- Brakes-line pressure, pedal pressure and travel, $\mathrm{ABS}$, line and pad temperature

- Engine-pressure, temperature, crank position, RPM, time-to-start, oil pump cavitation

- General vehicle-chassis monitoring, road noise, vehicle position and speed, steering, air bag hot/ cold soaks, wind tunnels, traction, CANbus, wiper speed and current, vehicle electrical loads

Other Applications

- Eddy covariance systems

- Wireless sensor/datalogger networks

- Mesonet systems

- Avalanche forecasting, snow science, polar, high altitude

- Fire weather

- Geotechnical

- Historic preservation 
CR1000 Specifications

\section{PROGRAM EXECUTION RATE}

$10 \mathrm{~ms}$ lo $30 \mathrm{~min}$. $10 \mathrm{~ms}$ increments

ANALOG INPUTS

8 differential (DF) or 16 single-ended (SE) individually configured. Channel expansion provided by AM16/32 and AM25T multiplexers

RANGES and RESOLUTION: Basic resolution (Basic Res) is the ADD resolution of a single conversion. Resolution of DF measurements with input reversal is half the Basic Res.

\section{with input reversal is haif the Basic Res.}

\begin{tabular}{|c|c|c|}
\hline \multirow[b]{2}{*}{ inoust } & \multicolumn{2}{|c|}{ Voise Voltage } \\
\hline & OF & Basic \\
\hline Range $(\mathrm{mV})^{1}$ & $\operatorname{Res}(\omega v)^{2}$ & Res (an) \\
\hline \pm 5000 & 667 & 1333 \\
\hline \pm 2500 & 333 & 667 \\
\hline \pm 250 & 333 & 66.7 \\
\hline \pm 25 & 333 & 6.7 \\
\hline \pm 75 & 1.0 & 2.0 \\
\hline \pm 2.5 & 0.33 & 0.67 \\
\hline
\end{tabular}

'Range coertead of 9\% exists on all ranges to guarante

that tull-scale values will not cause over-range.

${ }^{2}$ Resolution of DF measurements win input reversal:

ACCURACY ${ }^{3}$ :

$\pm(0.06 \%$ of reading + offsel $), 0^{\circ}$ 10 $40^{\circ} \mathrm{C}$

$\pm(0.12 \%$ of reading + offsel $),-25^{\circ}$ lo $50^{\circ} \mathrm{C}$

$\pm(0.18 \%$ of reading + oftsel $),-55^{\circ}$ lo $85^{\circ} \mathrm{C}$

${ }^{3}$ The sensor and measurement noise are not inoluded and

OHset for DF wfinput reversal $=1$ 5. Basic Res $+10 \mu \mathrm{V}$

Oftset for OF Wo irpu reversal $=3$. Basic Res $+2.0 \mu \mathrm{V}$

Ottsel for SE = 3 Dasio Ples +30 H'

INPUT NOISE VOLTAGE: For DF measurements

with input reversal on $\neq 2.5 \mathrm{mV}$ input range; digital

resolution dominates for higher ranges

$\begin{array}{ll}250 \mu \text { Integration } & 0.34 \mu \mathrm{N} \text { RMS } \\ 50 / 60 \mathrm{~Hz} \text { Integration: } & 0.19 \mu \mathrm{NMMS}\end{array}$

MINIMUM TIME BETWEEN VOLTAGE

MEASUREMENTS: Includes the measurement time

and comersion to engineering units. For

and conversion to enginering unils. For Voltage

signal for $0.25 \mathrm{~ms}$ or a full $16 \mathrm{fg} \mathrm{ms}$ or $20 \mathrm{~ms}$

cycle for $50.25 \mathrm{~ms}$ or a

cycle for $50 \% 0 \mathrm{~Hz}$ noise iejection. DF measure-

ments with inpul reversal incorporale two integra-
tions with reversed input polarities to reduce thermal

offset and common mode errors and therefore take

twice as long.

250 us Analog Integration: $\quad \sim 1 \mathrm{~ms} \mathrm{SE}$

$1 / 60 \mathrm{~Hz}$ Analog Integration: $\quad \sim 20 \mathrm{~ms} \mathrm{SE}$

$1 / 50 \mathrm{~Hz}$ Analog Integration: $\sim 25 \mathrm{~ms} \mathrm{SE}$

COMMON MODE RANGE: \pm 5 V

DC COMMON MODE REJECTION: $>100 \mathrm{~dB}$

NORMAL MODE REJECTION. $70 \mathrm{~dB} \oplus 60 \mathrm{~Hz}$ when using $60 \mathrm{~Hz}$ rejection

SUSTAINED INPUT VOLTAGE W/O DAMAGE: $\pm 16 \mathrm{Vdc} \max$

INPUT CURRENT: \pm 1 nA typical, \pm 6 nA max a $50^{\circ} \mathrm{C}, \pm 90 \mathrm{NA} \otimes 85^{\circ} \mathrm{C}$

INPUT RESISTANCE: 20 Gohms typical

ACCURACY OF BUILTIN REFERENCE JUNCTION

THERMISTOR (for thermocouple measurements)

$\pm 0.3^{\circ} \mathrm{C},-25^{\circ}$ 10 $50^{\circ} \mathrm{C}$

$\pm 0.8^{\circ} \mathrm{C},-55^{\circ}$ to $85^{\circ} \mathrm{C}$ (-XT only)

ANALOG OUTPUTS

3 swilched voltage, active only during measurement.

one al a lime.

RANGE AND RESOLUTION: Voltage outputs programmable between $\pm 2.5 \mathrm{~V}$ with $0.67 \mathrm{mV}$ resolution.

ACCURACY $\pm(0.06 \%$ of setting $+0.8 \mathrm{mV}), 0^{\circ}$ to $40^{\circ} \mathrm{C}$

$\pm(0.12 \%$ of selling $+0.8 \mathrm{mV}),-25^{\circ}$ lo $50^{\circ} \mathrm{C}$

$\pm(0.18 \%$ of setting $+0.8 \mathrm{mV}), 55^{\circ}$ to $85^{\circ} \mathrm{C}$ (XT only)
CURRENT SOURCING/SINKING: $\pm 25 \mathrm{~mA}$

\section{RESISTANCE MEASUREMENTS}

MEASUREMENT TYPES: The CR1000 provides

bridges, and 2-, 3-, and 4-wire hall bridges

Precise, dual polarity excitation using any of the

3 switched voltage excitations eliminales dc errors.

RATIO ACCURACY ${ }^{3}$. Assuming excitation voltage of

at least $1000 \mathrm{mV}$, not including bridge resistor error.

$\pm(0.04 \%$ of voltage reading + oftseb $), V_{,}$

The sensor and measurement noise are not included and

the offlsets are the following

Othet tor DF winput reversal $=1.5$. Easic Res $+10 \mu \mathrm{V}$ Ofliset bor DF wio mout reversal $=3.8$.

Offset values are reduced by a factor of 2 when

excilation reversal is used.

\section{PERIOD AVERAGING MEASUREMENTS}

The average period for a single cycle is delermined by for cyecilied the specined namber of cycles to be measured, $h$

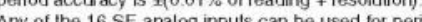
Any or his 16 SE analog inpuls can be used ior period averaging Signal limiting are lypically required for the $\mathrm{SE}$ analog channe

INPUT FREQUENCY RANGE

input Signal (peak to peak) ${ }^{4}$ Min. Max

Range Min Max PuiseW Freq

$+2500 \mathrm{mV} \quad \overline{500 \mathrm{mV}} \overline{10 \mathrm{~V}} \frac{\mathrm{m}}{2.5 \mu \mathrm{s}} 200 \mathrm{kHz}$

$+250 \mathrm{mV} \quad 10 \mathrm{mV} \quad 2 \mathrm{~V} \quad 10 \mathrm{\mu s} \quad 50 \mathrm{kHz}$

$+25 \mathrm{mV} \quad 5 \mathrm{mV} \quad 2 \mathrm{~V} \quad 62 \mu \mathrm{s} \quad 8 \mathrm{kHz}$

$+25 \mathrm{mV} \quad 2 \mathrm{mV} \quad 2 \mathrm{~V} \quad 100 \mu \mathrm{s} \quad 5 \mathrm{kHz}$

4The signal is centered at the datalogger ground.

The maximum frequency - 1RTTwice Minimum Pulse Width)

tor $50 \%$ of duty oycle signals

\section{PULSE COUNTERS}

Two 24-bit inpuls selectable for switch closure, highfrequency pulse, or low-tevel AC.

MAXIMUM COUNTS PER SCAN: $16.7 \times 10^{6}$

SWITCH CLOSURE MODE:

Minimum Swikh Closed Time: $5 \mathrm{~ms}$
Minimum Swilch Open Time: $6 \mathrm{~ms}$

Max. Bounce Time: $1 \mathrm{~ms}$ open W/o being counted

HIGH-FREQUENCY PULSE MODE:

Maximum Input Frequency: $250 \mathrm{kHz}$

Maximum Input Voltage: $\pm 20 \mathrm{~V}$

Voltage Thresholds Count upon transition from

below $0.9 \mathrm{~V}$ to above $2.2 \mathrm{~V}$ after input filter with

$1.2 \mu$ s time constant.

LOW-LEVEL AC MODE: Internal AC coupling removes

$A C$ ollsets up to $\pm 0.5 \mathrm{~V}$.

Input Hysteresis: $16 \mathrm{mV} \otimes 1 \mathrm{~Hz}$

Maximum ac Input Voltage: $\pm 20 \mathrm{~V}$

Minimum ac Input Voltage:

Sine wave ( $m$ V RMS

$$
\begin{gathered}
20 \\
200 \\
2000
\end{gathered}
$$

$\frac{\text { Range }(\mathrm{Hz})}{1.0 \text { to } 20}$

0.510200

5000

0.3 to 20,000

DIGITAL I/O PORTS

8 ports software selectable, as binary inputs or contro outputs. C1-C8 also provide edge liming, subroutine interrupts/wake up, switch closure pulse counting, high frequency pulse counting, asynchronous communications (UART) SDI-12 communications, and SDM communications

HIGH-FREQUENCY PULSE MAX: $400 \mathrm{KHZ}$
SWITCH CLOSURE FREQUENCY MAX: $150 \mathrm{HZ}$

OUTPUT VOLTAGES (no load): high $5.0 \mathrm{~V} \pm 0.1 \mathrm{~V}$

low <0.1

OUTPUT RESISTANCE: $330 \mathrm{ohms}$

INPUT STATE: high 3.8 to $16 \mathrm{~V}$ : low -8.0 to $1.2 \mathrm{~V}$

NPUT HYSTERESIS: $14 \mathrm{~V}$

INPUT RESISTANCE: 100 kohms

SERIAL DEVICE/RS-2 22 SUPPORT: 0 to $5 \mathrm{~V}$ UART

\section{SWITCHED $12 \mathrm{~V}$}

One independent $12 \mathrm{~V}$ unregulated sources switched on and off under program control. Thermal fuse hol (a) $85^{\circ} \mathrm{C}$

SDI-12 INTERFACE SUPPORT

Control ports $1,3,5$, and 7 may be configured for SDI-12 asynchronous communications. Up to ten SDI-12 sensors are supporled per port. II meets

SDI-12 Standard version 1.3 for datalogger mode.

CE COMPLIANCE

STANDARD(S) TO WHICH CONFORMITY IS DECLARED: IEC613262002

CPU AND INTERFACE

PROCESSOR: Renesas H8S 2322 (16-bit CPU with 32-bit internal $\cos \theta$ )

PROTOCOLS SUPPORTED: PakBus, Modbus, DNP3 MEMORY: 2 Mbytes of Flash for operating system;

4 Mbyles of battery-backed SRAM for CPU usage.

program storage and dala slorage

SERIAL INTERFACES: CS VO port is used to interlace with Campbell Scientific peripherals, RS-232 DCE port is for battery-powered computer or nonCSI modem connection

PARALLEL INTERFACE: 40-pin intertace for attaching CompactFlash or Ethernet peripherals

BAUD RATES: Selectable from $300 \mathrm{bps}$ to $1152 \mathrm{kbps}$ ASCll protocol is one start bit, one stop bit, eight data bits, and no parity.

CLOCK ACCURACY: \pm 3 min. per year

SYSTEM POWER REQUIREMENTS

VOLTAGE: 9.6 to $16 \mathrm{Vdc}$ (reverse polarity protected)

TYPICAL CURRENT DRAIN

Sleep Mode: $0.6 \mathrm{~mA}$

$1 \mathrm{~Hz}$ Scan (8 ditt meas, $60 \mathrm{~Hz}$ rei., 2 pulse meas) W/AS-232 communication $19 \mathrm{~mA}$ W/o RS-232 communication: $42 \mathrm{~mA}$

$1 \mathrm{~Hz}$ Scan (8 ditt. meas, $250 \mu \mathrm{s}$ integ., 2 pulse meas.)

W/RS-232 communication: $16.7 \mathrm{~mA}$ W/o RS-232 communication: $1 \mathrm{~mA}$

$100 \mathrm{~Hz}$ Scan (4 dift meas, 250 us integ. W/RS-232 communication: $27.6 \mathrm{~mA}$ w/o RS-232 communication: $162 \mathrm{~mA}$

CR100OKD CURRENT DRAIN.

Inactive negligible

Acke wo backight. $7 \mathrm{~mA}$

EXTERNAL BATTERIES: 12 Vdc nominal

PHYSICAL

MEASUREMENT \& CONTROL MODULE SIZE: $85^{\prime \prime} \times 3.9^{\prime \prime} \times 0.85^{*}(21.6 \times 9.9 \times 2.2 \mathrm{~cm})$

CR100OWP WIRING PANEL SIZE: $9.4^{*} \times 4^{*} \times 24^{*}$

$(23.9 \times 10.2 \times 6.1 \mathrm{~cm})$; additional clearance required lor serial cable and sensor leads.

WEIGHT: $2.1 \mathrm{lbs}(1 \mathrm{~kg})$

WARRANTY

3-years against defects in materials and workmanship.

Electrical specifications are valid over a $-25^{\circ}$ to $+50^{\circ} \mathrm{C}$ range unless otherwise specified; non-condensing environment required. To maintain electrical specifications, Campbell Scientific recommends recalibrating dataloggers every two years. We recommend that the system configuration and critical specifications are confirmed with Campbell Sctentific before purchase. 


\section{Appendix N: Campbell Scientific Raven XT Cellular Modem Data Sheet}

\section{RavenXT-series}

Sierra Wireless Airlink Digital Cellular Modems

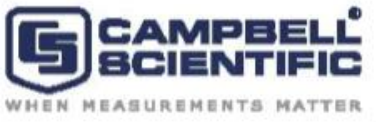

The RavenXT-series are full-duplex modems that transmit data to the local cellular tower. A PC retrieves the data from the cellular tower via the Internet ${ }^{1}$. Internet communications provide faster communication rates and eliminate dialing delays and long distance fees.

The following modems are offered:

- RavenXTA - Code Division Multiple Access (CDMA) modem configured for Alltel networks

- RavenXTV-CDMA modem configured for Verizon Wireless networks

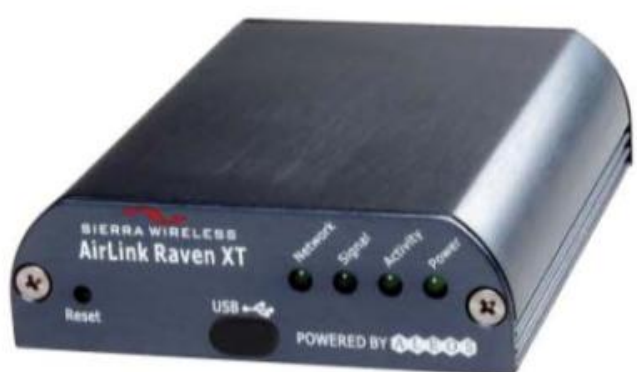

- RavenXTG-General Packet Radio Service (GPRS) modem configured for AT\&T networks

\section{Features}

- Eliminates the dialing delays and long distance fees that land-line phone modems experience

- Allows simultaneous communications with multiple dataloggers in the network

- Housed in a rugged aluminum case

- Operates over a wide operating temperature range (see specifications)

\section{Cellular Coverage}

Prior to purchase of the digital cellular modem, ensure that there is a CDMA or GPRS network with coverage at the datal ogger site. For the RavenXTA and RavenXTV, you'll need to contact Alltel or Verizon, and ask them about covererage. For the RavenXTG, a coverage map is available at: www.wireless.attcom/coverageviewer/
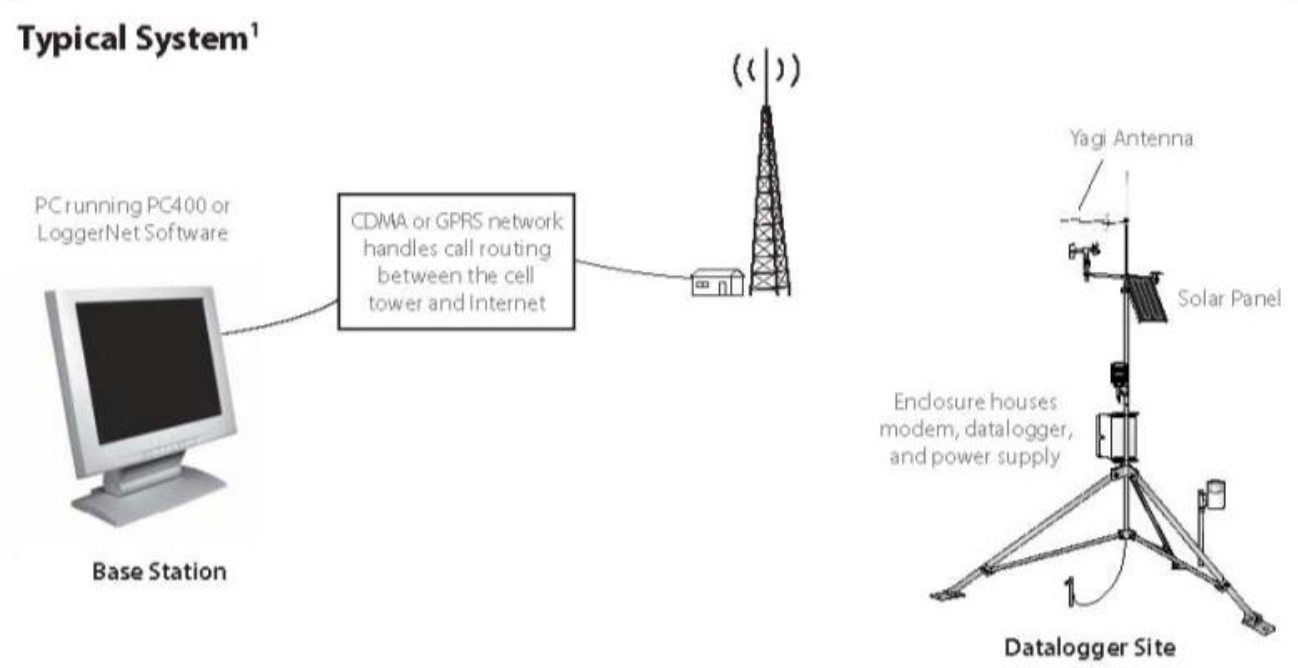

'The RavenXTA and RavenXTV use $2 x R T T / E V D O$ to communicate over the Internet. The RavenXTA and RavenXTV can also use IS-95 to communicate over standard telephone ines. Contact Campbell Scientific for system requirements if using IS-95. 


\section{Establishing Cellular Service}

RavenXTA \& Raven XTV

Contact Alltel or Verizon (1-888-384-1775) and setup an account. When setting up the account, you will need the ESN number, which is listed on the modem's label. To use 1xRTT/EVDO, you should ask for the Broadband Plan, and either a static or a dynamic IP account. A static account ${ }^{2}$ is often the best choice.

When using the RavenXTA, you will also need to ask for the Mobile Directory Number (MDN), Mobile Identification Number (MIN), and SID. If you do not ask, Alltel may only give you the MDN. You need to know these numbers to program your RavenXTA.

\section{RavenXTG}

Call AT\&T at 1-800-331-0500 and ask for an unrestricted data account for a GPRS modem. Either a static IP account ${ }^{2}$ or a dynamic IP account ${ }^{3}$ needs to be established. AT\&T will provide a SIMM card for each modem. In some cases the SIMM card can be picked up at a local AT\&T store. The SIMM card must be installed inside of the modem.

\section{Datalogger Site Equipment}

\section{Digital Cellular Modem}

The RavenXTA, RavenXTV, and RavenXTG are shipped with a power cable, our Resource $C D$, and a CD containing the Airlink software and the Airlink manual. The modems are configured using the following software:

- Airlink AceManager software-activates the modem and configures the generic parameters of the modem.

- Campbell Scientific's Raven CDMA Template (RavenXTA, RavenXTV) or Raven GPRS Template (RavenXTG) - used with Airlink AceManager software to configure the modem. The template sets up the Raven serial interface, which is specific to Campbell Scientific systems. The Raven CDMA Template and Raven GPRS Template are available, at no charge, from: www.campbellsci.com/downloads

Network connection information can be viewed using the Airlink AceManger or Airlink AceView software.

\section{Datalogger Connections}

All of our contemporary and many of our retired dataloggers are compatible. The datalogger connects with the modem using one of the following devices:

- 18663 Null Modem Cable - connects the modem directly to the datalogger's RS-232 port. This cable is the only option available for connecting the modem to a CR200-series datalogger.

- SC105 DCE Interface-connects the modem to the datalogger's CS I/O port via an SC12 cable. The $\mathrm{SC} 105$ is recommended for $\mathrm{PAKBUs}^{\bullet}$ dataloggers when the RS-232 port is unavailable.

- SC932A DCE Interface-connects the modem to the datalogger's CS I/O port via an SC12 cable. The SC932A is recommended for mixed-array dataloggers when the RS-232 port is unavailable.

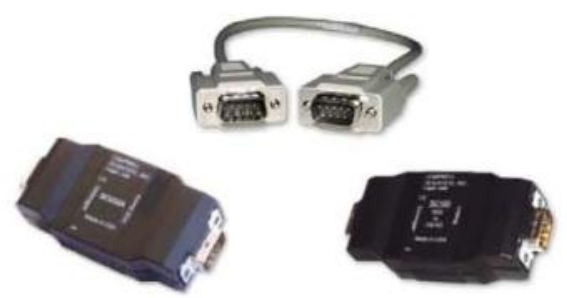

The datalogger attaches to the modem via the SC932A DCE Interface (left), 18663 Null Modem Cable (center), or SC105 DCE Interface. The best choice for your application depends on the datalogger used.

\section{Power Considerations}

A power cable included with the modem connects to the datalogger's $12 \mathrm{~V}$ or switched $12 \mathrm{~V}$ terminal. Connection to the switched $12 \mathrm{~V}$ terminal allows the datalogger to switch power to the modem during scheduled transmission intervals, thereby conserving power. When using the switched $12 \mathrm{~V}$ terminal, the modem can be powered with a BP12 battery, $\mathrm{CH} 100$ regulator, and SP10 solar panel. For help on analyzing your system's power requirements, refer to our Power Supply product literature or application note.

${ }^{2} A$ static IP account eliminates the need for a third party Dynamic Domain Name System (DDNS) such as IP manager. The DDNS transiates the domain name to a dymamic IP address so that the modem can be contacted as if it had a static IP address.

"For the RavenXTG, a dynamic account can be established by asking ATd T to add feature code "G821" to the account. Feature Code G821 configures the account for the "Internet" Access Point Name (APN), and the device to "Mobile Terminated", which makes the modem accessible by LoggerNet over the Internet. Feature Code G821 may be added after the account has been set up.

Another alternative for the RavenXTG is to have ATe $T$ setup a custom APN, which will take four to six weeks and cost about $\$ 1000.00$. A custom APN may offer more efficient routing, and better security. 
Antennas

A choice of four antennas is offered for the modems. Contact an Applications Engineer for help in determining the best antenna for your application.

- 218310 dBd, 1/2 Wave Dipole Whip Antennasupports the $800 \mathrm{MHz}$ band. It is intended for locations that have strong cellular coverage. This antenna attaches directly to the modem's SMA connector and must reside in an environmental enclosure or building.

- $182851 \mathrm{dBd}$, Omnidirectional Antenna-covers both the $800 \mathrm{MHz}$ and $1.9 \mathrm{GHz}$ bands. It includes a mounting bracket for attaching the antenna to a crossarm, tripod, tower, or pole. Connection to the modem requires either a 2184712 -foot cable or a COAXSMA-L cable (see Antenna Cables).

- $20679800 \mathrm{MHz} / 0 \mathrm{dBd} \& 1.9 \mathrm{GHz} / 3 \mathrm{dBd}$ Omnidirectional Antenna -includes a mounting bracket for attaching the antenna to a crossarm, tripod, tower, or pole. Connection to the modem requires either a 2184712 -foot cable or a COAXSMA-L cable (see Antenna Cables).

- 105309 dBd, Yagi Antenna-supports the $800 \mathrm{MHz}$ band and is intended for sites near the edge of the cellular coverage. It includes a bracket for attachment to a mast or pole (outer diameter of up to $\left.1.5^{n}(3.8 \mathrm{~cm})\right)$. Some sites may require the CM230 mount (see Adjustable Angle Mounting Kit). The antenna connects with the modem using either the 2184712 -foot cable or the COAXSMA-L cable (see Antenna Cables).

Antenna Cables

One of the following cables must be ordered when using a 18285,20679 , or 10530 antenna. Both cables have a type $\mathrm{N}$ male connector on the "antenna end" and an SMA connector on the "transceiver end." They differ in their length:

- 21847 Antenna Cable with 12-foot Length

- COAXSMA-L Antenna Cable with User-specified Length-enter cable length, in feet, after the $\mathrm{L}$. Length should not exceed $20 \mathrm{ft}(6 \mathrm{~m})$.

Adjustable Angle Mounting Kit

The CM230 Adjustable Angle Mounting Kit allows the 10530 Yagi antenna to be aimed at the service provider's antenna.
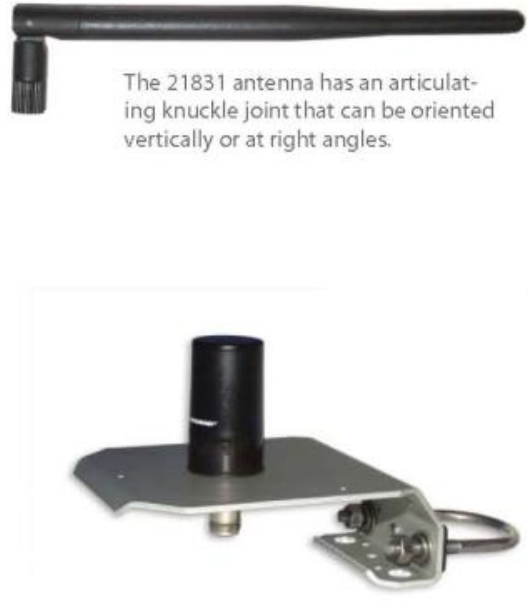

The 18285 antenna can be used for many of our applications.

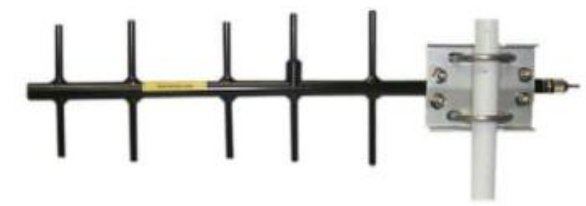

The 10530 Yagi antenna is intended for longer transmission distances.

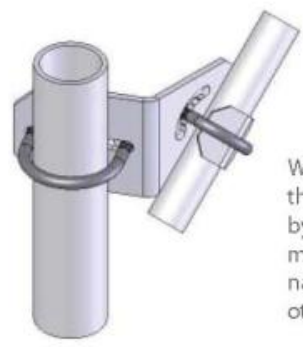

When using the CM230, fix the declination of the antenna by tightening the $\mathrm{u}$-bolt that mounts on the mast. The inclination is then adjusted with the other set of $u$-bolts and nuts. 
Enclosures and Mounting Bracket

An ENC12/14, ENC14/16, or ENC16/18 environmental enclosure can house the modem, datalogger, and power supply. The modem is secured to the enclosure's backplate via the 14394 Mounting Bracket.

\section{Base Station Requirements}

- PC running PC400 or LoggerNet Datalogger Support Software.

- Access to the Internet.

\section{Specifications}

\begin{tabular}{|c|c|c|}
\hline & RavenXTA \& RavenXTV & RavenXTG \\
\hline Technology & $\begin{array}{l}\text { CDMA 1xRTT, EVDO Rev. A, CDMA IS-95, } \\
\text { dual band }\end{array}$ & GPRS (MS-12), quad band \\
\hline Bands & $\begin{array}{c}\text { Dual band: } 800 \mathrm{MHz} \text { Cellular, } \\
1900 \mathrm{MHz} \text { PCS }\end{array}$ & $\begin{array}{r}\text { Quad band: } 850 / 1900 \mathrm{MHz} ; \\
900 / 1800 \mathrm{MHz}\end{array}$ \\
\hline Transmit Frequency & 1850 to $1910 \mathrm{MHz}$ and 824 to $849 \mathrm{MHz}$ & $\begin{aligned} 850 / 1900 \mathrm{MHz}: & 824 \text { to } 849 \mathrm{MHz} \\
& 1850 \text { to } 1910 \mathrm{MHz} \\
900 / 1800 \mathrm{MHz}: & 890 \text { to } 915 \mathrm{MHz} \\
& 1710 \text { to } 1785 \mathrm{MHz}\end{aligned}$ \\
\hline Transmit Power & $1.0 \mathrm{~W}$ for $1900 \mathrm{MHz} ; 0.8 \mathrm{~W}$ for $850 \mathrm{MHz}$ & $1.0 \mathrm{~W}$ for $1900 \mathrm{MHz} ; 0.8 \mathrm{~W}$ for $850 \mathrm{MHz}$ \\
\hline Receiver Frequency & 1930 to $1990 \mathrm{MHz}$ and 869 to $894 \mathrm{MHz}$ & $\begin{aligned} 850 / 1900 \mathrm{MHz}: & 869 \text { to } 894 \mathrm{MHz} \\
& 1930 \text { to } 1990 \mathrm{MHz} \\
900 / 1800 \mathrm{MHz}: & 935 \text { to } 960 \mathrm{MHz} \\
& 1805 \text { to } 1880 \mathrm{MHz}\end{aligned}$ \\
\hline CDMA or GPRS Throughput & up to $80 \mathrm{kbps}$ (CDMA) & up to $70 \mathrm{kbps}$ (GPRS) \\
\hline RS-232 Data Rates & 1200 bps to $115.2 \mathrm{kbps}$ & 1200 bps to $115.2 \mathrm{kbps}$ \\
\hline Serial Interface & RS-232, DB9-F & RS-232, DB9-F \\
\hline Serial Protocols & AT Commands, PPP, SLIP, UDP/IP, TCP/IP & AT Commands, PPP, SLIP, UDP, TCP \\
\hline RF Antenna Connector & $50 \mathrm{Ohm} \mathrm{SMA}$ & $50 \mathrm{Ohm} \mathrm{SMA}$ \\
\hline Input Current Range & 50 to $250 \mathrm{~mA}$ & 40 to $250 \mathrm{~mA}$ \\
\hline Typical Current Drain (at 12 Vdc) & $\begin{array}{l}50 \mathrm{~mA} \text { dormant (idle for } 10 \text { to } 20 \text { seconds), } \\
120 \mathrm{~mA} \text { transmit/receive }\end{array}$ & $\begin{array}{l}50 \mathrm{~mA} \text { dormant (idle for } 10 \text { to } 20 \text { seconds), } \\
120 \mathrm{~mA} \text { transmit/receive }\end{array}$ \\
\hline Input Voltage Range & 6 to $28 \mathrm{Vdc}$ & 6 to $28 \mathrm{Vdc}$ \\
\hline Operating Temperature Range & $-30^{\circ}$ to $+70^{\circ} \mathrm{C}$ & $-30^{\circ}$ to $+65^{\circ} \mathrm{C}$ \\
\hline Operating Humidity Range & $5 \%$ to $95 \% \mathrm{RH}$ non-condensing & $5 \%$ to $95 \%$ RH non-condensing \\
\hline Status LEDs & Power, Network, Signal, Activity & Power, Network, Signal, Activity \\
\hline Dimensions & $3^{\circ} \mathrm{W} \times 1^{\prime \prime} \mathrm{D} \times 4^{\circ} \mathrm{L}(7.6 \times 2.5 \times 10 \mathrm{~cm})$ & $3^{\prime \prime} \mathrm{W} \times 1^{\prime \prime} \mathrm{D} \times 4^{\prime \prime} \mathrm{L}(7.6 \times 2.5 \times 10 \mathrm{~cm})$ \\
\hline Weight & $<1 \mathrm{lb}(<0.5 \mathrm{~kg})$ & $<1 \mathrm{lb}(<0.5 \mathrm{~kg})$ \\
\hline
\end{tabular}




\section{Appendix 0: Campbell Scientific LoggerNet Software Data Sheet}

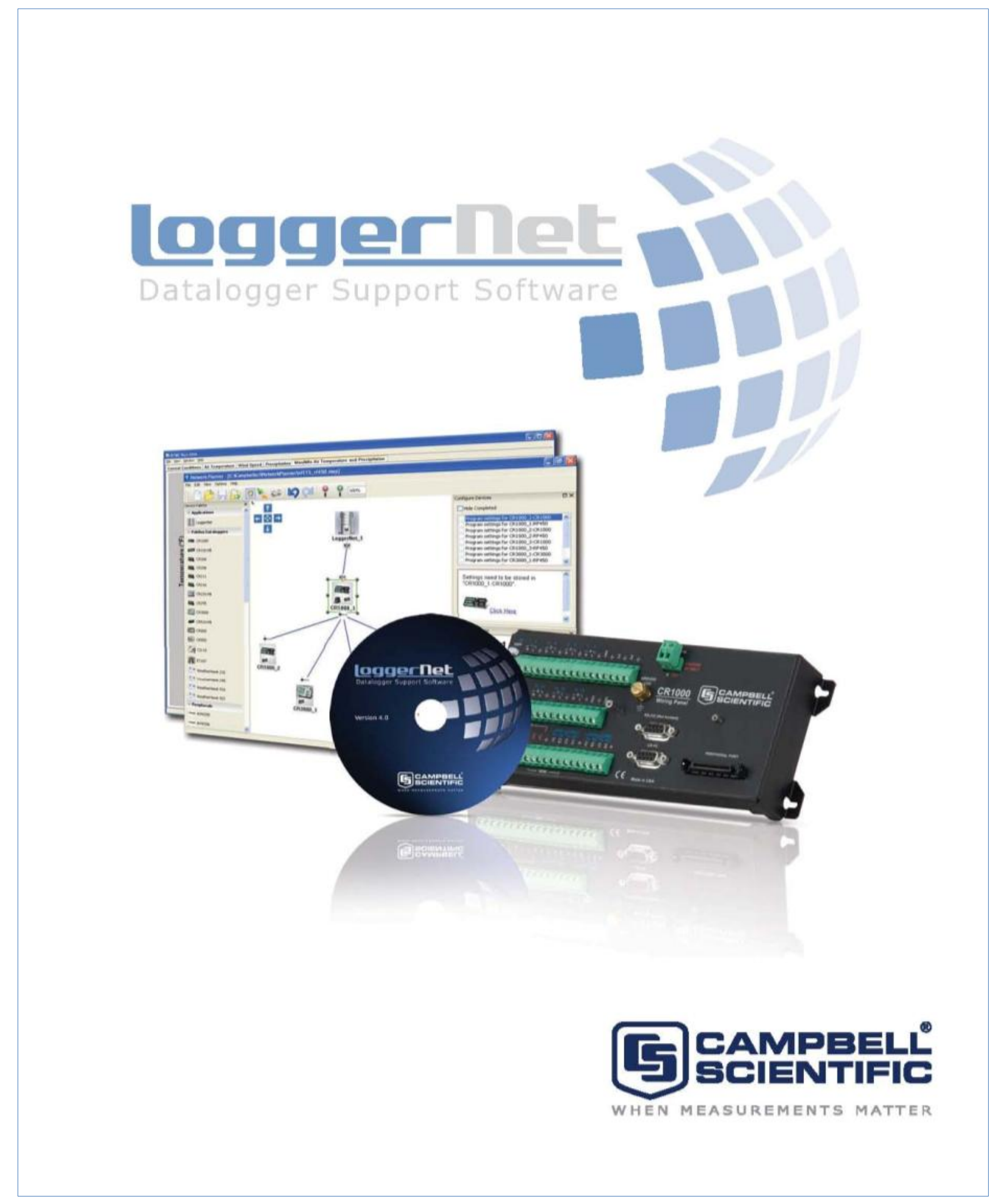




\section{LoggerNet 4.0 series Datalogger Support Software}

LoggerNet version 4.0 is Campbell Scientific's latest offering in its suite of datalogger support software packages. LoggerNet 4.0 is still buitt on a solid client/server architecture that allows data to be served to multiple LoggerNet clients simultaneously, while featuring a newly designed user-interface and new or updated clients. While the LoggerNet server does the work of communicating with the datalogger network, the client applications are used to manage the network. This inchudes network setup, configuration, monitoring, and backup; datalogger programming, maintenance, and data collection; and real-time or historical data display.

\section{Toolbar \& Navigation}

LoggerNet's Toolbar starts the LoggerNet server and is used to navigate to all the client applications. It has been redesigned to offer quick access to all LoggerNet clients. A new Favorites category has been added to the Toolbar. With the click of a button the Toolbar can be restored down to Favorites view, allowing easy access to those clients most important to your application.

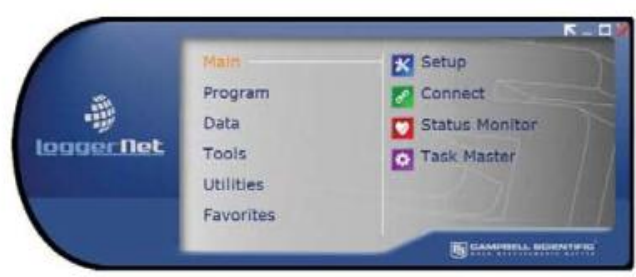

The Toolbar's Full view is shown on top right. The Favorites view reduces the size of the toolbar and provides access to your most-used applications.
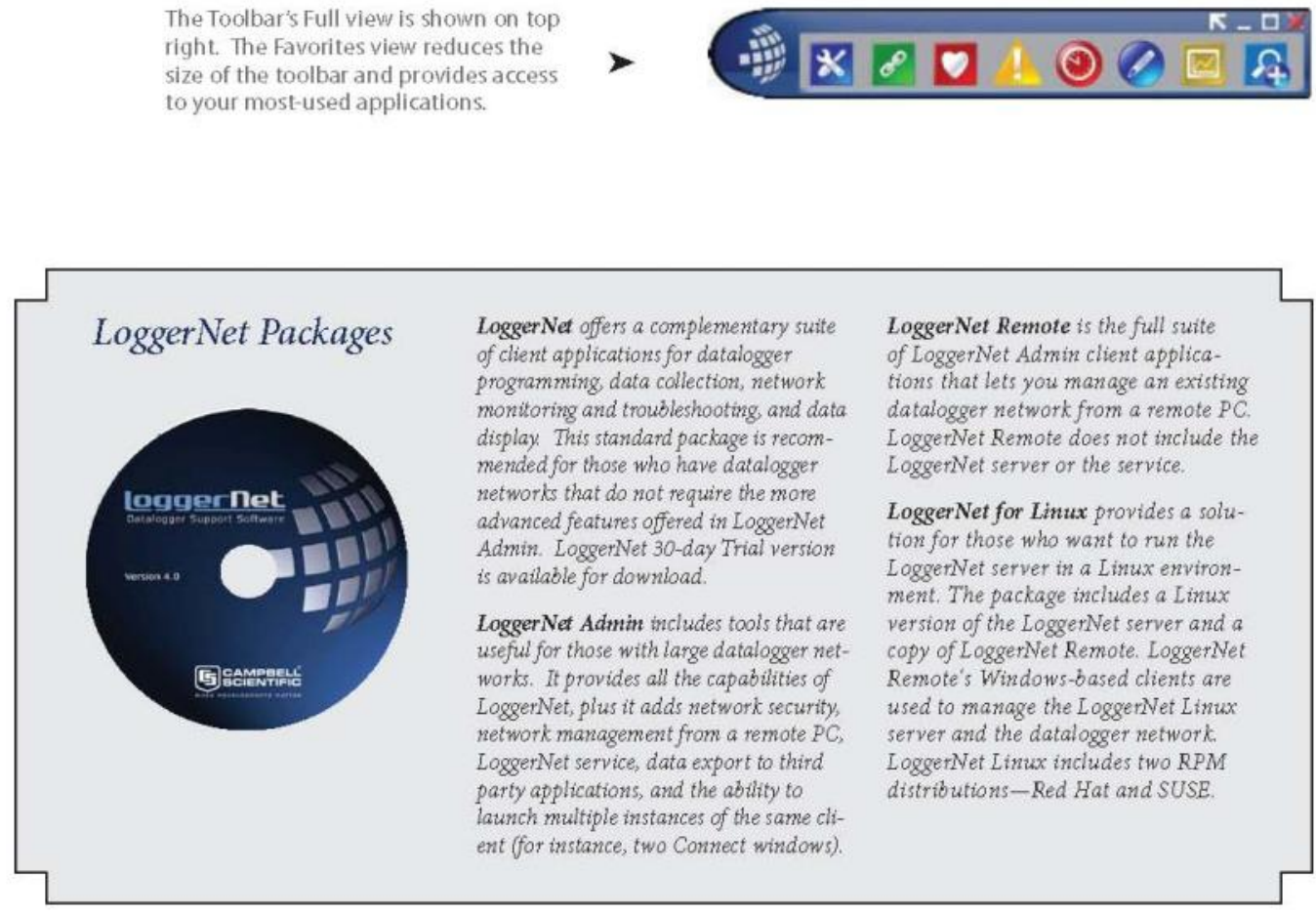


\section{Setup \& Network Configuration}

\section{Setup}

Setup and EZSetup have been combined into one application, providing you with a choice in setting up the datalogger network. EZSetup walks you through the process for each station step-by-step, while Setup allows you more flexibility and access to more advanced features. You can toggle between the two by pressing a button. When in Setup mode, you can choose to view all devices in the network or the datalogger stations only, to make finding a particular station easy.

New features for Setup include the ability to configure a scheduled datalogger network backup, the Image Files tab for scheduling retrieval of image or other files from a datalogger, the Notes tab for creating custom notes for a station, and the ability to cut and paste single devices or a branch of the network to another location in the network map. New file output options include support for CSIXML and incrementing file names with each data collection from a datalogger.

\section{Task Master}

The Task Master allows you to set up events (e.g., running a batch file) that occur on a schedule or based on some trigger event such as a successful or failed data collection attempt to a datalogger. LoggerNet 4.0's Task Master now supports sending files via FTP/SFTP and a new "After File Closed" trigger event. (Task Master not supported in LoggerNet Remote or LoggerNet Linux).

\section{Network Planner}

LoggerNet 4.0 includes the Network Planner, a new tool for designing your PakBus datalogger network. First, PakBus devices are selected from a list and placed on the network design palette. You then use a link tool to draw lines indicating the physical communication links between devices, and an activity tool to indicate activities that will take place between devices (schedule data collection, call-back, one-way data messages, or get/set variable transactions between dataloggers).

The Network Planner calculates the optimum settings for each device in the network and then allows you to send these settings to the device, or save them for later download via the Network Planner or the Device Configuration utility. If any change is made to a device in the network, that change is propagated to any other devices in the network that are affected. The configuration can then be imported into LoggerNet's network map, providing a start-to-finish solution for PakBus network setup.

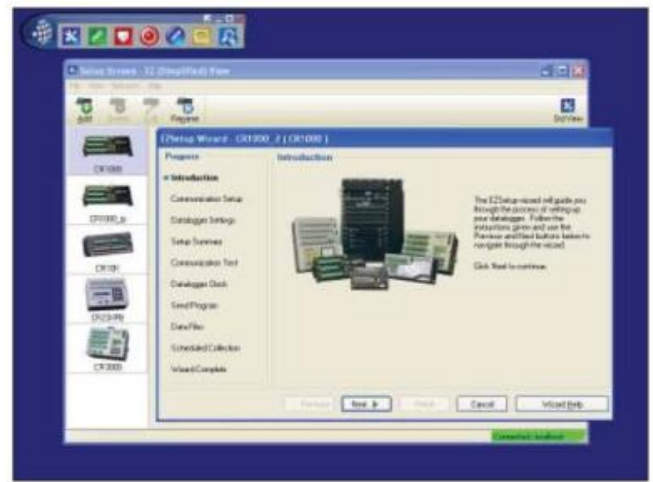

Select the EZSetup to walk through datalogger setup step-by-step.

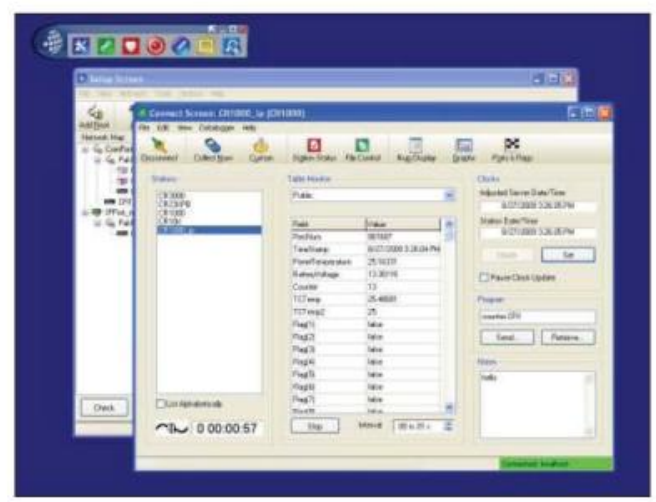

The standard Setup screen along with the Connect screen are shown above. Notes entered in the Setup screen are displayed in the Connect screen (lower right corner).

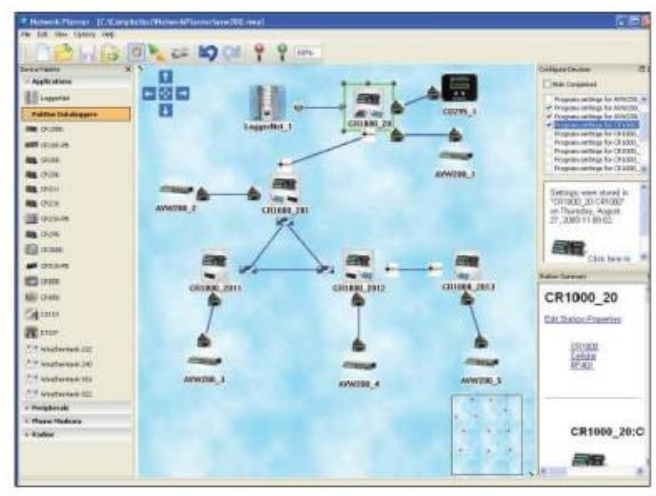

The Network Planner generates device settings and configures the LoggerNet network map for PakBus networks. 


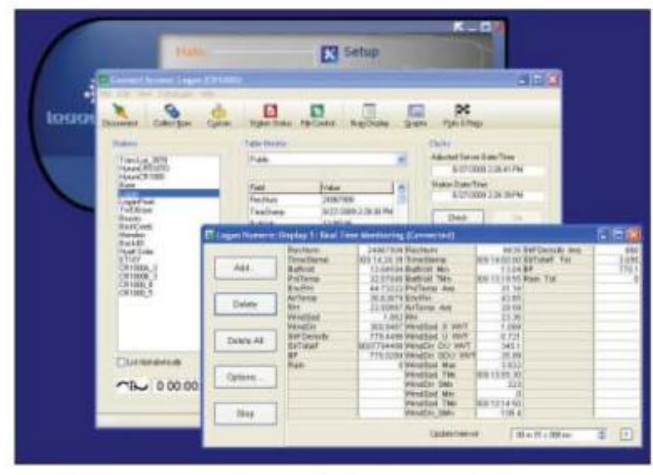

The Connect window's numerical monitor displays real-time and historical data.

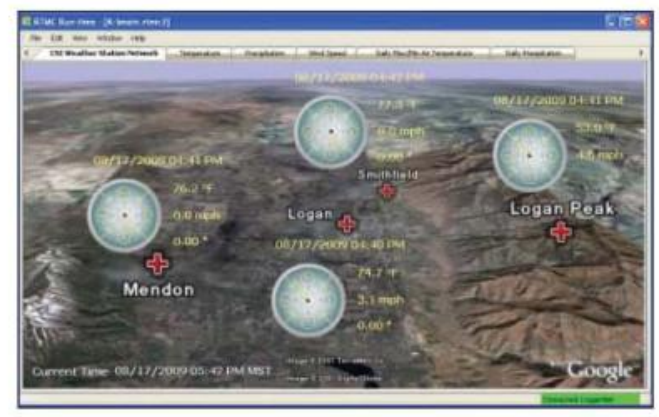

RTMC simultaneously displays data from any number of dataloggers on one display.

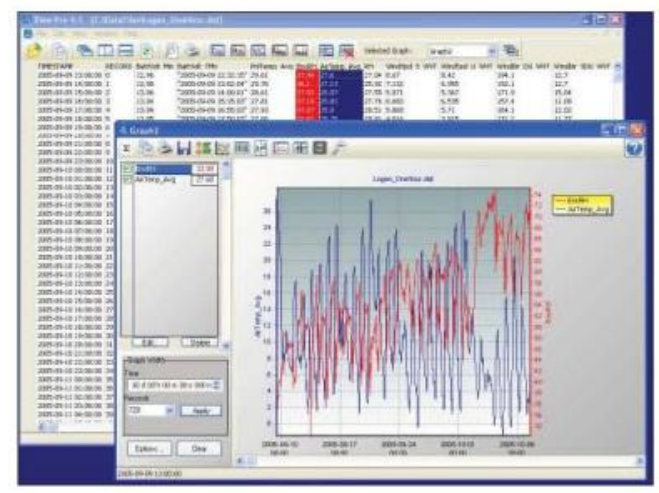

Vew Pro displays historical data in a tabular or graphical format.

\section{Connect \& Datalogger Status}

Connect

Connect allows you to perform maintenance on a station (including sending a program and setting the clock) while also viewing important datalogger status information, managing program and other files on a datalogger's CPU, and displaying numerical and graphical data. A new Table Monitor has been designed within the Connect window so that a table can be quickly selected from a drop-down list, and all values from that table displayed. The numerical and graphical displays are fully configurable and now allow saving a configuration that can then be reloaded for the original station or a different station. Any notes that have been added for a station during Setup will be displayed at the bottom right of the Connect window.

\section{Status Monitor}

The Status monitor is used to view the communication and data collection status of the overall datalogger network. The Status Monitor now allows for the configuration of custom Views, which was previously available only in LoggerNet Admin.

\section{Advanced Data Display \& File Viewing}

RTMC Development, RTMC Run-Time

RTMC is used to create custom displays of real-time data, flags, and ports. It provides digital, tabular, graphical, and Boolean data display objects, as well as alarms. You can combine data from multiple dataloggers on one display. Complex displays can be organized on multi-tabbed windows.

\section{View Pro}

View Pro is our newly designed data file viewer. Data files can be viewed in numeric format or in one of several graphical layouts, including a line graph, $\mathrm{X} / \mathrm{Y}$ plot, histogram, rainflow, and 2D/3D FFTs. Multiple data files can be opened at once, allowing side-byside comparison of the data. There is no limit to the number of traces that can be displayed on a graph. The Zoom feature offers a closer look at important data, and the Statistical window provides the average, standard deviation, minimum, and maximum for all points displayed on a graph. Graphs can be saved to a file (BMP, JPG, WMF, EMF, or PCX), and View Pro supports all Campbell Scientific data file types (including the new CSIXML format). 


\section{Programming}

Full-featured Programming Tools LoggerNet offers two full-featured programming tools-the CRBasic Editor and Edlog. The CRBasic Editor uses syntax similar to BASIC programming language to provide sophisticated programming capabilities for our CR200-series, CR800/CR850, CR1000, CR3000, CR5000, and CR9000(X) dataloggers. The CRBasic Editor in LoggerNet 4.0 includes new functionality to support encrypting a file prior to sending it to the datalogger and support for userdefined functions. Edlog provides programming capabilities for our CR500, CR510, CR10(X), 21X, CR23X, and CR7 dataloggers.

Simple Program Generator

For those who prefer a simpler means of programming their dataloggers, LoggerNet 4.0 includes Short Cut for Windows (SCWin). SCWin provides a wizard-like interface for generating programs for all Campbell Scientific dataloggers and supports all of the popular sensors we offer, as well as user-created custom sensor files (using an existing sensor file as the starting point). You can use a program as generated by SCWin, or open it in the CRBasic Editor for further editing (for CR200-series, CR800, CR850, CR1000, CR3000, CR5000, and CR9000(X) dataloggers).

\section{Troubleshooting}

Troubleshooter

Troubleshooter helps you discover the cause of communication problems. Troubleshooter can be customized to display only the warnings of interest. In addition, you can click on any highlighted warning to bring up additional information about the warning.

\section{PakBus Graph}

PakBus Graph provides a graphical display of a PakBus network as known by the LoggerNet server, and quick access to the PakBus settings in LoggerNet and other PakBus devices.

\section{Log Tool}

The LogTool application is available to view operational log messages for the server as well as the low-level communication between the datalogger and the server.

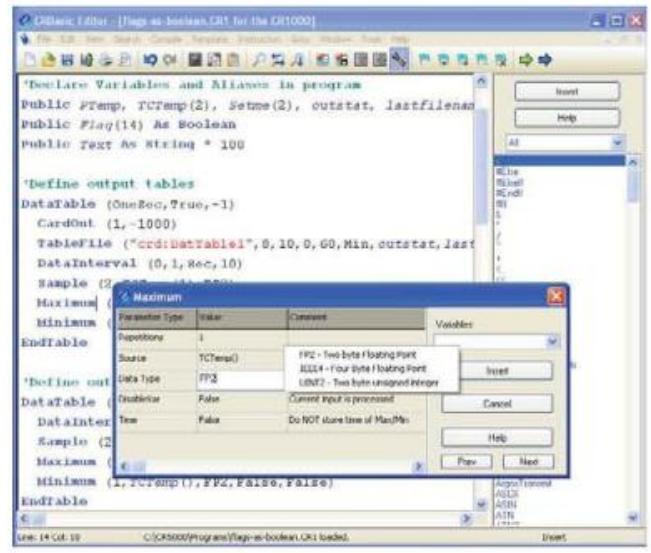

CRBasic Editor offers keyword and other syntax highlighting and a parameter dialog box with drop-down lists for CRBasic programming.

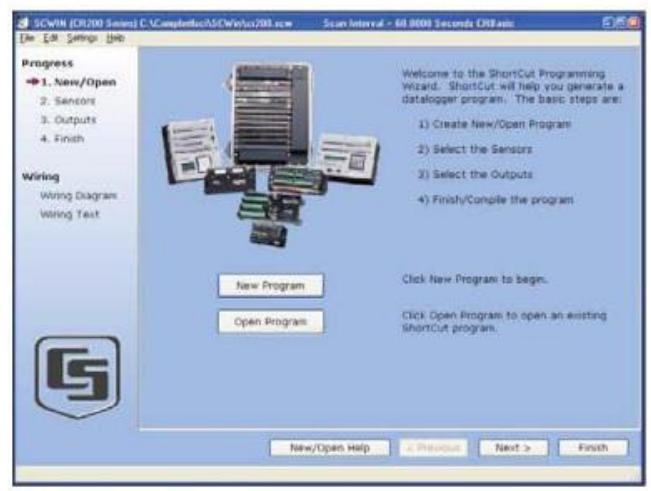

Short Cut provides a wizard-like interface for generating datalogger programs.

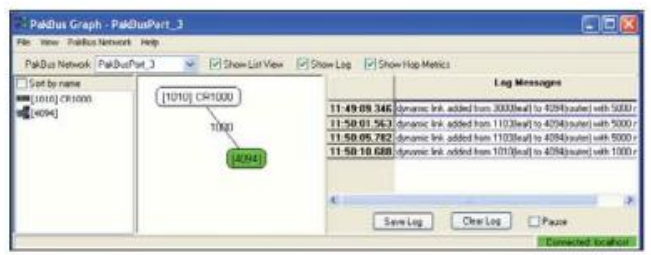

Troubleshooter, PakBus Graph (shown above), and Log Tool are tools available for monitoring the status of a datalogger network and troubleshooting communication problems within that network. 


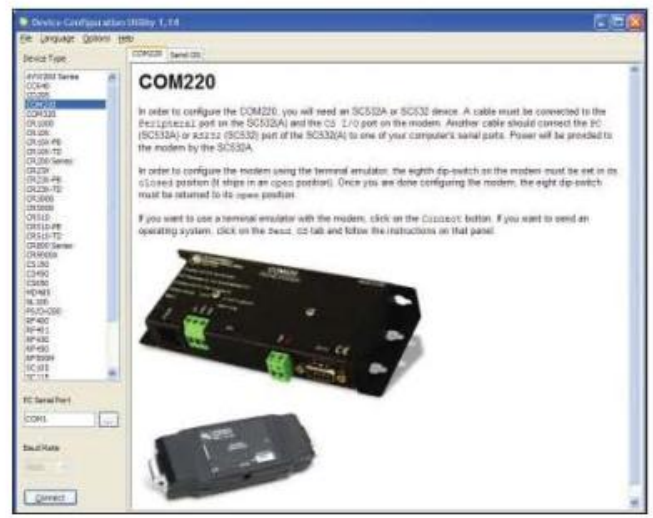

DevConfig is used to configure dataloggers, communication devices, and programmable sensors.

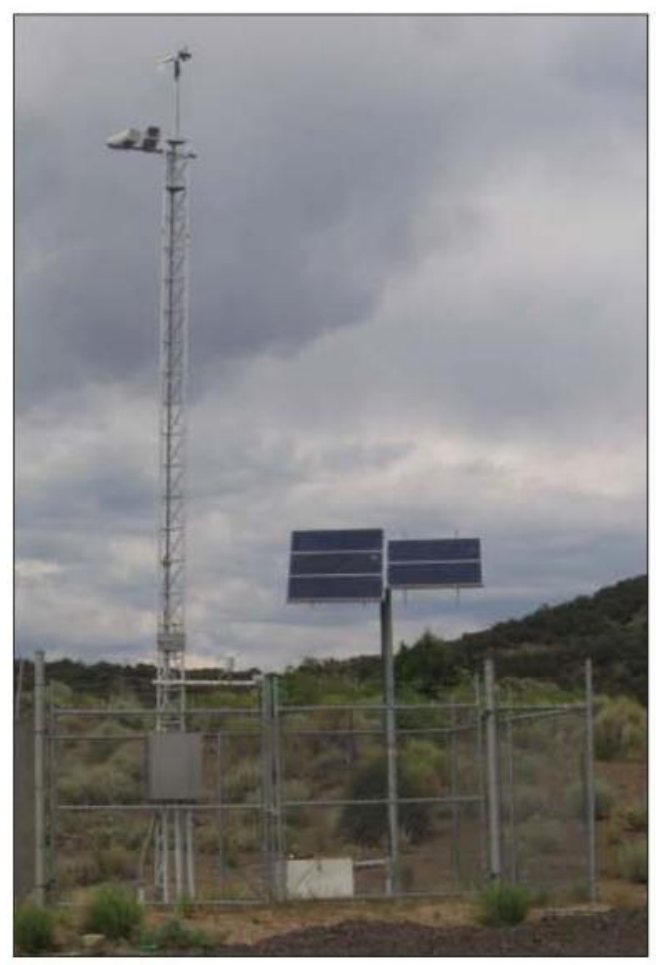

The RWIS Administrator supports communication with RWIS weather stations such as the one shown above.

\section{Other Applications}

Device Configuration Utility (DevConfig)

DevConfig allows you to send new operating systems to dataloggers and other devices with flash memory, configure various $\mathrm{PakBus}{ }^{*}$ settings in dataloggers, and edit settings for communication peripherals such as the MD485 and RF401. DevConfig can now be launched from within LoggerNet, without conflict with the remainder of the datalogger network. The latest DevConfig can be downloaded from our website.

\section{RWIS Administrator}

New in LoggerNet 4.0 is the RWIS Administrator. With the RWIS Administrator, LoggerNet is able to communicate with any station that implements the NTCIP (National Transportation Communications for ITS Protocol) Environmental Sensor Station interface.

\section{Card Convert \\ CardConvert is used to convert and save binary data from a PC Card or CompactFlash ${ }^{\circ}$ (CF) card. It can also perform other conversions. PC Cards are com- patible with our CR5000 and CR9000X dataloggers. CF cards are compatible with our CR1000, CR 3000 , CR5000, and CR9000X dataloggers.}

\section{Split}

Split is used to post-process data files and create printed reports. It sorts and combines data based on time or conditions, performs calculations on data values, converts between mixed-array "day of year" calendar dates and more traditional date/time stamps, and generates simple HTML-formatted reports.

\section{Transformer}

The Transformer tool converts Edlog programs to CRBasic programs. Specifically, it can convert a CR510 or CR10X program to a CR $1000, \mathrm{CR} 800$, or CR850 program, or a CR23X program to a CR3000 program.

\section{Data Filer}

(LoggerNet Admin \&. LoggerNet Remote onily) Data Filer is an application used to retrieve data from the LoggerNet server's data cache and save that data to a file. It provides a way to manually retrieve data from a remote LoggerNet server and store the data on the local computer. 
Data Export

(LoggerNet Admin \& LoggerNet Remote only) Data Export is an application used to export data from the LoggerNet server's data cache to a third party computer program. Data Export "listens" for a request from another application and sends the requested data via a socket connection.

Service Manager (LoggerNet Admin only) Service Manager is used to install LoggerNet as a service, and to manage the service on the PC. When run as a service, after a power failure, LoggerNet will resume data collection and scheduled task activities when power is restored to the computer-regardless of whether or not a user logs on to the computer.

\section{Security Manager}

(LoggerNet Admin \& LoggerNet Remote only) Security Manager is used to set up security within the LoggerNet application to restrict access to certain functions. Individual user accounts are set up and assigned one of five levels of security, with different user privileges assigned to each level.

\section{LoggerNet Server Monitor}

(LoggerNet Admin \& LoggerNet Remote only) The LoggerNet Server Monitor is a utility that runs minimized with an icon in the Windows Status Area. It monitors the status of a LoggerNet server when it is being run as a service or being run on a remote computer. Multiple instances of the LoggerNet Server Monitor can be launched to monitor more than one server running on remote computers.

Hole Monitor

(LoggerNet Admin \& LoggerNet Remote only)

The Hole Monitor is used to monitor the hole collection activity for the dataloggers in a LoggerNet network. Holes are most often encountered with data collected from table-based dataloggers via data advise (data advise is used for data collection in large tabledata RF networks). A hole occurs when there are missing records of data in the LoggerNet server's data cache for a datalogger.

\section{CoraScript}

CoraScript is a command line scripting tool, which can be used to configure the datalogger network from a command prompt.

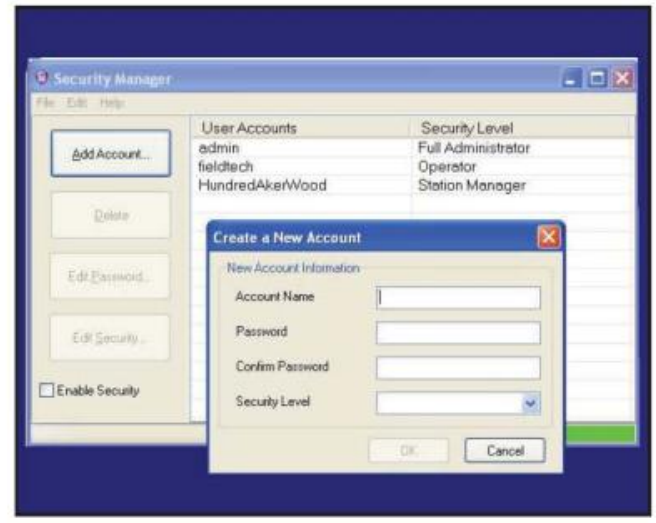

Security Manager lets you set up multiple security accounts for access to the datalogger network.

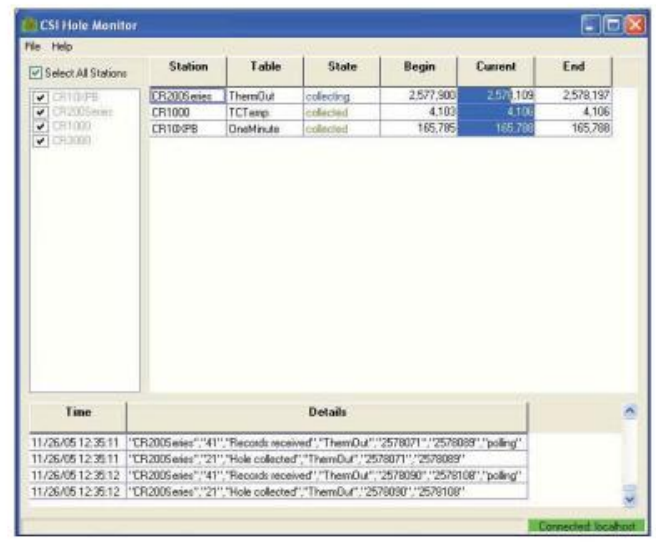

The Hole Monitor lists datalogger stations and collection status for missing records in LoggerNet's data cache.

Computer Requirements LoggerNet is a collection of 32-bit programs designed to run on Intel-based computers rumning Microsoft Windows operating systems. The recommended minimum computer configuration for running LoggerNet is Windows 2000. LoggerNet also runs on Windows XP, Windows Vista, and Windows 7. 


\section{Upgrades}

Upgrade pricing is available for current licenses of any version of LoggerNet or PC400. Contact Campbell Scientific for details.

\section{Software Developers Kits}

LoggerNet-SDK and LoggerNet Server-SDK allow software developers to create custom applications that communicate with the LoggerNet server and through the server to one or more dataloggers. Refer to the Software Development Kit product brochure for more information.

\section{Separately Purchased Clients}

Several clients may be purchased to add functionality to our LoggerNet and LoggerNetAdmin software packages. To use the clients, a licensed copy of the datalogger support software needs to be running on a PC. Functions supported by these clients include distributing data to remote files, OPC interface, PC displays, and web browsers. Refer to the Software Client product brochure for more information.

\section{Alternate Language Files}

Campbell Scientific offers language files to convert the LoggerNet user interface to languages other than English. To obtain the language files, go to www.campbellsci.com/downloads and select "Software Language Files". They are simple to install and you can easily switch from one language to another. The applications that support alternate languages are Setup, Connect, Status Monitor, Task Master, Short Cut, CRBasic Editor, View Pro, Card Convert, TroubleShooter, Network Planner, PakBus Graph, LogTool, the Device Configuration Utility, Data Export, and the RWIS Administrator.

\section{License for Use}

LoggerNet is protected by United States copyright law and international copyright treaty provisions. Installation of Log gerNet (including the trial version) constitutes an agreement to abide by the provisions of its licensing agreement. The agreement grants the user a non-exclusive license to use the software in accordance with the following:

(1) The purchase of this software allows you to instail and use the software on one computer only.

(2) This software cannot be loaded on a network server for the purposes of distribution or for access to the soft ware by multiple operators. If the software can be used from any computer other than the computer on which it is installed. you must license a copy of the soft ware for each additional computer from which the software may be accessed.

(3) If this copy of the software is an upgrade from a previous version, you must possess a valid license for the earlier version of software. You may continue to use the earlier copy of software only if the upgrade copy and earlier version are instailed and used on the same computer. The earilier version of software may not be installed and used on a separate computer or transferred to another party.

(4) This software package is licensed as a single product. Its component parts may not be separated for use on more than one computer.

(5) You may make one (1) backup copy of this software onto media similar to the original distribution, to protect your investment in the software in case of damage or loss. This backup copy can be used only to replace an unusable copy of the original installation media.

Logger Net software or its trial may not be sold, inciuded, or redistributed in any other software or altered in any way without prior written permission from Campbell Scientific. 


\section{Appendix P: Canary Systems MLWeb Software Data Sheet}

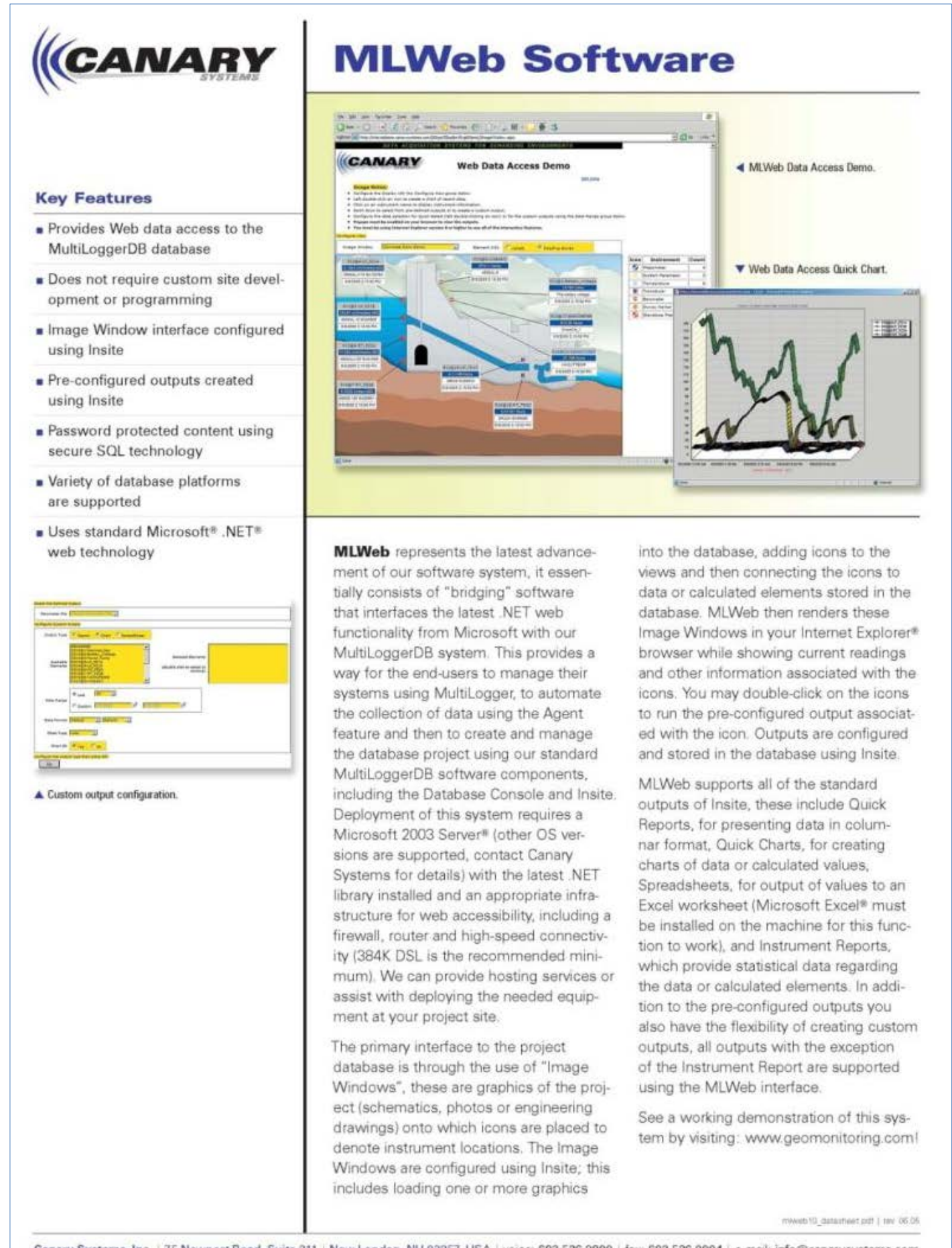




\section{Appendix Q: Bridge Load-Testing Report}

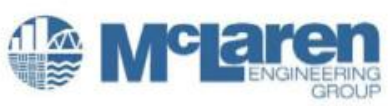

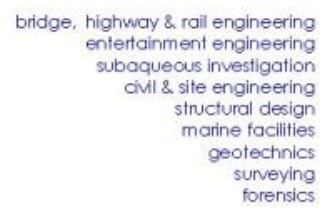

December 17, 2010

Engineered Monitoring Solutions

617 N. Main Street

Newberg, OR 97132

Attention: Barry Meyers, P.E.

Subject: Camp Mackall Plastic Bridges

Fort Bragg, North Carolina

MGM File No. 107248.02

\section{INTRODUCTION}

At the request of Engineered Monitoring Solutions, McLaren Engineering Group (McLaren) performed a limited evaluation of the load testing conducted on Bridge T-8518. Parameters evaluated are:

1. Lateral load distribution

2. Modulus of elasticity

3. Creep behavior

4. Elastic behavior

5. Temperature effect

6. Impact

McLaren utilized the load testing results performed by Engineered Monitoring Solutions for an M1 Tank between June 2009 and July 2010 as well as the load testing results conducted by Bridge Diagnostic Inc (BDI) for a 30 ton dump truck and a 72 ton M1 Tank on June 10, 2009.

\section{BRIDGE DESCRIPTION}

Bridge T-8518 is a 3-span structure with a total length of $38^{\prime}-4^{\prime \prime}$ and a width of $16^{\prime}-6^{\prime \prime}$. The superstructure consists of recycled plastic lumber (RPL) continuous I-beams supported on RPL pile caps. Each pile cap is founded on 4 RPL piles driven to approximately 60 feet. The longitudinal beams are $18^{\prime \prime} \times 18^{\prime \prime}$ and consist of two T-sections with the webs glued and bolted together. The beams are placed adjacent to each other with virtually no space between the flanges. The deck consists of $3^{\prime \prime} \times 12^{\prime \prime}$ RPL planks placed transversely to the longitudinal beams and attached by deck screws.

\section{Evaluation}

The following parameters were evaluated:
A. Lateral Load Distribution
B. Modulus of Elasticity
C. Creep Behavior
D. Elastic Behavior

M. G. MCLAREN, P.C.

100 Snake Hill Road West Nyack, New York 10994 Phone (845) 353-6400 Fax (845) 353-6509 
Evaluation of Testing Results

Page 2

MEG File No. 107248.02

December 17, 2010

E. Temperature Effect
F. Impact

\section{A. Lateral Load Distribution}

The analysis was based on a lateral load distribution of 0.1875 computed per AASHTO specifications as follows: $\mathrm{S} / 4=1.5^{\prime} / 4=0.375$ for a wheel load or 0.1875 for an axle load where $\mathrm{S}$ is the centerline to centerline spacing between beams,

The testing performed by BDI revealed lateral load distribution factors of 0.172 for the 72 -ton M1 Tank and 0.211 for a 30-ton dump truck (Figure 1). Since the design was based on the M1 Tank, it is considered consenative. However, it should be noted that the narrow wheel width of the dump truck produced a higher distribution factor than the AASHTO design load.

\section{B. Modulus of Elasticity}

The design was based on a modulus of elasticity of $100 \mathrm{ksi}$ for dead loads and $350 \mathrm{ksi}$ for live loads. The reduced modulus of elasticity for dead loads was utilized to minimize the effect of creep due to dead loads.

Engineered Monitoring Solutions conducted a load test using a slow moving M1 Tank on September 17 , 2009. The vertical displacement or deflection at Girder G3 in Span 3 and adjacent pile caps 3 and 4 were plotted in Figure 2. This figure clearly displays the flexibility of the pile cap support system. Pile cap 3 deflected more than pile cap 4 since the piles were mostly buried beneath pile cap 4 and did not deflect as much as the piles supporting pile cap 3 .

Girder and pile cap deflections for all spans were recorded then the net girder deflection was computed and plotted along with the theoretical deflection for simple spans as well as continuous spans as shown in Figure 3. It is not surprising that the bridge behavior is close to simple spans rather than continuous spans, especially in span 1 and 3. This is mainly due to the flexibility of the pile cap supports that deflected nearly $50 \%$ of the girder deflection. It could be concluded that the design modulus of elasticity of 350 ksi provides a conservative estimate of girder deflection when calculated using the simple span approach.

\section{Creep Behavior}

Creep is defined as an increase in deformation of the structure under constant load. Creep was tested on the bridge when the tank was allowed to sit on the bridge for approximately 15 minutes. Figure 4 provides a comparison between a slow moving tank on the bridge and a tank sitting on the bridge for 15 minutes. Girder deflection for a tank sitting on the bridge is approximately $25 \%$ larger than girder deflection for a slow moving tank.

\section{Elastic Behavior}

Elastic behavior was noted on this bridge even when the tank is allowed to sit on the bridge for 15 minutes (Figure 5). Both pile caps and girder deflections returned to original values without any notable permanent deformation (Figure 2). 
Evaluation of Testing Results

Page 3

MEG File No. 107248.02

December 17, 2010

\section{E. Temperature Effect}

Girder deformation was recorded for a period of one year (July 2009 to June 2010). Girder and pile cap deflections due to temperature are shown in Figure 6. Displacement up to 0.15 inch was recorded in January 2010. This is mainly due to shrinkage of the piles and subsequent deflection of the pile caps rather than girder deflection. It should be noted that pile cap and girder deflections did return to original values without any permanent deformation. However, strain measurements due to temperature variations recorded over the same period were not consistent amongst all girders similar to the deflection measurements. A few girders displayed very high strain measurements that differ tremendously from adjacent girders. Additional testing is recommended with strain gages placed on all girders in a span to clearly demonstrate the effect of temperature variations on the behavior of the bridge.

\section{F. Impact}

The strain was recorded at Girder G3 for the Tank traveling over the bridge at various speeds ( $3 \mathrm{mph}, 10$ $\mathrm{mph}, 15 \mathrm{mph}, 20 \mathrm{mph}$, and $25 \mathrm{mph}$ ). The results are shown in Figures 7 through 11 . Figure 12 provides a comparison between the tank speed and the impact ratio. The results revealed that the impact is highest at tank speed of $15 \mathrm{mph}$. The results revealed that lateral load distribution to adjacent girders diminishes at higher speeds, producing higher loads on the girder directly beneath the wheel load. However, it is not clear why the impact is highest at tank speed of $15 \mathrm{mph}$. Additional testing is recommended with strain gages placed on all girders in a span to clearly demonstrate the effect of impact.

Should you have any questions or comments, or if you require additional information, please feel free to contact our office at any time.

Very truly yours,

The Office of

McLaren Engineering Group

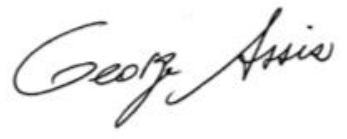

George F. Assis, P.E., Ph. D.

Project Manager

Attachments

cc: Malcolm McLaren - Internal

File 107248.02

P:IProj107107248.02VReports\Bridge Monitoring Report.doc 


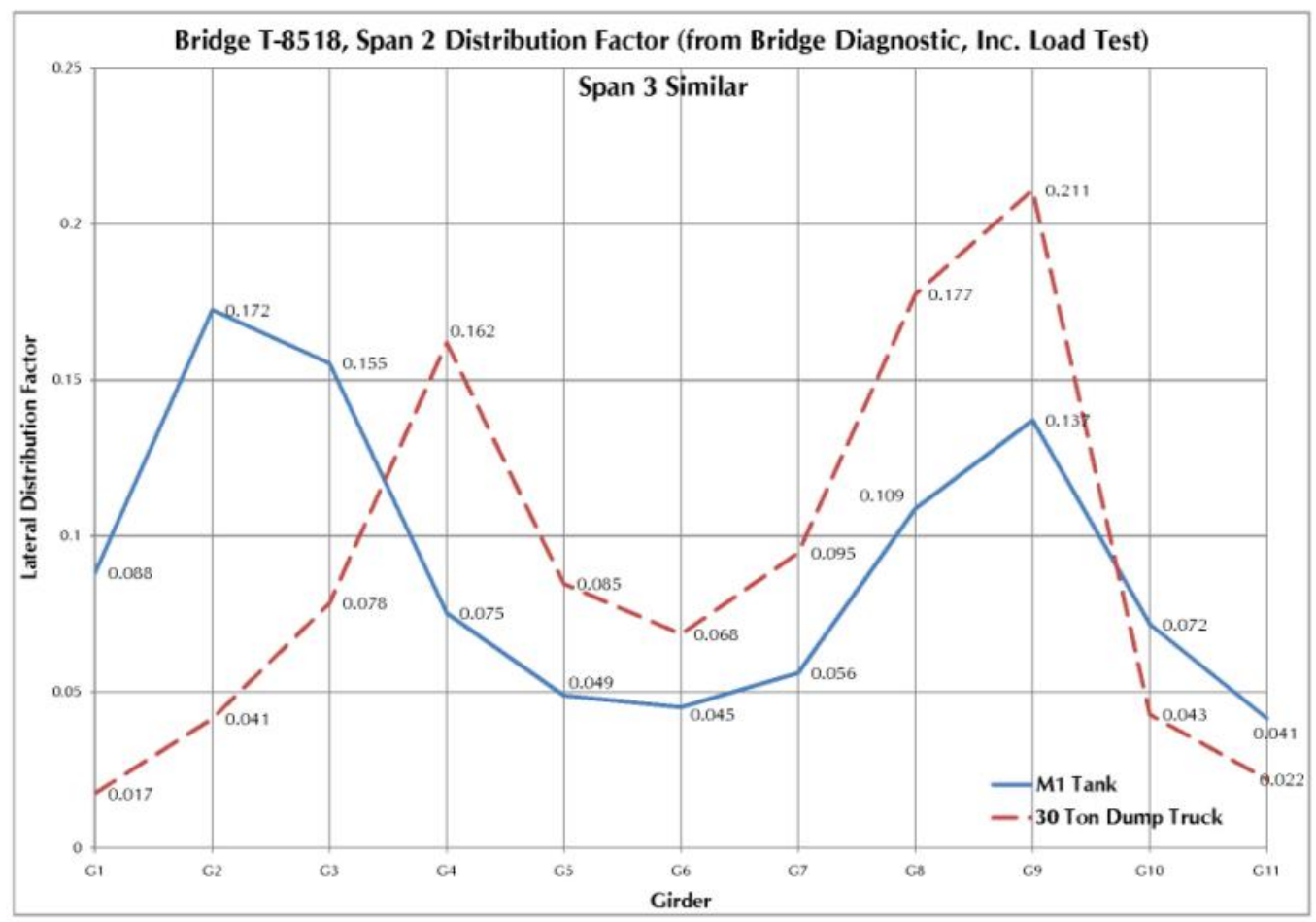

Figure 1

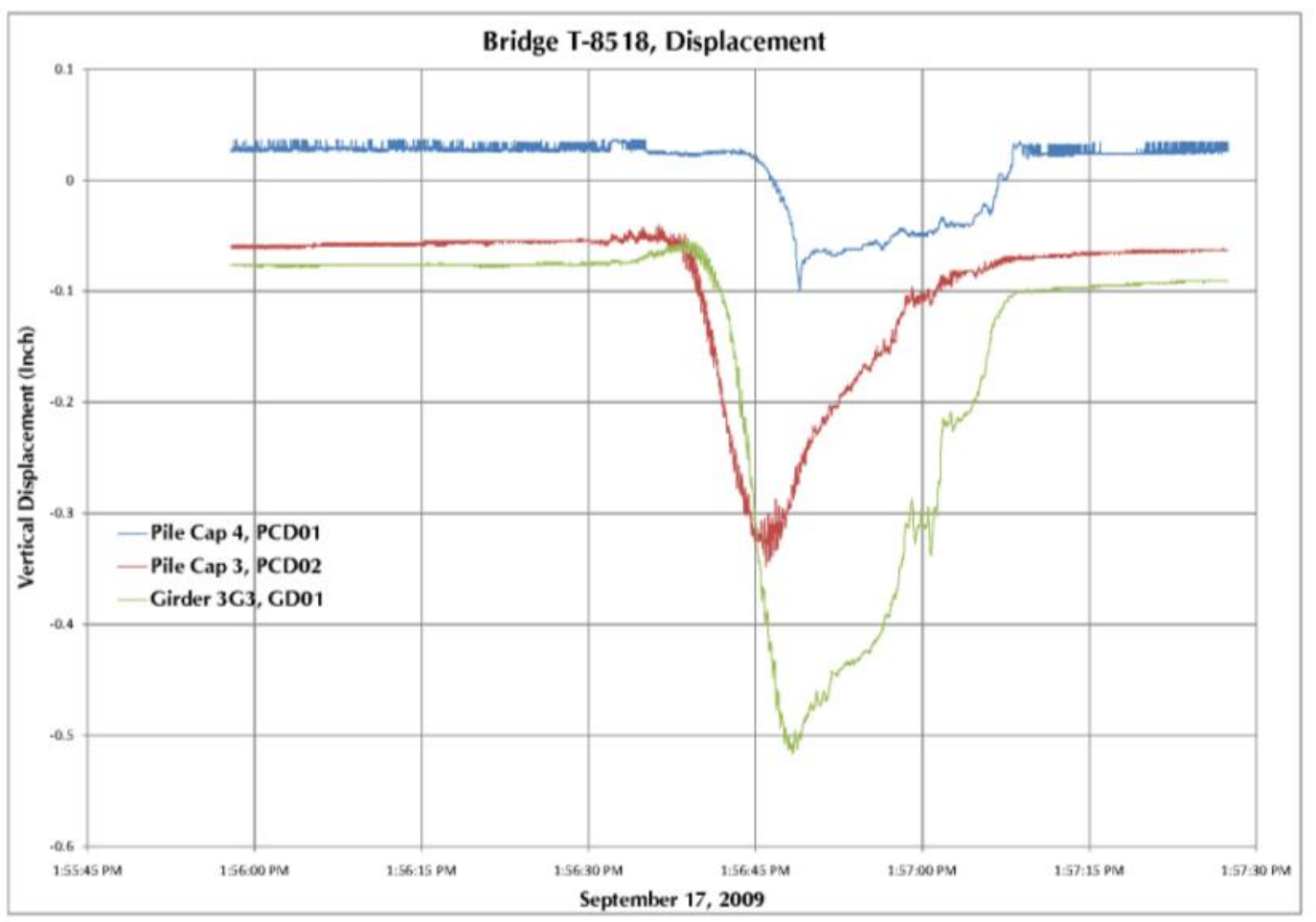

Figure 2 - Span 3 Displacement - Slow Moving Tank 


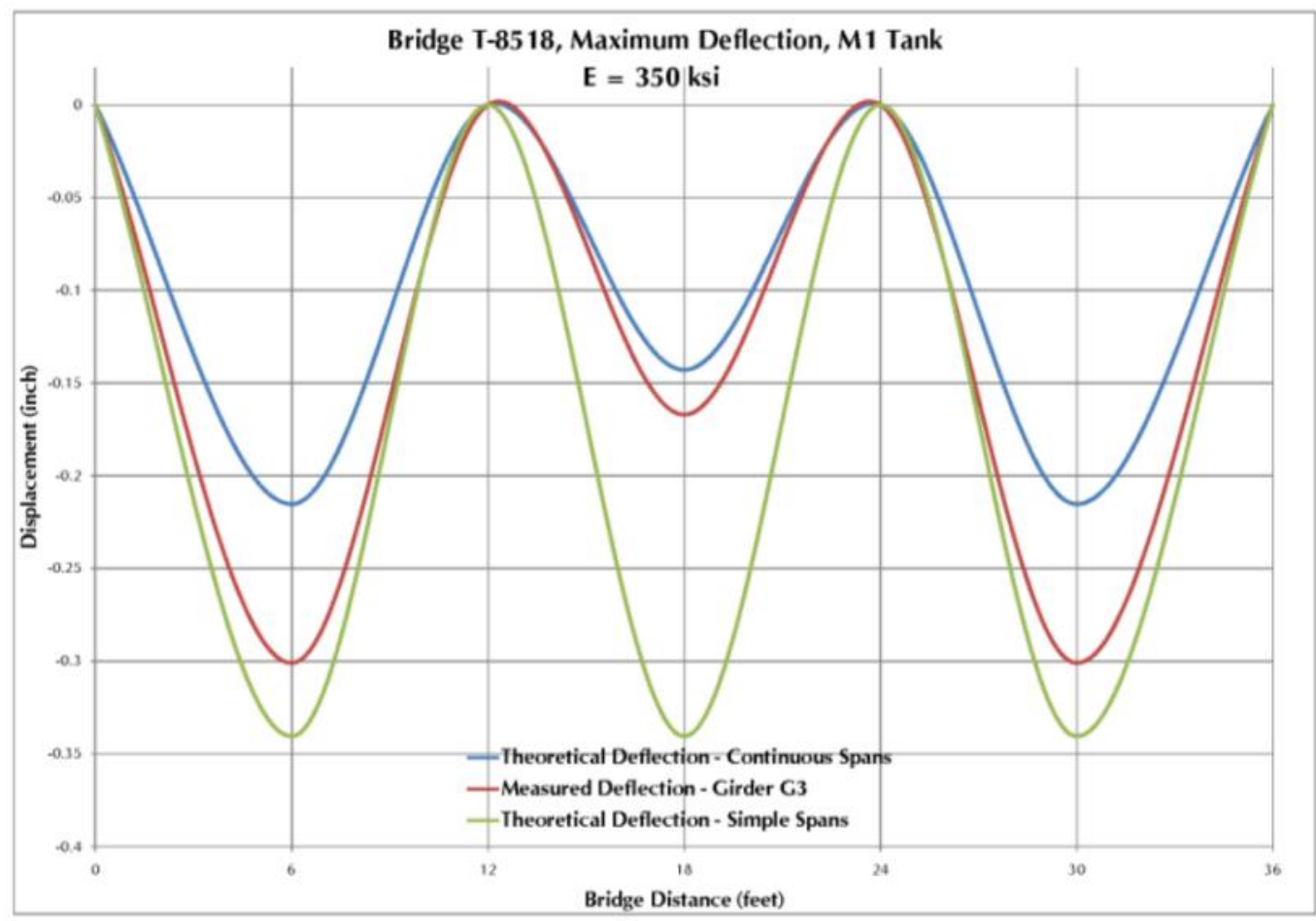

Figure 3 - Girder Net Deflection - Slow Moving Tank

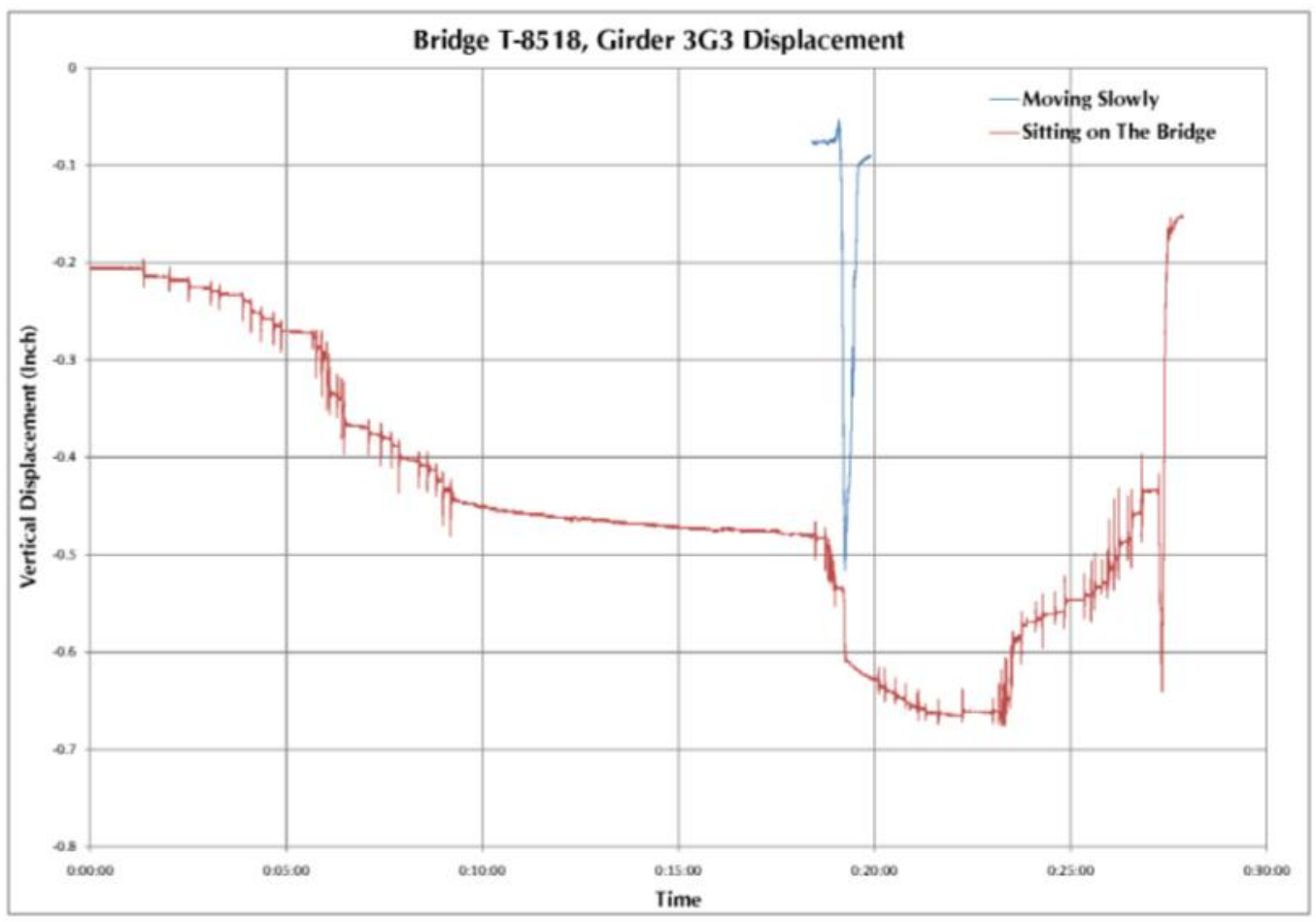

Figure 4 - Effect of Creep 


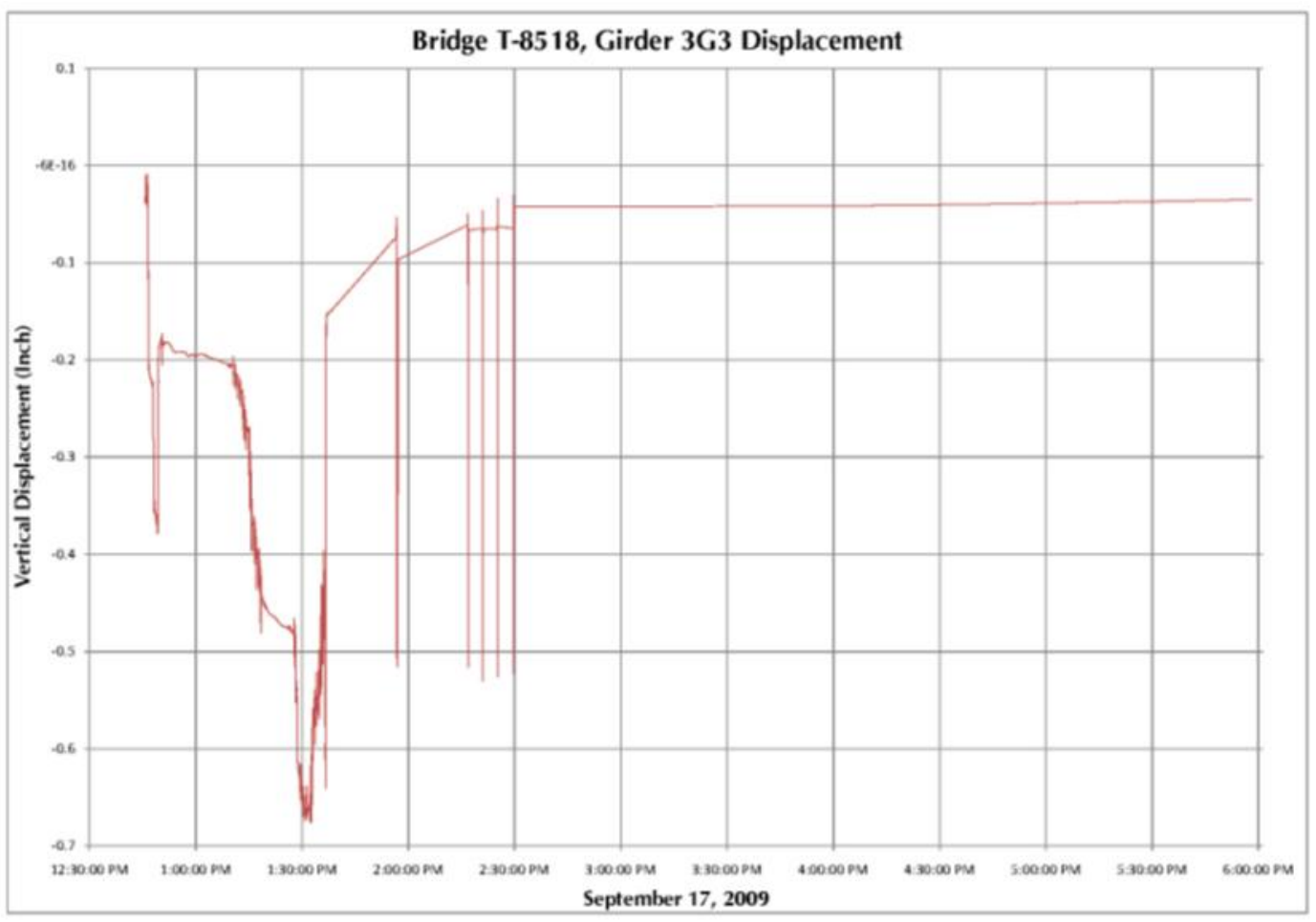

Figure 5 - Girder Displacement at Span 3 - Tank Sitting on Span for 15 Minutes

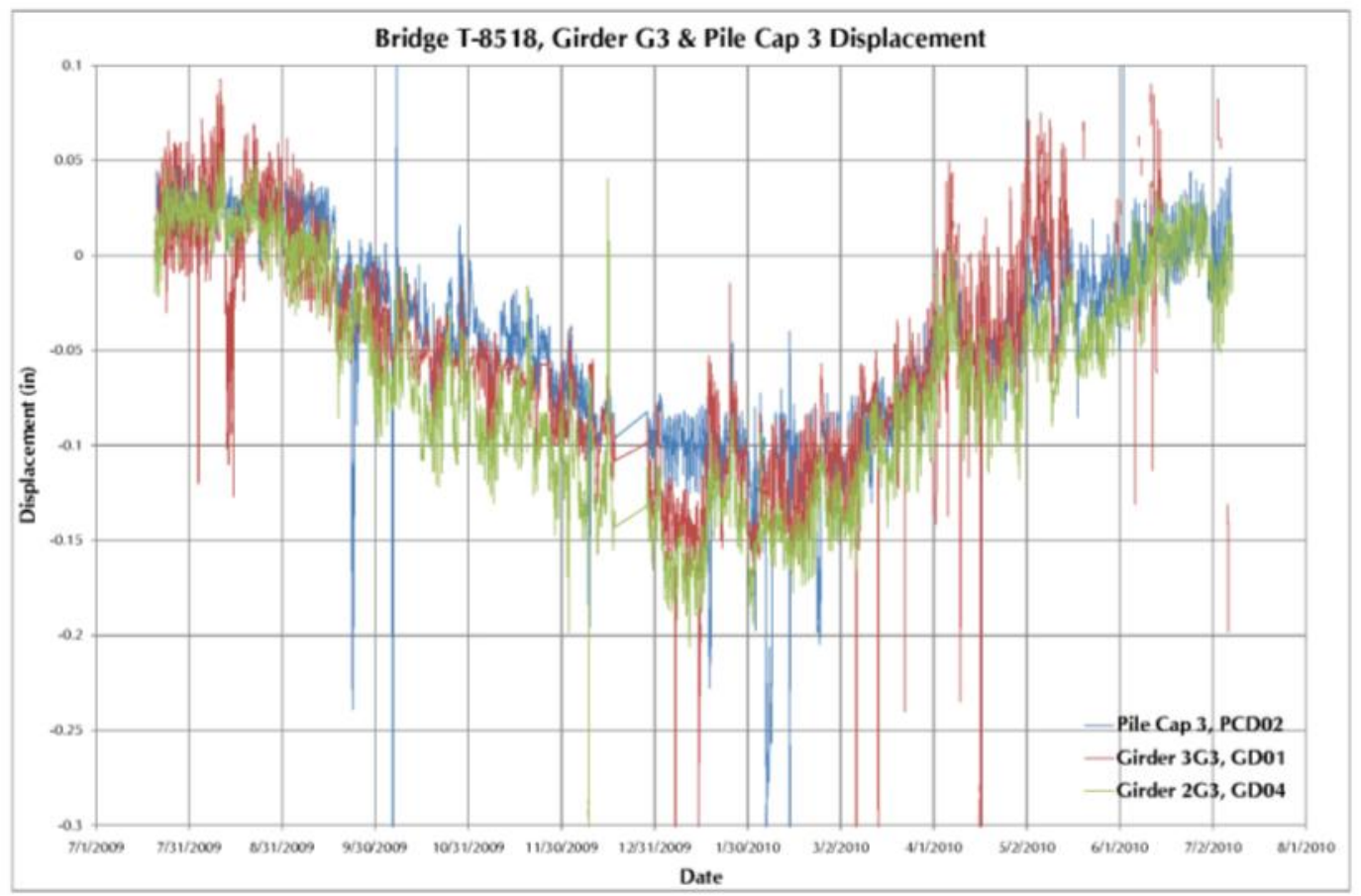

Figure 6 - Displacement due to Temperature 


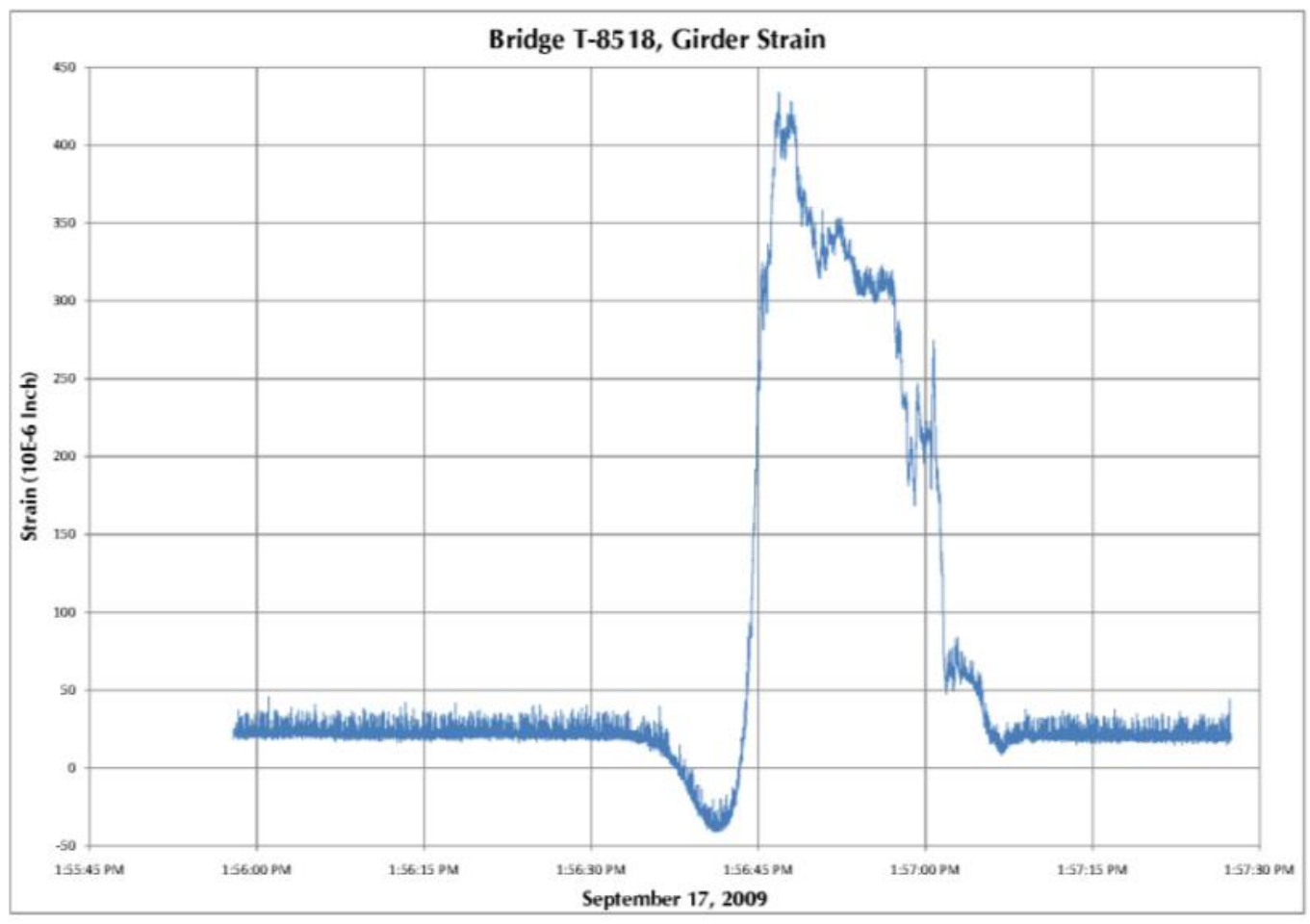

Figure 7 - Girder 3G3 Strain @ Mid-Span (3 mph Tank Speed)

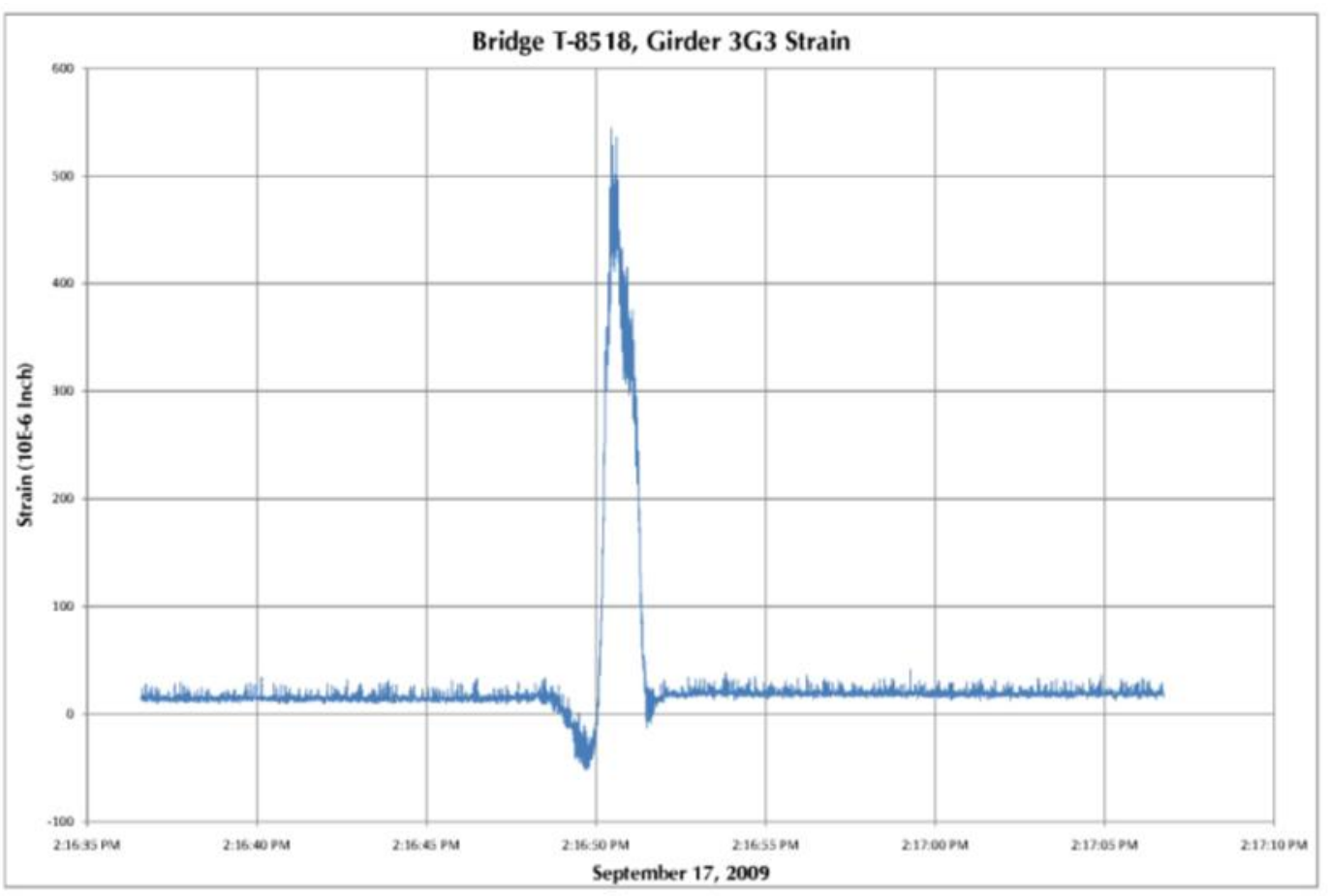

Figure 8 - Girder 3G3 Strain @ Mid-Span (10 mph Tank Speed) 


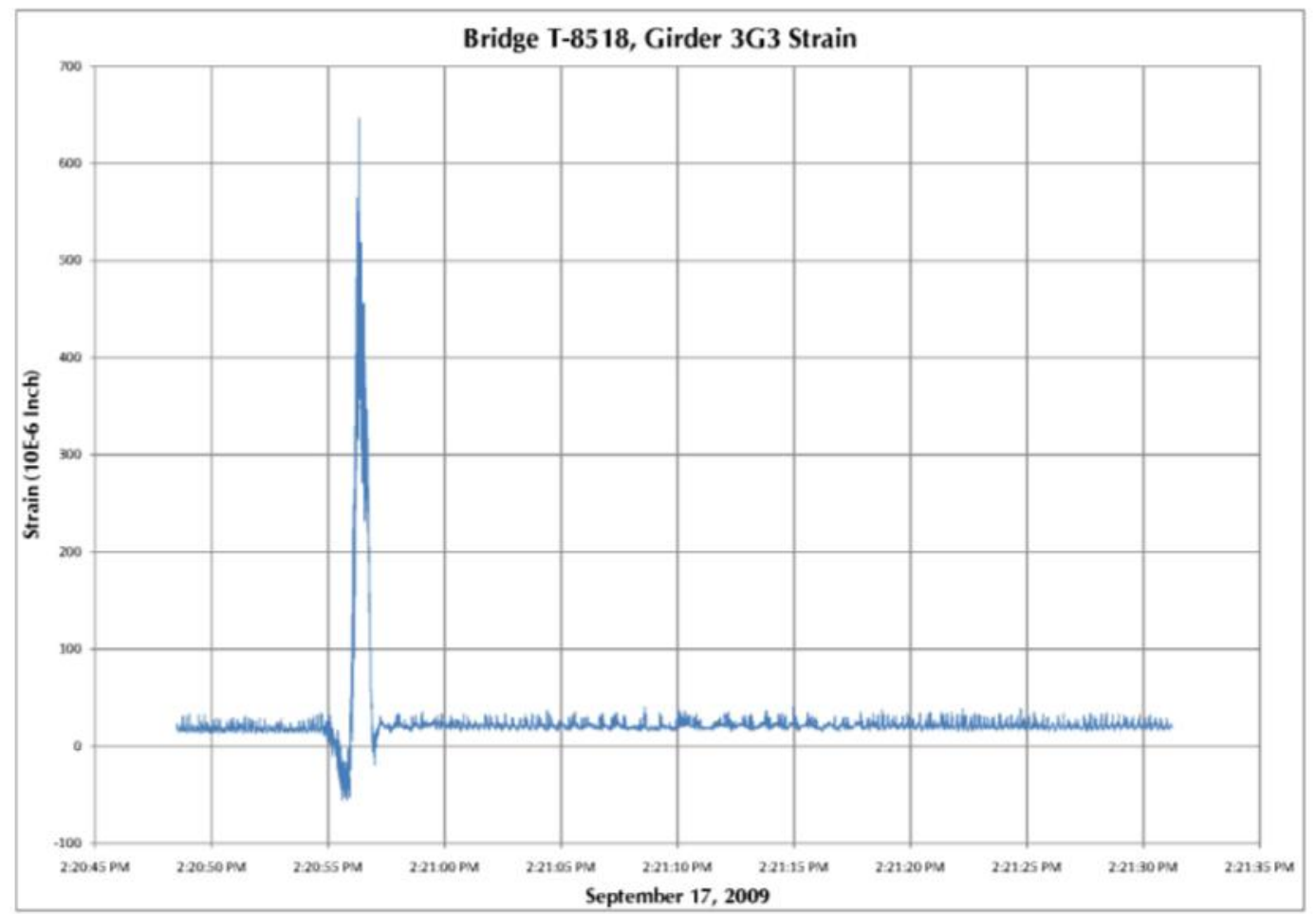

Figure 9 - Girder 3G3 Strain @ Mid-Span (15 mph Tank Speed)

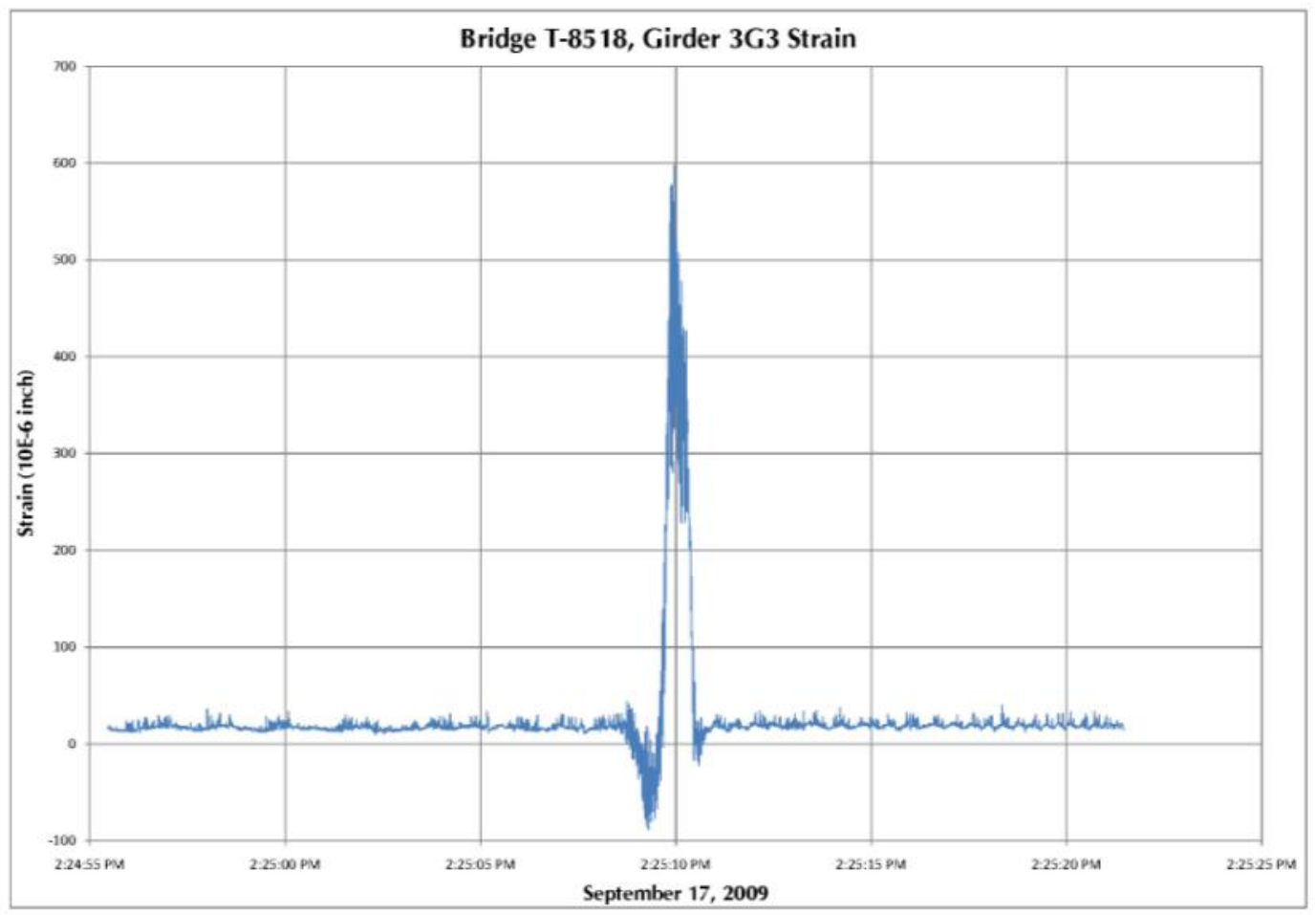

Figure 10-Girder3G3 Strain@ Mid-Span (20 mph Tank Speed) 


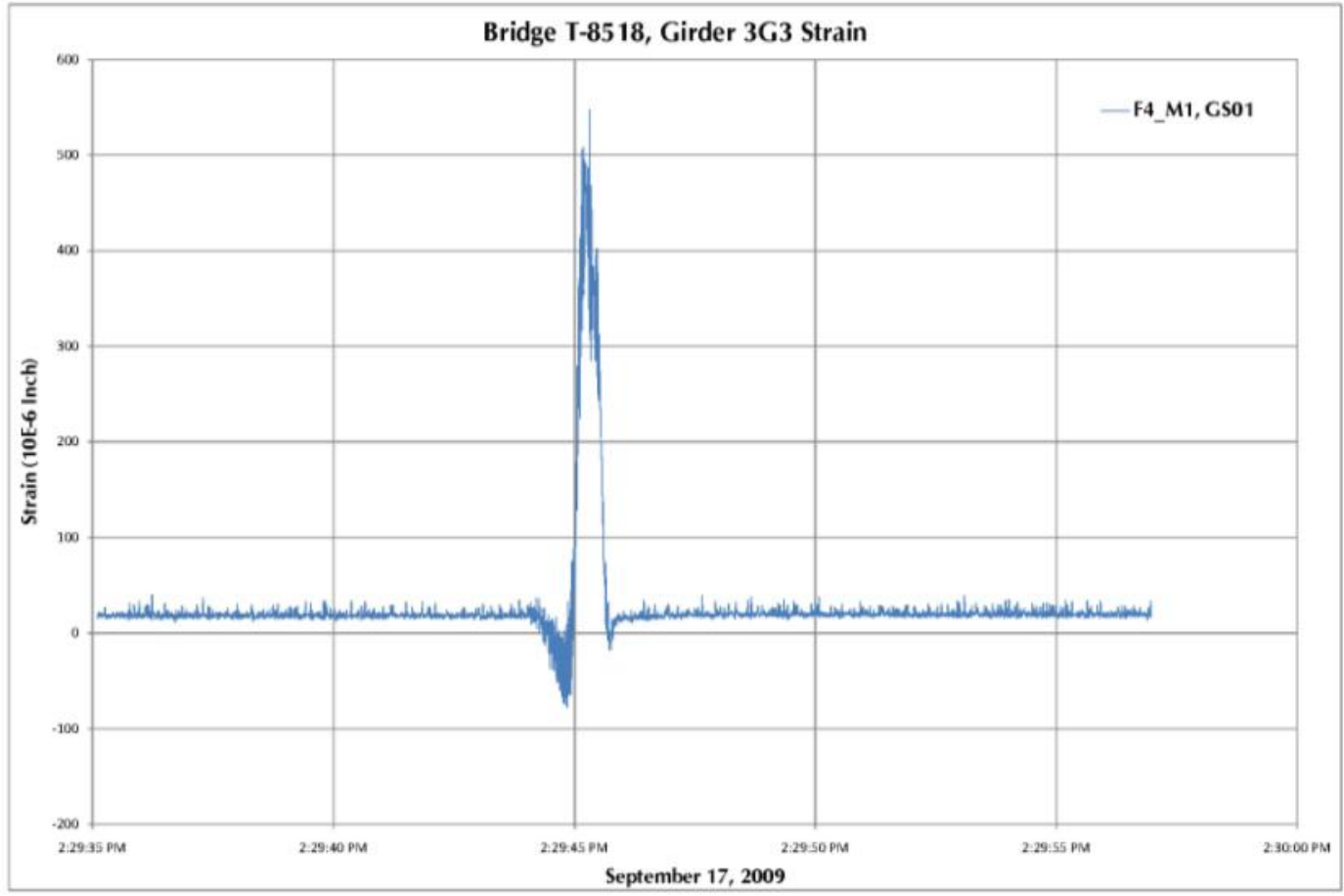

Figure 11 - Girder 3G3 Strain @ Mid-Span (25 mph Tank Speed)

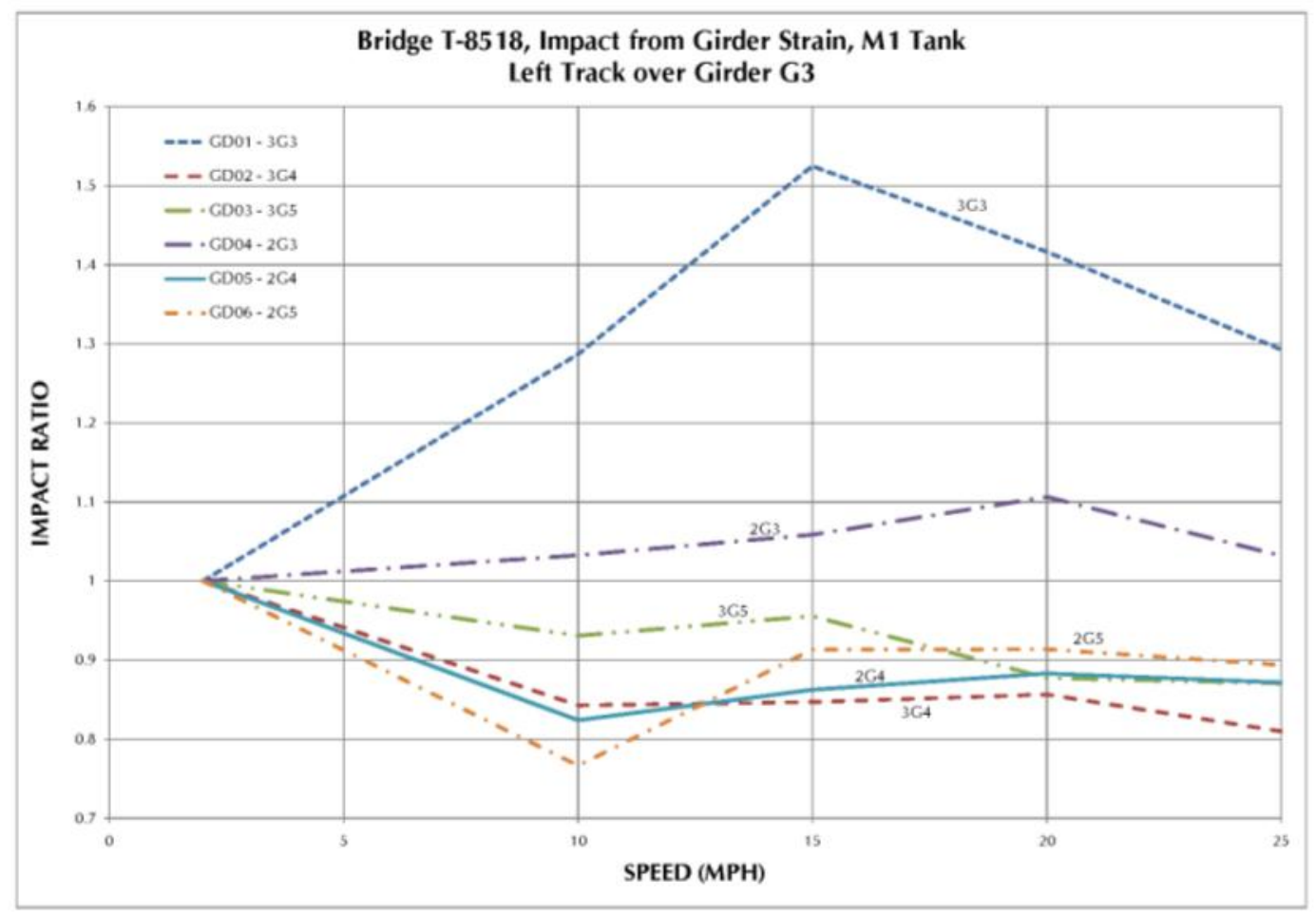

FIGURE 12 - Impact 


\section{Appendix R: Deck Board Bend Test Report}

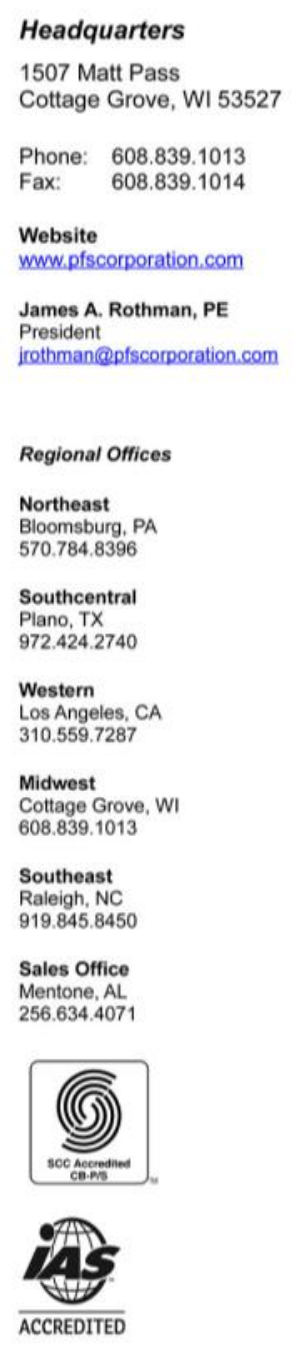

PFS Test Report: \#12-007

Test Date: $12 / 8 / 12$

Report Date: $2 / 10 / 12$

Page: 1 of 6

\section{GENERAL}

PFS Corporation, Cottage Grove, Wisconsin, was contracted by the client, US Army Corps of Engineering, Construction Engineering Research Laboratory, to evaluate the performance of deck board samples. PFS Laboratory received the test samples on 2/7/2012. The tests were conducted on 12/8/12 at the PFS Testing Laboratory in Cottage Grove, Wisconsin.

\section{TEST SPECIMENS}

The client submitted nominal 2x4-in. boards identified as 0,6 , and 12 (Photo 1). Five replicate samples were submitted for each group. The compression side of each board was identified for testing.

\section{CONDITIONING}

The samples were stored and tested in the ambient laboratory atmosphere of approximately 70 $-75^{\circ} \mathrm{F}$ and $40-50 \%$ relative humidity.

\section{TEST PROCEDURE and RESULTS}

\section{Bending Strength Test}

The bending tests were conducted according to methods described in ASTM D6109-05

"Standard Test Methods for Flexural Properties of Unreinforced and Reinforced Plastic Lumber and Related Products." The samples were weighed and dimensions were measured. The sample was mounted in a universal test machine such that the on-center support span was 24-in., and it could be symmetrically loaded at 8-in. from the supports. A displacement transducer was mounted to record the mid-span deflection (Photo 2). The sample was loaded 
PFS Test Report \#12-m?

Test Dat: $26 / 12$

Beport Dat: :2/10/12

Page 2016

at a uniform cross head speed of 0.71 -in. per minute urtil the sample was no longer able to sustain increasing load. The load and deflection were contimous ly moritored. A typical faibure consisted of exces sive deflection (Photo 2.3). None of the samples ruptured.

A summary of the test results are shown below, see Tab le 1 for details. Bending stength at $L / 180$ deflection (Fb @L/180), Moduhus of Fupture (MOR), Tangent Moduhs of Elasticity (MOE), and Secart MOE were deternined for each test based on the load deflection data. MOE is based on the data between 10 to $40 \%$ of the max load.

Secant MOE is based on $1 \%$ strain. Midspan deflection plots for each group of s armels are shown in Fhoto 46.

\begin{tabular}{|c|c|c|c|c|c|}
\hline Sample ID & $\begin{array}{c}\text { P@Fail } \\
\text { (Ibf) }\end{array}$ & $\begin{array}{c}\text { Fb @ L/180 } \\
\text { (lbf) }\end{array}$ & $\begin{array}{c}\text { MOR } \\
\text { (psi) }\end{array}$ & $\begin{array}{c}\text { Linear(Targent) } \\
\text { MOE } \\
\text { (psi) }\end{array}$ & $\begin{array}{c}\text { Secant MOE } \\
\text { @ 1\% Strain } \\
\text { (psi) }\end{array}$ \\
\hline Sample 0 & 1402 & 271 & 4150 & 195074 & 202705 \\
\hline Sample 6 & 1441 & 280 & 4284 & 200957 & 207182 \\
\hline S armle 12 & 1416 & 276 & 4217 & 197256 & 203674 \\
\hline
\end{tabular}

\section{TEST REPORT DURLICATION}

This report shall not be reproduced, except in full, without the written approval of PFS Corporation, Cottage Grove, Ws consin

Test Conducted by.

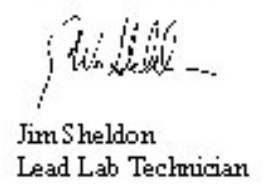

Reprot Prepared by.

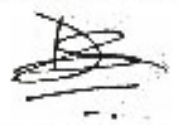

Deepak Slrestha, $\mathrm{PhD}, \mathrm{PE}$ General Manager - PFS Lab 
PFS Test Report: \#12-007

Test Date: 2/8/12

Report Date: 2/10/12

Page 3 of 6

Photo 1: Test samples
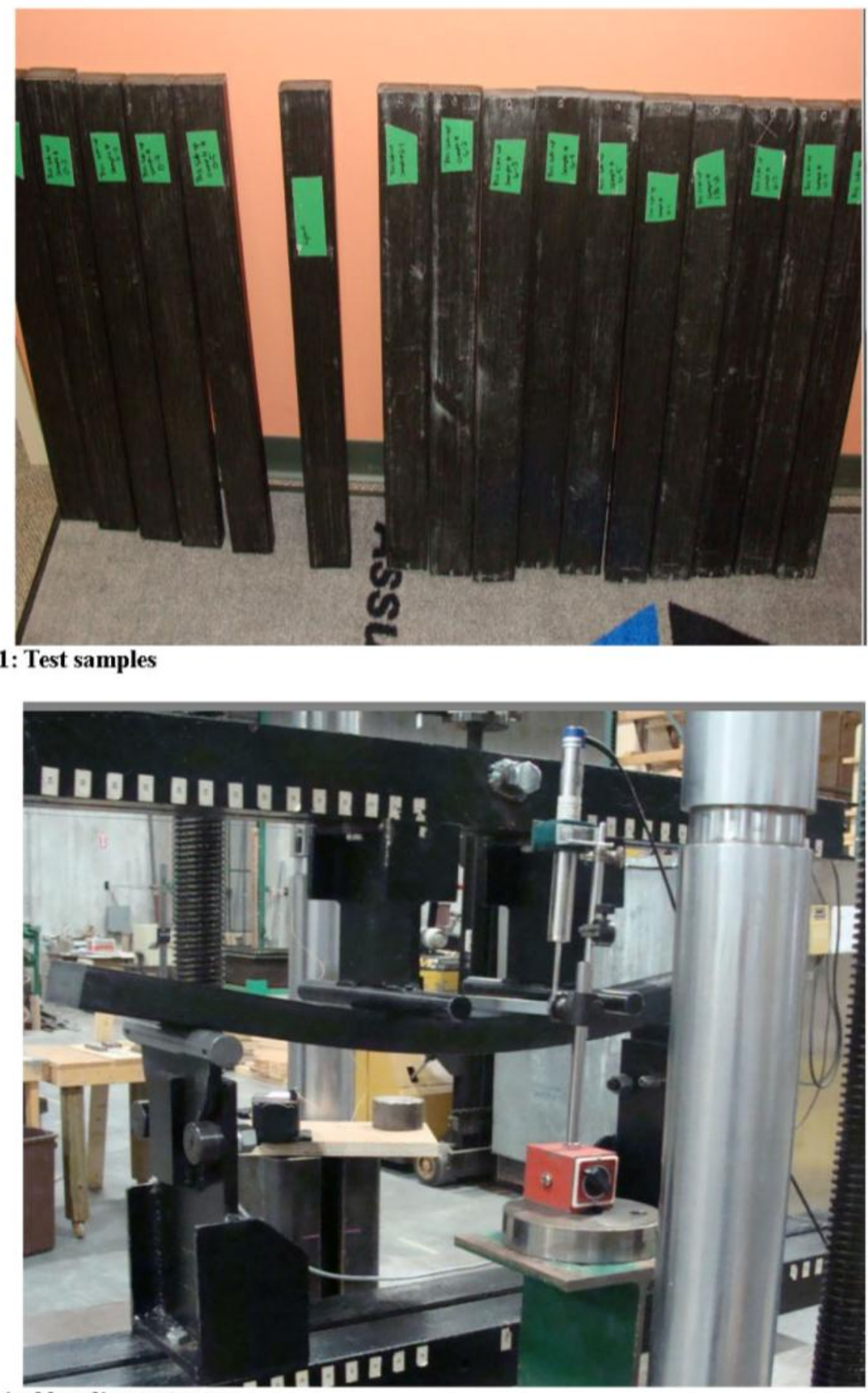

Photo 2: Typical bending test setup 
PFS Test Report: \#12-007

Test Date: $2 / 8 / 12$

Report Date: $2 / 10 / 12$

Page 4 of 6

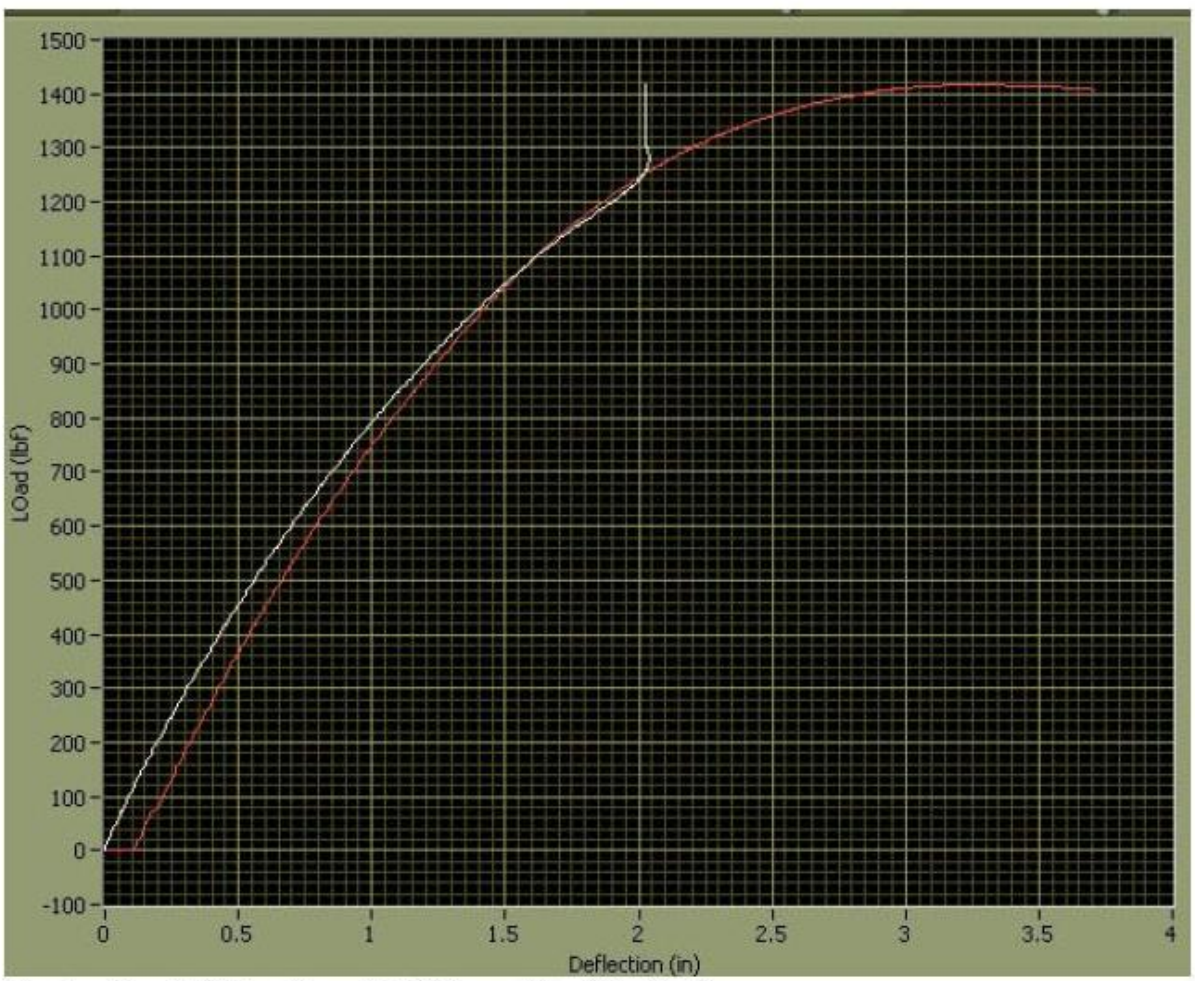

Photo 3: Typical load deflection plot (Cross Head is Red)

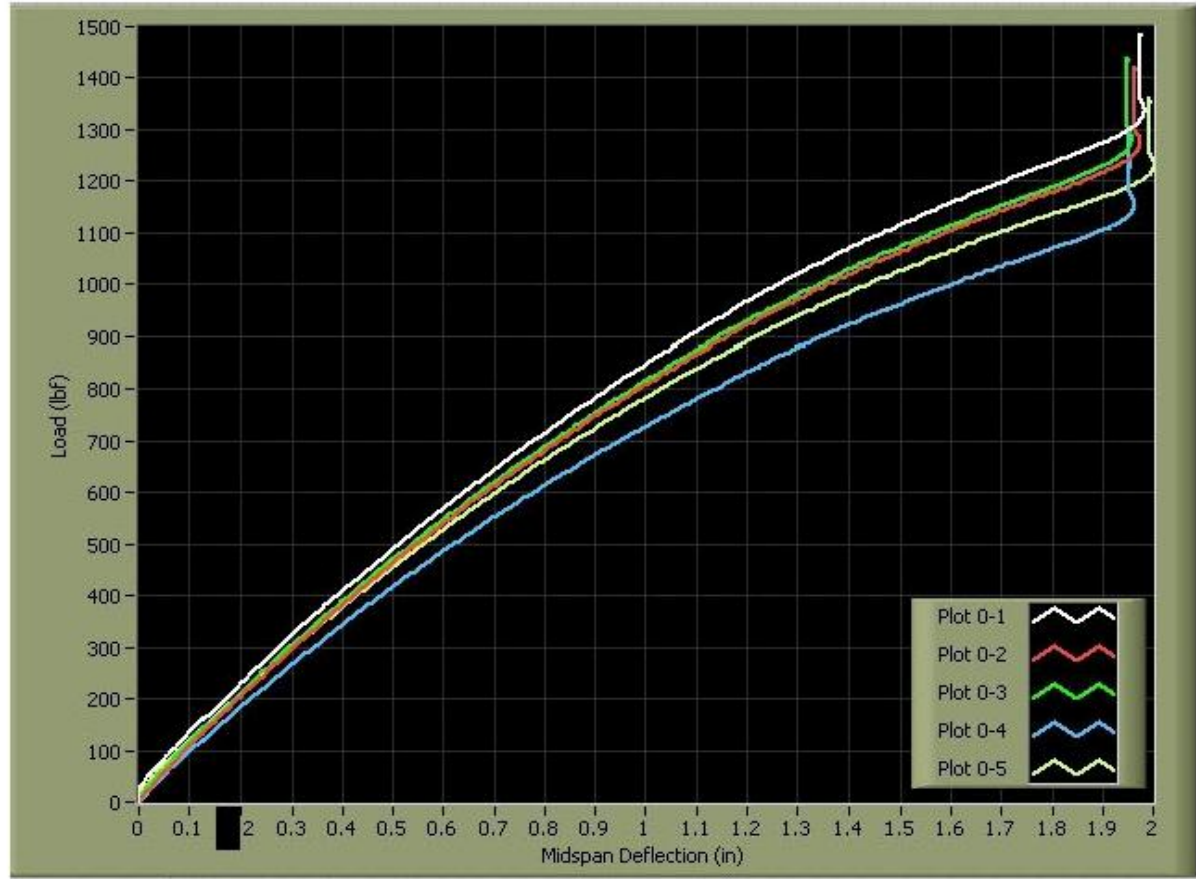

Photo 4: Midspan deflection, Sample 0 
PFS T est Report: \#12-007

Test Date: $2 / 8 / 12$

Report Date: $2 / 10 / 12$

Page 5 of 6

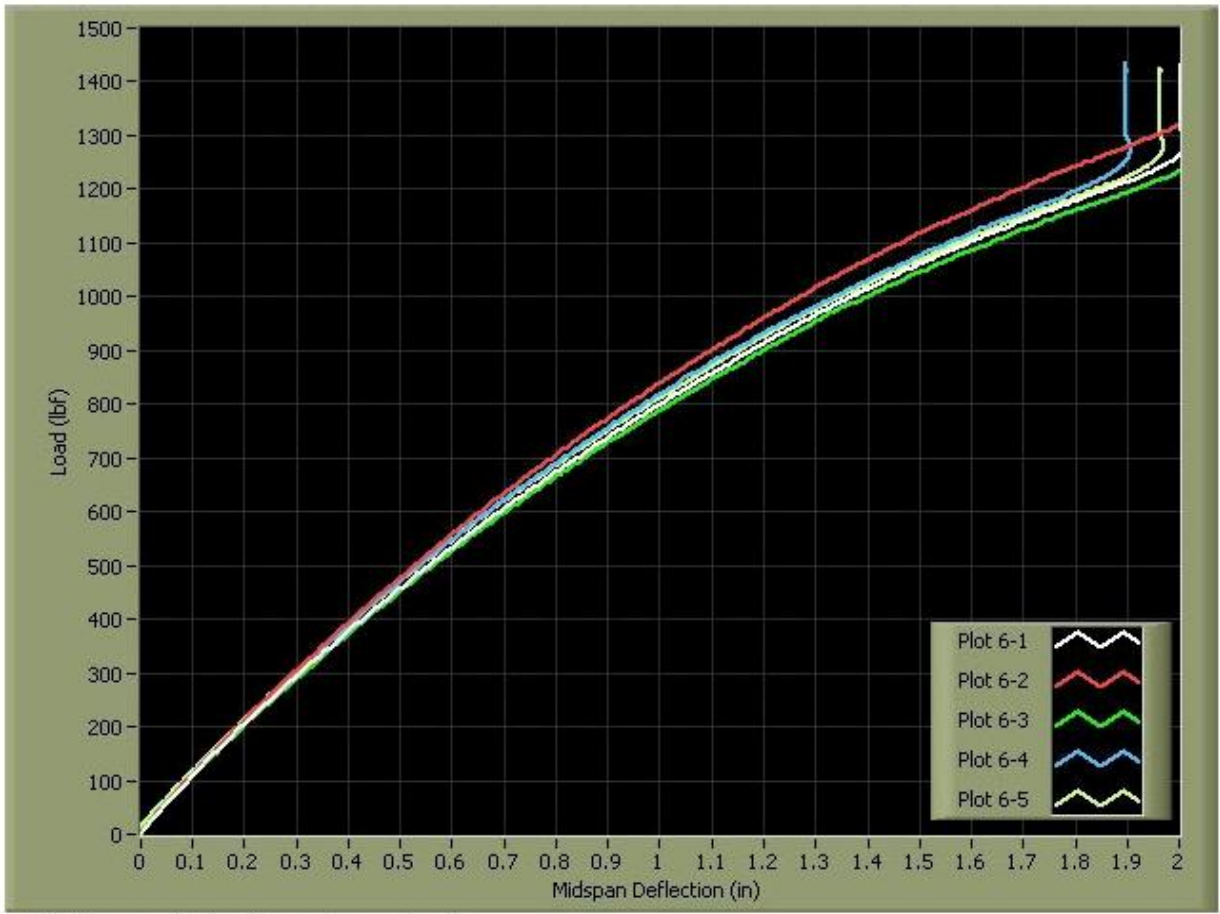

\section{Photo 5: Midspan deflection, Sample 6}

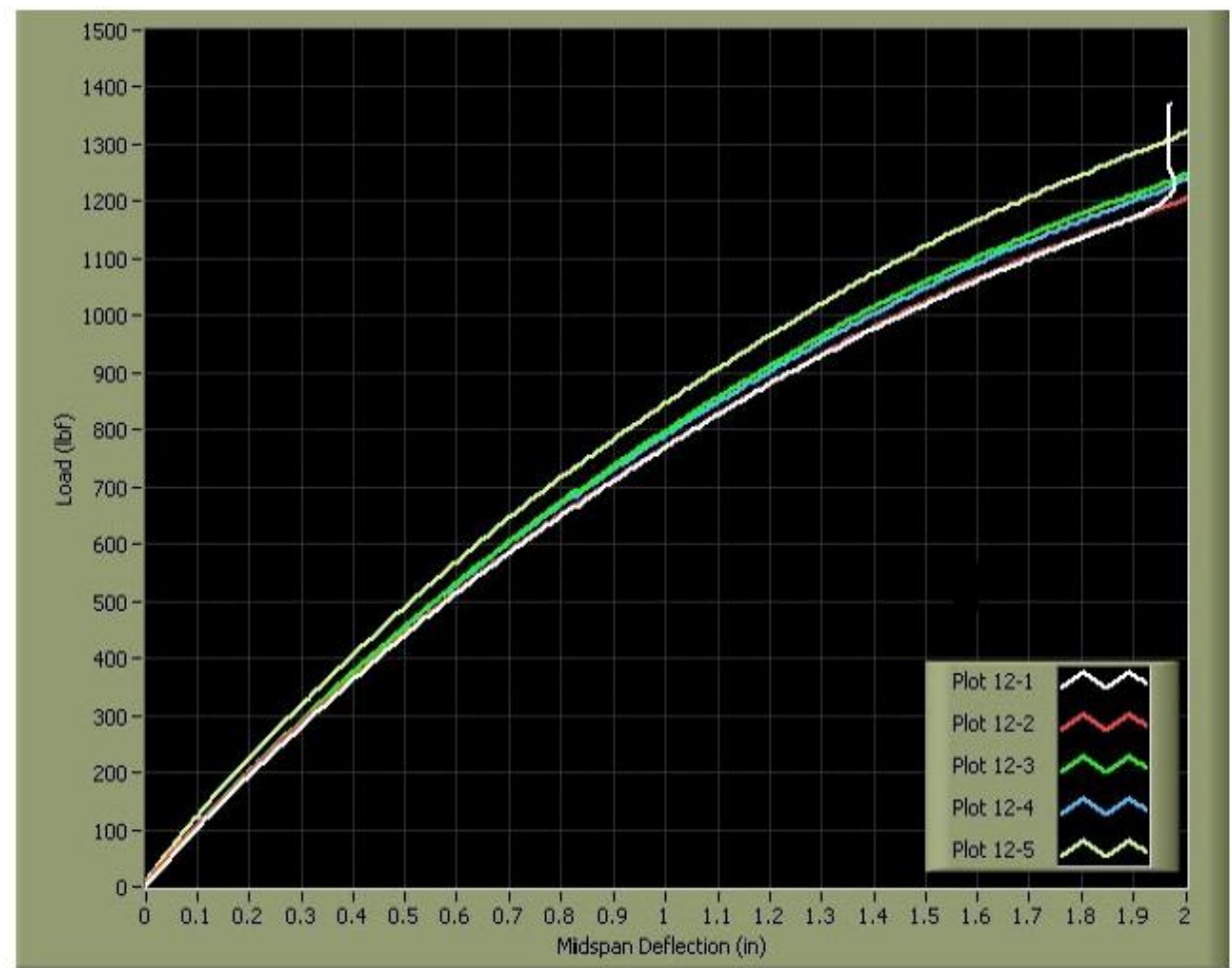

Photo 6: Midspan deflection, Sample 12 
PFS Test Report \#12-007

Test Date: $2 / 8 / 12$

Report Date: $2 / 10 / 12$

Page 6 of 6

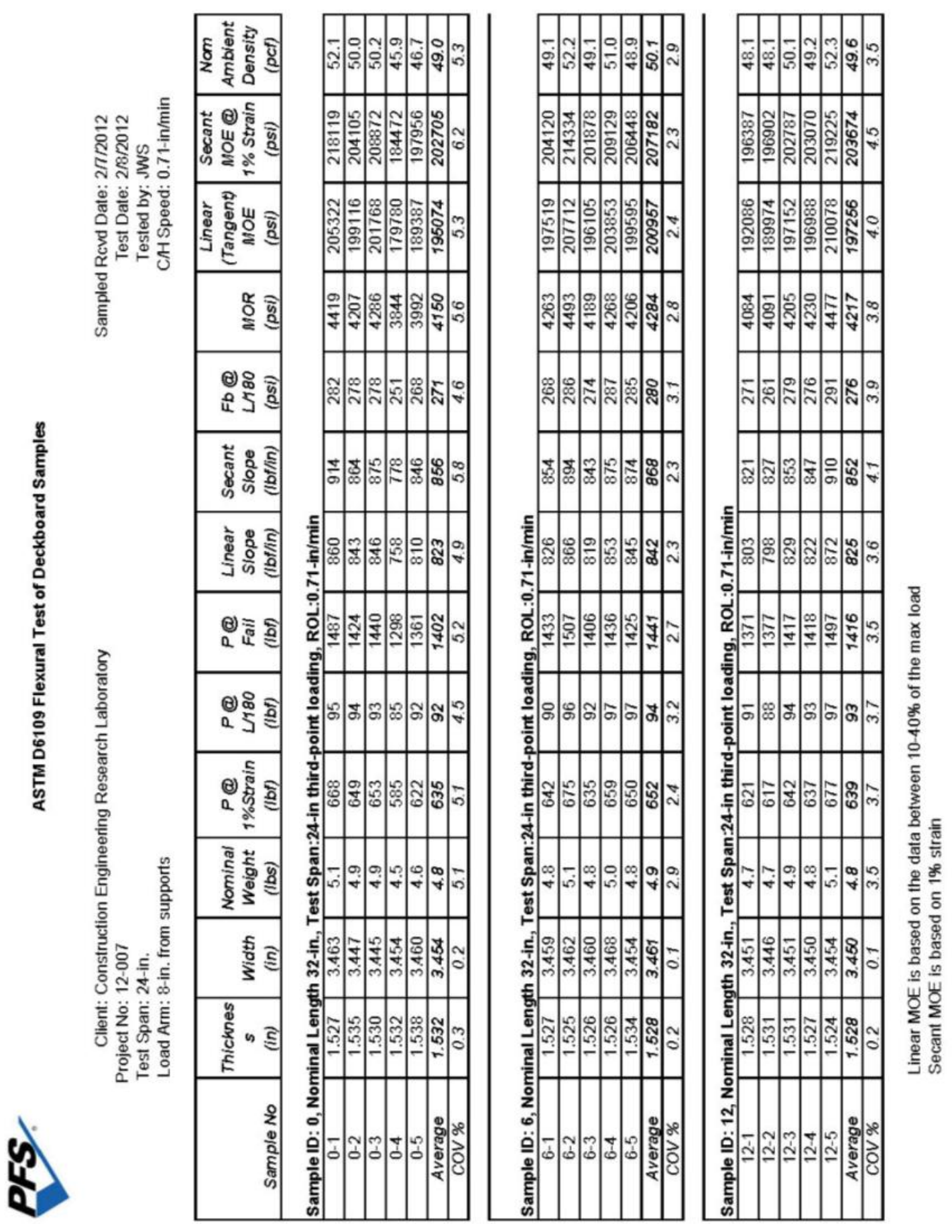




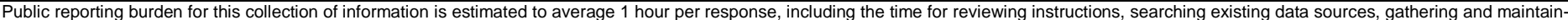

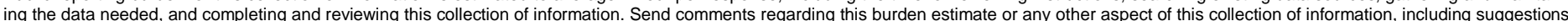

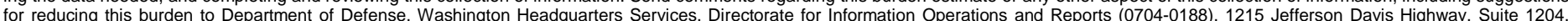

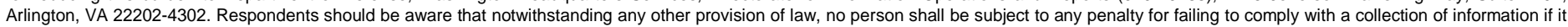
does not display a currently valid OMB control number. PLEASE DO NOT RETURN YOUR FORM TO THE ABOVE ADDRESS.

\begin{tabular}{l|l} 
1. REPORT DATE (DD-MM-YYYY) & 2. REPORT TYPE
\end{tabular} November 2011 Final

\section{TITLE AND SUBTITLE}

Remote Performance Monitoring of a Thermoplastic Composite Bridge at Camp Mackall, NC: Final Report on Project F08-AR13, Task A-Thermoplastic Composite Bridges

\section{AUTHOR(S)}

Richard G. Lampo, Barry K. Myers, Karl Palutke, and Darryl M. Butler

3. DATES COVERED (From - To)
5a. CONTRACT NUMBER

\section{5a. CONTRACT NUMBER}

5b. GRANT NUMBER

5c. PROGRAM ELEMENT NUMBER Corrosion Prevention and Control 5d. PROJECT NUMBER F08-AR13

5e. TASK NUMBER

MIPR5CCERB1011, MIPR5CROBB1012

5f. WORK UNIT NUMBER

\section{PERFORMING ORGANIZATION NAME(S) AND ADDRESS(ES)}

US Army Engineer Research and Development Center

8. PERFORMING ORGANIZATION REPORT
NUMBER

ERDC/CERL TR-11-43

Construction Engineering Research Laboratory

P.O. Box 9005

Champaign, IL 61826-9005

9. SPONSORING I MONITORING AGENCY NAME(S) AND ADDRESS(ES)

10. SPONSOR/MONITOR'S ACRONYM(S)

Office of the Secretary of Defense (OUSD(AT\&L))

3090 Defense Pentagon

Washington, DC 20301-3090

11. SPONSOR/MONITOR'S REPORT NUMBER(S)

\section{DISTRIBUTION / AVAILABILITY STATEMENT}

Approved for public release; distribution is unlimited.

\section{SUPPLEMENTARY NOTES}

\section{ABSTRACT}

This Corrosion Prevention and Control project demonstrated the use of an automated structural performance monitoring (SPM) system to remotely monitor the long-term performance of an innovative bridge constructed of recycled thermoplastics. The SPM system was designed to automatically collect the desired performance data and to provide the data to remote users for ongoing evaluation of the bridge. The system utilizes resistance-type strain gages and laser displacement sensors to monitor the strain and displacements imposed both by thermal impacts under static loading and dynamic loading created by vehicle crossing events. The system uses programmable automated data acquisition equipment to detect a vehicle event of interest, capture the strain and displacement time histories, and make a photograph of the vehicle for identification purposes.

This report documents the installation and configuration of the SPM system, and describes the data collected to date from remote monitoring and load testing activities. A review of the data collected to date indicates that good-quality continuous data are being collected with minimal labor requirement. The data are being used to evaluate how the bridge is performing relative to design assumptions, and establish a baseline of bridge static and dynamic response for structural performance evaluation over time.

\section{SUBJECT TERMS}

corrosion, remote monitoring, structural performance, evaluation, bridges, thermoplastic composite materials

16. SECURITY CLASSIFICATION OF:

\section{a. REPORT}

Unclassified

\section{b. ABSTRACT}

Unclassified c. THIS PAGE

Unclassified

\section{LIMITATION \\ 18. NUMBER} OF ABSTRACT OF PAGES

147 19a. NAME OF RESPONSIBLE PERSON 19b. TELEPHONE NUMBER (include area code) 